\title{
INTRODUCTION TO \\ RISK ASSESSMENT FOR \\ MATERIALS SAFETY AND \\ WASTE MANAGEMENT \\ $P-400$
}

May 2014

United States

Nuclear Regulatory Commission
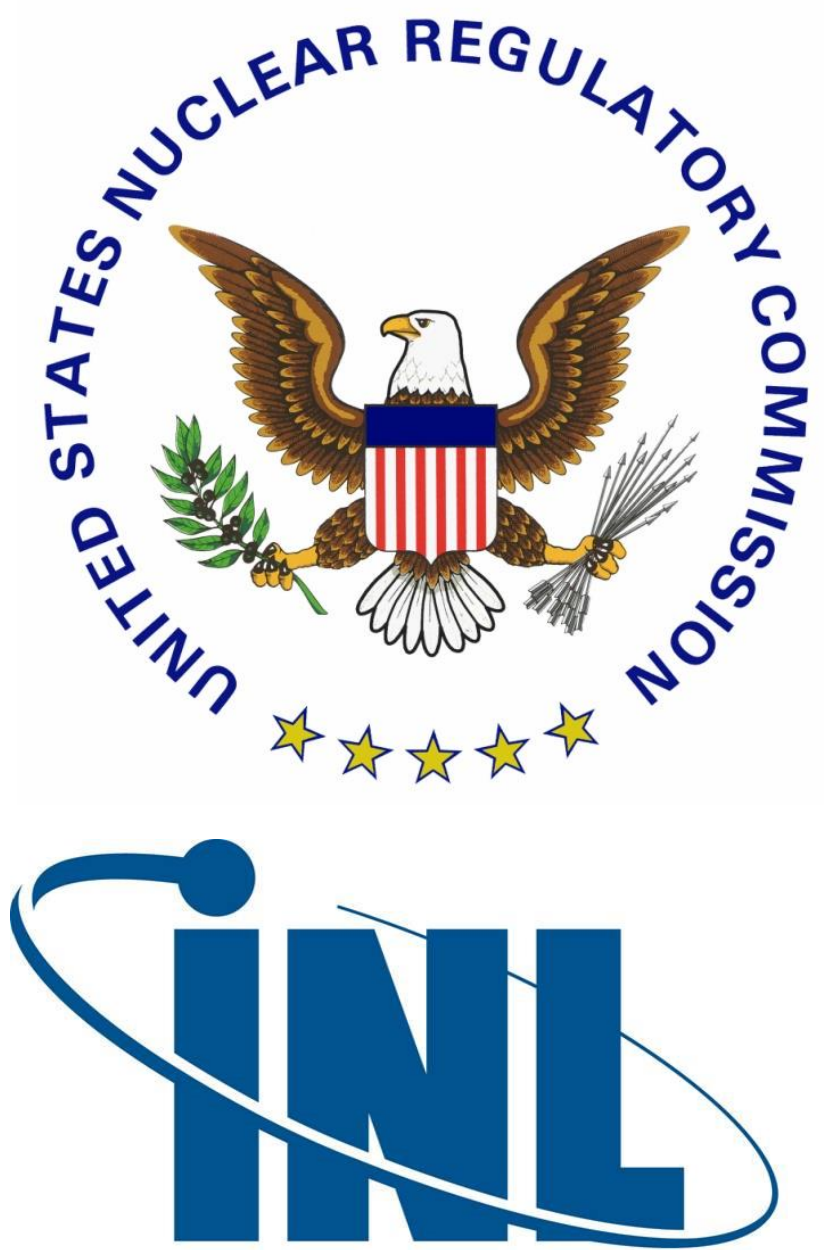

Idaho National Laboratory 


\section{DISCLAIMER NOTICE}

This report was prepared as an account of work sponsored by an agency of the United States Government. Neither the United States Government nor any agency thereof, or any of their employees, makes any warranty, expressed or implied, or assumes any legal liability of responsibility for any third party's use, or the results of such use, or any information, apparatus, product or process disclosed in this report, or represents that its use by such third party would not infringe privately owned rights. 


\section{INTRODUCTION TO RISK ASSESSMENT FOR MATERIALS SAFETY AND WASTE MANAGEMENT P-400}

Course Presented by:

Mike Calley, INL Michael.Calley@inl.gov 208-526-9230

Jim Knudsen, INL James.Knudsen@inl.gov 208-526-6432

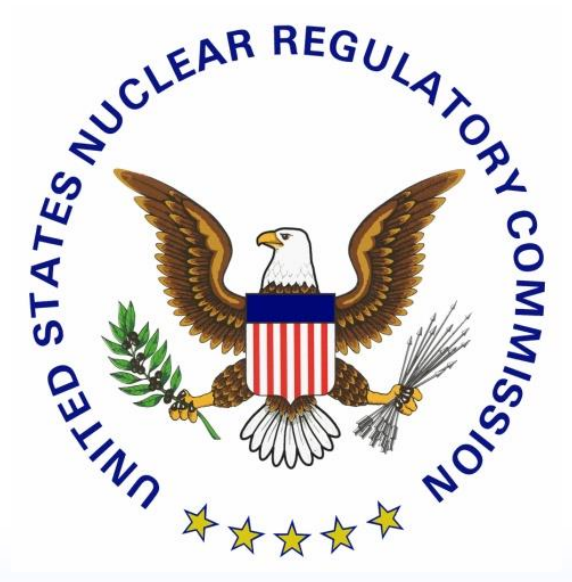

May 13-15, 2014 NRC Professional Development Center Rockville, $M D$ 


\section{Page Intentionally Left Blank}




\section{INTRODUCTION TO RISK ASSESSMENT FOR MATERIALS SAFETY AND WASTE MANAGEMENT P-400}

Introduction

List of Acronyms

Module 1 - Introduction to NRC Policy on the Use of Risk Information

Module 2 - Framework for Risk-Informed Regulation in NMSS

Module 3 - Risk Concepts and Methodology

Module 4 - Application of Risk Insights to Regulatory Decision Making Activities

Module 5 - Workshops

Module 6 - Case Studies and Reference Documents 


\section{Page Intentionally Left Blank}




\section{Introduction}

- Course Purpose:

- To provide an introduction to the use of risk assessment tools and techniques for Nuclear Material Safety and Safeguards (NMSS) activities

- To provide an understanding of;

- Why risk concepts are used in the NRC.

- What risk methods are being used, and what should be known about these risk methods.

- How risk concepts are applied, and how the application of risk concepts influences regulatory decision making. 


\section{Introduction (continued)}

- Course Objectives:

To have an understanding of the following:

- NRC Policy on the Use of Risk Information

- Framework for Risk-Informed Regulation in NMSS

- Risk Concepts and Methodology

- Risk Assessment Examples and Risk Insights for Regulatory Decision Making

- Risk Results

- Perception

- Communication

- Management 
NMSS Activities

Idaho National Laboratory

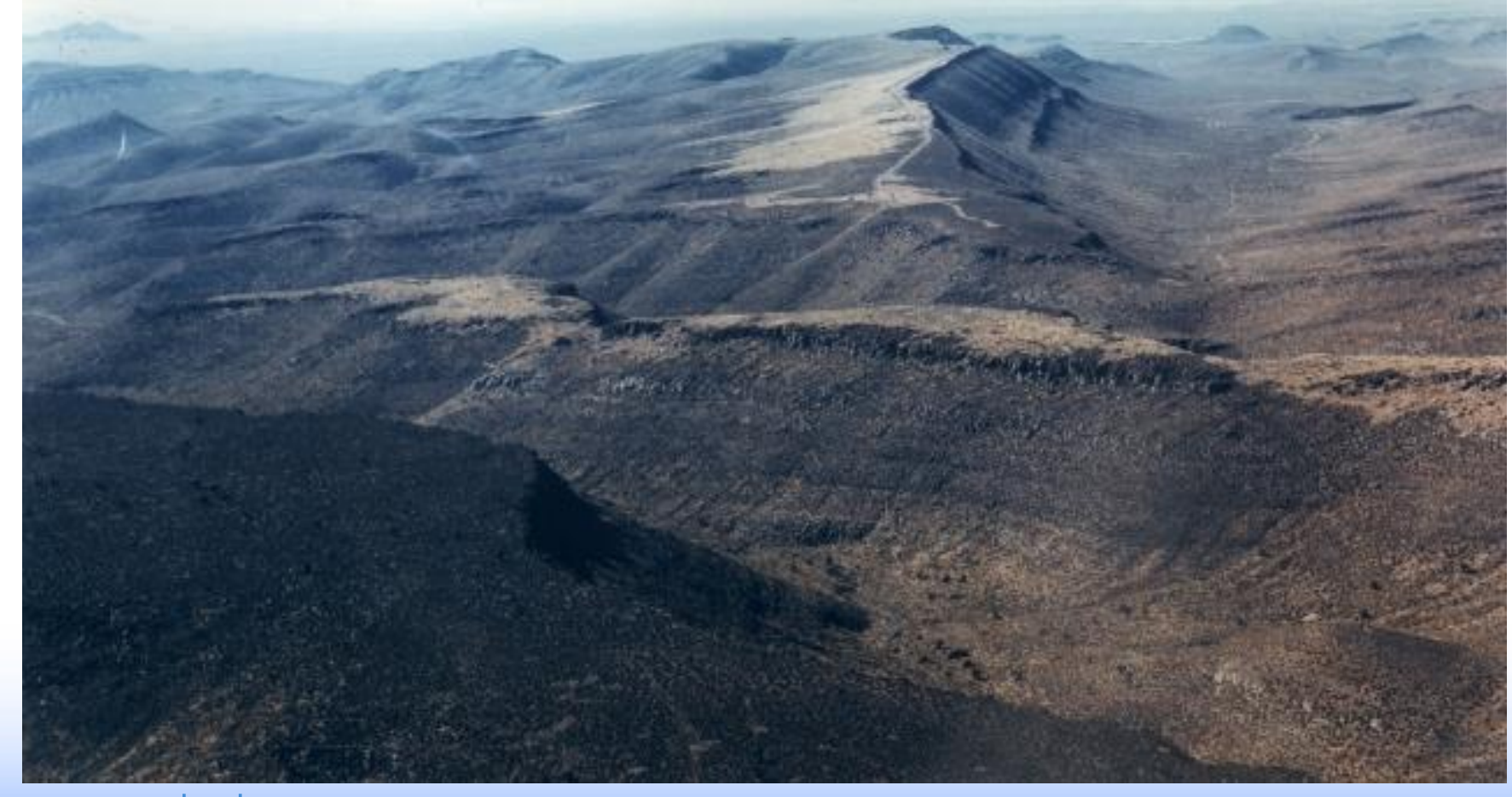




\section{NMSS Activities (continued)}

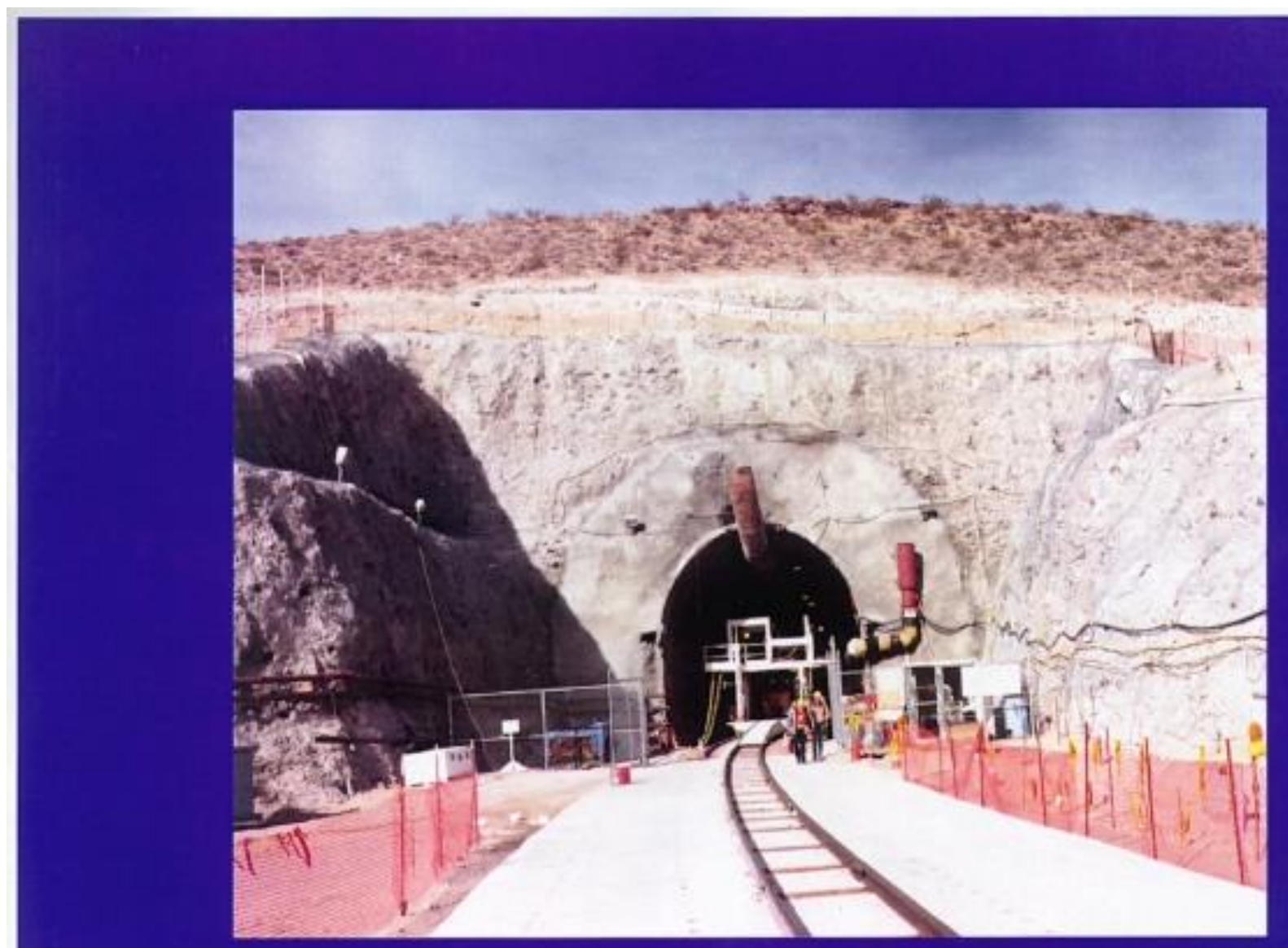

STARTER TUNNEL ENTRANCE AT YUCCA MOUNTAIN 


\section{NMSS Activities (continued)}

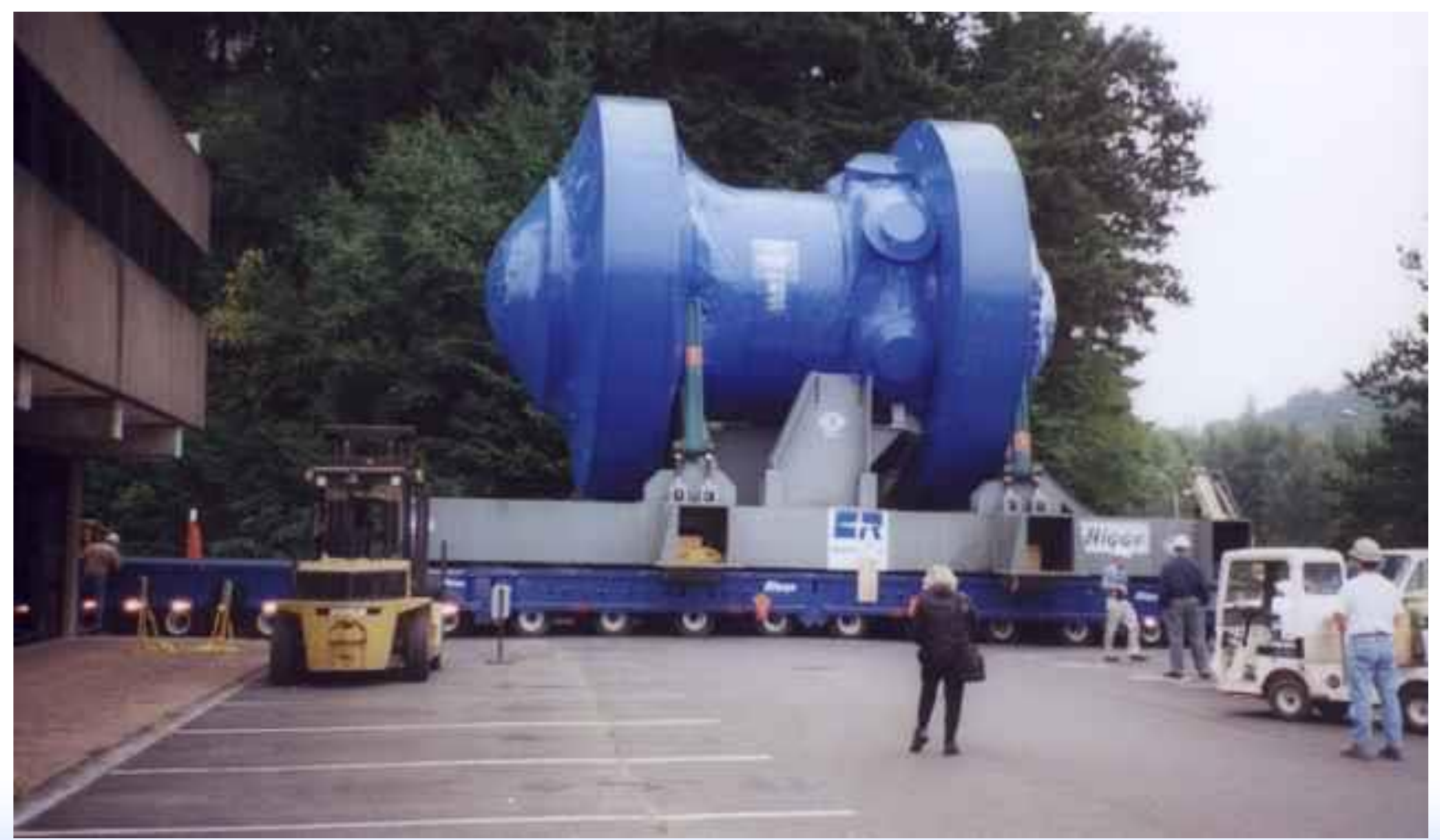

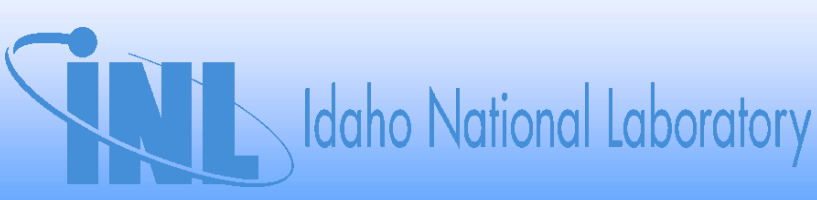




\section{NMSS Activities (continued)}

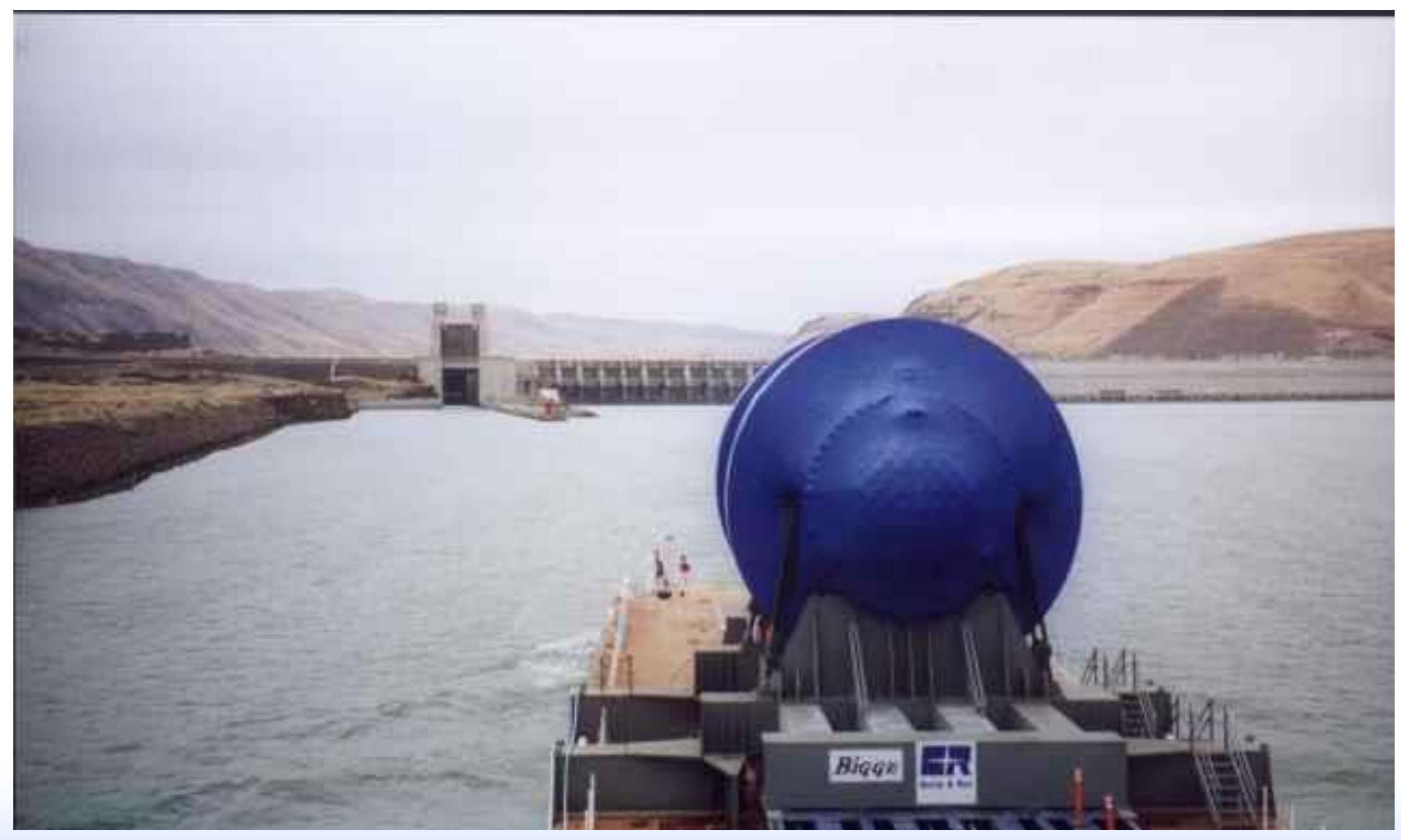

Idaho National Laboratory 


\section{NMSS Activities (continued)}

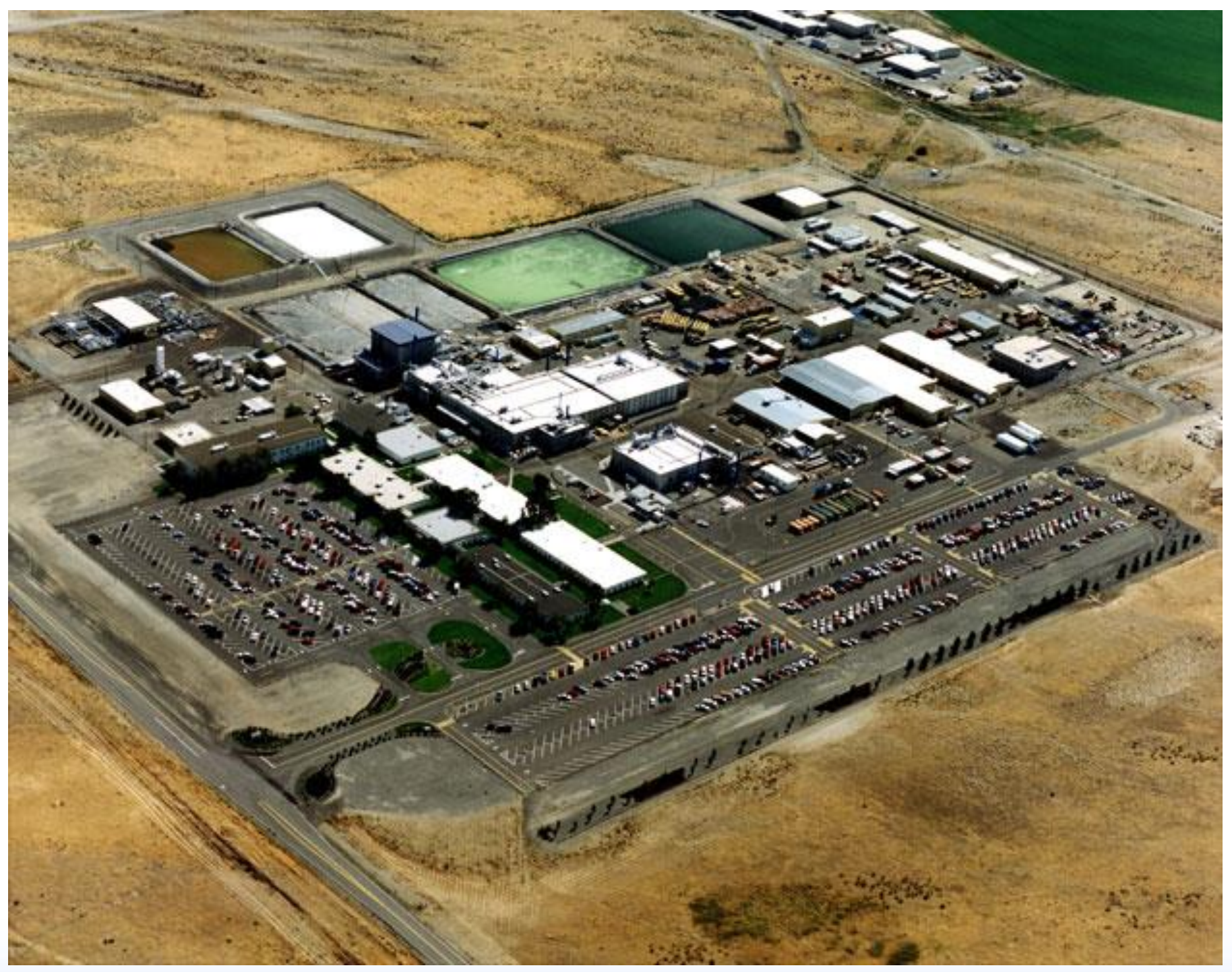

Photograph provided by Siemens Power Corporation (Richland, WA) 


\section{NMSS Activities (continued)}

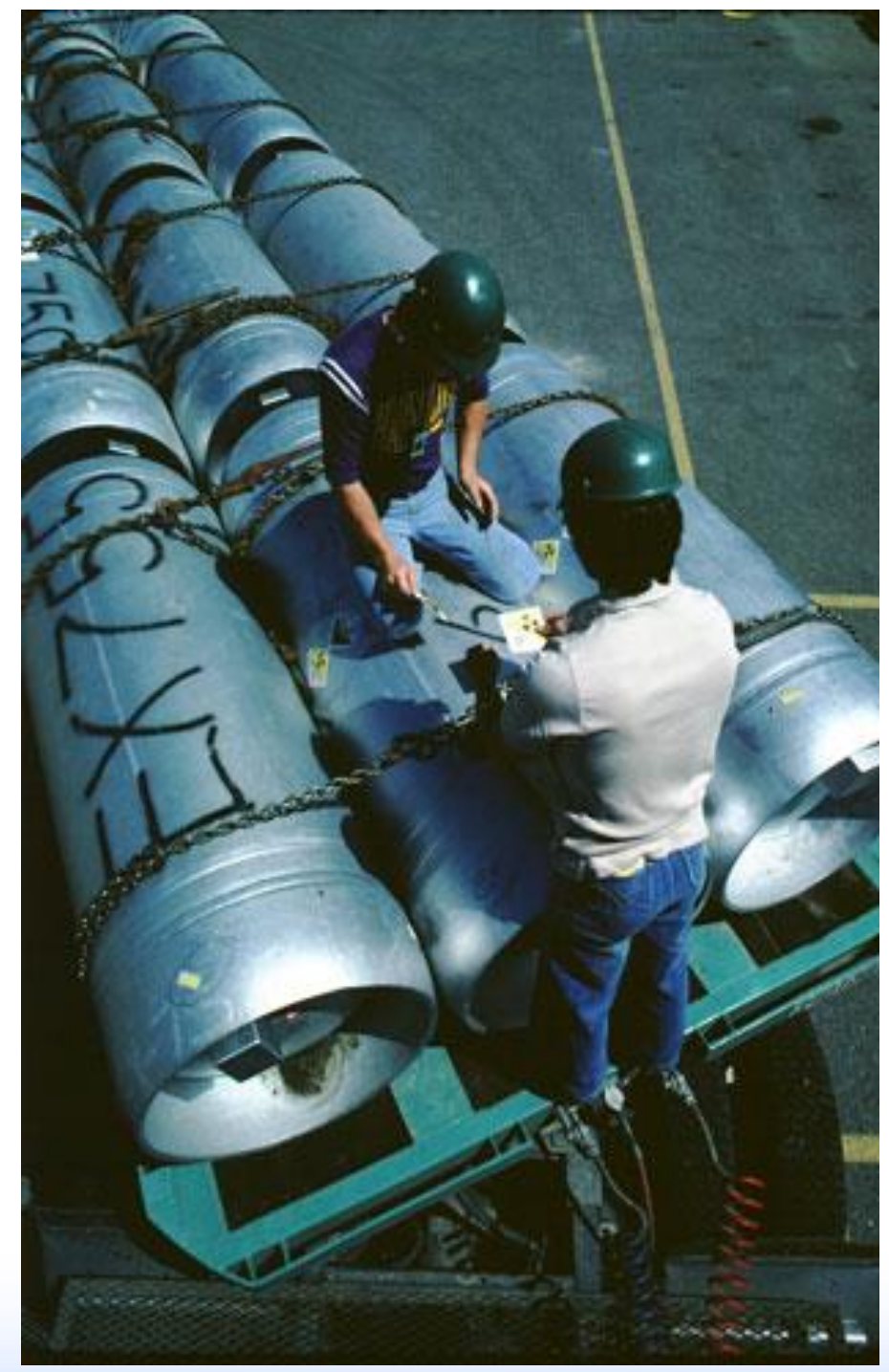

Photograph provided by Siemens Power Corporation (Richland, WA) Idaho National Laboratory 


\section{NMSS Activities (continued)}

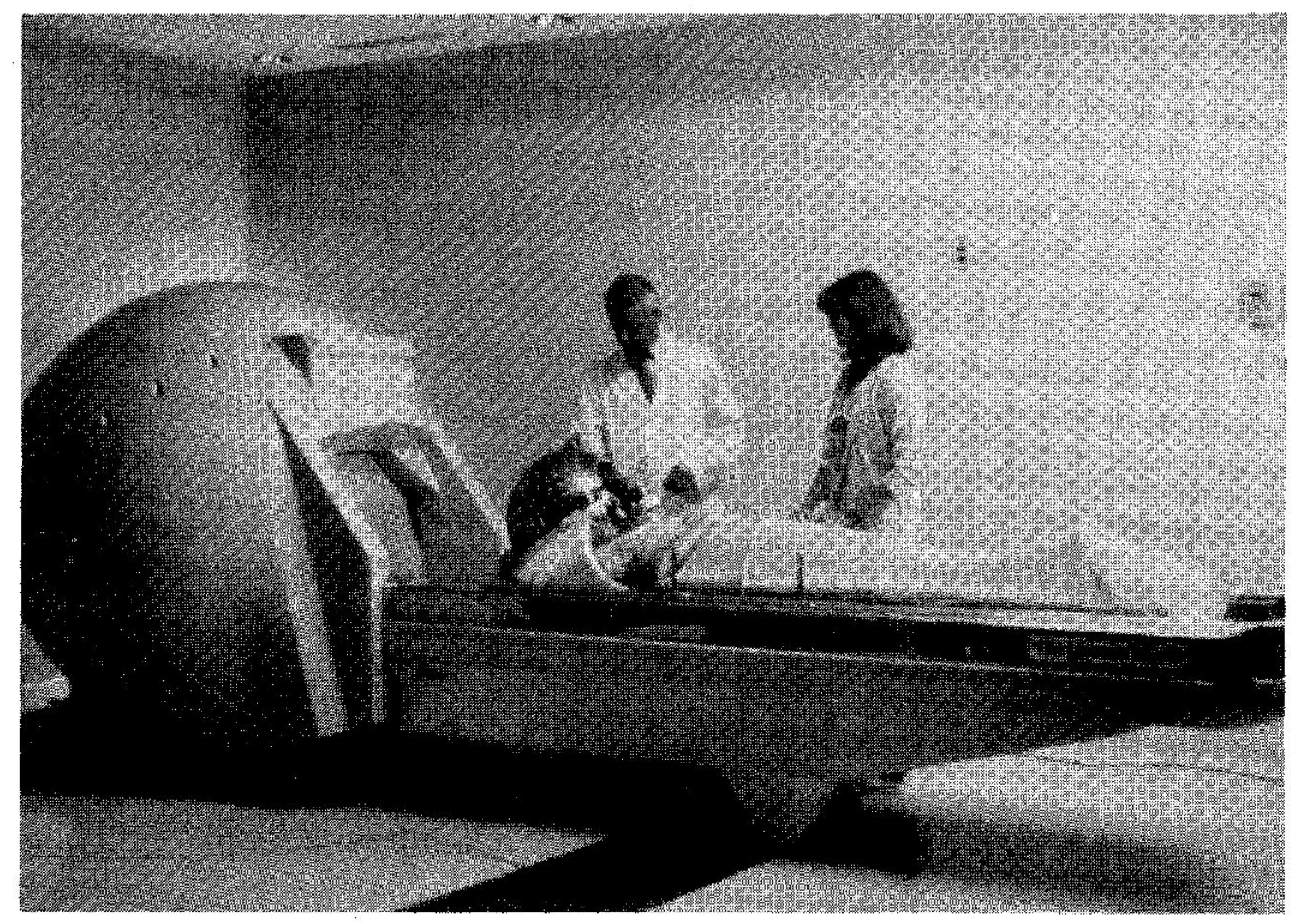

The Gamma Knife 


\section{NMSS Activities (continued)}

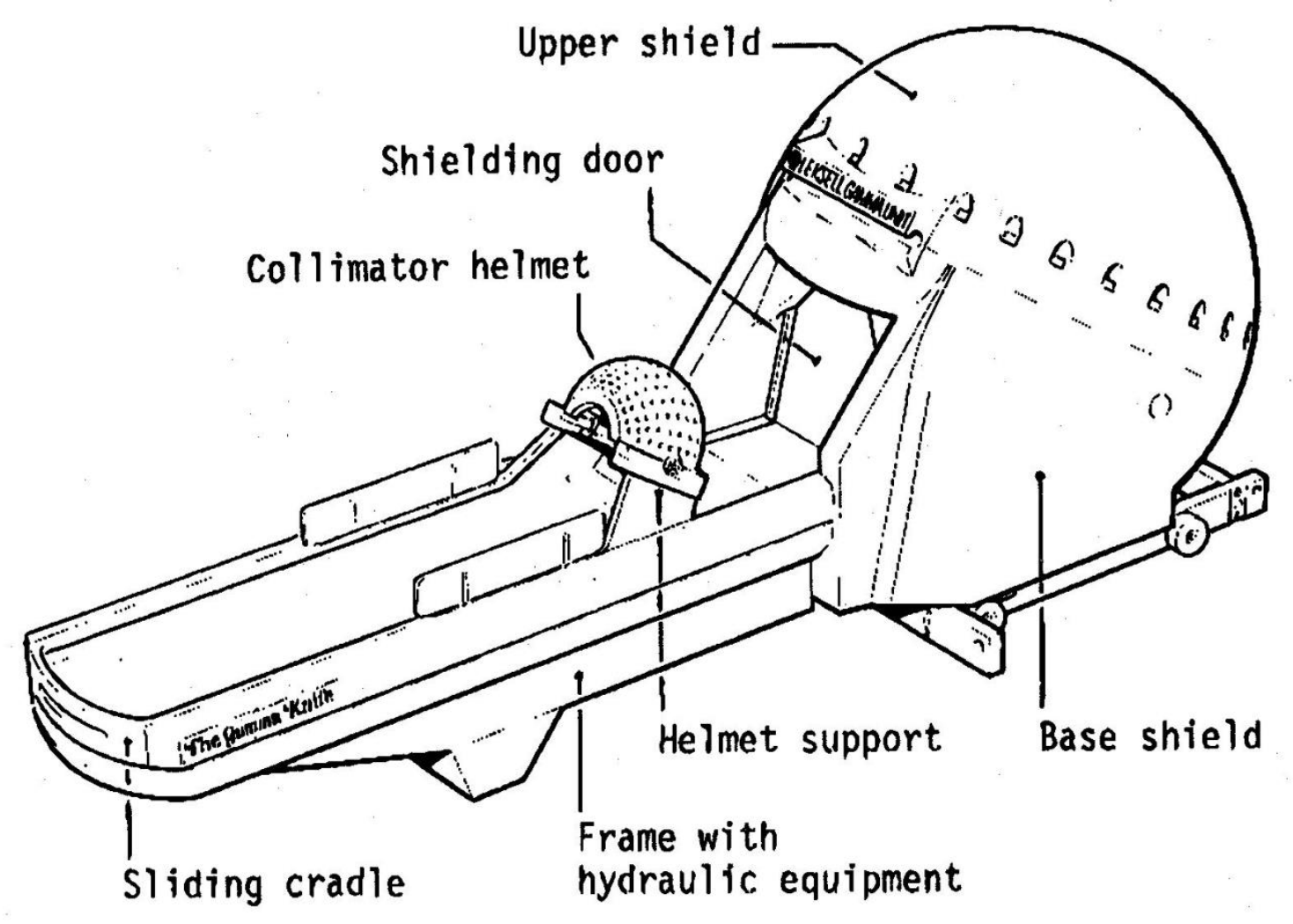

Major components of the Gamma Unit 


\section{Introduction (continued)}

- NMSS example activities have "risk" associated with them.

- What is risk?

- Conditions of exposure to the risk

- Normal conditions

- Off-normal (accident) conditions 


\section{Introduction (continued)}

- Motivation to use risk assessment in NMSS

- Additional analysis tools

- Consistent approach applied

- Improve decision making

- Maintain safety

- Increase efficiency and effectiveness

- Reduce unnecessary regulatory burden

- Enhance public confidence

- Why are you here and what is in it for you to use risk assessment

- Learn different risk assessment methods

- Gain an understanding of risk assessment results

- Determine what is most likely/highest consequences

- Better allocation of resources

- Gain an understanding of the NRC's policy on the use of risk assessment 


\section{Introduction (continued)}

Remarks by former Chairman Richard A. Meserve, U.S. Nuclear Regulatory Commission, at the Institute for Nuclear Power Operations Conference Atlanta, GA, November 2, 2000, http://www.nrc.gov/OPA/gmo/nrarcv/s00-26.html

Excellence in Nuclear Safety in Today's Regulatory Environment; A Status Report and a Look Toward the Future at the NRC

"We also are in a period of dynamic change on the safety regulatory front as we move from a prescriptive, deterministic approach to a risk-informed and performance-based paradigm. This initiative is extraordinarily ambitious, because it involves both rethinking the entire regulatory structure and changing attitudes. Nonetheless, we need to make this change to take advantage of what we have learned over the past 40 years, employing that knowledge both to focus on concerns that are truly significant for safety and to reduce needless regulatory burdens. I am pleased to acknowledge the support and active participation of our stakeholders in this effort." 


\section{Introduction (continued)}

- Various risk assessment training courses available through the NRC Technical Training Center (TTC)

- papaya.nrc.gov/catalog/catalog.htm (internal)

- www-nrc-training.ornl.gov/Nrc/ttd/catalog.htm (external)

- P-101 Risk-Informed Regulation for Technical Staff - (1 day) This course introduces students to the concept of riskinformed regulation, primarily as it is applied to nuclear power plant regulation. The NRC's policy for integrating risk information with deterministic insights is presented, and the many applications of risk information at the NRC are discussed. Students are introduced to the basic elements of a probabilistic risk assessment (PRA), the insights that technical reviewers can gain from PRA, and the ways that risk analysts compensate for uncertainty. This course also addresses the topic of risk communication.

- P-102 Bayesian Inference in Risk Assessment - (5 days) This course covers basic applications of Bayesian statistical inference in risk assessment. Through lectures, workshop problems, and case studies participants are presented with mathematical techniques from probability and Bayesian inference that are currently being applied in risk assessments. The topics covered include a review of probability, selected probability models important to risk assessment, elementary Bayesian parameter estimation, introduction to Bayesian model validation, and uncertainty propagation through risk assessment models. The course is computer-based and utilizes Excel, RADS, and SAPHIRE, with an introduction to WinBUGS, which is useful for more advanced problems. Students should be familiar with the basic operations of Excel, but do not need to be familiar with RADS, SAPHIRE, or WinBUGS.

- P-502 Bayesian Inference in Risk Assessment - Advanced Topics - (5 days) This course explores advanced applications of Bayesian statistical inference in risk assessment through lectures and hands-on case studies using WinBUGS and SAPHIRE. Students should have completed Bayesian Inference in Risk assessment (P-102) course. Students are expected to be familiar with WinBugs at the level as presented in P-102. 


\section{Introduction (continued)}

- Various risk assessment training courses available through the NRC Technical Training Center (TTC) (continued)

- $\quad$ P-105 PRA Basics for Regulatory Applications - (3 days) This course addresses the special needs of the regulator who requires knowledge of probabilistlc risk assessment (PRA) issues and insights to better evaluate the effects of design, testing, maintenance, and operating strategies on system reliability. The full range of PRA topics is presented in abbreviated form with the goal of introducing the regulatory staffs to the basic concepts and terminology of PRA as applied to the inspection process. The course uses actual plant PRAs and IPEs and stresses the uses and applications of these publications in planning audits and inspections and evaluating plant safety issues.

- P-107 PRA for Technical Managers - (3 days) This course introduces the NRC supervisor/manager to the concept of risk-informed regulation, primarily as it is applied to nuclear power plant regulation. The many applications of risk information at the NRC are discussed. Students are introduced to the basic elements of a probabilistic risk assessment (PRA), the insights that technical reviewers can gain from PRA, and the ways that risk analysts compensate for uncertainty. The NRC's policy for making integrated decisions based on risk information and deterministic insights is presented, with special emphasis on the process for risk-informed decision making on emergent issues (NRR Office Instruction LIC-504). This course also addresses the topic of risk communication.

- P-108 NRC MC 0609 Appendix F Fire Protection SDP Training - (3 days) This course introduces the methodology described in Appendix $F$ to the NRC Manaul Chapter 0609, Fire Protection Significance Determination Process (SDP). Students will be introduced to the underlying theory of this SDP and will be taught to use PC-based tool for aiding in the execution of the SDP. 


\section{Introduction (continued)}

\section{- Various risk assessment training courses available through the NRC Technical Training Center (TTC) (continued)}

- P-109 Assessing the Adequacy of Models for Risk-Informed Decisions - (1 day) This course is aimed at improving awareness of the factors that contribute to uncertainty in predictive models (both probabilistic and deterministic), and the need to identify, characterize and communicate the uncertainties to risk-informed decision makers. This course discusses the fact that all models are just estimates of reality and subject to many implicit assumptions and biases. It is the responsibility of the analyst to explicitly understand and communicate those assumptions, the limits of model applicability, and the uncertainty on the output. Much time is spent in the class on developing an appreciation for the value of a questioning attitude toward model use and reliance.

- P-111 PRA Technology and Regulatory Perspectives - (9 days) This course addresses the special needs of Regional Inspectors, Resident inspectors, and other technical personnel who require knowledge of PRA issues and insights to better evaluate the effects of design, testing, maintenance, and operating strategies on system reliability. The course will concentrate on the use of PRA results in inspection planning, monitoring licensee performance, and reviewing licensee risk-informed submittals.

- $\quad$ P-200 System Modeling Techniques for PRA -.(4 days) This course will help develop advanced user level skills in performing event tree and fault tree analysis, with numerous practice workshops. The course covers the calculation of initiating event frequencies, component failure rate, and the use of "super components" to create fault trees. A second focus of the course is dependent failure analysis, including multiple Greek letter, binomial failure rate, basic parameter methods, and alpha factor methods for estimating common cause/common mode failure probabilities. 


\section{Introduction (continued)}

\section{- Various risk assessment training courses available through the NRC Technical Training Center (TTC) (continued)}

- P-201 SAPHIRE Basics - (4 days) This course provides hands-on training in the use of Systems Analysis Programs for Hands-on Integrated Reliability Evaluation (SAPHIRE) for Windows to perform PRA on a PC. When the course is completed, the participants are able to: build fault tree models on the PC, assign reliability data, analyze the fault trees and develop minimal cut sets, calculate various importance measures, perform uncertainty analysis, analyze accident sequences, create and quantify accident sequences, and generate reports.

- $\quad$ P-202 Advanced SAPHIRE - (4 days) This course provides hands-on training in the advanced features of Systems Analysis Programs for Hands-on Integrated Reliability Evaluation (SAPHIRE) for Windows to perform PRA on a PC. SAPHIRE allows the user to build and evaluate the models used in PRA.

- P-203 Human Reliability Assessment - (4 days) This course serves as an introduction to Human Reliability Assessment (HRA) including the methods used in modeling of human errors and various methods of estimating their probabilities. This course is designed to teach introductory level skills in HRA and includes a broad introduction to HRA and its applications. A discussion of HRA strengths, limitations, and results is also included.

- P-204 External Events - (4 days) This course deals with the analysis of external events such as fires, floods, earthquakes, high winds, and transportation accidents. The course has been developed to provide the student with information that can be used in the review of IPEEE results. 


\section{Introduction (continued)}

\section{- Various risk assessment training courses available through the NRC Technical Training Center (TTC) (continued)}

- $\quad$ P-300 Accident Progression Analysis - (3 days) This course deals with the portion of probabilistic risk assessment typically referred to as Level 2 analysis. The course will address accident phenomenology under post-core damage conditions and will discuss development of PRA models for this severe accident regime. The emphasis of the course is on the important modeling issues and how they are dealt with, rather than how to use specific modeling software.

- $\quad$ P-301 Accident Consequence Analysis - (3 days) This course deals with the portion of PRA typically referred to as Level 3 analysis. The course addresses environmental transport of radio nuclides and the estimation of offsite consequences from core damage accidents. The emphasis of the course is on important modeling issues and how they are dealt with, rather than how to use specific modeling software.

- P-302 Risk Assessment in Event Evaluation - (4 days) This course covers the use of PRA techniques to assess the risk significance of initiating events and condition assessments that occur at operating reactors. The course addresses the use of simplified PRA models to estimate conditional damage probability using the Graphical Evaluation Module (GEM) of the SAPHIRE suite of programs. In addition, common cause and non-recovery probabilities will also be addressed. The course includes conventional workshops and GEM program workshops.

- P-501 Advanced Risk Assessment Topics (4 days). The primary objective of this course is to provide a hands-on approach to the investigation and application of a variety of advanced risk assessment methods, tools, and techniques. This objective will be accomplished by discussing select topics followed by hands-on application for example exercises. As a result of these hands-on exercises, the student will become more proficient with Bayesian methods and the use of tools such as SAPHIRE, Excel, and WinBUGS for numerical analysis. 


\section{Introduction (continued)}

\section{- Various risk assessment training courses available through the NRC Technical Training Center (TTC) (continued)}

- P-400 Introduction to Risk Assessment in NMSS - (3 days) This course introduces risk assessment concepts for Nuclear Material Safety and Safeguards (NMSS) applications. The NRC's policy on the use of risk information as well as the framework for employing risk-informed regulation within NMSS is presented. Various risk assessment concepts and methodologies are introduced and discussed. Examples of the risk assessment methodologies are presented, and some of the strengths and weaknesses associated with the various methodologies are addressed. Several case studies are presented to demonstrate the risk assessment methodology used for the respective study and the risk insights gained are discussed. This course also addresses the perception and management of risk based on the results obtained from the risk assessment.

- P-401 Introduction to Risk Assessment in NMSS Overview - (1 day) This course provides an overview of risk assessment concepts for Nuclear Materials Safety and Nuclear Waste Safety applications. The NRC's policy on the use of risk information as well as the framework for employing risk-informed regulation within the Office of Nuclear Material Safety and Safeguards (NMSS) is presented. Various risk assessment concepts and methodologies are introduced and discussed. Examples of the risk assessment methodologies are presented, and some of the strengths and weaknesses associated with the various methodologies are addressed. This course also addresses the topics of risk perception, risk communication, and risk management. 


\section{Introduction (continued)}

- Various risk assessment training courses available through the NRC Technical Training Center (TTC) (continued)

- P-405 Byproduct Materials System of Risk Analysis and Evaluation in NMSS - (1 day) This course provides a general understanding of the process of developing risk analysis to populate the underlying database of NUREG/CR 6642,"Risk Analysis and Evaluation of Regulatory Options for Nuclear Byproduct Material Systems." Examples are presented of possible uses of the information in regulatory decision making and also provided is an overview of the risk analysis methodology, methods to define systems, uncertainty in human performance assessment, and basic utilization of the Byproduct Material System (BMS)-Risk database.

- $\quad$ P-406 Human Error Analysis/Human Reliability Analysis for NMSS - (2-1/2 days) This course serves as an introduction to Human Error Analysis/Human Reliability Analysis for Nuclear Material Safety and Safeguards (NMSS) applications. This course provides an overview of HRA, introduces the concepts and methods us eful in examining human error, sensitizes staff to recognize the need and importance of HRA in their daily work, and reviews the contribution of human error to select NMSS events. As part of this overview, students are introduced to key components of HRA - error taxonomies, performance shaping factors and context, error identification, error modeling and error quantification. This course also introduces various methods used when estimating human error probabilities. A discussion of human error analysis/human reliability analysis strengths, limitations, and results is also included.

- H-410 RESRAD Course (4 day) This course provides NRC technical personnel with an overview and history of the RESRAD and RESRAD-BUILD computer codes (both deterministic and probabilistic versions), the calculation methodologies used, special features of the codes, their application to site cleanups, and code verification and validation. Interactive computer demonstrations will guide the participants through data input and output steps. Instructor support will help the students complete the hands-on problem solving sessions throughout the course. 


\section{Introduction (continued)}

- Various risk assessment training courses available outside the NRC

- Harvard University Risk Communication Class

- www.hsph.harvard.edu/ccpe

- Harvard Center for Risk Analysis

- www.hcra.harvard.edu

- Johns Hopkins University, the Risk Sciences and Public Policy Institute,

- www.jhsph.edu/RiskSciences

- Worcester Polytechnic Institute, Fire Protection Engineering course on Risk Management FPE 563

- www.wpi.edu/Academics/Depts/Fire/Courses

- University of Maryland, Reliability/Nuclear Engineering course, Risk Assessment for Engineers, ENRE 670/ENNU 651

- www.testudo.umd.edu/ScheduleOfClasses.html

- University of Maryland, Fire Protection Engineering, Risk Analysis courses,

- www.enpm.umd.edu/fire.htm

- Process Safety Institute Quantitative Risk Analysis Courses

- www.abs-jbfa.com/psi.html

- Texas A\&M University, Mary Kay O’Connor Process Safety Center Risk Courses

- mkopsc.tamu.edu

- Southern Methodist University Risk Courses

- www.smu.edu/catalogs/graduate/seas/mshwmm.html 


\section{Introduction (continued)}

- Three Tier Approach to Training

- Tier 1: Managers and Supervisors (1 day course)

- Tier 2: Technical Staff (3 to 3-1/2 day course)

- Introduction to risk assessment

- Introduction to NRC policy and framework for increase use of risk assessment

- Presentation of risk assessment applications within NMSS

- Tier 3: Risk Analysts and Specialist (course length to be determined)

- Risk assessment software: SAPHIRE

- Hands-on computer modeling 


\section{Acronyms}

ACNW Advisory Committee on Nuclear Waste (now part of ACRS)

ACRS Advisory Committee on Reactor Safeguards

AEA Atomic Energy Act

ALARA As Low As Reasonably Achievable

AVM Arteriovenous Malformation

BEIR Biological Effects of lonizing Radiation

BMS Byproduct Material System

CFR Code of Federal Regulations

CRGR Committee To Review Generic Requirements

CT Computed Tomography

DBA Design Basis Accident

DOE Department of Energy

DSFST Division of Spent Fuel Storage and Transportation

DWM Division of Waste Management

EnPA Energy Policy Act

EPA Environmental protection Agency

FCSS Fuel Cycle Safety and Safeguards 


\section{Acronyms (continued)}

FEIS Final Environmental Impact Statement

FMEA Failure Modes and Effects Analysis

FMECA Failure Modes, Effects, and Criticality Analysis

FY Fiscal Year

GAO General Accounting Office

HAZOP Hazard and Operability Analysis

HLW High-Level Waste

HRA Human Reliability Analysis

ICRP International Commission on Radiological Protection

IMNS Industrial and Medical Nuclear Safety

INL Idaho National Laboratory

IPE Individual Plant Examination

IPEEEs Individual Plant Examination of External Events

IROFS Items Relied on for Safety

ISA Integrated Safety Analysis

ISI Integrated Subissues 


\title{
Acronyms (continued)
}

\author{
LLW Low-Level Waste \\ MLD Master Logic Diagram \\ MOX Mixed Oxide \\ MRI Magnetic Resonance Imaging \\ NAS National Academy of Science's \\ NCRP National Council on Radiation Protection and Measurements \\ NMED Nuclear Materials Events Database \\ NMSS Office of Nuclear Material Safety and Safeguards \\ NRC National Research Council: \\ NRC Nuclear Regulatory Commission \\ NUREG Nuclear Regulatory Commission technical report designation \\ NWPA Nuclear Waste Policy Act \\ OOS Out-of-Service \\ PCSA Pre-closure Safety Analysis \\ PA Performance Assessment \\ PHA Preliminary Hazard Analysis \\ PRA Probabilistic Risk Assessment \\ PRA-IP PRA Implementation Plan \\ PSA Probabilistic Safety Assessment
}




\section{Acronyms (continued)}

$\begin{array}{ll}\text { PSFs } & \text { Performance Shaping Factors } \\ \text { RERF } & \text { Radiation Effects Research Foundation } \\ \text { RES } & \text { NRC Office of Regulatory Research } \\ \text { RIRIP } & \text { Risk-Informed Regulation Implementation Plan } \\ \text { RPP } & \text { Risk-informed Performance-based Plan } \\ \text { RTG } & \text { Risk Task Group } \\ \text { SAPHIRE } & \text { Systems Analysis Program for Hands-on Integrated Reliability Evaluation } \\ \text { SECY } & \text { Office of the Secretary of the Commission } \\ \text { SFPO } & \text { Spent Fuel Project Office } \\ \text { SNM } & \text { Special Nuclear Material } \\ \text { SRM } & \text { Staff Requirements Memorandum/Memoranda } \\ \text { SRP } & \text { Standard Review Plan } \\ \text { SSC } & \text { Structure, System, and Component } \\ \text { TMI } & \text { Three Mile Island } \\ \text { TRD } & \text { Technical Review Directorate } \\ \text { TSPA } & \text { Total System Performance Assessment } \\ \text { UNSCEAR } & \text { United Nations Scientific Committee on Effects of Atomic Radiation }\end{array}$


1. Introduction to NRC Policy on the Use of Risk Information 


\section{Page Intentionally Left Blank}




\section{Introduction to NRC Policy on the Use of Risk Information}

- Purpose: Provide an overview of information that shapes NRC policy on the use of risk.

- Events Leading to Increased Use of Risk Information

- PRA Policy Statement

- Risk-Informed and Performance-Based Regulation White Paper

- Draft for review NRC Strategic Plan FY 2014 - 2018

- NRC Strategic Plan FY 2008 - 2013

- NRC Strategic Plan FY 2000 - 2005

- NRC Strategic Plan FY 2004 - 2009

- Risk-informed Performance-based Plan (RPP) 


\section{Introduction to NRC Policy on the Use of Risk Information (continued)}

- Objectives: To have an understanding of the following:

- Why the Risk-Informed and Performance Based Regulation is used

- Key concepts in Risk-Informed and PerformanceBased Regulation

- How Risk-informed Performance-based Plan (RPP) supports NRC's Strategic Plan 


\section{Introduction to NRC Policy on the Use of Risk Information}

- References:

- Federal Register, "Use of Probabilistic Risk Assessment Methods in Nuclear Regulatory Activities: Final Policy Statement," Volume 60, Number 158, August 16, 1995.

- SRM-SECY-98-144, "Staff Requirements - SECY-98-144 - White Paper on RiskInformed and Performance-Based Regulation," March 1999.

- NUREG-1614, "U.S. Nuclear Regulatory Commission Strategic Plan, FY 2000 2005," Volume 2, Part 1 and Part 2.

- NUREG-1614, "U.S. Nuclear Regulatory Commission Strategic Plan, FY 2004 2009," Volume 3.

- NUREG-1614, "U.S. Nuclear Regulatory Commission Strategic Plan, FY 2008 2013," Volume 4.

- NUREG-1614, “U.S. Nuclear Regulatory Commission Strategic Plan, FY 2008 2013," Volume 5.

- Draft NUREG-1614, "U.S. Nuclear Regulatory Commission Strategic Plan, FY 2014 - 2018," Volume 6.

- SECY-13-0118 "Annual Update of the Risk-Informed and Performance-Based Plan," November 7, 2013 (updated approximately every year and available via NRC public web site summarizing each RPP initiative). 


\section{Timeline of NRC Policy on the Use of Risk Information}

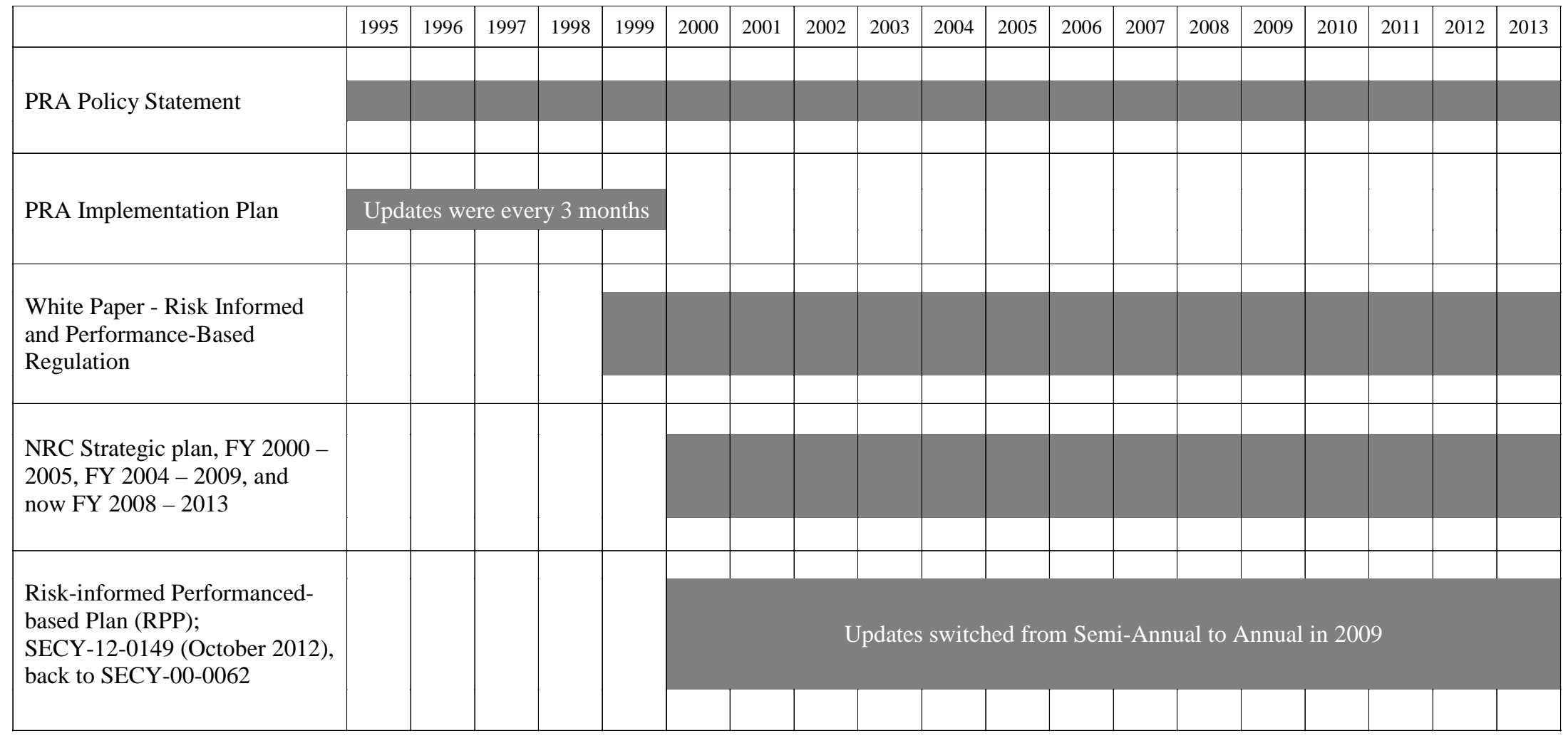




\section{Events and Factors Leading to Increased Use of Risk Assessment}

- Three Mile Island (TMI)-2 accident - March 28, 1979 desire to increase safety

- Safety insights revealed by early risk assessments

- NUREG 1150; Severe Accident Risks: An Assessment for Five U.S. Nuclear Power Plants - Final Summary Report, October 1990

- Individual Plant Examinations (IPEs); NRC Generic Letter 88-20, November 1988

- Individual Plant Examination of External Events (IPEEEs); NRC Generic Letter 88-20 Supplement 4, June 1991

- Increased understanding and acceptance of methods

- Economic pressures 


\section{PRA Policy Statement}

- Developed from concern that:

- Commission not deriving full benefit from agency and industry investment in risk assessment methods and available data

- PRA methods are not consistently applied throughout agency

- Sufficient PRA/statistics expertise not available 


\section{PRA Policy Statement (continued)}

- NRC had generally regulated the use of nuclear material based on deterministic approaches

- Deterministic approaches to regulation;

- Consider a set of challenges to safety, and

- Determine how those challenges should be mitigated 


\section{PRA Policy Statement (continued)}

- Probabilistic approach to regulation enhances and extends the traditional, deterministic approach, by:

- allowing consideration of a broader set of potential challenges to safety,

- providing a logical means for prioritizing these challenges based on risk significance, and

- allowing consideration of a broader set of resources to defend against these challenges. 


\section{PRA Policy Statement (continued)}

- General objectives:

- Improve regulatory decision making and therefore, improve safety

- Make more efficient use of agency resources

- Reduce unnecessary regulatory burden on licensees

- Staff takes consistent approach to regulatory decision making

- Process to allow increased use of PRA and risk insights 


\section{Risk-Informed and Performance- Based Regulation White Paper}

- Key Concepts

- Risk and Risk Assessment

- Deterministic and Probabilistic Analyses

- Risk Insights

- Risk-Based Approach

- Risk-Informed Approach

- Defense-in-Depth

- Performance-Based Approach

- Risk-Informed, Performance-Based Approach 


\section{Risk-Informed and Performance-Based Regulation White Paper (continued)}

- Risk and Risk Assessment

- Risk = Frequency(or Probability) * Consequences

- Risk Assessment

- Systematic method for addressing risk triplets;

- (1) What can happen?

- (2) How likely?

- (3) What are consequences?

- Systematic method addressing the risk triplet to;

- Understand likely outcomes, sensitivities, areas of importance, system (including human component) interactions and areas of uncertainty.

- Identify important scenarios 


\section{Risk-Informed and Performance-Based Regulation White Paper (continued)}

- Deterministic and Probabilistic Analyses

- Deterministic Analyses

- Involves implied, but unquantified, elements of probability of specific events to be analyzed as design basis events. Design includes safety functions capable of preventing and/or mitigating the consequences.

- Probabilistic Analyses

- Considers the risk triplets in a more coherent, explicit, and quantitative manner. Safety functions are examined in an integrated, comprehensive manner. Broad spectrum of events and event frequency are considered.

Consequences of the events are also considered, thus giving a measure of the risk. 


\section{Risk-Informed and Performance-Based Regulation White Paper (continued)}

- Risk Insights

- Results and findings from a risk assessment.

- Risk curves for disposal facilities for radioactive wastes

- Frequency of and cost associated with accidental smelting of sealed sources at steel mills

- Frequency of occupational exposures

- Predicted dose from decommissioned sites

- Successfully incorporated into numerous regulatory activities, proven to be a valuable complement to traditional deterministic approaches.

- Explicitly incorporated more into regulatory process to improve efficiency and effectiveness of regulatory requirements. 


\section{Risk-Informed and Performance-Based Regulation White Paper (continued)}

- Risk-Based Approach

- Regulatory decision-making in which decisionmaking is solely based on the numerical results of a risk assessment.

- NOTE: The Commission does not endorse an approach that is risk-based; however, this does not invalidate the use of probabilistic calculations to demonstrate compliance with certain criteria, such as dose limits. 


\section{Risk-Informed and Performance-Based Regulation White Paper (continued)}

- Risk-Informed Approach

- Risk insights are considered together with other factors to establish requirements that better focus licensee and regulatory attention on design and operational issues commensurate with their importance to public health and safety. 


\section{Risk-Informed and Performance-Based Regulation White Paper (continued)}

- Risk-Informed Approach (continued)

- Enhances deterministic approach and leads to better decision-making by:

- (a) allowing explicit consideration of a broader set of potential challenges to safety,

- (b) providing a logical means for prioritizing these challenges based on risk significance, operating experience, and/or engineering judgment,

- (c) facilitating consideration of a broader set of resources to defend against these challenges,

- (d) explicitly identifying and quantifying sources of uncertainty in the analysis (does not necessarily reflect all important sources of uncertainty), and

- (e) providing a means to test the sensitivity of the results to key assumptions 


\section{Risk-Informed and Performance-Based Regulation White Paper (continued)}

- Risk-Informed Approach (continued)

- Risk-Informed approach, where appropriate, can be used to;

- reduce unnecessary conservatism in purely deterministic approaches

- identify areas with insufficient conservatism in deterministic analyses

- provide the bases for additional requirements or regulatory actions 


\section{Risk-Informed and Performance-Based Regulation White Paper (continued)}

- Risk-Informed Approach (continued)

- Risk-Informed approaches lie between the risk-based and purely deterministic approaches.

- Details of the regulatory issue under consideration will determine where the risk-informed decision falls within the spectrum of risk-based and purely deterministic approaches. 


\section{Risk-Informed and Performance-Based Regulation White Paper (continued)}

- Defense-in-Depth

- Traditionally, the NRC has required defenses to prevent radionuclide releases, to mitigate releases, and to limit human exposures to releases.

- Requires successive compensatory measures to prevent radiation exposures and to prevent accidents or mitigate damage during a malfunction, an accident, or a natural event such as an earthquake or a tornado.

- In mechanical systems, defense-in-depth assured by redundancy and diversity of power sources and physical separation of mitigation systems. 


\section{Risk-Informed and Performance-Based Regulation White Paper (continued)}

- Performance-Based Approach

- A performance-based requirement relies upon measurable (or calculable) outcomes (i.e., performance results) to be met, but provides more flexibility to the licensee as to the means of meeting those outcomes.

- Guidance subsequently developed

- NUREG/BR-0303, "Guidance for Performance-Based Regulation," December 2002 


\section{Risk-Informed and Performance-Based Regulation White Paper (continued)}

- Performance-Based Approach (continued)

- Establishes performance and results as the primary basis for regulatory decision-making and compliance, and incorporates the following attributes:

- (1) measurable (or calculable) parameters (i.e., direct measurement of the physical parameter of interest or of related parameters that can be used to calculate the parameter of interest) exist to monitor system, including facility and licensee performance,

- (2) objective criteria to assess performance are established based on risk insights, deterministic analyses and/or performance history,

- (3) licensees have flexibility to determine how to meet established performance criteria in ways that will encourage and reward improved outcomes; and

- (4) a framework exists in which the failure to meet a performance criterion, while undesirable, will not in and of itself constitute or result in an immediate safety concern. 


\section{Risk-Informed and Performance-Based Regulation White Paper (continued)}

- Performance-Based Approach (continued)

- The measurable (or calculable) parameters may be included in the regulation itself or in formal license conditions, including reference to regulatory guidance adopted by the licensee.

- This regulatory approach is not new to the NRC.

- Commission previously has approved performancebased approaches in 10 CFR Parts 20, 50, 60, 61, and 63. 


\section{Risk-Informed and Performance-Based Regulation White Paper (continued)}

- Performance-Based Approach (continued)

- Can be implemented without the use of risk insights.

- Would require objective performance criteria based on deterministic safety analysis and performance history.

- Would still provide flexibility to the licensee in determining how to meet the performance criteria.

- Establishing objective performance criteria for performance monitoring may not be feasible for some applications and, in such cases, a performance-based approach would not be feasible. 


\section{Risk-Informed and Performance-Based Regulation White Paper (continued)}

- Risk-Informed, Performance-Based Approach

- Combines the "risk-informed" and "performancebased" elements and applies these concepts to NRC rulemaking, licensing, inspection, assessment, enforcement, and other decision-making. 


\section{Risk-Informed and Performance-Based Regulation White Paper (continued)}

- Risk-Informed, Performance-Based Approach

- An approach in which risk insights, engineering analysis and judgment including the principle of defense-in-depth and the incorporation of safety margins, and performance history are used, to

- (1) focus attention on the most important activities,

- (2) establish objective criteria for evaluating performance,

- (3) develop measurable or calculable parameters for monitoring system and licensee performance,

- (4) provide flexibility to determine how to meet the established performance criteria in a way that will encourage and reward improved outcomes, and

- (5) focus on the results as the primary basis for regulatory decision-making. 


\section{NRC Strategic Plan}

- FY $2000-2005$

- First strategic plan which Risk-Informed Regulation Implementation Plan has relevance to

- Strategic Plan FY 2008 - 2013

- Nuclear Regulatory Commission Mission

- License and regulate the Nation's civilian use of byproduct, source, and special nuclear materials to ensure adequate protection of public health and safety, promote the common defense and security, and protect the environment.

- Draft for public review Strategic Plan FY 2014 - 2018 


\section{Risk-informed Performance-based}

Plan

- Risk-informed Performance-based Plan (RPP), formerly known as the Risk-Informed Regulation Implementation Plan (RIRIP), is an improvement to the RIRIP which allows an integrated master plan for activities designed to help the U.S. NRC achieve its goal of a holistic, risk-informed and performance-based regulatory structure and to more transparently communicate the purpose and use of PRAs in the agency's reactor, materials, and waste regulatory programs to the public and stakeholders.

- Previously, the NRC's work to expand the use of PRA had been tracked in the RIRIP, and prior to RIRIP was in the PRA Implementation Plan (PRA-IP).

- PRA-IP had been updated quarterly and provided to the Commission to summarize ongoing work, key accomplishments, and significant changes in the plan. 


\section{Risk-informed Performance-based Plan (continued)}

- As described in former-Chairman Jackson's letter of June 18, 1999, to Senator Thompson and others, the RIRIP was developed in response to a General Accounting Office (GAO) recommendation.

- "PRA Implementation Plan" title changed to the "Risk-Informed Regulation Implementation Plan" (RIRIP) as RIRIP better characterizes the nature and purpose.

- "Risk-Informed Regulation Implementation Plan (RIRIP)" title changed to "Risk-Informed Performance-based Plan" (RPP) in SECY-07-0074 to achieve new goals set forth. 


\section{Risk-informed Performance-based Plan (continued)}

- SECY-00-0062, (March 15, 2000) first (incomplete) version of the RIRIP provided to the Commission from the staff.

- SECY-00-0213, (October 26, 2000) first complete version of RIRIP provided to the Commission from the staff.

- SECY-06-0217, (October 25,2006$)$ directives to improve and update the RIRIP

- SECY-07-00074, (April 26, 2007) objectives expanded to include performance-based regulatory structure, name is changed from RIRIP to RPP.

- SECY-07-0191, (October 31, 2007), first version as RPP.

- SECY-08-00169 (October 31, 2008), last Semi-Annual version of the RPP provided to the Commission from the staff.

- SECY-09-0159 (October 27, 2009), first Annual version of the RPP provided to the Commission from the staff.

- SECY-13-0118 (November 7, 2013), latest RPP. 


\section{Risk-informed Performance-based Plan (continued)}

- RIRIP contained:

- Relevance to Strategic Plan

- Guidelines for Selecting "Candidate" Requirements, Practices, and Processes

- Factors to Consider in the Transition to Risk-Informed Regulation

- Communication Plans

- Training Program

- Success Measures

- Organization of the RIRIP 


\section{Risk-informed Performance-based Plan (continued)}

- RPP then added improvements to RIRIP:

- Focus on the up-front planning process and on the backend following completion of initiatives

- Focus on the NRC's three arena's (reactor, materials, and waste) and sub-arenas (operating reactors, new reactors, advanced reactors, and non-power reactors) and the three functional regulatory areas (licensing, rulemaking, and oversight)

- Define objectives for each arena (sub-arena)

- Maintain a separate plan for each individual identified initiative

- Perform an effective review of selected initiatives 


\section{Framework for Risk- Informed Regulation in NMSS}




\section{Page Intentionally Left Blank}




\section{Framework for Risk-Informed Regulation in NMSS}

- Purpose: Provide an introduction to

- NMSS policy on risk-informing

- History of risk informing in NMSS 


\section{Framework for Risk-Informed Regulation in NMSS}

- Objectives: To have an understanding of the following:

- SECY-99-100 - Framework for Risk-Informed Regulation in NMSS

- Current Implementation Process 


\section{Framework for Risk-Informed Regulation in NMSS}

- References:

- ML080720238 "Risk-Informed Decision-Making for Nuclear Material and Waste Applications," February 2008, Revision 1.

- ML042730524, "Risk-Informed Decision-Making for Nuclear Material and Waste Applications," Draft for Trial Use, May 11, 2005

- SECY-03-0126, "Risk-informed Regulation for the Office of Nuclear Material Safety and Safeguards: Status Report and Plan for Future Work," July 24, 2003.

- SECY-99-100, "Framework for Risk-Informed Regulation in the Office of Nuclear Material Safety and Safeguards," March 31, 1999.

- SECY-98-138, "Risk-Informed, Performance-Based and Risk-Informed, LessPrescriptive Regulation in the Office of Nuclear Material Safety and Safeguards," June 11, 1998.

- Dr. William Travers, NRC, to Dr. B. J. Garrick of ACNW and Dr. D. A. Powers of ACRS, Subject: "Use of Defense in Depth in Risk-Informing NMSS Activities," July 14, 2000.

- ML013610447, "Risk Informing the Materials and Waste Arenas: Integration of Case Studies and Related Risk Assessments," Volume 1: Main Report -- December 2001, Revised February 2002. 


\section{Framework for Risk-Informed Regulation in NMSS}

- Policy

- April 1997 Commission Direction: Develop a framework for applying PRA to nuclear materials uses similar to the reactor framework

- March 1999 SECY 99-100, "Framework for Risk-Informed Regulation in NMSS"

- Commission approved the staff recommendations in SECY 99-100 in June 1999

- NMSS established a Task Force on Risk Assessment and Risk Management in July 1999 


\section{Tasking from SECY 99-100}

- Identify

- Candidate regulatory applications

- Responsible staff organizations

- Interact with staff and stakeholders to decide how to modify current regulatory approaches

- Change current regulatory approach

- Staff training in risk assessment techniques

- Development and adoption of tools 


\section{Transition to Implementation}

- NMSS Risk Task group led response to SECY-99100

- Task Group disbanded October 2004

- Implementation is now through specific activities budgeted by Divisions (see RPP)

- Technical support from Division of Spent Fuel Storage and Transportation (DSFST) $l$ Technical Review Directorate (TRD) and NRC Office of Nuclear Regulatory Research (RES) 


\section{Ongoing Risk-Informing Activities}

- Risk-Informing process for Materials and Waste

- Risk-Informed Decision-Making process developed

- Implementation of Risk-Informing Activities by Divisions

- See SECY-08-00169, Implementation and Update of the Risk-Informed and Performance-Based Plan

- Risk Training (see previous module)

- Risk Communication (internal \& external guidelines) 


\section{Risk-Informed Decision Process}

1. Identify the issue and preliminary alternative regulatory actions that might address it;

2. Decide whether to use risk information, based on the screening considerations

- Risk information useful or necessary

- Development and use of risk information feasible, worth the cost, and not precluded by other considerations

3. If a risk-informed approach to be used, perform risk assessment as needed; and

4. Apply a risk-informed decision method 


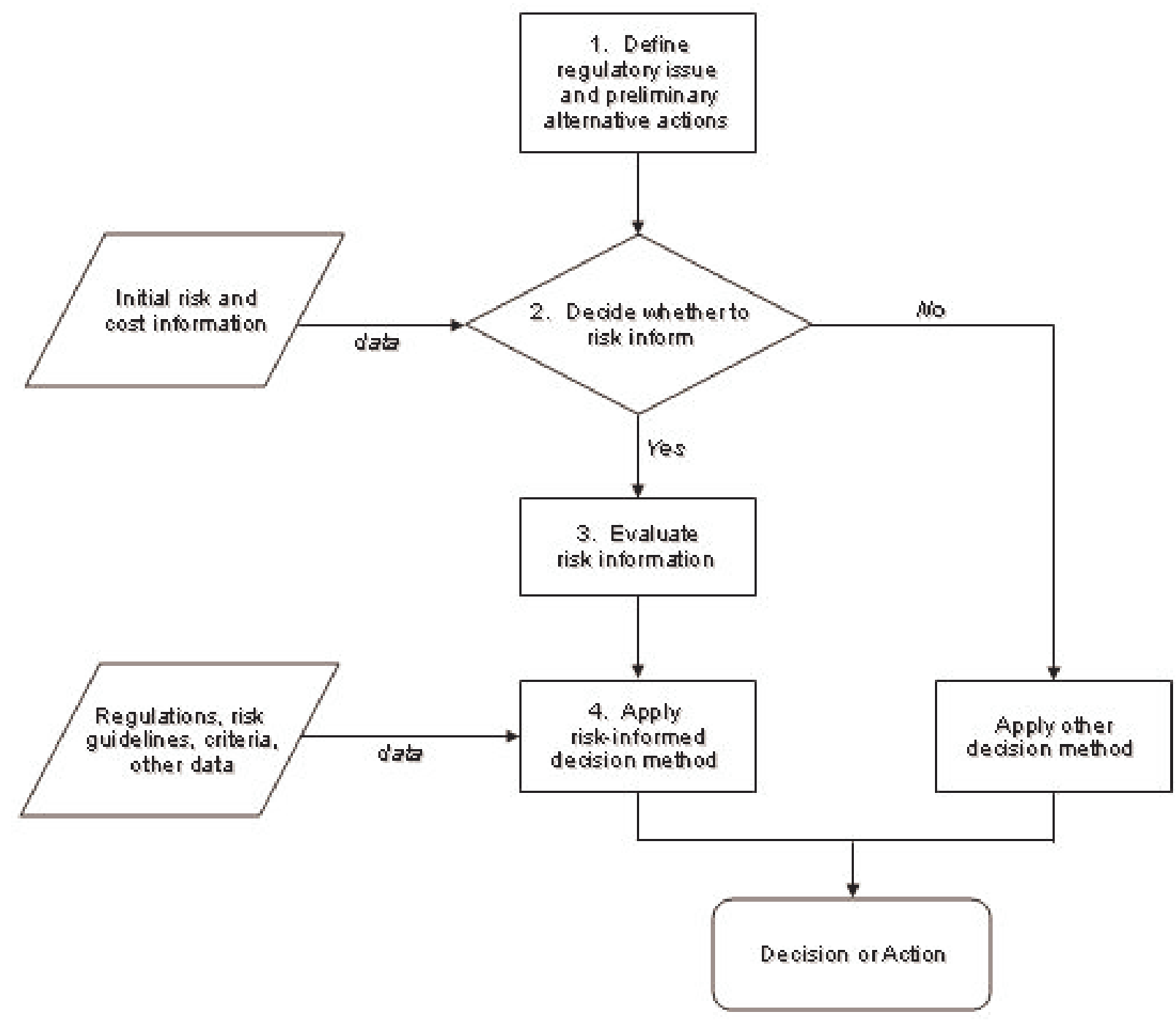


3. Risk Concepts and Methodology 


\section{Page Intentionally Left Blank}




\section{Risk Concepts and Methodology}

- Purpose: Provide an introduction to the fundamental concepts which underlie risk assessment. This introduction will include discussions on the:

- Definition of risk

- Various approaches to risk assessment

- Strengths and limitations of these approaches 


\section{Risk Concepts and Methodology}

- Objectives: At the conclusion of this section, students will be able to:

- Define risk, and the risk triplets

- Identify different approaches to risk assessment

- List some strengths and limitations associated with the various approaches 


\section{Risk Concepts and Methodology}

- References:

- Guidelines for Hazard Evaluation Procedures, American Institute of Chemical Engineers, Center for Chemical Process Safety, 1992 (see www.aiche.org)

- NUREG 1513, Integrated Safety Analysis Guidance Document, May 2001

- NUREG 1520, Standard Review Plan for the Review of a License Application for a Fuel Cycle Facility, March 2002

- NUREG 1718, Standard Review Plan for the Review of an Application for a Mixed Oxide (MOX) Fuel Fabrication Facility: Final Report, August 2000

- A. A. Lakner and R. T. Anderson, Reliability Engineering for Nuclear and Other High Technology Systems, Elsevier Applied Science Publishers LTD, 1985

- NUREG/CR-5485, Guidelines on modeling Common-Cause failures in PRA

- C. B. Meinhold, Radiation Health Risk Assessment, Course Presentation October 1997 


\section{What is Risk?}

- Arises from a "Danger" or "Hazard"

- Always associated with undesired event

- Involves both:

- likelihood of undesired event

- severity (magnitude) of the consequences

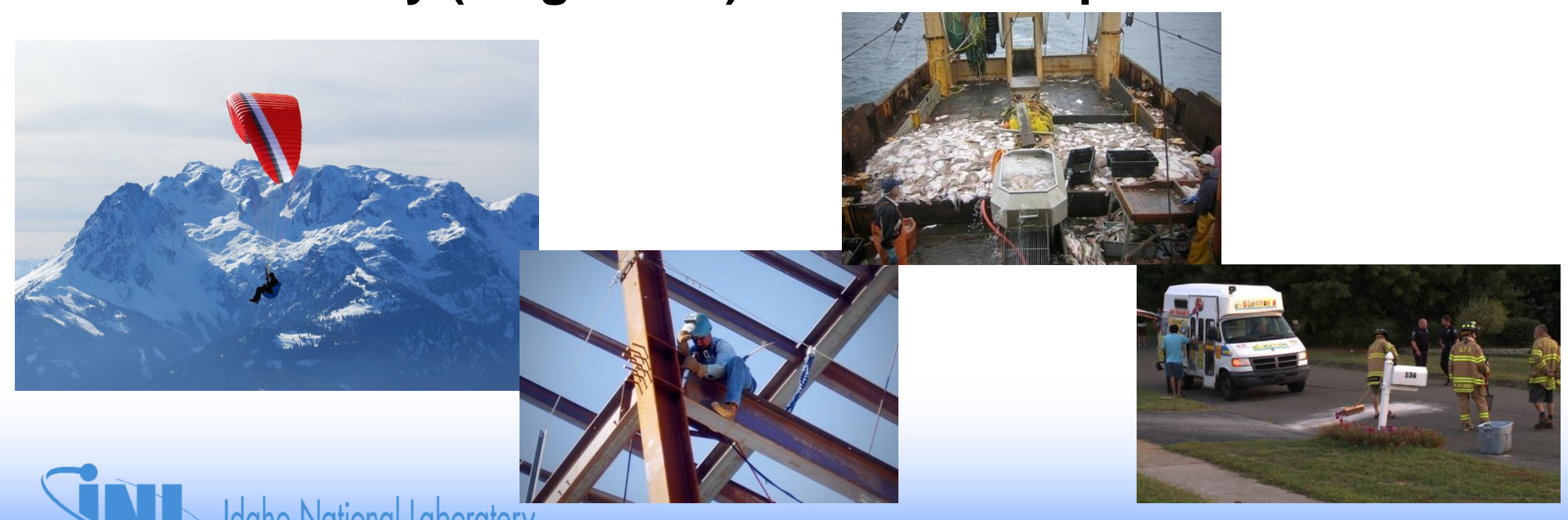




\section{Definition of Risk Triplet}

- What can happen (i.e., normal and/or off-normal conditions)?

- (possible scenario)

- How likely is it?

- (frequency, probability)

- What will be the outcome?

- (consequences)

- A fourth question, reflecting the importance of uncertainty, should also be addressed

- How confident are we in our answers to these three questions? 


\section{Risk = Frequency (Probability) $\mathrm{x}$ Consequences}

\section{Traditional definition of risk}

- Frequency, or rate, is the number of occurrences of some event of interest in some defined interval of time

- Risk then represented by a scalar quantity

- Overall risk represented by a single point

- Each accident scenario represented by a point on a scale (i.e., most risk significant accident scenario has largest product of frequency and consequence) 


\section{An Operational Definition for Risk}

- Risk is a set of triplets $<\mathrm{Si}$, $\mathrm{Pi}, \mathrm{Ci}>$ that answer the questions :

- What can go wrong? (scenarios, $\mathrm{Si}$ )

- How likely is it? (probabilities, $\mathrm{Pi}$ )

\begin{tabular}{|c|c|c|}
\hline Scenario & Probability & Consequence \\
\hline & & \\
$\mathrm{S}_{1}$ & $p_{1}$ & $\mathrm{C}_{1}$ \\
$\mathrm{~S}_{2}$ & $p_{2}$ & $\mathrm{C}_{2}$ \\
$\mathrm{~S}_{3}$ & $p_{3}$ & $\mathrm{C}_{3}$ \\
$\vdots$ & $\vdots$ & $\vdots$ \\
$\mathrm{S}_{\mathrm{N}}$ & $p_{\mathrm{N}}$ & $\mathrm{C}_{\mathrm{N}}$ \\
\hline
\end{tabular}

- What are the consequences? (adverse effects, $\mathrm{Ci}$ )

\section{$\mathrm{R}=\mathrm{RISK}=\left\{\left\langle\mathrm{S}_{\mathrm{i}}, P_{\mathrm{i}}, \mathrm{C}_{\mathrm{i}}\right\rangle\right\}$}

- Kaplan \& Garrick, Risk Analysis, 1981

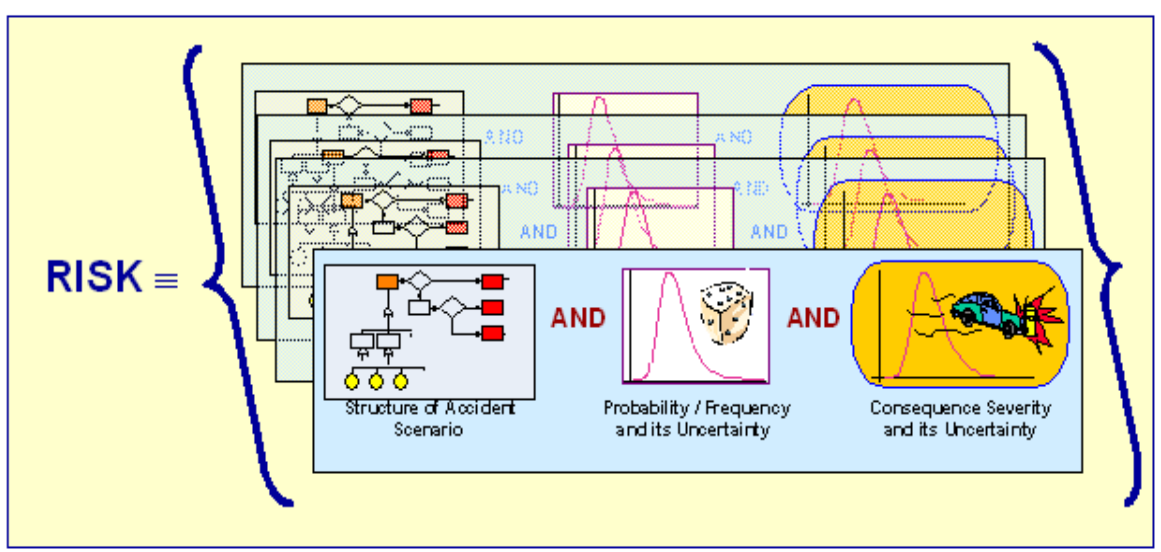




\section{Risk $\quad\left[\frac{\text { Magnitude of Consequences }}{\text { Unit of Time }}\right]=$}

Frequency $\quad\left[\frac{\text { Scenario }}{\text { Unit of Time }}\right] \mathrm{X}$

Consequences $\quad\left[\frac{\text { Magnitude }}{\text { Scenario }}\right]$ 


\section{Example of Risk Equation}

$$
\text { Risk } \quad\left[\frac{\text { Deaths from Accidents }}{\text { Year }}\right]=
$$

Frequency $\left[\frac{\text { Total Number of Accidents }}{\text { Year }}\right]$

$$
\mathrm{X}
$$

Consequences $\left[\frac{\text { Total Number of Accidents that Resulted in a Death }}{\text { Total Number of Accidents }}\right]$ 


\section{Risk Example - Death Due to Accidents}

- Societal Risk = 122,777 accidental-deaths/year

- Average Individual Risk

$=(122,777$ Deaths/Year $) / 311,577,557$ Est. U.S. Population

= 3.94E-04 Deaths/Person-Year

$\approx$ 1/2,538 Deaths/Person-Year

- In any given year, approximately 1 out of every 2,538 people in the entire U.S. population will die from an accidental death

Note: Figures presented above are based on the National Vital Statistics Reports, Deaths: Preliminary Data for 2011, October 10, 2012, Volume 61, Number 6, at www.cdc.gov which is the Centers for Disease Control and Prevention (CDC) National Center for Health Statistics (NCHS) for the United States. Unintentional injuries is the preferred term to accidental deaths in the public health community. The average individual risk for accidental deaths in the 1980 s was approximately 5.0E-04 Deaths/Person-year. 


\section{Risk Example - Death Due to Cancer}

- Societal Risk = 575,313 cancer-deaths/year

- Average Individual Risk

$=(575,313$ Cancer-Deaths $/$ Year $) / 311,577,557$ Est. U.S. Population

$=1.85 \mathrm{E}-03$ Cancer-Deaths $/$ Person-Year

$\approx$ 1/542 Cancer-Deaths/Person-Year

- In any given year, approximately 1 person out of every 542 people in the entire U.S. population will die from cancer

Note: Figures presented above are based on the National Vital Statistics Reports, Deaths: Preliminary Data for 2011, October 10, 2012, Volume 61, Number 6, at www.cdc.gov which is the Centers for Disease Control and Prevention (CDC) National Center for Health Statistics (NCHS) for the United States. U.S. Malignant neoplasms is the preferred term to cancer deaths in the public health community. The average individual risk for cancer deaths in the 1980s was 2.0E-03 Deaths/Person-year. 


\section{Risk Assessment}

- Systematic method that:

- Addresses risk triplet as it relates to performance of a particular system

- hardware components (e.g., pumps and valves)

- structures

- humans

- Provides an understanding of

- likely outcomes

- system interaction

- sensitivities

- areas of importance

- areas of uncertainty 


\section{Approaches to Risk Management/Assessment}

- Traditional Approaches

- Maximum Credible Accident

- Design Basis Accident (DBA)

- Actuarial Analysis

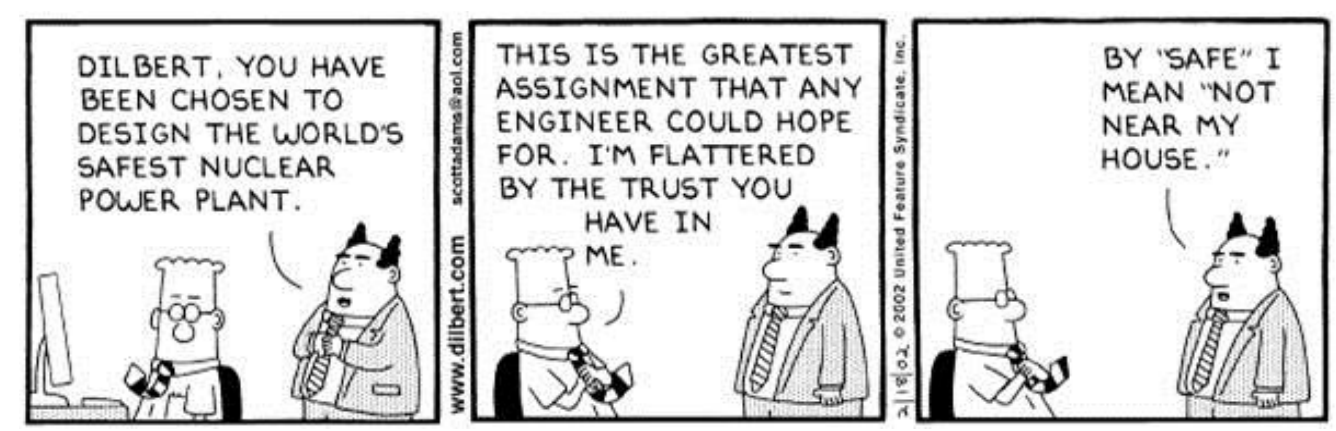




\section{Approaches to Risk Management/Assessment (continued)}

- Broad Identification and Overview of Hazards

- Hazard/Barrier Analysis

- Safety Review

- Checklist Analysis

- Relative Ranking

- Preliminary Hazard Analysis (PHA)

- What-If Analysis 


\section{Approaches to Risk Management/Assessment (continued)}

- Detailed analysis of wide range of hazards to identify possible scenarios

- What-If/Checklist Analysis

- Hazard and Operability Analysis (HAZOP)

- Failure Modes and Effects Analysis (FMEA)

- In-depth analysis of specific scenarios; requires higher degree of analyst expertise, and increased time and effort

- Probabilistic Risk Assessment (PRA)/Probabilistic Safety Assessment (PSA)

- Integrated Safety Analysis (ISA)

- Performance Assessment (PA)

- PRA/ISA/PA may include

- Fault Tree Analysis

- Event Tree Analysis

- Cause-Consequence Analysis

- Human Reliability Analysis 


\section{Approaches to Risk Management/Assessment (continued)}

- Choice of method or combinations of methods will depend on

- Reason for conducting the analysis

- Results needed from the analysis

- Available information

- Complexity of the process being analyzed

- Personnel and experience available 


\section{Maximum Credible Accident}

- Requires worst-case, credible accident to be postulated

- Consequences of accident are typically estimated

- Example: Fuel Facility Design

- 10CFR70.61(b),(c),(d): Performance Requirements - the risk of each credible high-consequence event; each credible intermediate-consequence event; and each credible normal and abnormal event... 


\section{Maximum Credible Accident (continued)}

- Drawbacks to Maximum Credible Accident Approach

- How to define "credible"

- Specification of worst-case accident is subjective

- Is two 747 jets colliding mid-air a "worst-case" accident?

- $\mathbf{5 0} \%$ of a hazardous material released during a fire?

- May lead to overly conservative design, regulation or inappropriate focus

- Typically, no consideration given to likelihood (probability or frequency) of worst-case accident

- Can lead to belief that "worst case" is bounding 


\section{Design Basis Accident}

- Definition (NRC)

- A postulated accident that a nuclear facility must be designed and built to withstand without loss to the systems, structures, and components necessary to ensure public health and safety.

- Traditional, deterministic approach

- Typically involves implied (may or may not be quantified) elements of probability or frequency of specific accidents

- Facility/system designed to cope with specified set of accidents

- Design Basis Accident typically considers only single active failures

- Example: 50-year flood for a waste storage facility 


\section{Design Basis Accident (continued)}

- Drawbacks to Design Basis Accident Approach

- Because the specific accidents typically only have implied elements of probability or frequency, the understanding of more likely or less-likely accidents may not be attainable.

- Because only single failures are typically considered, available layers of defense-in-depth may not be accounted for or given credit. 


\section{Actuarial Analysis}

- Estimates frequencies of accidents from statistical databases

- Requires large empirical database

- Used widely by insurance industry

- Examples:

- NUREG-0170, Final Environmental Statement on the Transportation of Radioactive Material by Air and Other Modes, December 1977

- NUREG/CR-6672, Reexamination of Spent Fuel Shipment Risk Estimates, March 2000 


\section{Actuarial Analysis (continued)}

- Drawbacks to Actuarial Analysis

- Large empirical databases not available, not tracked and recorded

- Numerator typically available, denominator not always known or properly accounted for

- Not a good technique for rare events 


\section{Hazard/Barrier Analysis}

- Analysis that evaluates the barriers that prevent exposure to a hazard

- Analysis includes

- Identification of targets (i.e., workers, public, facility, environment)

- Identification and evaluation of hazards

- Identification and evaluation of barriers

- Barriers are levels of protection; physical and administrative

- Increased barriers as hazards and risk increase 


\section{Hazard/Barrier Analysis (continued)}

- Drawbacks of Hazard/Barrier Analysis

- Likelihood may not be considered

- Interactions between barriers may not be considered, only if the barrier is available 


\section{Relative Ranking Analysis}

- Risk evaluated on a relative basis (i.e., weighted from most significant to least significant)

- Risk is calculated as a product of three parameters (likelihood, exposure, possible consequence)

- Example values:

\begin{tabular}{|c|l|c|l|c|l|}
\hline \multicolumn{2}{|c|}{ Likelihood } & \multicolumn{2}{c|}{ Exposure } & \multicolumn{2}{c|}{ Possible Consequence } \\
\hline 0.1 & Virtually impossible & 0.5 & Very rare (<yearly) & 1 & Noticeable (e.g. minor first aid accident) \\
\hline 0.2 & Practically impossible & 1 & Rare (yearly) & 3 & Important (sickness absence) \\
\hline 0.5 & Conceivable but very unlikely & 2 & Unusual (monthly) & 7 & Serious (irreversible injury) \\
\hline 1 & Only remotely possible & 3 & Occasional (weekly) & 15 & Very serious (fatality) \\
\hline 3 & Unusual but possible & 6 & Frequent (daily) & 40 & Disaster (few fatalities) \\
\hline 6 & Quite possible & 10 & Continuous & & \\
\hline 10 & Might well be expected & & & & \\
\hline
\end{tabular}




\section{Relative Ranking Analysis (cont.)}

- Risk score is evaluated as product (Likelihood) $x$ (Exposure) x (Possible Consequence)

- Risk scores are then ranked to help make decisions

- Drawbacks

- Values not necessarily derived from data, based more on perception

- Subjective 


\section{Preliminary Hazard Analysis}

- A Preliminary Hazard Analysis (PHA) is a qualitative assessment of potential hazardous conditions

- Objectives of PHA

- Gross hazard identification

- Identification of previous event causes

- Identification of potential initiators

- Identification of possible mitigating systems and/or actions

- Categorization and screening of events requiring further analysis 


\section{What-If and What-If/Checklist Analysis}

- A qualitative assessment typically by a group of personnel familiar with the process

- Assessment focus is on undesirable events, determined by "what-if" events postulated by the group of experienced personnel. 


\section{Example What-If Analysis of a Pelletizing, Rod- loading, and Fuel Bundle Assembly Steps}

In this example, the what-if method is used to study criticality hazards in a uranium fuel fabrication operation. The process begins with a roll-type compaction unit that takes uranium oxide $\left(\mathrm{UO}_{2}\right)$ powder and binder-lubricant and combines it before feeding to the pellet presses where pellets are formed. The pellets are transferred in boats to the sintering furnace, where the pellets are sintered in a hydrogen atmosphere to 95 percent theoretical density. The pellets are then ground to precise dimensions, and dried. Dried and inspected pellets are loaded into empty fuel tubes that are pressurized and sealed. Finished fuel rods are bundled into assemblies and stored.

In the following analysis, it is assumed that the prevention of an inadvertent criticality is accomplished by preventing the presence of excess moderating material and by maintaining appropriate geometric controls.

Reference: NUREG 1513 Appendix B 


\section{Uranium Fuel Fabrication - What-if Example}

$\mathrm{UO}_{2}$ Powder and Binder-Lubricant
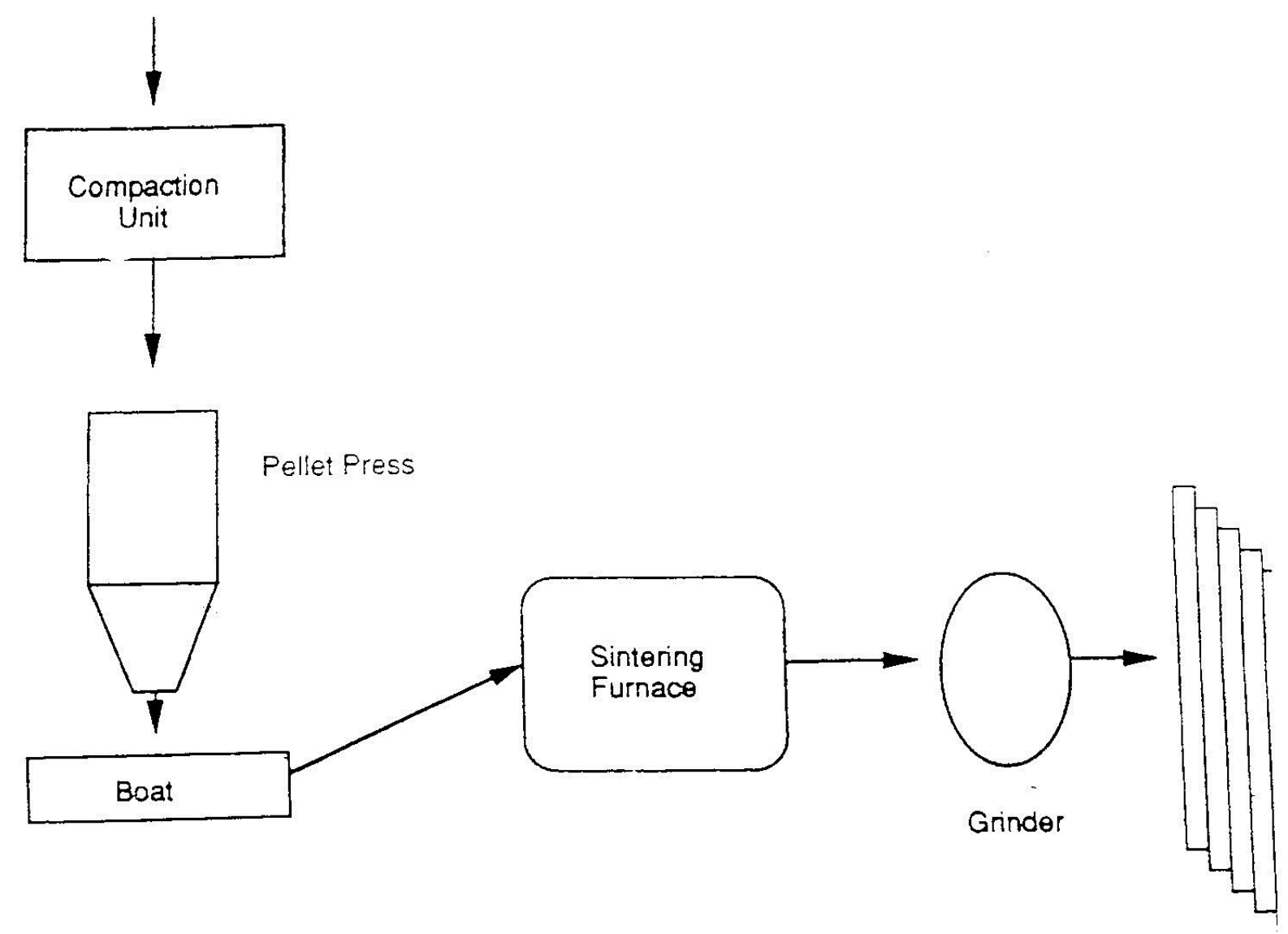


\section{What-If Analysis Example}

\begin{tabular}{|c|c|c|}
\hline & $\begin{array}{l}\text { What-if Analysis of Pelletizing Step } \\
\text { Subject: Criticality }\end{array}$ & \\
\hline What-if/Cause & Consequence/Hazard & Safeguards \\
\hline \multicolumn{3}{|l|}{ Moderation Control Fails Because: } \\
\hline Hydraulic fluid leaks. & Moderator reaches powder/criticality. & $\begin{array}{l}\text { All hydraulic fluid systems are shielded } \\
\text { from powder. }\end{array}$ \\
\hline Powder is not dry enough. & Moderator reaches powder/criticality. & $\begin{array}{l}\text { Multiple quality control steps for } \\
\text { analytical results. }\end{array}$ \\
\hline Room floods. & Moderator reaches powder/criticality. & $\begin{array}{l}\text { No piped water systems in bulk powder } \\
\text { handling areas. }\end{array}$ \\
\hline $\begin{array}{l}\text { Bulk powder storage container collects } \\
\text { and holds liquid. }\end{array}$ & Moderator reaches powder/criticality. & $\begin{array}{l}\text { Bulk containers are moved with sealed } \\
\text { opening facing down. }\end{array}$ \\
\hline \multicolumn{3}{|l|}{ Geometry Control Fails Because: } \\
\hline Cart tips over. & Safe geometry exceeded/criticality. & Passive stops welded to bottom of carts. \\
\hline $\begin{array}{l}\text { Powder builds up in pelletizing } \\
\text { equipment. }\end{array}$ & Safe geometry exceeded/criticality. & $\begin{array}{l}\text { Buildup prevention devises within } \\
\text { equipment. }\end{array}$ \\
\hline Small powder storage container breaks. & Safe geometry exceeded/criticality. & $\begin{array}{l}\text { Containers are of rugged construction, } \\
\text { containers are administratively } \\
\text { protected. }\end{array}$ \\
\hline Sintering boats are stacked too high. & Safe geometry exceeded/criticality. & Training, administrative controls. \\
\hline
\end{tabular}




\section{Hazard and Operability Analysis}

- A Hazard and Operability Analysis (HAZOP) is a qualitative detailed analysis evaluating each process, line by line, in an exhaustive manner.

- Typically, analysis documented in a table format using data base software

- Each process with variables or parameters (e.g., quantity, flow, temperature, pressure, level, $\mathrm{pH}$, etc.)

- Description of deviation from normal operation - guide words (no, less, more, part of, as well as, reverse, other than)

- Potential consequences of the deviations

- Existing mitigating factors and controls 


\section{Hazard and Operability Analysis (continued)}

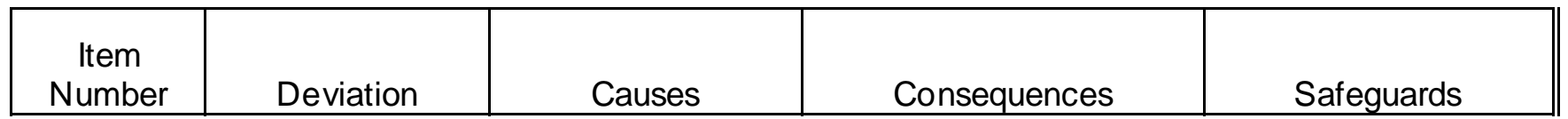

5.0 VESSEL - VAPORIZER STEAM CHEST (Continued)

5.11 Leak of $\mathrm{UF}_{6}$ cylinder in vaporizer steam chest

High temperature
(Item 5.3)
Faulty
connections on
the

the cylinder valve

High pressure

(Item 5.5)

Cylinder valve

leaking

Corrosion

External impact

Valve or gasket

failure

Improper

maintenance
Potential criticality concern

Potential release or personnel exposure to $\mathrm{UF}_{6}$ and/or HF acid
Administrative controls for checking for leaks

Startup checklist
Conductivity monitor

Ventilation scrubber to remove potential $\mathrm{UF}_{6}$ or HF releases and prevent release to the atmosphere

Reference: NUREG 1513 Appendix B 


\section{Failure Modes and Effects Analysis}

(FMEA)

- A Failure Modes and Effects Analysis (FMEA) is similar to a HAZOP analysis, extends analysis by identifying failure modes and the effects of the failures.

- Often, failure effect categories are identified and assigned to each failure mode.

- Sometimes, a FMEA is extended to a Failure Modes, Effects, and Criticality Analysis (FMECA), where criticality is associated with how critical the failure would be to operations (i.e., no stop in process, stop in process with equipment needing replacement, or complete loss of process and/or facility). 


\section{PRA/PSA}

- An analytical tool to...........

- identify possible scenarios

- estimate their likelihood of occurrence

- estimate their consequences

- Specific technical analysis that systematically answers the risk triplet

- What can happen (i.e., normal conditions and/or offnormal conditions)? (scenario)

- How likely is it to occur? (probability, frequency)

- What will be the outcome? (consequences) 


\section{Specific Strengths of PRA}

- Quantifies risks associated with performance measures

- PRA metrics are integral risk metrics

- Captures dependences and other relationships between sub-systems

- Works within scenario-based concept of risk that best informs decision-making

- Identifies contributing elements (initiating events, pivotal events, basic events)

- Quantifies the risk significance of contributing elements, helping focus on where improvements will be effective

- Provides a framework for a monitoring / trending program to detect risk-significant adverse trends in performance 


\section{Specific Strengths of PRA}

- Rigorous, systematic analysis tool

- Information integration (multidisciplinary)

- Allows consideration of complex interactions

- Develops qualitative design insights

- Develops quantitative measures for decision making

- Provides a structure for sensitivity studies

- Explicitly highlights and treats principal sources of uncertainty 


\section{Principal Limitations of PRA}

- Adequacy of data base

- Level of understanding of physical processes

- Sensitivity of results to analytical assumptions

- Modeling constraints and approximations

- Bounds on analytical tasks, including truncation

- PRA is often only a snapshot analysis -- there may be a need for a "living" PRA

- Model typically reflects a "frozen" configuration

- All modifications or specific configurations may not be addressed

- Lack of completeness 


\section{Definition of Integrated Safety Analysis}

- An Integrated Safety Analysis (ISA) is a systematic examination of a facility's processes, equipment, structures, and personnel activities to ensure that all relevant hazards that could result in unacceptable consequences have been adequately evaluated and appropriate protective measures identified. (NUREG-1513)

- Multiple hazards are considered, such as

- radiological

- chemical

- criticality

- fire

- Intent of ISA is not to necessarily quantify risk, but to identify and evaluate the adequacy of safety controls. 


\section{Definition of Integrated Safety Analysis (continued)}

- ISA should provide:

- Description of the structures, equipment, and process activities at the facility

- Identification and systematic analysis of hazards at the facility

- Comprehensive identification of potential accident/event sequences that would result in unacceptable consequences, and the expected likelihoods of those sequences,

- Identification and description of controls (i.e., structures, systems, equipment, or components) that are relied on to limit or prevent potential accidents or mitigate their consequences

- Identification of measures taken to ensure the availability and reliability of identified safety systems. 


\section{ISA Analysis Method Matched to}

Need

- Methods developed to analyze process hazards at chemical facilities

- Deductive (from general to specific) and inductive (from individual cases to general conclusion) approaches acceptable

- Deterministic, qualitative approaches preferred by industry - emphasis on failure sequences and controls

- Full range of deterministic and probabilistic techniques available 


\section{ISA Approach at Fuel Fabrication Plants}

- Conduct hazard analysis on systems; consider likelihood and unmitigated consequences of failure sequences

- Assign risk importance to failure sequences

- Identify controls (active and passive engineered controls, administrative controls) to prevent or reduce likelihood and mitigate consequences

- Apply graded level of management programs to ensure controls remain available and reliable; higher level programs for controls that protect against higher risk sequences

- Management programs include functional testing, quality assurance, preventive maintenance, configuration control, training, and others 


\section{ISA - Example Standard Review Plan 1718 (NUREG 1718 - Appendix A)}

\section{Consequence Category 3-High Consequences}

An accident resulting in any consequence specified in $\S 70.61$ (b); that is: an acute worker exposure of $1 \mathrm{~Sv}(100 \mathrm{rem})^{1}$ or greater TEDE ${ }^{2}$, or a chemical exposure that could endanger the life of a worker (as defined by the applicant); or acute exposure of a member of the public outside the controlled area to a radiation dose (D) of $0.25 \mathrm{~Sv}(25 \mathrm{rem})$ or greater TEDE, a 30 mg soluble uranium intake, or a chemical exposure that could lead to irreversible or other serious long-lasting health effects, as defined by the applicant (represented herein as CHEM3).

\section{Consequence Category 2-Intermediate Consequences}

An accident resulting in any consequence specified in $\S 70.61$ (c). That is, acute exposure of a worker to a radiation dose of $0.25 \mathrm{~Sv}(25 \mathrm{rem})$ or greater but less than $1 \mathrm{~Sv}(100 \mathrm{rem}) \mathrm{TEDE}$, or chemical exposure that could lead to irreversible or other serious long-lasting health effects, as defined by the applicant (represented herein as CHEM2); or acute exposure of a member of the public outside the controlled area to a radiation dose of $0.05(5 \mathrm{rem})$ or greater but less than $0.25 \mathrm{~Sv}(25 \mathrm{rem}) \mathrm{TEDE}$, or a chemical exposure that could cause mild transient health effects, as defined by the applicant (represented herein as CHEM1); or prompt release of radiation outside the restricted area that would, if averaged over a 24-hour period, exceed 5,000 times the values specified in Table 2 of Appendix B to 10 CFR Part 20.

\section{Consequence Category 1-Low Consequences}

Any accident with potential adverse radiological or chemical consequences but at exposures less than consequence Categories 3 and 2 above.

'A nuclear criticality would normally be considered a high consequence event because of the potential for producing a high radiation dose to a worker.

${ }^{2}$ TEDE is Total Effective Dose Equivalent (see 10 CFR Part 20), represented by 'D'. 


\section{ISA - Example Standard Review Plan 1718 (NUREG 1718) (continued)}

TABLE A-1: Consequence Severity Categories Based on 10 CFR 70.61

\begin{tabular}{|c|c|c|c|}
\hline & Workers & Offsite Public & Environment \\
\hline $\begin{array}{l}\text { Consequence } \\
\text { Category 3: } \\
\text { High }\end{array}$ & $\begin{array}{l}\mathrm{D}^{2} \geq 1 \mathrm{~Sv}(100 \mathrm{rem}) \\
\geq \text { CHEM3 }\end{array}$ & $\begin{array}{l}\mathrm{D} \geq 0.25 \mathrm{~Sv}(25 \mathrm{rem}) \\
30 \mathrm{mg} \mathrm{sol} \mathrm{U} \text { intake } \\
\geq \mathrm{CHEM} 2\end{array}$ & \\
\hline $\begin{array}{l}\text { Consequence } \\
\text { Category 2: } \\
\text { Intermediate }\end{array}$ & $\begin{array}{l}0.25 \mathrm{~Sv} \leq \mathrm{D}<1 \mathrm{~Sv} \\
\geq \mathrm{CHEM} 2 \\
\text { but } \\
<\mathrm{CHEM} 3\end{array}$ & $\begin{array}{l}0.05 \mathrm{~Sv} \leq \mathrm{D}<0.25 \mathrm{~Sv} \\
\geq \mathrm{CHEM} 1 \\
\text { but } \\
<\mathrm{CHEM} 2\end{array}$ & $\begin{array}{l}\text { radioactive release } \\
>5,000 \mathrm{x} \\
\text { Table } 2 \text { App. B } \\
10 \text { CFR } 20\end{array}$ \\
\hline $\begin{array}{l}\text { Consequence } \\
\text { Category 1: } \\
\text { Low }\end{array}$ & $\begin{array}{l}\text { Accidents of lesser } \\
\text { radiological and chemical } \\
\text { exposures to workers than } \\
\text { those above in this column }\end{array}$ & $\begin{array}{l}\text { Accidents of lesser radiological } \\
\text { and chemical exposures to the } \\
\text { public than those above in this } \\
\text { column }\end{array}$ & $\begin{array}{l}\text { Radioactive releases } \\
\text { producing effects less than } \\
\text { those specified above in } \\
\text { this column }\end{array}$ \\
\hline
\end{tabular}




\section{ISA - Example Standard Review Plan 1718 (NUREG 1718) (continued)}

- Consequence Category 3 - High Consequences

- CHEM3

- chemical exposure that could endanger the life of a worker (as defined by the applicant)

- chemical exposure that could lead to irreversible or other serious long-lasting health effects of public (as defined by the applicant)

- Consequence Category 2 - Intermediate Consequences

- CHEM2

- chemical exposure that could lead to irreversible or other serious long-lasting health effects of a worker (as defined by the applicant)

- CHEM1

- chemical exposure that could cause mild transient health effects of public (as defined by the applicant) 


\section{ISA - Example Standard Review Plan 1718 (NUREG 1718) (continued)}

- CHEM3, CHEM2, and CHEM1 Levels

- Applicant evaluates criteria for each chemical

- AEGL - Acute Exposure Guideline Level

- ERPG - Emergency Response Exposure Guideline

- Applicant uses guidelines from organizations such as;

- OSHA - Occupational Safety and Health Administration

- ACGIH - American Conference of Governmental Industrial Hygienists

- NIOSH - National Institute for Occupational Safety and Health

- and others

- AEGL and/or ERPG exposure level criteria (typically in ppm or $\mathrm{mg} / \mathrm{m3}$ ) such as;

- TLV - Threshold Limit Value

- TLV-TWA - TLV Time Weighted Average

- IDLH - Immediately Dangerous to Life and Health

- LOC - Level of Concern

- PEL - Permissible Exposure Level

- etc. 


\section{ISA - Example Standard Review Plan 1718 (NUREG 1718) (continued)}

- Likelihood Category 1: Consequence Category 3 accidents must be "highly unlikely."

- Likelihood Category 2: Consequence Category 2 accidents must be "unlikely."

- Likelihood Category 3: "Not unlikely." Although this likelihood category includes unintended events that might actually be expected to happen, others might be less frequent. For this reason, the term "likely" was not used for these events. 


\section{ISA - Example Standard Review Plan 1718 (NUREG 1718) (continued)}

- The following numerical guidelines are used for the purposes of this example. The underlying frequencies are based on definite assumptions about the numbers of intermediate and high consequence events, as discussed in SRP Section 5.4.3.2.

- Likelihood Category 1: Highly unlikely, a frequency of less than $1 \times 10-5$ per year per accident.

- Likelihood Category 2: Unlikely, a frequency of less than $4 \times 10-4$ per year per accident (but more frequent than 10-5).

- Likelihood Category 3: Not unlikely, more frequent than $4 \times 10-4$ per year per accident. 


\section{ISA - Example Standard Review Plan 1718 (NUREG 1718) (continued)}

TABLE A-2: Risk Matrix

\begin{tabular}{|l||l|l|l|}
\hline & $\begin{array}{l}\text { Likelihood Category 1: } \\
\text { Highly Unlikely }\end{array}$ & $\begin{array}{l}\text { Likelihood Category 2: } \\
\text { Unlikely }\end{array}$ & $\begin{array}{l}\text { Likelihood Category 3: } \\
\text { Not Unlikely }\end{array}$ \\
\hline \hline $\begin{array}{l}\text { Consequence Category 3: } \\
\text { High }\end{array}$ & 3 acceptable & 6 unacceptable & 9 unacceptable \\
\hline $\begin{array}{l}\text { Consequence Category 2: } \\
\text { Intermediate }\end{array}$ & 2 acceptable & 4 acceptable & 6 unacceptable \\
\hline $\begin{array}{l}\text { Consequence Category 1: } \\
\text { Low }\end{array}$ & 1 acceptable & 2 acceptable & 3 acceptable \\
\hline
\end{tabular}




\section{ISA - Example Standard Review Plan 1718 (NUREG 1718) (continued)}

Table A-9: Example Accident Sequence Summary and Risk Index Assignment

Process: $\mathrm{P}^{3}$ (Plutonium Purification Process) Node: 2SX (Second-Pass Solvent Extraction)

\begin{tabular}{|c|c|c|c|c|c|c|c|}
\hline $\begin{array}{l}\text { Accident } \\
\text { Sequence }\end{array}$ & $\begin{array}{l}\text { Initiating Event } \\
\text { (a) }\end{array}$ & $\begin{array}{l}\text { Preventive } \\
\text { Control } 1 \\
\text { (b) }\end{array}$ & $\begin{array}{l}\text { Preventive } \\
\text { Controt } 2 \\
\text { (c) }\end{array}$ & $\begin{array}{l}\text { Likelihoud" } \\
\text { Index T and } \\
\text { Calegory C } \\
\quad \text { (d) }\end{array}$ & $\begin{array}{l}\text { Conse- } \\
\text { quence } \\
\text { Category } \\
\text { (e) }\end{array}$ & $\begin{array}{c}\text { Risk } \\
\text { Indices } \\
(f=d \times \theta)\end{array}$ & $\begin{array}{l}\text { Comments } \\
\& \\
\text { Recommendatians }\end{array}$ \\
\hline $28 x-001$ & Pump chamber leaks & $\begin{array}{l}\text { 2SX-PE1: Pump chamber is safe volume } \\
\text { F1 =-1. Regular maintenance prevents frequent pump } \\
\text { tailure. } \\
\text { D1 =-3. Pump failure would be detected by oil } \\
\text { presence in the solution } h \text { clear glass columns. } \\
\text { Process conthualy monitored by operalors. }\end{array}$ & 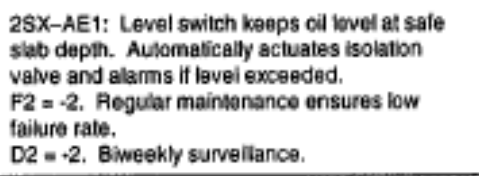 & $\begin{array}{l}T=-5 \\
C=1\end{array}$ & 3 & 3 & \\
\hline $28 x-002$ & $\begin{array}{l}\text { Heat exchanger tube } \\
\text { leaks }\end{array}$ & $\begin{array}{l}\text { 2SX-AE2: Diflerental gauge alarms if pressure } \\
\text { differential across evaporator not maintained. } \\
F 1=-1 \text {. Regular maintenance ensures low failure rate. } \\
\text { D1 }=-3 \text {. FaĽure would be detecled during one shitt } \\
\text { because concentration monitored frequently for } Q A \text {. }\end{array}$ & 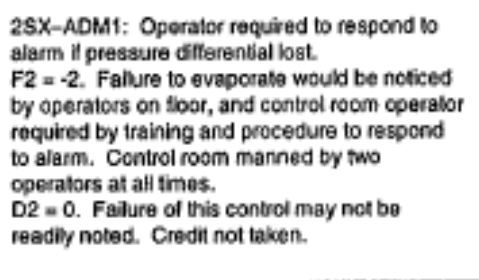 & $\begin{array}{l}T=-4 \\
C=2\end{array}$ & 3 & 6 & $\begin{array}{l}\text { This scenario requires } \\
\text { othar controls to ensure } \\
\text { adequale low } \\
\text { likelincod. } \\
\text { Recommend } \\
\text { installation of a drain } \\
\text { ine on the steam } \\
\text { supply to prevent liquid } \\
\text { accumulaston. }\end{array}$ \\
\hline $25 x-003$ & $\begin{array}{l}\text { Movve force causes } \\
\text { potonfial backllow to } \\
\text { nitric acid }\end{array}$ & $\begin{array}{l}\text { 2SX-PE2: Siphon break instaled on supply Ine. } \\
\text { F1 *-4. The most ikely scenario is that the siphon } \\
\text { break was never instalod in the first placo. There is a } \\
\text { rigocous configuration control program for safety grade } \\
\text { items. } \\
\text { O1 }=0 \text {. Al salesy grade items audited annualy io } \\
\text { conltrm ther conlinued presence. }\end{array}$ & 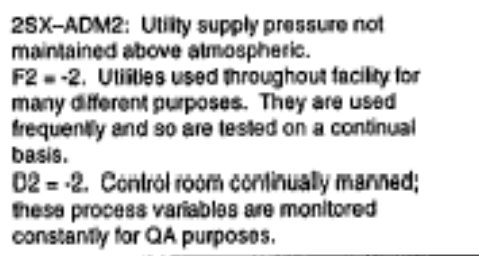 & $\begin{array}{l}T=+6 \\
C=1\end{array}$ & 3 & 3 & \\
\hline $28 x-004$ & $\begin{array}{l}\text { Moltive force causes } \\
\text { polential baclotiow to } \\
\text { DWW }\end{array}$ & $\begin{array}{l}\text { 2SX-PE3: Sphon break installed on supply line. } \\
\text { soe 2SX-003 for explanation. }\end{array}$ & $\begin{array}{l}\text { 2SX-AOM3: U6ily sLpply pressure not } \\
\text { mahtained above atmospheric. } \\
\text { see } 2 S X-003 \text { lor explanation. }\end{array}$ & $\begin{array}{l}\mathrm{T}=5.5 \\
\mathrm{C}=1\end{array}$ & 3 & 3 & . \\
\hline
\end{tabular}




\section{ISA - Example Standard Review Plan 1718 (NUREG 1718) (continued)}

\begin{tabular}{|c|c|c|c|c|c|c|c|}
\hline $\begin{array}{l}\text { Accident } \\
\text { Sequence }\end{array}$ & $\begin{array}{l}\text { Initiating Event } \\
\text { (a) }\end{array}$ & $\begin{array}{l}\text { Preventive } \\
\text { Confrol } 1 \\
\text { (b) }\end{array}$ & $\begin{array}{l}\text { Preventive } \\
\text { Coniroi } 2 \\
\text { (c) }\end{array}$ & $\begin{array}{l}\text { Likelihood" } \\
\text { hdex T and } \\
\text { Calegory C } \\
\text { (d) }\end{array}$ & $\begin{array}{c}\text { Conse- } \\
\text { quence } \\
\text { Calegory } \\
(e)\end{array}$ & $\begin{array}{c}\text { Risk } \\
\text { Indices } \\
(f=d \times 0)\end{array}$ & $\begin{array}{l}\text { Comments } \\
\& \\
\text { Reccemmendations }\end{array}$ \\
\hline $25 x-005$ & $\begin{array}{l}\text { Concenirated } \\
\text { plutonium not } \\
\text { stripped froen arganic }\end{array}$ & 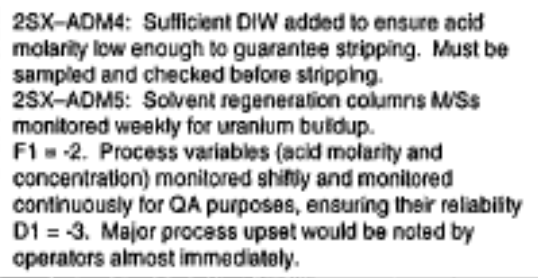 & $\begin{array}{l}\text { 2SX-PE4: BFP on organio buk chemical } \\
\text { supply ine. } \\
F 2=-2 \text {. Regular mathlenance ensures low } \\
\text { fallure rate. } \\
D 2=-2 \text {. Falure would be devected during } \\
\text { weekly survoillance. }\end{array}$ & $\begin{array}{l}T=-8 \\
C=1\end{array}$ & 3 & 3 & \\
\hline $28 x-006$ & $\begin{array}{l}\text { Solution spils from } \\
\text { column }\end{array}$ & 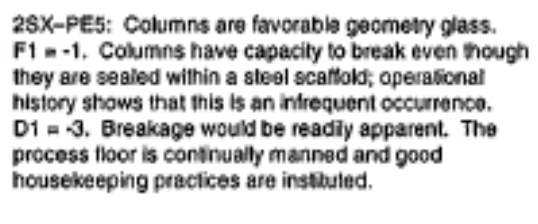 & 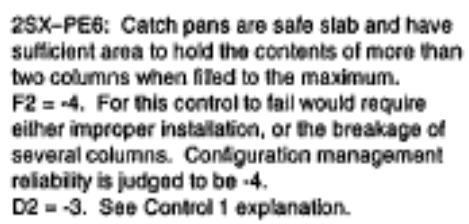 & $\begin{array}{l}T=\cdot 7 \\
C=1\end{array}$ & 3 & 3 & \\
\hline \multicolumn{8}{|c|}{...additonal accident sequences would follow this... } \\
\hline $28 x-008$ & $\begin{array}{l}\text { Earthquake occurs of } \\
\text { sufficient strength to } \\
\text { cause siructural } \\
\text { tailure } \\
F=-5 \text {. }\end{array}$ & 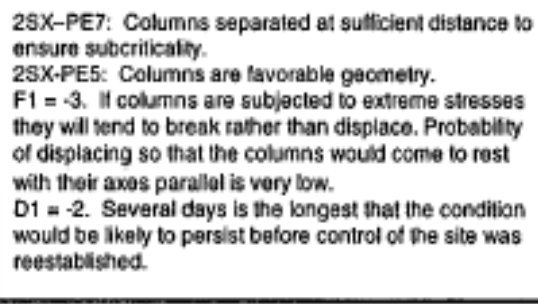 & $\begin{array}{l}\text { 2SX-PE8: There are no water ines or other } \\
\text { sources of water installed to burst in the event } \\
\text { of an earthquake. } \\
\text { F2 }=-4 \text {. This is the standard trequency used } \\
\text { eisewhere where a passive design feature that } \\
\text { reies only cn conliguration management is } \\
\text { used, whian trere are no other failure } \\
\text { mechanisms. } \\
\text { D2 }-2 \text {. The presence of water would be } \\
\text { raadly detected by responders toliowing the } \\
\text { earthougake. }\end{array}$ & $\begin{array}{l}T=-12 \\
C=1\end{array}$ & 3 & 3 & $\begin{array}{l}\text { This scenario takes } \\
\text { credit for an external } \\
\text { event. } \\
\text { Site characteristics } \\
\text { provide the likalhood of } \\
\text { seismic activity and } \\
\text { flood levels quobed. }\end{array}$ \\
\hline
\end{tabular}

* Likelihood index $T$ is a sum. Uncontrolled: T=frqi or frq1; Controlled: includes all indices $T=a+b+c+d$

Note 1: For these sequences, the initiating event is failure of one of the controls, hence the frequency is assigned under that control. 
Acceptance Criteria for Quantitative Definitions of Likelihood Fuel Cycle Facility Standard Review Plan NUREG 1520

- NUREG 1520 Section 3.4.3.2 (9)

- Likelihood Category 1: Highly unlikely, a frequency of less than 1x10-5 per event per year.

- Likelihood Category 2: Unlikely, a guideline frequency of $4 \times 10-5$ per event per year. This guideline may be more generally considered as a range between $1 \times 10-4$ and $1 \times 10-5$ per event per year, since exact frequencies at such levels cannot accurately be determined.

- Likelihood Category 3: Not unlikely, more frequent than $1 \times 10-4$ per event per year. 


\section{Similarities Between ISA and PRA}

- Both are used by staff to focus regulatory programs and improve effectiveness and efficiency

- Both may be used to revise unnecessarily burdensome (overly conservative) regulatory requirements, while maintaining public health and safety

- Both may employ formal expert elicitation methods to help assess likelihood and consequences of failure sequences

- Both use methods applied and accepted within and outside of the nuclear industry

- Both apply well to facilities that employ engineered and administrative controls 


\section{Differences Between ISA and PRA}

- As applied to fuel fabricators, ISA does not generally quantify likelihood and consequences

- Qualitative classes used to rank relative importance of risks

- PRA quantifies risks associated with failure sequences

- ISA does not generally explicitly quantify uncertainty (e.g., use of probability distributions) 


\section{Conclusions}

- ISA and PRA both provide risk information

- ISA and PRA may differ in terms of level of quantification

- Differences driven by differences in system complexities, risk levels, knowledge of systems, and types of hazards 


\section{Definition of Performance Assessment (PA)}

- Performance Assessment (PA) is a technique for evaluating long-term dose rates due to radioactive materials at decommissioned sites or engineered waste sites.

- A type of systematic analysis:

- 1. What can happen?

- 2. How likely?

- 3. What are impacts? 


\section{PA Analysis Method is Matched to}

Need

- PA models physical processes such as waste package degradation, transport of the radionuclides through various paths (e.g., in air or water), and exposure to the radionuclides by the various paths

- Deterministic, bounding analyses for some issues

- Probabilistic analyses for more complex problems, with large uncertainties 


\section{Differences Between PA and PRA}

- Both PRA and PA are adaptable to hazards and complexity of application

- PRA has traditionally been applied to active systems while PA has been applied to largely passive systems 


\section{Some Technical Similarities}

- Consideration of both likely and rare events

- Probabilistic analysis employed

- Yet, may reduce to deterministic for simple problems

- Structure of analysis 


\section{PRA and PA Analysis Sequences}

PRA Analysis Sequence

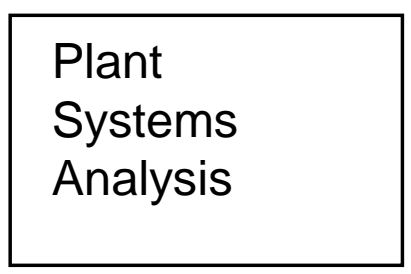

Level 1
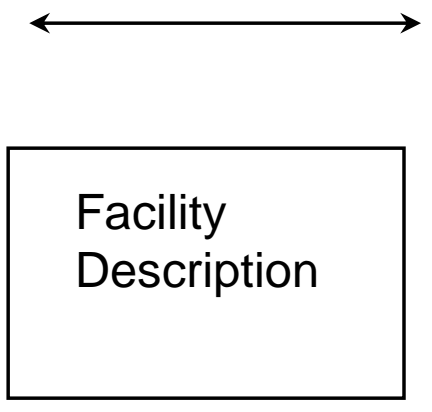
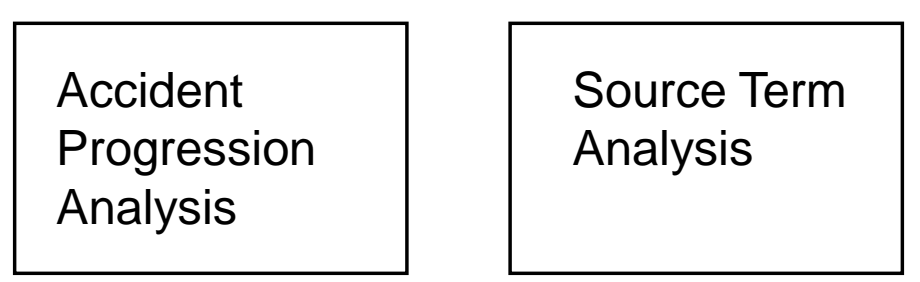

Level 2

PA Analysis Sequence

Scenario

Analysis
Facility Source

Term Analysis

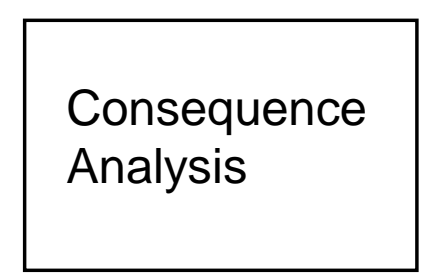

Level 3

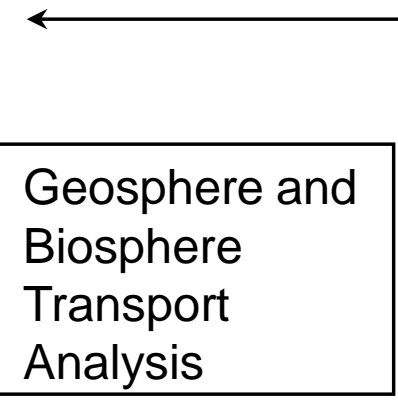

Risk Integration

Facility Risk

Integration 


\section{PA of Geologic Repository versus PRA of a Reactor}

\begin{tabular}{l|l|l} 
Attribute & Repository PA & Reactor PRA \\
\hline System Type & Passive System & $\begin{array}{l}\text { Active System (in current } \\
\text { reactors) }\end{array}$ \\
\hline Failure Type & $\begin{array}{l}\text { Few components fail in a } \\
\text { binary fashion }\end{array}$ & $\begin{array}{l}\text { Many components either fail or } \\
\text { work }\end{array}$ \\
\hline $\begin{array}{l}\text { Mission Time/ } \\
\text { Consequence Time }\end{array}$ & $\begin{array}{l}\text { Time for development of } \\
\text { consequences } \geq \text { mission } \\
\text { time }\end{array}$ & $\begin{array}{l}\text { Time for development of } \\
\text { consequences << mission time }\end{array}$ \\
\hline Failure Modes & $\begin{array}{l}\text { External events affecting } \\
\text { several subsystems } \\
\text { simultaneously dominate } \\
\text { performance }\end{array}$ & $\begin{array}{l}\text { Internal failure of highly-redundant } \\
\text { subsystems dominates; some } \\
\text { common-cause failures }\end{array}$ \\
\hline Failure Probability & $\begin{array}{l}\text { Scenario probabilities } \\
\text { projected from nature and } \\
\text { rates of geologic processes } \\
\text { acting on repository }\end{array}$ & $\begin{array}{l}\text { Projected from rates of failure of } \\
\text { components and subsystems, } \\
\text { combined with fault tree analysis }\end{array}$ \\
\hline \multicolumn{2}{|l}{}
\end{tabular}




\section{PA of Geologic Repository versus PRA of a Reactor (continued)}

\begin{tabular}{l|l|l} 
Attribute & Repository PA & Reactor PRA \\
\hline $\begin{array}{l}\text { Role of Natural } \\
\text { System }\end{array}$ & $\begin{array}{l}\text { Natural system is an } \\
\text { important component of } \\
\text { geologic repository }\end{array}$ & $\begin{array}{l}\text { Natural system provides setting } \\
\text { for operation of reactor system }\end{array}$ \\
\hline $\begin{array}{l}\text { Uncertainty of } \\
\text { System Description }\end{array}$ & $\begin{array}{l}\text { Description of natural } \\
\text { system has large, } \\
\text { practically irreducible } \\
\text { uncertainties }\end{array}$ & $\begin{array}{l}\text { Description of reactor system is } \\
\text { well defined; uncertainty from } \\
\text { design vs. as built and resolution } \\
\text { of analysis }\end{array}$ \\
\hline Subsystem & $\begin{array}{l}\text { Consists of large number } \\
\text { of similar } \\
\text { components/subsystems }\end{array}$ & $\begin{array}{l}\text { Some subsystem and component } \\
\text { duplication, some of which is } \\
\text { treated in PRA }\end{array}$ \\
\hline Size & $\begin{array}{l}\text { Large physical extent } \\
\text { (acres), spatial variability } \\
\text { significant }\end{array}$ & $\begin{array}{l}\text { Smaller physical extent; spatial } \\
\text { variability less important }\end{array}$ \\
\hline Population at Risk & $\begin{array}{l}\text { Current population and } \\
\text { populations in the far future }\end{array}$ & $\begin{array}{l}\text { Current population and } \\
\text { populations in the near future }\end{array}$ \\
\hline Hazard Potential & $\begin{array}{l}\text { Underground isolation and } \\
\text { absence of high pressure } \\
\text { and heat sources, reduces } \\
\text { hazard \& its immediacy }\end{array}$ & $\begin{array}{l}\text { Surface location and high } \\
\text { pressures and heat sources } \\
\text { increase immediacy of hazard }\end{array}$ \\
\cline { 2 - 2 }
\end{tabular}




\section{Conclusions}

- PA and PRA share

- Common origin

- Similar structure

- Quantitative, probabilistic approach 


\section{Basic Probability Concepts}

- Elementary probability concepts

- Basic probability operations

- Difference between frequency and probability

- How to calculated probability from a frequency

- Cut sets

- Reference: NUREG-0492 (available in PDF on NRC web site) 


\section{Basic Probability Concepts Used in PRAs}

$$
\begin{aligned}
& A \text { or } B \\
& A+B
\end{aligned}
$$

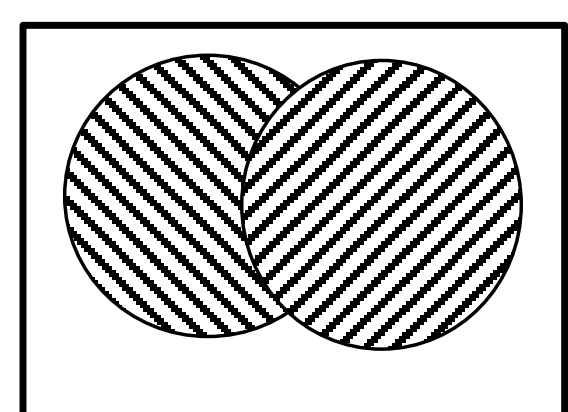

$A$ and $/ B$ $A * / B$

$A$ and $B$

$A{ }^{*} B$

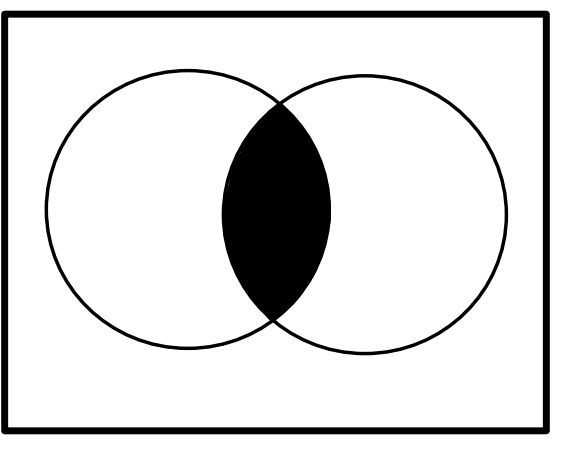

$A$ or $B$

$A+B$

with the two events mutually exclusive

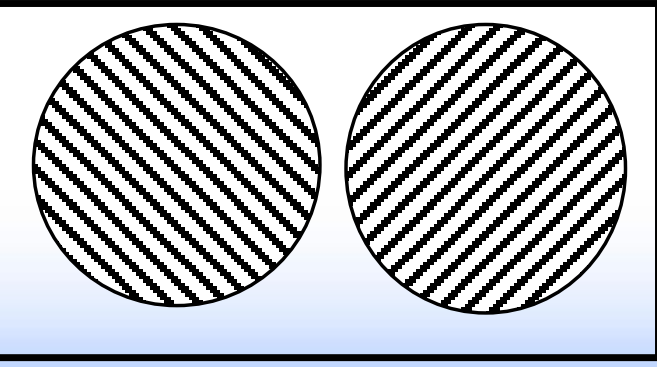




\section{Rules for Manipulating Probabilities - OR (Union)}

- The OR (or union) operation

- A OR B = combined event containing everything in $A$ or in $B$

- Also written $A \cup B$

- Rules for the OR Operation

- In general, if A, B are not disjoint (not mutually exclusive)

- $\operatorname{Pr}(A$ or $B)=\operatorname{Pr}(A)+\operatorname{Pr}(B)-\operatorname{Pr}(A$ AND $B)$

- Can extend to three or more events

- If A, B are disjoint (mutually exclusive)

- $\operatorname{Pr}(A$ or $B)=\operatorname{Pr}(A)+\operatorname{Pr}(B)$

- Example:

with a die, $\operatorname{Pr}(1$ or 2$)=\operatorname{Pr}(1)+\operatorname{Pr}(2)$ because outcomes are disjoint

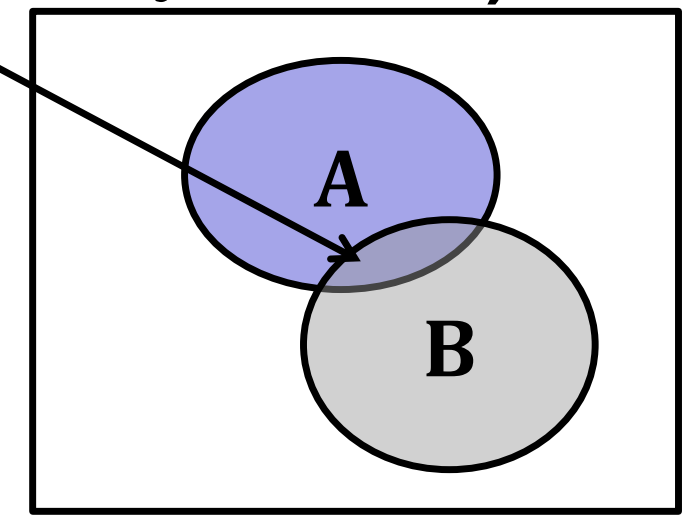

Venn Diagram 


\section{Rules for Manipulating Probabilities - AND (Intersection)}

- The AND (or intersection) operation

- A AND B = combined event containing everything that is both in $A$ or in $B$

- Also written A $\cap B$

- Rules for the AND operation

- If $A, B$ are independent

- $\operatorname{Pr}(A$ AND $B)=\operatorname{Pr}(A) \cdot \operatorname{Pr}(B)($ definition $)$

- If $A, B$ are not independent (i.e., dependent)

- $\operatorname{Pr}(A$ AND $B)=\operatorname{Pr}(A) \cdot \operatorname{Pr}(B \mid A)=\operatorname{Pr}(B) \cdot \operatorname{Pr}(A \mid B)$

- $\operatorname{Pr}(B \mid A)$ read as "probability of $B$ occurring, given that $A$ occurs," or more simply, "probability of B, given A"

- The "|" is statistical shorthand for "given that" 


\section{Definition of "Conditional Probability"}

- Conditional probability definition

- We said that in general

- $\operatorname{Pr}(\mathrm{A}$ AND $\mathrm{B})=\operatorname{Pr}(\mathrm{A}) \cdot \operatorname{Pr}(\mathrm{B} \mid \mathrm{A})$

- The conditional probability is last term, $\operatorname{Pr}(B \mid A)$, so

- $\operatorname{Pr}(B \mid A)=\operatorname{Pr}(A$ AND B $) / \operatorname{Pr}(A), \operatorname{Pr}(A) \neq 0$

- $\operatorname{Pr}(\mathrm{A} \mid \mathrm{B})=\operatorname{Pr}(\mathrm{A}$ AND B) $/ \operatorname{Pr}(\mathrm{B}), \operatorname{Pr}(\mathrm{B}) \neq 0$

- These last equations define "conditional probability". 


\section{Basic Probability Concepts}

- Mutually Independent

- Means that the occurrence (or non-occurrence) of an event (such as A) has no influence on the subsequent occurrence (or non-occurrence) of another event (such as B) and vice versa

- If a fair coin is tossed randomly, the occurrence of Heads on the first toss should not influence the probability of Tails on the second toss.

- This property allows us to write:

- If $A$ and $B$ are two mutually independent events, then $\operatorname{Pr}(A$ and $B)=$ $\operatorname{Pr}(A) * \operatorname{Pr}(B)$.

- Example: $\operatorname{Pr}(\mathrm{H}$ and $\mathrm{T} \mid$ two tosses $)=\operatorname{Pr}(\mathrm{H}){ }^{*} \operatorname{Pr}(\mathrm{T})$

- Mutually Exclusive

- Means that events (such as A and B) cannot both happen on a single trial of an experiment

- With the toss of a coin, either a Head or a Tail is the expected outcome, cannot possibly get both a Head and a Tail as an outcome on a single toss

- This property allows us to write:

- If $A$ and $B$ are two mutually exclusive events, the $\operatorname{Pr}(A$ or $B)=\operatorname{Pr}(A)+$ $\operatorname{Pr}(B)$

- If Mutually Exclusive, $\operatorname{Pr}(A$ and $B)=\operatorname{Pr}(A) * \operatorname{Pr}(B \mid A)=\operatorname{Pr}(B){ }^{\star} \operatorname{Pr}(A \mid B)=0$

- Example: $\operatorname{Pr}(\mathrm{H}$ or $\mathrm{T} \mid$ one toss $)=\operatorname{Pr}(\mathrm{H})+\operatorname{Pr}(\mathrm{T}) \therefore \operatorname{Pr}(\mathrm{H}$ and $\mathrm{T} \mid$ one toss $)=0$ 


\section{Basic Probability Concepts (cont.)}

- Mutually Interdependent (or also called dependent)

- Means that the occurrence (or non-occurrence) of an event (such as A) has an influence on the subsequent occurrence (or nonoccurrence) of another event (such as B) and vice versa

- For example, if a resistor overheats in an electronic circuit, it may very well change the failure probability of a nearby transistor or related circuitry.

- This property allows us to write

- If $A$ and $B$ are two mutually interdependent events, then $\operatorname{Pr}(A$ and $B)=\operatorname{Pr}(A)$ ${ }^{*} \operatorname{Pr}(B \mid A)=\operatorname{Pr}(B){ }^{*} \operatorname{Pr}(A \mid B)$

- Term $\operatorname{Pr}(B \mid A)$ represents the probability of $B$ given that $A$ has happened

- Note: if they are independent then $\operatorname{Pr}(B \mid A)=\operatorname{Pr}(B)$ and $\operatorname{Pr}(A \mid B)=\operatorname{Pr}(A)$

- Complement (or "not")

- Means the probability is " 1 -" the probability of event

- $\operatorname{Pr}(\operatorname{not} A)=1-\operatorname{Pr}(A)$ 


\section{Independent versus Disjoint}

- An example using disjoint events

- If two events $A$ and $B$ are disjoint (mutually exclusive)

- $\operatorname{Pr}(\mathrm{A}$ AND B $)=0$

- If $\operatorname{Pr}(A)=0.6$ while $\operatorname{Pr}(B)=0.2$ then the "Venn" diagram is
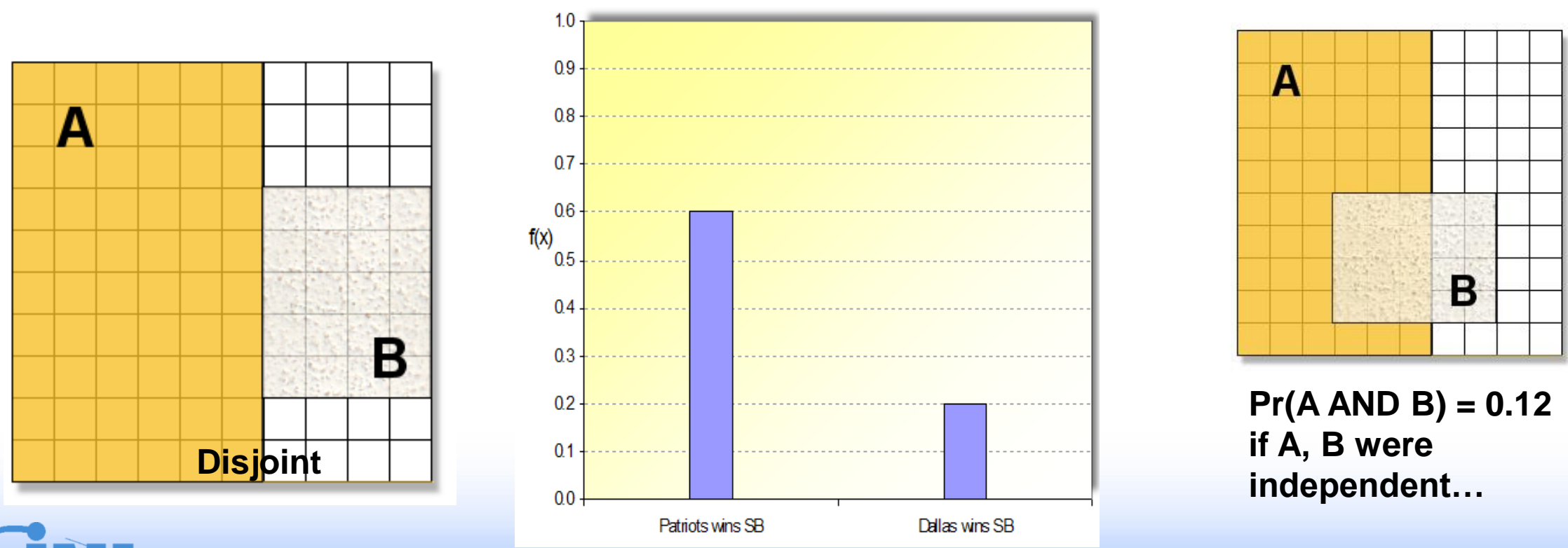

$\operatorname{Pr}(\mathrm{A}$ AND $\mathrm{B})=\mathbf{0 . 1 2}$ if $A, B$ were independent... 


\section{Independent versus Dependent}

- An example using dependent events

- If $\operatorname{Pr}(A)=0.6, \operatorname{Pr}(B)=0.2$, and $\operatorname{Pr}(A$ AND $B)=0.16$, then

- $\operatorname{Pr}(B \mid A)=\operatorname{Pr}(A$ AND $B) / \operatorname{Pr}(A)=0.16 / 0.6=0.2667$

- since $\operatorname{Pr}(A$ AND $B)=\operatorname{Pr}(A) \cdot \operatorname{Pr}(B \mid A)$

- $\operatorname{Pr}(A \mid B)=\operatorname{Pr}(A$ AND $B) / \operatorname{Pr}(B)=0.16 / 0.2=0.80$

- since $\operatorname{Pr}(A$ AND $B)=\operatorname{Pr}(B) \cdot \operatorname{Pr}(A \mid B)$

$A$ and $B$ are dependent

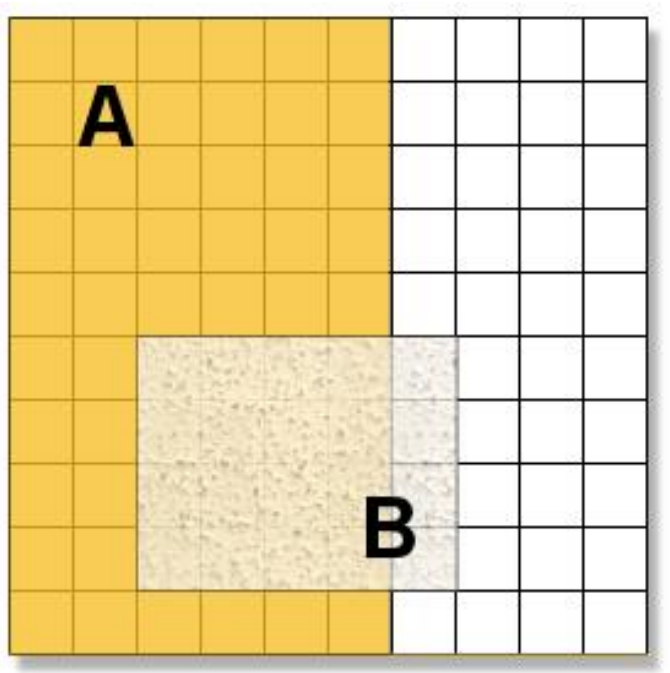

Where is $\operatorname{Pr}(B \mid A)$ on the Venn diagram?? 16 blocks $/ 60$ blocks $=0.26667$

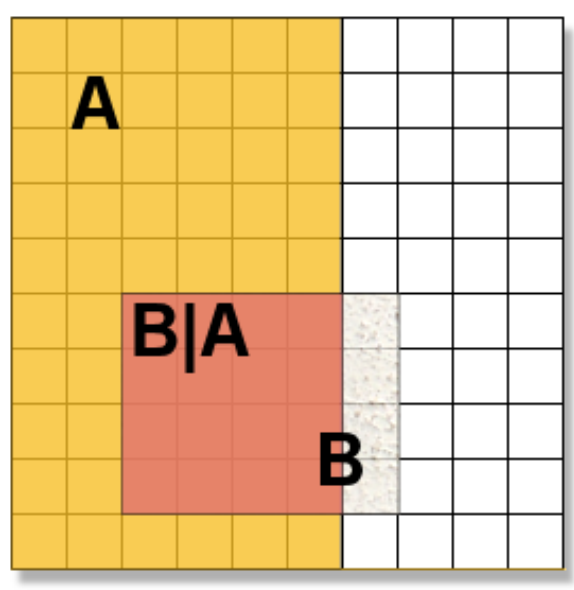

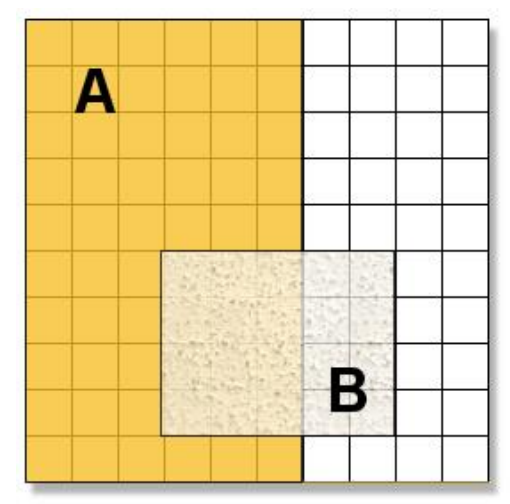

$\operatorname{Pr}(\mathrm{A}$ AND $\mathrm{B})=\mathbf{0 . 1 2}$ if $A, B$ were independent... 


\section{Each Event has a Frequency which is used to Calculate a Probability}

- Frequency

- Parameter used in model for stochastic (aleatory) uncertainty

- Units of per-demand or per-unit-of-time

- Time-based frequencies can be any positive value (i.e., can be greater than one)

- Typically used for initiating events and failure rates

- Probability

- Internal measure of certainty about the truth of a proposition

- Always conditional

- Unitless

- Value between 0 and 1

- Typically used for all events except the initiating event

- Different concepts; sometimes numerically equal 


\section{Common Probability Models}

- Bernoulli processes $\rightarrow$ Binomial model

- Tossing a coin

- Starting a pump

- Opening a closed valve

- Turning on a light

- Launching a rocket

- Poisson processes $\rightarrow$ Poisson model

- Counting radioactive particles

- Number of (lit) lights failing

- Operation of (running) pump

- Earthquakes

- Initiating events 


\section{Common Probability Models}

- Binomial (used for failures on demand)

- $\mathbf{P}\{\mathbf{r}$ failures in $\mathbf{N}$ trials $\mid \mathbf{p}\}=\left(\begin{array}{l}N \\ r\end{array}\right) p^{r}(1-p)^{N-r}$

- Recall: $\left(\begin{array}{l}N \\ r\end{array}\right)=\frac{N !}{(N-r) ! r !}$

- Probability of failure for a single demand

$\mathbf{P}\{1$ failure in 1 trial $\mid \mathbf{p}\}=\frac{N !}{(N-r) ! r !} p^{r}(1-p)^{N-r}=\frac{1 !}{(1-1) ! !} p^{1}(1-p)^{1-1}=(1) p^{1}(1)=p$

- Binomial Example:

- Pump data failing to start on demand $p=0.001$

- Probability of 1 failure to start in $\mathbf{1}$ demand?

$\mathbf{P}\{1$ failure in 1 trial $\mid 0.001\}=\frac{1 !}{(1-1) ! ! !} 0.001^{1}(1-0.001)^{1-1}=\frac{1 !}{(0) ! ! !} 0.001^{1}(0.999)^{0}=(1)(0.001)(1)=0.001$ 


\section{Common Probability Models (cont.)}

- Poisson (used for failures/events in time)

- $\mathbf{P}\{\mathbf{r}$ failures in $(0, \mathbf{t}) \mid \lambda\}=\frac{(\lambda t)^{r} e^{-\lambda t}}{r !}$

- Probability of one or more failures (Poisson simplifies to exponential)

- $P\left\{T_{f}<t \mid \lambda\right\}=1-e^{-\lambda t} \approx \lambda t$ (for small $\lambda t$; when $\lambda t<0.1$ )

- Example of exact 1 - $\mathrm{e}^{-\lambda t}$ versus product $\lambda t$ estimate 0.39

0.095

0.04877

0.00995

0.0049875

vs 0.5

vs 0.1

vs 0.05

vs 0.01

vs 0.005

- Poisson Example:

- Pump data failing to run $\lambda=1 \mathrm{E}-4$ failures per operating hour

- Probability of failure to run for 24 hours?

- $P\left\{T_{f}<24\right.$ hours $\mid 1 E-4$ failures/hour $\}$

$=1-\mathrm{e}^{-(1 \mathrm{E}-4 \mathrm{fail} u r e s / h o u r)(24 \text { hours })}=1-\mathrm{e}^{-(2.4 \mathrm{E}-3)}=1-(0.997602878)=0.002397122$

$\approx 2.4 \mathrm{E}-3$ [i.e., product of $\lambda t=(1 \mathrm{E}-4)(24)]$ 


\section{Cut Sets}

- Combinations of events that result in a particular outcome

- Minimal Cut Sets are those combinations that are both necessary and sufficient to produce the particular outcome

- i.e., minimal combination

- Each cut set represents a failure scenario that must be "ORed" together with all other cut sets for the top event when calculating the total probability of the top event

- Boolean algebra (discussed later) used for processing cut sets 


\section{Cut Set Example}

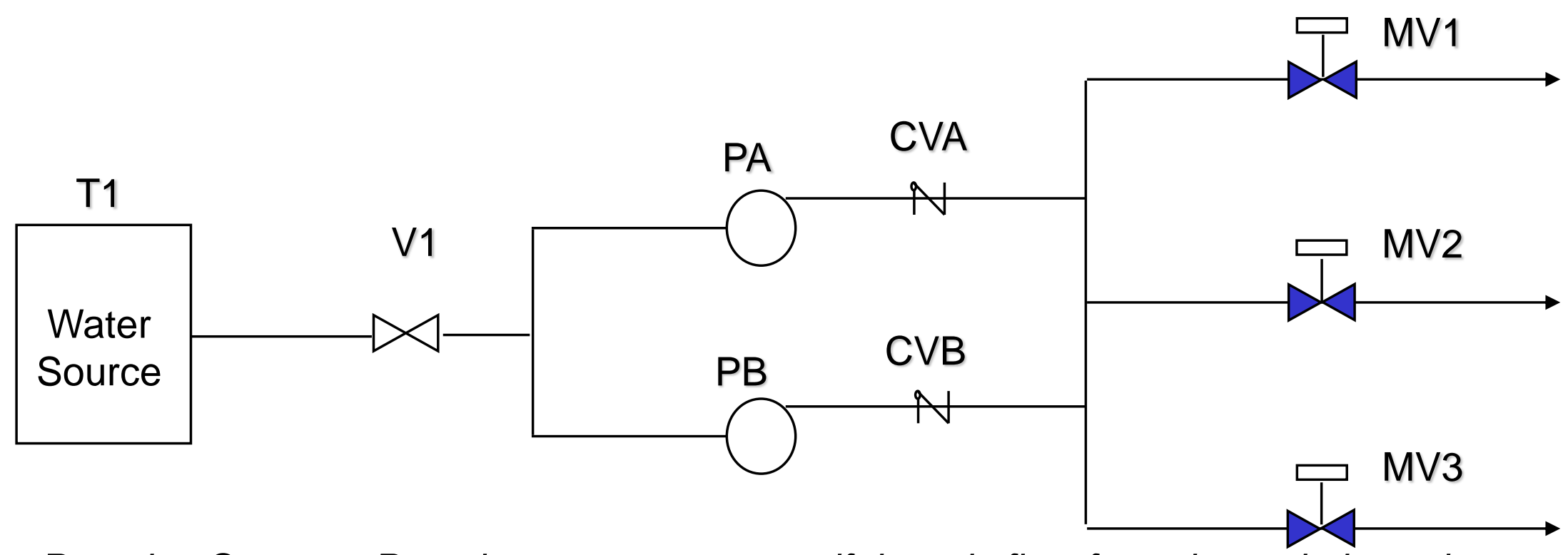

Pumping System: Pumping system success if there is flow from the tank through any one pump trains through any one motor-operated valve. System components include;

T\# - tank

V\# - manual valve, normally open

P\# - pump

CV\# - check valve

MV\# - motor-operated valve, normally closed 


\section{Cut Sets for Pumping System}

By inspection of the pumping system piping and instrumentation diagram (P\&ID):

Pumping-System-Failure $=$

$$
\begin{aligned}
& T 1+ \\
& V 1+ \\
& P A{ }^{*} P B+ \\
& P A{ }^{*} C V B+ \\
& P B{ }^{*} C V A+ \\
& C V A{ }^{*} C V B+ \\
& M V 1{ }^{*} M V 2{ }^{*} M V 3
\end{aligned}
$$




\section{Quantifying Cut Sets}

- Three different quantification methods to quantify the probability of cut sets:

- Exact Solution

- Rare-Event Approximation

- Minimal Cut Set Upper Bound Approximation 


\section{Exact Solution}

- Exact Solution for Cut Sets $=A+B$

- $P($ Exact Solution for Cut Sets $)=P(A+B)=P(A)+P(B)-P(A B)$

- Cross terms become unwieldy for large lists of cut sets. e.g., if Cut Sets $=A+B+C$, then:

- $P($ Exact Solution for Cut Sets $)=$ $P(A)+P(B)+P(C)-$ $[P(A B)-P(A C)-P(B C)]+$ $P(A B C)$ 


\section{Rare Event Approximation}

- Rare Event Approximation for Cut Sets = A + B

- $P$ (Union of Cut Sets $)=$ sum of the probabilities of each individual cut set

- $\mathbf{P}$ (Union of Cut Sets) $=\sum_{k=1}^{K} P\left(\right.$ Cutset $\left._{k}\right)$

- P(AB) judged to be sufficiently small (rare) and thus can be ignored (i.e., cross-terms are simply dropped)

- In general,

- $\mathbf{P}\{$ Exact Solution for Cut Sets $\} \leq \sum_{k=1}^{K} P\left(\right.$ Cutset $\left._{k}\right)$ 


\section{Minimal Cut Set Upper Bound}

- Minimal Cut Set Upper Bound Approximation for Cut Sets $=A+B$

- P(Minimal Cut Set Upper Bound for Cut Sets) = 1.0 minus the product of each individual cut set NOT occurring

- $\mathbf{P}($ MCSUB for Cut Sets $)=1-\prod_{k=1}^{K}\left[1-P\left(\right.\right.$ Cutset $\left.\left._{k}\right)\right]$

- $P($ MCSUB for Cut Sets $)=1-[(1-P(A)) *(1-P(B))]$

- Assumes cut sets are independent (i.e., no shared basic events in individual cut sets)

- In general,

- $\mathrm{P}\{$ Exact Solution for Cut Sets $\} \leq \mathrm{P}($ MCSUB for Cut Sets) $\leq \mathrm{P}$ (Rare Event for Cut Sets) 


\section{Examples of Cut Set Quantification Methods for $\mathrm{P}(\mathrm{A}+\mathrm{B})$}

\begin{tabular}{|c|c|c|c|}
\hline & $\begin{array}{l}\text { Cut Sets A \& B } \\
\text { independent; individual cut } \\
\text { set values low }\end{array}$ & $\begin{array}{l}\text { Cut Sets A \& B } \\
\text { independent; individual } \\
\text { cut set values high }\end{array}$ & $\begin{array}{l}\text { Cut Sets A \& B are not independent (they have } \\
\text { shared basic events); individual cut set values low }\end{array}$ \\
\hline $\begin{array}{l}\text { Cut-Sets } \\
\quad=A+B\end{array}$ & $\begin{array}{l}P(A)=0.01 \\
P(B)=0.03\end{array}$ & $\begin{array}{l}P(A)=0.4 \\
P(B)=0.6\end{array}$ & $\begin{array}{l}\text { Cut Set } A=B E 1 * B E 2 \\
\text { Cut Set } B=B E 2 * B E 3 \\
P(B E 1)=0.1 \\
P(B E 2)=0.1 \\
P(B E 3)=0.3\end{array}$ \\
\hline Exact & $\begin{array}{l}=0.01+0.03-\left(0.01{ }^{*} 0.03\right) \\
=0.04-0.0003 \\
=0.0397\end{array}$ & $\begin{array}{l}=0.4+0.6-(0.4 * 0.6) \\
=1.0-(0.24) \\
=0.76\end{array}$ & $\begin{array}{l}=\left(B E 1{ }^{*} B E 2\right)+(B E 2 * B E 3)-(B E 1 * B E 2) *\left(B E 2{ }^{*} B E 3\right) \\
=\left(B E 1{ }^{*} B E 2\right)+(B E 2 * B E 3)-(B E 1 * B E 2 * B E 3) \\
=0.01+0.03-0.003 \\
=0.04-0.003 \\
=0.037\end{array}$ \\
\hline Rare Event & $\begin{array}{l}=0.01+0.03 \\
=0.04\end{array}$ & $\begin{array}{l}=0.4+0.6 \\
=1.0\end{array}$ & $\begin{array}{l}=0.01+0.03 \\
=0.04\end{array}$ \\
\hline MinCut UB & $\begin{array}{l}=1-[(1-0.01) *(1-0.03)] \\
=1-[(0.99) *(0.97)] \\
=1-[0.9603] \\
=0.0397\end{array}$ & $\begin{array}{l}=1-[(1-0.4) *(1-0.6)] \\
=1-[(0.6) *(0.4)] \\
=1-[0.24] \\
=0.76\end{array}$ & $\begin{array}{l}=1-[(1-0.01) *(1-0.03)] \\
=1-[(0.99) *(0.97)] \\
=1-[0.9603] \\
=0.0397\end{array}$ \\
\hline
\end{tabular}

\section{Idaho National Laboratory}




\section{Useful Values for Workshops}

$\mathrm{e}^{-0.02}=0.9802$

$\mathrm{e}^{-0.10}=0.9048$

$e^{-0.30}=0.7408$

$e^{-0.50}=0.6065$

$e^{-1.00}=0.3679$

$e^{-1.50}=0.2231$ 


\section{WORKSHOP - Probability and Frequency Questions - (question 1 of 3)}

- 1. An event occurs with a frequency of 0.02 per year.

- 1.1. What is the probability that at least one event will occur within a given year?

- 1.2. What is the probability that at least one event will occur within 50 years? 


\section{WORKSHOP - Probability and Frequency Questions - (question 2 of 3)}

- 2. Event A occurs with a frequency of 0.1 per year. Event B occurs with a frequency of 0.3 per year.

- 2.1. What is the probability that at least one event (either A or B) will occur within a given year?

- 2.2. What is the probability that at least one event (either A or B) will occur within 5 years? 


\section{WORKSHOP - Probability and Frequency Questions - (question 3 of 3)}

- 3. An experiment has a probability of 0.1 of producing a failure.

- 3.1. What is the probability of observing at exactly one failure if the experiment is repeated 4 times?

- 3.2. What is the probability of observing at least one failure if the experiment is repeated 4 times? 


\section{Initiating Events}

- Definition - Any potential occurrence that could disrupt operations or nominal behavior of the system. (Initiating events are quantified in terms of their frequency of occurrence.)

- Initiating event identification consists of

- identifying a comprehensive list of potential initiators that could upset system performance

- for a large number of initiators, to simplify the analysis, grouping the initiating events into categories based on analysis criteria (e.g., types of events, SSCs involved), and

- quantifying applicable initiating event or event category frequencies. 


\section{Role of Initiating Events in a Risk Assessment}

- Identifying initiating events is the first step in development of possible scenarios or event sequences.

- What can happen and how often?

- Scenario or event sequences can be conceptually thought of as:

- An initiating event, which triggers a series of system and/or operator responses; depending on the outcome of the various responses, either a safe condition or an undesired condition will result.

- Initiating event identification is an iterative process that requires feedback from other risk assessment processes for completeness.

- Support/dependency analysis

- Review of facility experience and data 


\section{Sources Used to Identify Initiating}

Events

- Review of facility experience and procedures

- Past operating experience, including similar facilities

- Feedback from other risk assessment tasks

- Review of other risk assessments

- FMEA

- Master logic diagram (special type of fault tree) 


\section{External Events}

- External events are important because

- they can be the start of the scenario

- they can negate or compromise facility operations or procedures used to prevent or mitigate consequences

- If allowed by the regulatory practices, certain external events (and internal initiators) can be excluded from the risk assessment

- Likelihood is lower than some threshold value

- Projected consequence is minimal 


\section{Possible External Events}

\section{Event}

- Aircraft

- Avalanche

- Earthquake

- Fire in facility

- Fire outside facility, but on site

- Fire off site

- Flammable fluid release

- Fog

- Flooding, external (including seiche, storm surge, dam failure, and tsunami)

- Flooding, internal

\section{Usual cause for exclusion}

- Physically impossible at most sites

$--$

- No means to propagate to facility

- Considered under fire (onsite) or pipeline accident (offsite)

- Included in aircraft or ship impact 


\section{Possible External Events (continued)}

\section{Event}

- High winds (including tornadoes)

- Hurricane

- Ice

- Industrial or military accident offsite

- Landslide

- Lightning

- Meteorite impact

\section{Usual cause for exclusion}

-

- Wind damage covered under high winds, water damage covered under flooding

- Ice formation on aircraft covered under aircraft impact; ice formation on transmission lines covered under loss of offsite power; ice blockage of river or lake covered in facility design -loss of cooling

- Physically impossible for most sites

- Included in facility design

- Frequency less than earthquake or tornado 


\section{Possible External Events (continued)}

\section{Event}

- Pipeline accident

- Sabotage

- Ship impact

- Toxic gas release

- Transportation accident

- Turbine missile

- Volcanic activity

- War

\section{Usual cause for exclusion}

- Typically covered by facility security analysis, performed by safeguards

- Geologic setting of most sites makes this extremely difficult to assess, and volcanic activity is extremely unlikely

- Outside scope - impossible to assess 
External events typically excluded because they occur slowly enough that mitigative action may be taken or their effects are inconsequential

\section{Event}

- Blizzard/Snow

- Drought

- Erosion

- Hail

- Heavy rain

- High temperature

- Low Temperature

- River diversion or change in lake level

\section{Remarks}

- Runoff due to melting considered under flooding, external; winds less than tornado

- --

- -

- -

- Runoff considered under flooding, external

- Considered in design

- Considered in design

-- 


\section{Event Trees}

- Features:

- Related to systems/functions

- Identifies relative timing of event occurrence

- Event sequence progression

- End-to-end traceability of scenarios

- Primary use

- Identification of event sequences which result in some outcome of interest

- Basis for scenario quantification 


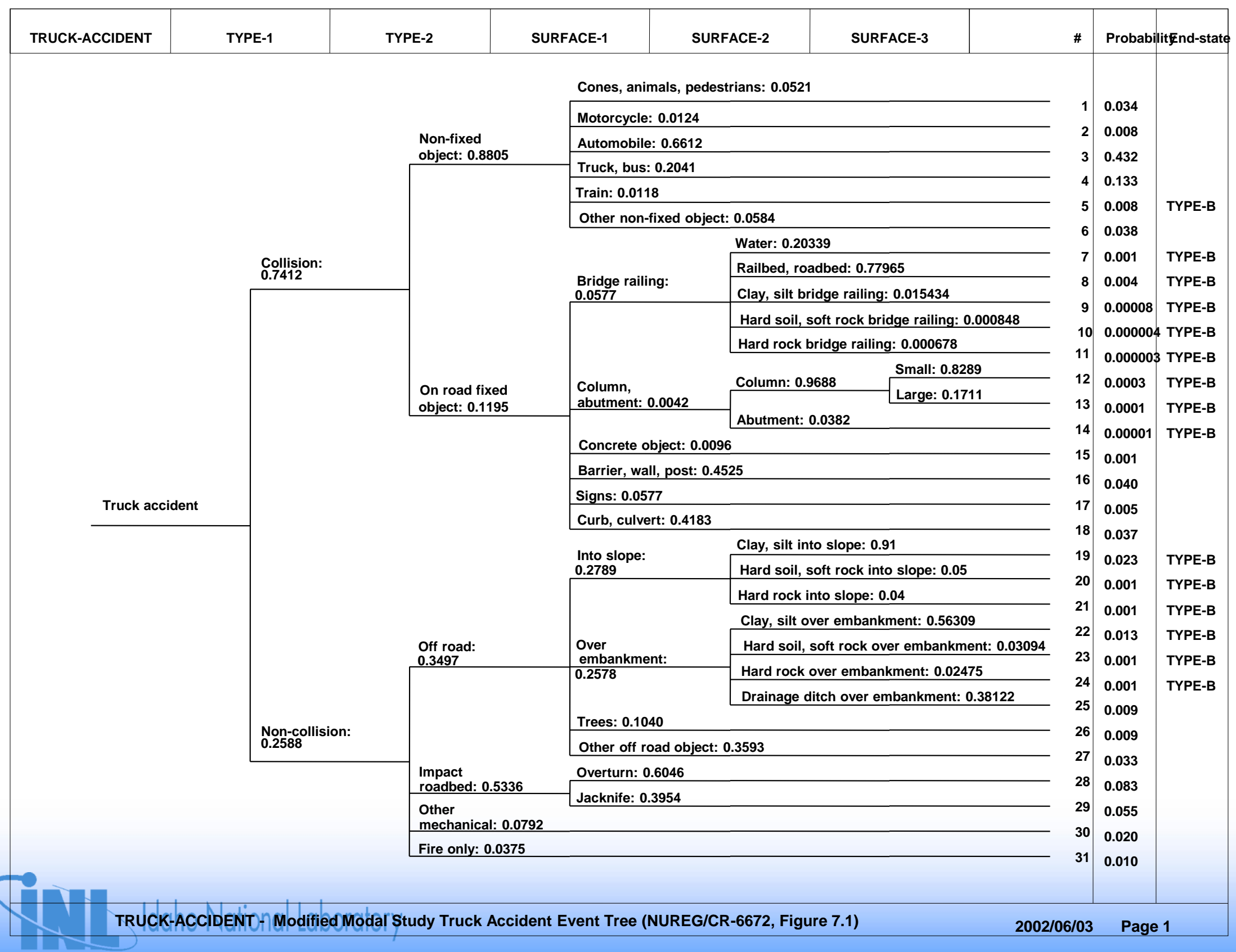




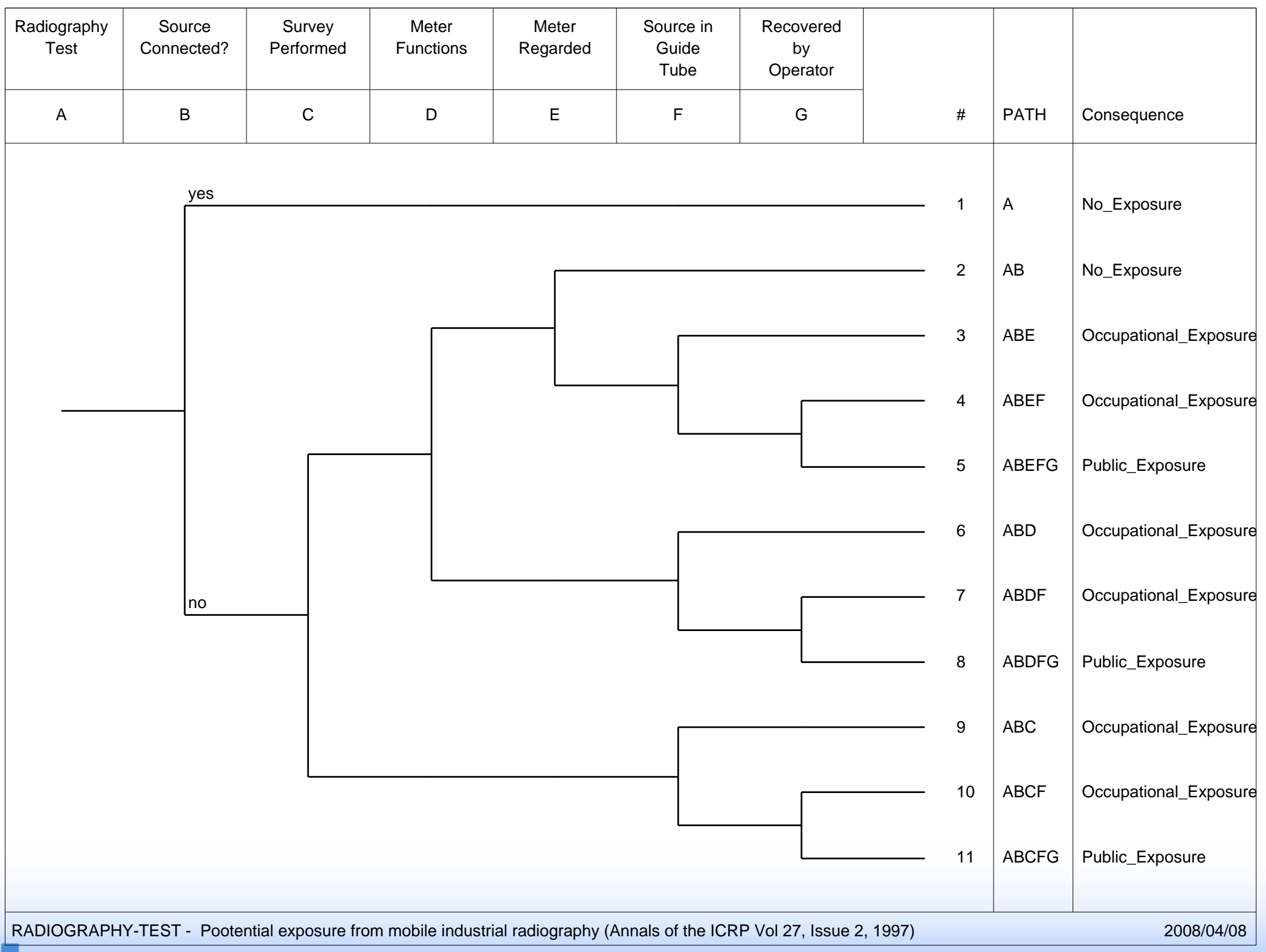




\section{Principal Steps in Event Tree Development}

- Determine boundaries of analysis

- Define safety functions required for initiating event

- Determine systems available to perform each critical plant safety function

- Determine success criteria

- Event tree heading - order \& development

- Sequence delineation 


\section{Determining Boundaries}

- Mission time

- End States

- Waste package failure

- Overexposure

- Criticality

- Extent of operator recovery 


\section{Success Criteria}

- Start with functional event tree

- Identify the essential system characteristics (Top Events) that could impact the End States

- End states identify either OK situation or off-normal situation that is evaluated 


\section{Success Criteria (continued)}

- Identify structures, systems, and components (SSCs), physical features, processes, or events which can perform each function

- Identify minimum complement (i.e., successes) of SSCs, physical features, processes, events necessary to perform function 


\section{Event Tree Development Rules of Thumb}

- One event tree per initiating event category

- Systems involved in success criteria become headings

- Logic typically binary (success/failure), but logic can have more than two branches (degraded situations modeled)

- Ordered in anticipated sequential fashion where possible

- Sequence delineation 


\section{Fault Tree Analysis Definition}

"An analytical technique, whereby an undesired state of the system is specified (usually a state that is critical from a safety standpoint), and the system is then analyzed in the context of its environment and operation to find all credible ways in which the undesired event can occur."

NUREG-0492 


\section{Fault Trees}

- Deductive analysis (event trees are inductive)

- Top down approach starting with undesired event (top event) definition

- Used to estimate system unreliability

- Probability of top event fails to perform intended function

- Explicitly models multiple failures

- As many things as it takes to cause the top to occur

- Provides event relationships (i.e., combinations of events leading to undesired event) 


\section{Purpose of Fault Tree Analysis}

- Identify ways in which a system can fail

- Fault tree models can be used to determine:

- Interrelationships between fault events

- System "weaknesses"

- Qualitative

- Quantitative

- System unreliability (failure probability) 


\section{Fault Tree Development Process}

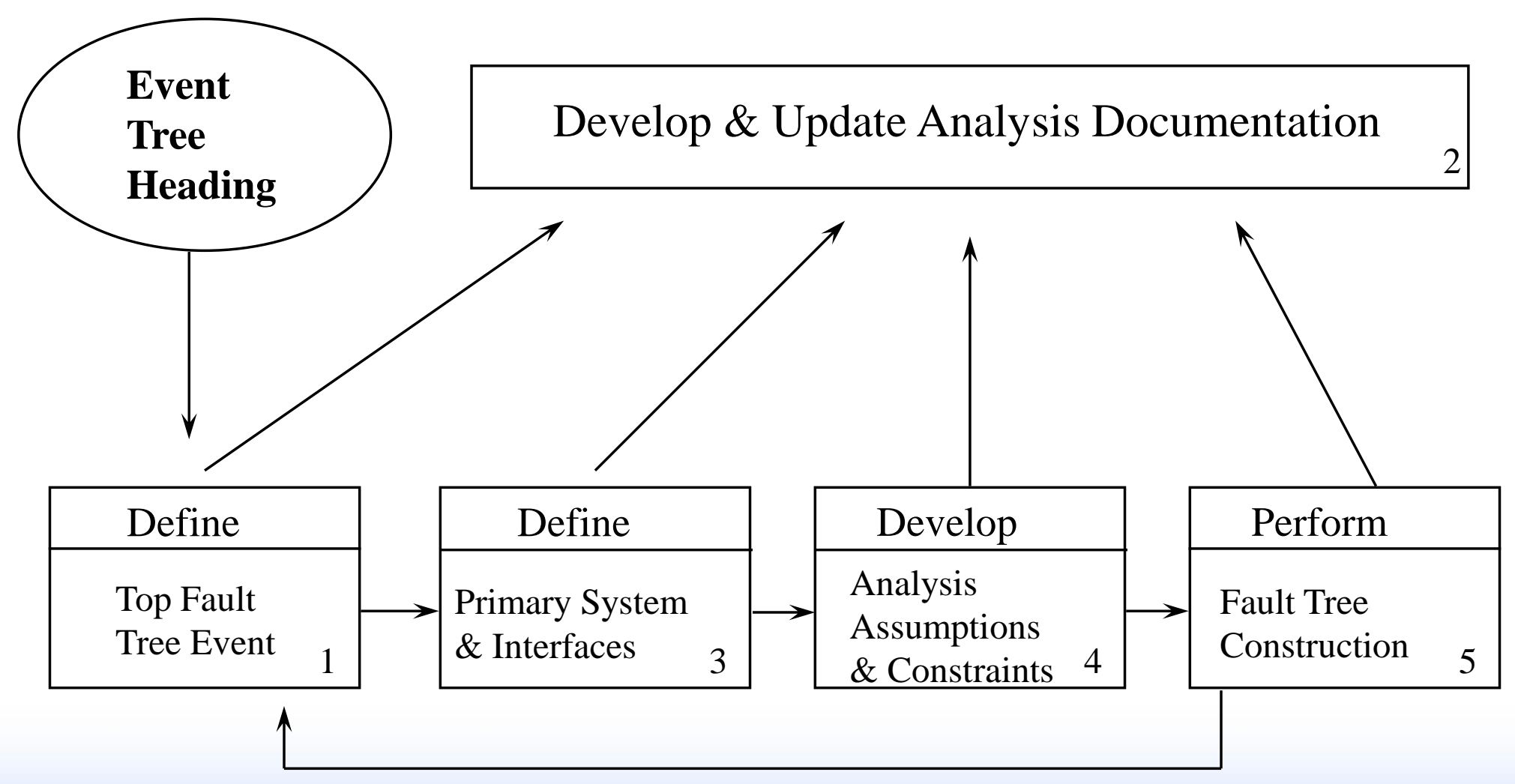


1. Define Top Event

- Undesired event or state of system

- Based on success criterion for system

- Often corresponds to a top event on an event tree 


\section{Develop \& Maintain Analysis Documentation}

- Scope of analysis and system definition

- Documentation should include;

- system design and operation information,

- technical specifications,

- test and maintenance data,

- pertinent analytical assumptions,

- etc.

- Documentation reflects the iterative nature of fault tree analysis. 


\section{Define Primary System \&}

Interfaces

- "A collection of discrete elements which interact to perform, in total or in part, a function or set of functions"

- System boundary definition depends on:

- Information required from analysis

- Level of resolution of data

- Identify shared components with other systems

- Clear documentation of system boundary definition is essential 
4. Develop Analysis Assumptions \& Constraints

- Analytical assumptions must be developed to compensate for incomplete knowledge

- Rationale for assumptions should be specified and, wherever possible, supported by engineering analysis

- Time and/or budget constraints, as well as the tools available for performing the analysis, can often contribute to defining the scope of the analysis 


\section{Fault Tree Construction}

- Step-by-step postulation of system faults

- Utilization of standard symbology

- Postulation consistent with level of resolution of data \& assumptions

- Iterative process requiring feedback from other PRA processes

- Can employ different strategies for construction

- Output-to-input

- Functional blocks 


\section{Common Fault Tree Symbols}

Symbol
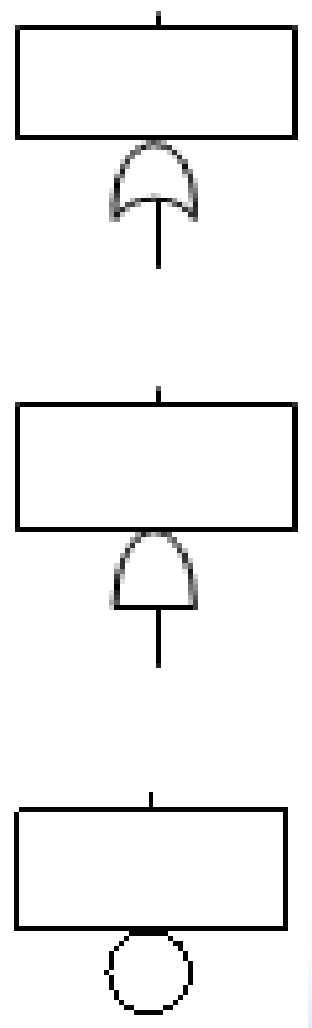

"OR" Gate

"AND" Gate

Basic Event
Description

Logic gate providing a representation of the Boolean union of input events. The output will occur if at least one of the inputs occur.

Logic gate providing a representation of the Boolean intersection of input events. The output will occur if all of the inputs occur.

A basic component fault which requires no further development. Consistent with level of resolution in databases of component faults. 


\section{Additional Fault Tree Symbols}

Symbol

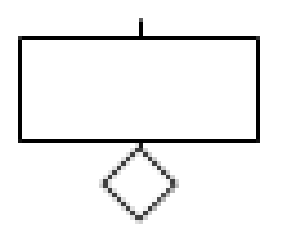

Undeveloped

Event
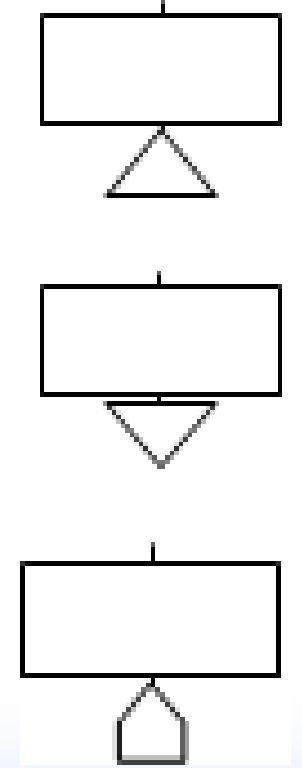

Undeveloped

House Event
Description

A fault event whose development

is limited due to insufficient consequence or lack of additional detailed information

Transfer Gate Transfer Event
A transfer symbol to connect various portions of the fault tree

A fault event for which a detailed development is provided as a separate fault tree and a numerical value is derived

Used as a trigger event for logic structure changes within the fault tree. Used to impose boundary conditions on FT. Used to model changes in plant system status. 


\section{Demonstration of the Fault Tree Construction \& Solution Process}

- Build fault tree for the schematic provided

- Some assumptions:

- Ignore wire faults

- Do not model details of 125V dc power supply

- Will solve fault tree and discuss "meaning" of the solution process 


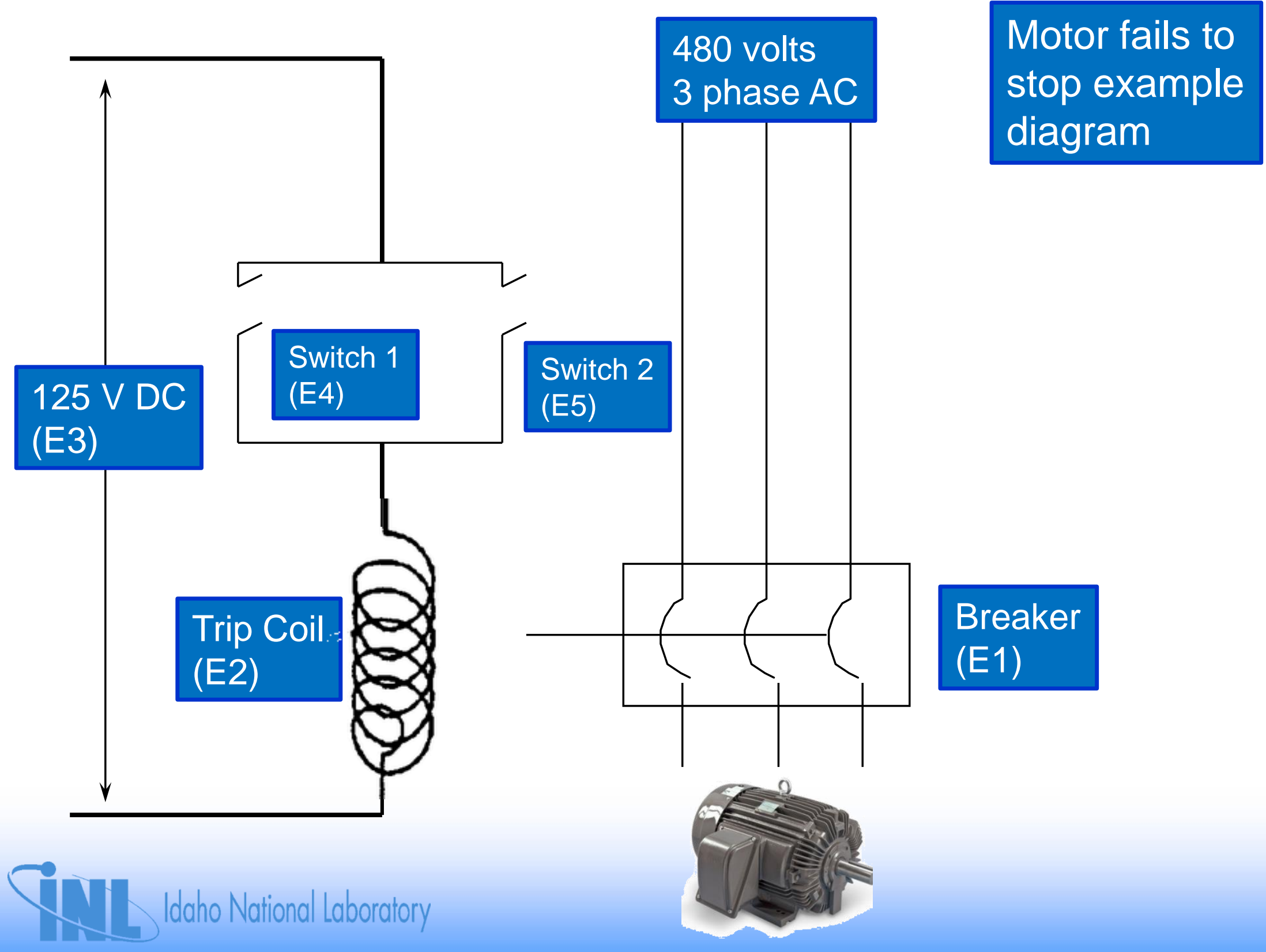




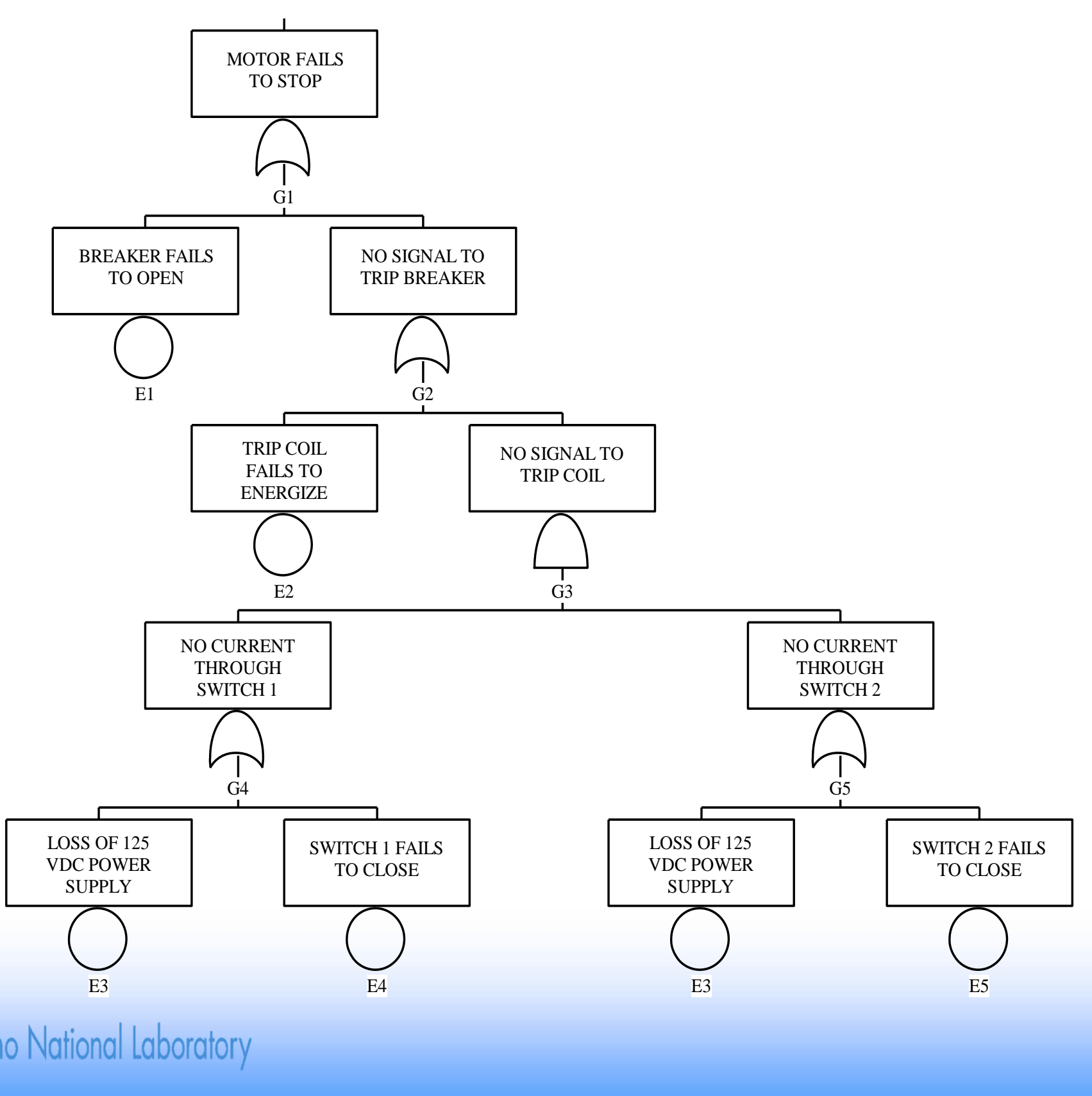




\section{Boolean Fault Tree Reduction}

- Express fault tree logic as Boolean equation

- Apply rules of Boolean algebra to reduce terms

- Results in reduced form of Boolean equation

- Minimal cut sets appear in this reduced Boolean equation, separated by OR (+) operator 


\section{Rules of Boolean Algebra}

Mathematical Symbolism

Engineering Symbolism

Designation

(1a) $X \cap Y=Y \cap X$

(1b) $X \cup Y=Y \cup X$

$X{ }^{*} Y=Y * X$

$X+Y=Y+X$

Commutative Law

(2a) $X \cap(Y \cap Z)=(X \cap Y) \cap Z$

$X^{*}(Y * Z)=(X * Y) * Z$

Associative Law

(2b) $X \cup(Y \cup Z)=(X \cup Y) \cup Z$

$X+(Y+Z)=(X+Y)+Z$

(3a) $X \cap(Y \cup Z)=(X \cap Y) \cup(X \cap Z)$

$X^{*}(Y+Z)=(X * Y)+(X * Z)$

(3b) $X \cup(Y \cap Z)=(X \cup Y) \cap(X \cup Z)$

$X+(Y * Z)=(X+Y) *(X+Z)$

Distributive Law

(4a) $X \cap X=X$

(4b) $X \cup X=X$

$X{ }^{*} X=X$

$X+X=X$

Idempotent Law

(5a) $X \cap(X \cup Y)=X$

$X^{*}(X+Y)=X$

$X+\left(X^{*} Y\right)=X$

Law of Absorption 


\section{Minimal Cut Set}

A group of basic failures (component failures and/or

human errors) that are

collectively necessary and sufficient to cause the TOP event to occur.

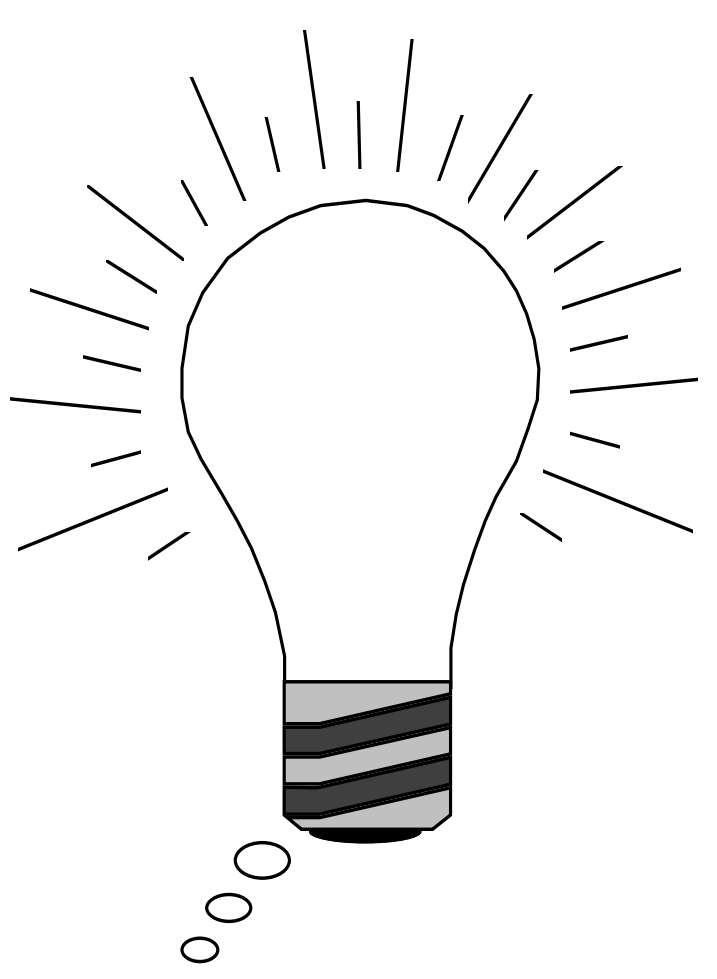
Idaho National Laboratory 


\section{Reduction of Example Fault Tree}

- Top down logic equations (+ = "OR”, * = "AND”)

$\mathrm{G} 1=\mathrm{G} 2+\mathrm{E} 1$

$\mathrm{G} 2=\mathrm{G} 3+\mathrm{E} 2$

$\mathrm{G} 3=\mathbf{G} 4 * \mathbf{G} 5$

$\mathrm{G} 4=\mathrm{E} 3+\mathrm{E} 4$

$\mathrm{G} 5=\mathrm{E} 3+\mathrm{E} 5$

- Back-substitute

$\mathrm{G} 3=(\mathrm{E} 3+\mathrm{E} 4) *(\mathrm{E} 3+\mathrm{E} 5)$

$\mathrm{G} 2=\mathrm{E} 2+[(\mathrm{E} 3+\mathrm{E} 4) *(\mathrm{E} 3+\mathrm{E} 5)]$

$\mathrm{G} 1=\mathrm{E} 1+\mathrm{E} 2+[(\mathrm{E} 3+\mathrm{E} 4) *(\mathrm{E} 3+\mathrm{E} 5)]$

- Expand terms in parentheses and brackets

$\mathrm{G} 1=\mathrm{E} 1+\mathrm{E} 2+\mathrm{E} 3 * \mathrm{E} 3+\mathrm{E} 3 * \mathrm{E} 5+\mathrm{E} 4 * \mathrm{E} 3+\mathrm{E} 4 * \mathrm{E} 5$

$\mathrm{G} 1=\mathrm{E} 1+\mathrm{E} 2+\left(\mathrm{E3}{ }^{*} \mathrm{E} 3\right)+\left(\mathrm{E3}{ }^{*} \mathrm{E} 5\right)+\left(\mathrm{E} 4{ }^{*} \mathrm{E} 3\right)+\left(\mathrm{E} 4{ }^{*} \mathrm{E} 5\right)$ 


\section{Reduction of Example Fault Tree (continued)}

- Reduce terms using rules of Boolean algebra

Idempotent Law applies to $\quad \mathrm{E} 3 * \mathrm{E} 3=\mathrm{E} 3$

Law of Absorption applies to $E 3+(E 3$ * "X") $=E 3$

$\mathrm{G} 1=\mathrm{E} 1+\mathrm{E} 2+[\mathrm{E} 3 * \mathrm{E} 3]+(\mathrm{E} 3 * \mathrm{E} 5)+(\mathrm{E} 4 * \mathrm{E} 3)+(\mathrm{E} 4 * \mathrm{E} 5)$

$\mathrm{G} 1=\mathrm{E} 1+\mathrm{E} 2+[\mathrm{E} 3]+(\mathrm{E} 3 * \mathrm{E} 5)+(\mathrm{E} 4 * \mathrm{E} 3)+(\mathrm{E} 4 * \mathrm{E} 5)$

$\mathrm{G} 1=\mathrm{E} 1+\mathrm{E} 2+[\mathrm{E} 3+(\mathrm{E} 3 * \mathrm{E} 5)]+(\mathrm{E} 4 * \mathrm{E} 3)+(\mathrm{E} 4 * \mathrm{E} 5)$

$\mathrm{G} 1=\mathrm{E} 1+\mathrm{E} 2+[\mathrm{E} 3]+(\mathrm{E} 4 * \mathrm{E} 3)+(\mathrm{E} 4 * \mathrm{E} 5)$

$\mathrm{G} 1=\mathrm{E} 1+\mathrm{E} 2+[\mathrm{E3}+(\mathrm{E} 4 * \mathrm{E} 3)]+(\mathrm{E} 4 * \mathrm{E} 5)$

$\mathrm{G} 1=\mathrm{E} 1+\mathrm{E} 2+[\mathrm{E} 3]+(\mathrm{E} 4 * \mathrm{E} 5)$

- Reduced equation is list of minimal cut sets, each minimal cut set separated by "+"

$$
\mathrm{G} 1=\mathrm{E} 1+\mathrm{E} 2+\mathrm{E} 3+\mathrm{E} 4 * \mathrm{E} 5
$$

- Quantify the minimal cut sets to calculate probability of the top gate which is Motor Fails to Stop; using rare event approximation

$$
\operatorname{Pr}(\mathrm{G} 1) \approx \operatorname{Pr}(E 1)+\operatorname{Pr}(E 2)+\operatorname{Pr}(E 3)+[\operatorname{Pr}(E 4) * \operatorname{Pr}(E 5)]
$$




\section{Failure Data and Failure Modes}

- Demand failure

$-Q_{d}=p$

- Need number of failures and valid demands to estimate $p$

- Mission time failure (failure to run)

$-Q_{r}=1-e^{-\lambda}{ }_{h m}^{t}$

- $Q_{r} \approx \lambda_{h} t_{m}$ (for small $\lambda t$; when $\lambda t<0.1$ )

- Need number of failures and run time to estimate $\lambda_{h}$

- Standby failure

$-Q_{s} \approx \lambda_{s} t_{i} / 2$

- Need number of failures and time in standby to estimate $\lambda_{\mathrm{s}}$

- Test and maintenance unavailability

$-Q_{m}=\lambda_{m} d_{m}$

- $Q_{m}=t_{\text {oos }} / t_{\text {total }}$

- Need either

- maintenance frequency $\left(\lambda_{m}\right)$ and duration $\left(d_{m}\right)$

- Out-of-Service (OOS) time ( $\left.t_{\text {oos }}\right)$ and total time $\left(t_{\text {total }}\right)$ 


\section{Definition of Terms}

- $\mathbf{Q}=$ Failure probability (unreliability or unavailability)

- $\mathbf{p}=$ Failure rate (per demand)

- $\lambda_{h}=$ Failure rate (per hour) operating

- $t_{\mathrm{m}}=$ mission time (hours)

- $\lambda_{s}=$ Failure rate (per hour) standby

- $t_{i}=$ surveillance test interval (hours)

- $\lambda_{\mathrm{m}}=$ maintenance frequency

- $d_{m}=$ maintenance duration

- $t_{\mathrm{oos}}=$ total time out of service

- $t_{\text {total }}=$ total time 


\section{Data Sources for Parameter Estimation}

- Generic data

- Facility or system specific data

- Bayesian updated data

- Prior distribution

- Updated estimate 


\section{Facility or System Specific Data Sources}

- Preliminary Notification/Nuclear Materials Events Database (NMED)

- Maintenance reports and work orders

- System engineer files

- Operation logs

- Site characterization studies 


\section{Facility or System Specific Data Issues}

- Combination of data sources

- Adequacy of sample size

- Accuracy/uniformity of reporting

- Difficulty in interpreting "raw" data 


\section{Bayes' Theorem is Basis for Bayesian Updating of Data}

- Typical use: sparse facility or system specific data combined with generic data using Bayes' Theorem:

$$
\pi_{1}(\theta \mid E)=\frac{L(E \mid \theta) \pi_{0}(\theta)}{\int L(E \mid \theta) \pi_{0}(\theta) d \theta}
$$

- Where:

- $\theta$ is parameter of interest

- $\pi_{o}(\theta)$ is prior distribution (generic data)

- $L(E / \theta)$ is likelihood function (facility or system specific data)

- $\pi_{1}(\theta / E)$ is posterior distribution (updated estimate) 


\section{Bayesian Updating}

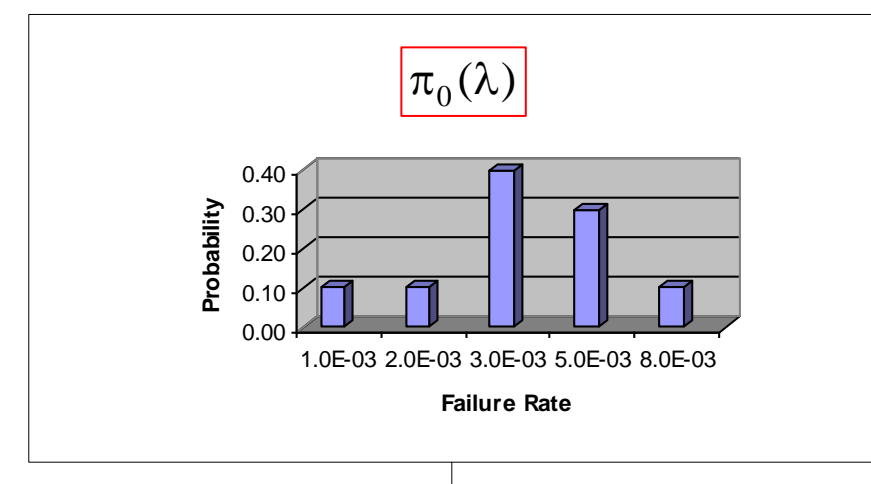

$$
L(E \mid \lambda)=\frac{(\lambda t)^{k} e^{-\lambda t}}{k !}
$$

Model: Poisson

Evidence: $K$ failures in $t$ hours of operation

$\mathrm{K}=2 ; \mathrm{t}=1000$ hours

\section{Our prior knowledge about the} failure rate

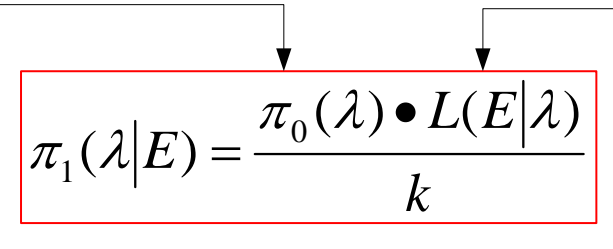

\section{Comparison of Prior and Posterior}

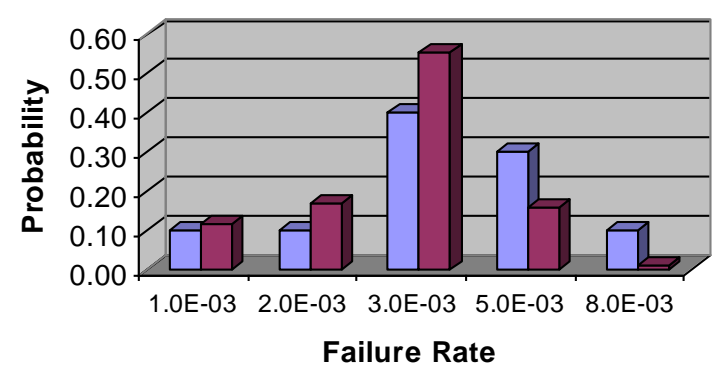

Use Bayes' Theorem to combine our prior knowledge and our

evidence 


\section{The "Bathtub" Curve}

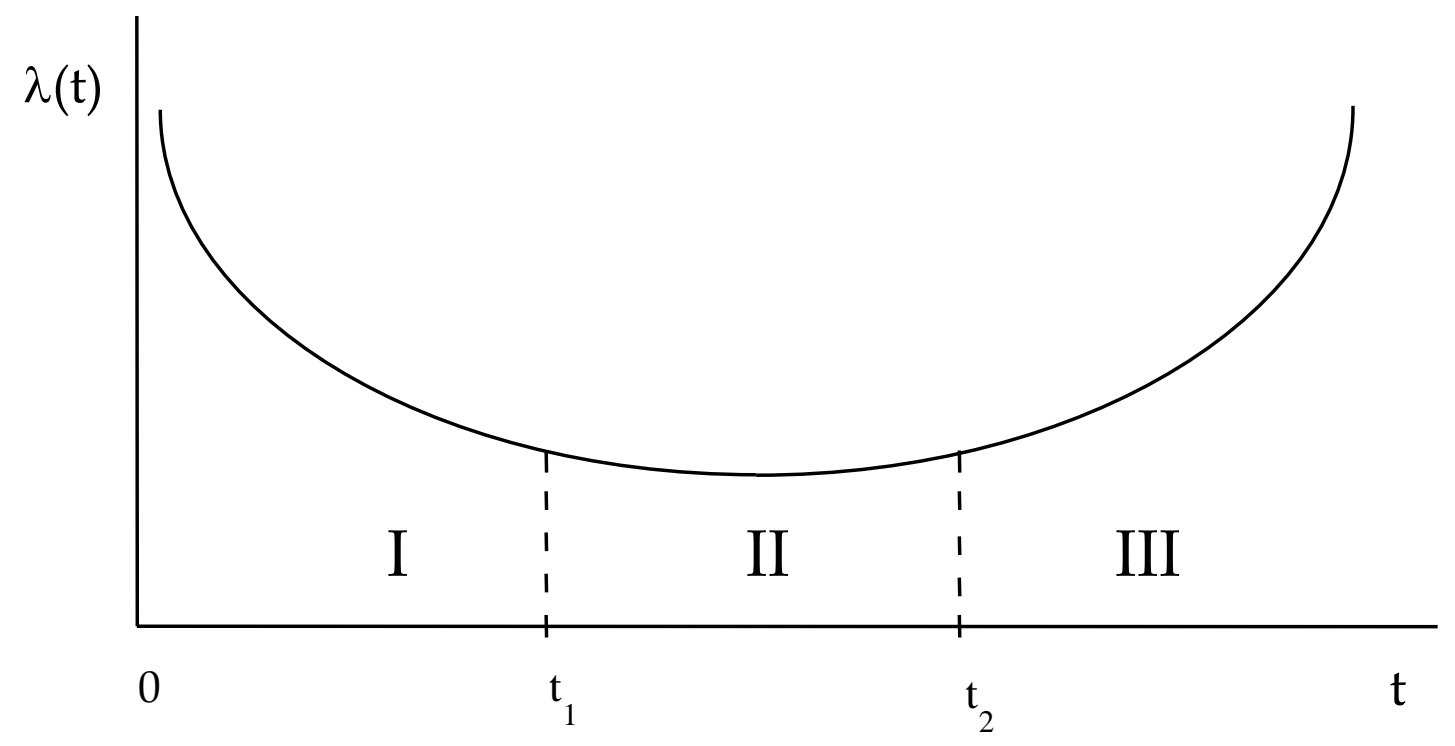

I: Burn-in (Infant Mortality)

II: Maturity (Useful Life)

III: Wear-out (Aging) 


\section{The "Bathtub" Curve (continued)}

- Most risk assessments assume constant failure rates, failure rates in "flat" portion of bathtub curve

- May not be all that bad of an assumption considering quality level of equipment, maintenance, and testing requirements

- However, this assumption does imply that aging (increasing failure rate) may not be modeled in the risk assessment 


\section{Definition of Dependent Failures}

- Three general types of dependent failures:

- Certain initiating events ( e.g., fires, floods, earthquakes)

- Intersystem dependencies including:

- Functional dependencies (e.g., dependence on AC power)

- Shared-eguipment dependencies (e.g., FUEL CYCLE or SFPO EXAMPLES)

- Human interaction dependencies (e.g., FUEL CYCLE or SFPO EXAMPLES)

- Intercomponent dependencies (e.g., design defect exists in multiple similar valves)

- The first two types are captured by event tree and fault tree modeling; the third type is known as common cause failure (CCF)

- Represents residual dependencies not explicitly modeled

- Treated parametrically 


\section{Common Cause Failures}

- Conditions which may result in failure of more than one component, subsystem, or system

- Concerns:

- Defeats redundancy and/or diversity

- Data suggest high probability of occurrence relative to multiple independent failures 


\section{Common Cause Failure Mechanisms}

- Environment

- Radioactivity

- Temperature

- Corrosive environment

- Design deficiency

- Design error

- Manufacturing error

- Test or Maintenance error

- Operational error 


\section{CCF Modeling}

- Three parametric models used

- Beta factor (original CCF model)

- Multiple Greek Letter (MGL) model (expanded on betafactor)

- Alpha factor model (addressed uncertainty concerns in MGL)

- Apply to components containing same failure mode within the same system and perform the same operation

- Valves

- Pumps

- Motors

- Filters

- Batteries 


\section{CCF Modeling}

\begin{tabular}{|c|c|c|}
\hline Model & Parameters & General Form for Multiple Component Failure Frequency \\
\hline Beta Factor & 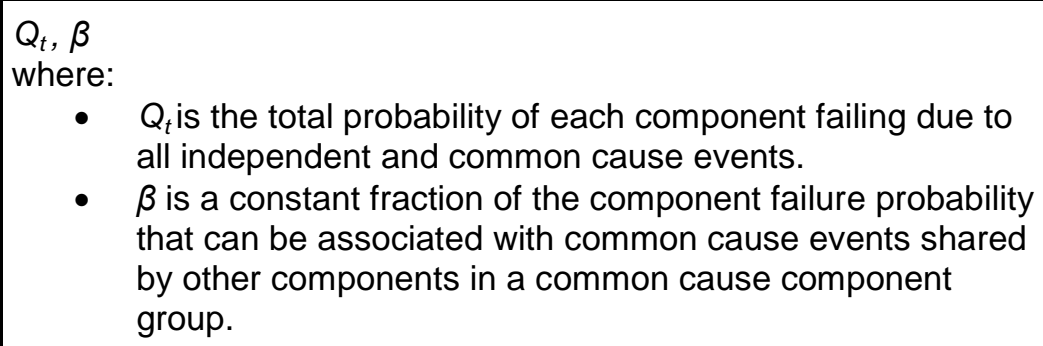 & $Q_{k}^{(m)}=\left\{\begin{array}{l}(1-\beta) Q_{t} \\
0, \\
\beta Q_{t}\end{array}\right.$ \\
\hline $\begin{array}{l}\text { Multiple Greek } \\
\text { Letters (MGL) }\end{array}$ & 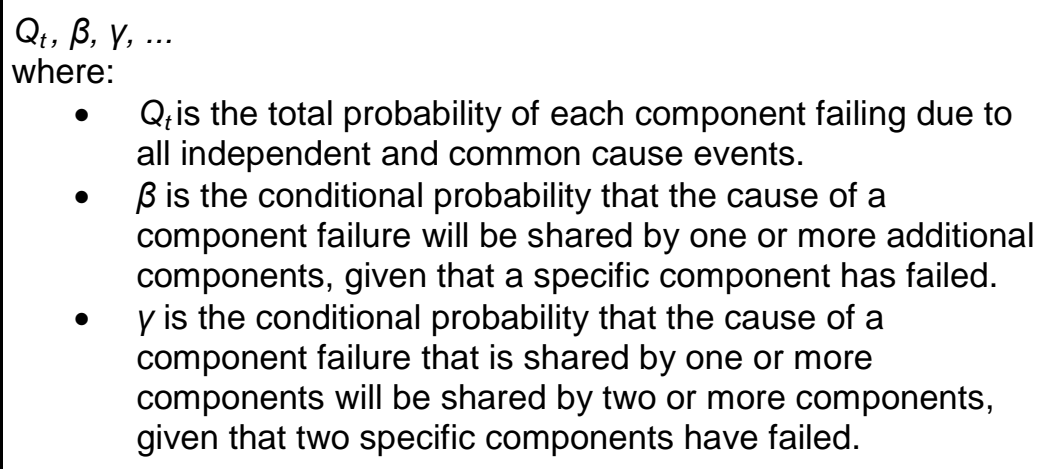 & $\begin{array}{c}Q_{k}^{(m)}=\frac{1}{\left(\begin{array}{c}m-1 \\
k-1\end{array}\right)} \prod_{i=1}^{k} \rho_{i}\left(1-\rho_{k-1}\right) Q_{t} \\
\rho_{1}=1, \rho_{2}=\beta, \rho_{3}=\gamma, \ldots, \rho_{m+1}=0\end{array}$ \\
\hline Alpha Factor & $\begin{array}{l}\text { Qt, } \alpha_{1}, \alpha_{2}, \alpha_{3}, \ldots, \alpha_{m} \\
\text { where: } \\
\text { - } Q_{t} \text { is the total probability of each component failing due to } \\
\text { all independent and common cause events. } \\
\text { - } \alpha_{k} \text { is the probability that when a common cause basic } \\
\text { event occurs in a common cause group of size } m \text {, it } \\
\text { involves the failure of } k \text { components. }\end{array}$ & $\begin{array}{l}\text { Non-staggered testing (all components tested simultaneously): } \\
\qquad Q_{k}^{(m)}=\frac{k}{\left(\begin{array}{l}m-1 \\
k-1\end{array}\right)} \frac{\alpha_{k}}{\alpha_{t}} Q_{t} \quad k=1, \ldots, m \\
\text { Staggered testing (components tested sequentially): } \\
\qquad Q_{k}^{(m)}=\frac{1}{\left(\begin{array}{l}m-1 \\
k-1\end{array}\right)} \alpha_{k} Q_{t} \quad k=1, \ldots, m \\
\text { where: } \quad \alpha_{t}=\sum_{k=1}^{m} k \alpha_{k} \\
\qquad\left(\begin{array}{c}m-1 \\
k-1\end{array}\right)=\frac{(m-1) !}{(m-k) !(m-1) !}\end{array}$ \\
\hline
\end{tabular}




\section{CCF - Beta Factor}

$$
\beta=\frac{\text { Number of common cause failures }}{\text { Total number of failures }}
$$

- Beta factor (subset of multiple Greek letter method)

- Similar for three or more failures

- Applied to cut sets containing same failure mode for sample component type

- Valves

- Pumps

- Motors

- Filters

- Batteries 


\section{Beta Factor Example}

- Basic events for example MDP-FS-A, MDP-FS-B)

- Data - 47 failures to start of motor driven pumps in approximately 15,667 demands

- Thus, MDP-FS $\approx$ (47 failures)/(15,667 demands) $\approx 3.0 \mathrm{E}-3$

- CCF Beta Factor method

- 10 common cause failures out of the 47 total failures

$$
\begin{aligned}
& \beta \approx \frac{\text { Number of common cause failures }}{\text { Total number of failures }} \\
& \beta \approx \frac{10 \text { CCF failures }}{47 \text { total failures }} \approx 2.1 \mathrm{E}-1
\end{aligned}
$$

- Thus, MDP-FS-CCFAB $\approx(2.1 \mathrm{E}-1$ * $3.0 \mathrm{E}-3) \approx 6.3 \mathrm{E}-4$

- Total system failure to start for the redundant system MDP-FS-A * MDP-FS-B + MDP-CF-CCFAB $(3.0 \mathrm{E}-3)$ * $(3.0 \mathrm{E}-3)+6.3 \mathrm{E}-4 \approx 9.0 \mathrm{E}-6+6.3 \mathrm{E}-4 \approx 6.39 \mathrm{E}-4$ 


\section{Human Reliability Analysis: Human Error Contribution to Risk Can Be Large}

- Human error has been shown to be significant contributor to overall risk:

- Past studies have indicated that human error may contribute a large percentage of total risk

- Human errors may have significantly higher probabilities than hardware failure probabilities

- Humans can circumvent the system design (e.g., stopping mitigative systems or methods) 


\section{Human Reliability Analysis (HRA)}

- Starts with the basic premise that the humans are, in effect, part of the system; i.e., "human-machine systems."

- Identifies and quantifies the ways in which human actions contribute to the

- Initiation

- Propagation

- Termination of event sequences 


\section{"Human Reliability" is the probability that a person will:}

1. Correctly perform some system-required activity, and

2. Perform no extraneous activity that can degrade the system 


\section{Categories Of Human Error}

- Errors can occur throughout the event sequence

- Pre-initiator errors (latent errors)

- Incorrect identification of patient/site

- Failure to restore

- Miscalibration

- As a contribution or cause to initiating events 


\section{Categories Of Human Error (continued)}

- Post-initiator errors

- Operation of components during the event

- Operation of components that have failed to operate automatically

- "Sequence level" errors modeled in the event trees

- Recovery actions (consideration of actions that may be taken to recover from a fault depending upon actions required and amount of time available) 


\section{Types Of Human Error}

- Generally, two types of human errors are defined:

- Errors of omission --Failure to perform a required action or step, e.g., failure to monitor demineralized makeup water level at a pool irradiator facility

- Errors of commission-- Action performed incorrectly or wrong action performed, e.g., wrong number of enriched uranium storage units placed in same work station

- Normally only the first type is modeled due to uncertainty in being able to identify errors of commission, and lack of modeling and quantification methods to address such errors 


\section{HRA Process}

- Identify Human Errors to be considered:

- Normal Plant Operations

- Identify potential errors involving miscalibration or failure to restore equipment by observing test and maintenance

- Upset Conditions

- Determine potential errors in manipulating equipment in response to various events

- Review procedures to identify potential human errors

- List human actions that could affect the course of events 


\section{HRA Process (continued)}

- Conduct Human Reliability Task Analyses

- Breakdown required actions (tasks) into each of the physical or mental steps to be performed

- Develop and quantify HRA model of event

- Assign nominal human error estimates

- Determine facility-specific adjustments to nominal human error estimates

- Account for dependence between tasks 


\section{Performance Shaping Factors}

(PSFs)

- PSFs are people-, task-, environmental-centered influences which serve to alter base error rates.

- Most HRA modeling techniques allow the analyst to account for PSFs during their quantification procedure.

- PSFs can positively or negatively impact human error probabilities

- PSFs are identified in human reliability task analysis 


\section{PSFs Shown Graphically}

- PSFs influence performance, which determines likelihood of human error probability

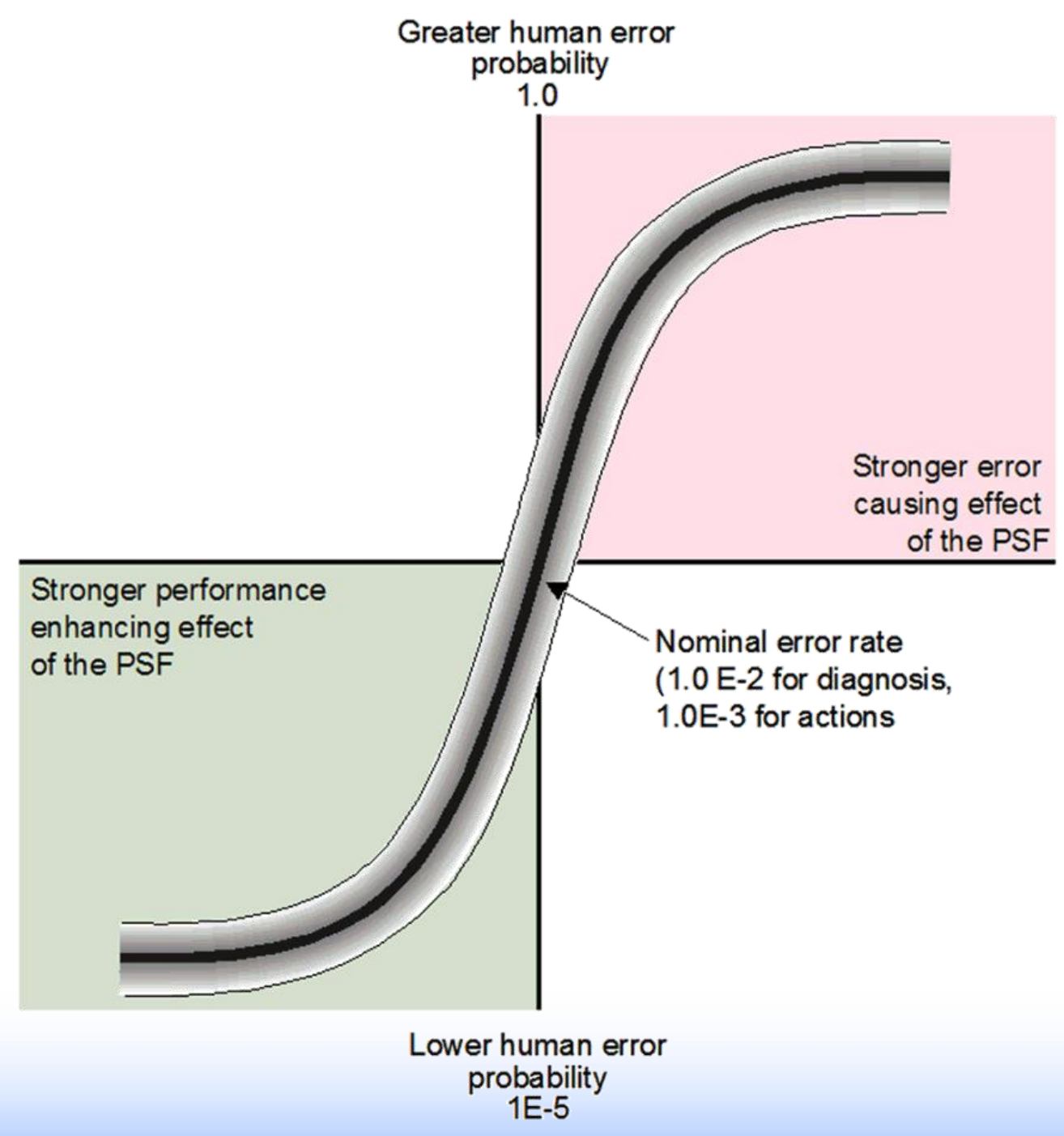




\section{Evaluating PSFs}

\begin{tabular}{l|l}
\multicolumn{1}{c|}{ PSF } & \multicolumn{1}{c}{ Considerations } \\
\hline Stress & $\begin{array}{l}\text { Knowledge of consequences of act performed improperly, } \\
\text { insufficient time, etc. }\end{array}$ \\
\hline Training & How frequent does it cover the task being evaluated \\
\hline Skill level & What is time in grade (master tech) \\
\hline Motivation, morale & $\begin{array}{l}\text { Poor facility housekeeping, lack of procedures, compliance, } \\
\text { high absenteeism }\end{array}$ \\
\hline Procedures & $\begin{array}{l}\text { Labels which don't exist, steps which are incomplete or } \\
\text { confusing, placement and clarity of caution statements }\end{array}$ \\
\hline Interface & Indicator and control switch design and layout \\
\hline Noise & Evaluate in terms of Db
\end{tabular}




\section{How Human Actions Are Incorporated Into Risk Assessment}

- Most human errors appear as fault tree basic events

- Some errors modeled in event trees

- Recovery actions added manually to results of model solution 


\section{HRA in NMSS Risk Assessment}

- One of the major gaps in the methods is the identification and development of a robust and simple method for incorporating human factors and estimating human reliability in the very wide range of situations and activities encountered and performed by NMSS licensees

- Development of HRA capability that tailors to materials and waste applications through user need with Office of Nuclear Regulatory Research (ML030310233)

- HRA course (P-406) 


\section{Sources of HRA Data}

- Nuclear, chemical, medical, and allied industries

- Military

- Other government agencies

- Simulators

- Expert elicitation

- Preliminary Notification/NMED 


\section{Preview of Quantification: Plug HEP data into the model and calculate paths and total HEP}

\section{Success Paths}

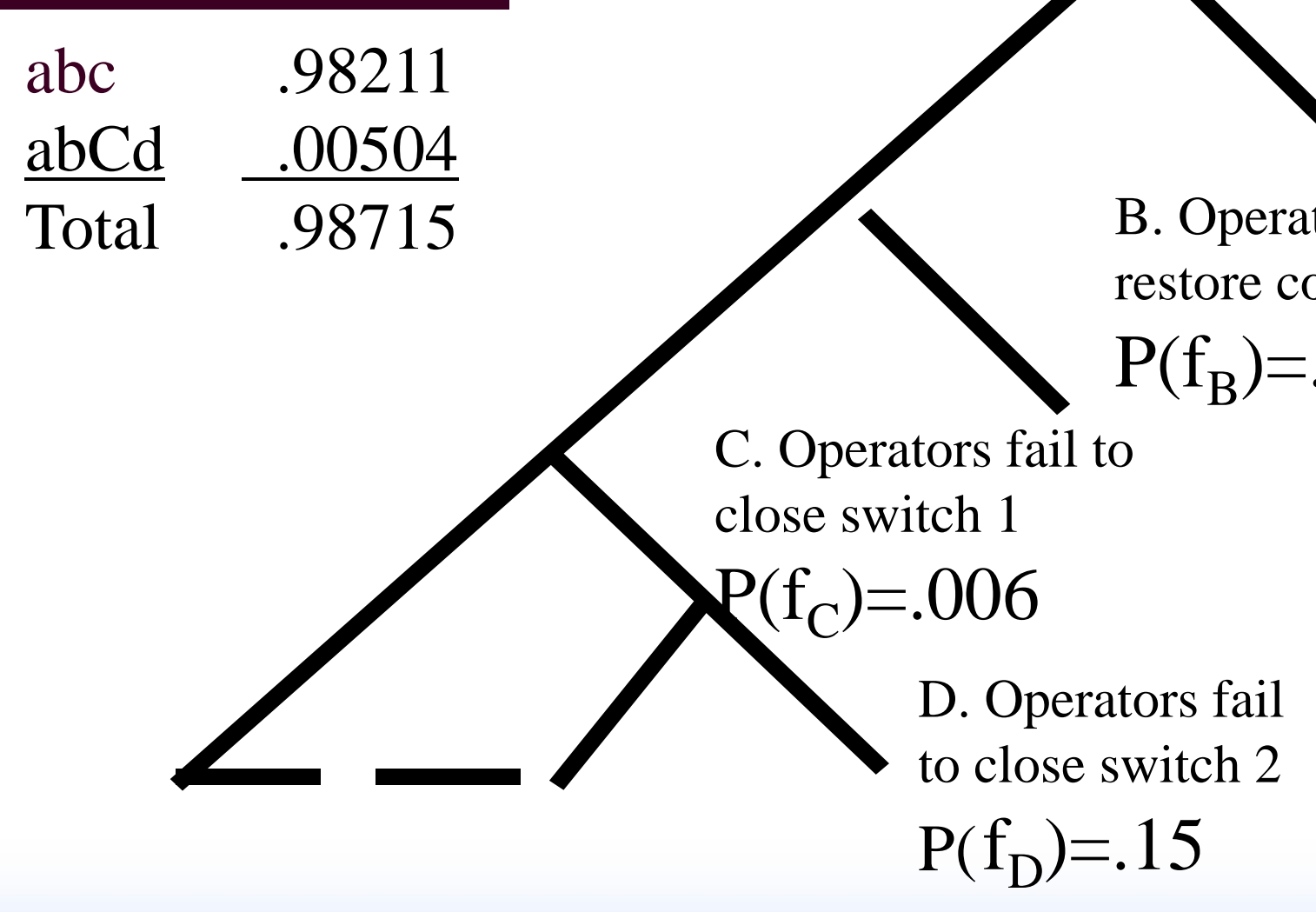

A. Operators fail to restore signal power $P\left(f_{A}\right)=.006$

B. Operators fail to

restore control power

$P\left(f_{B}\right)=.006$

C. Operators fail to

close switch 1

Failure Paths

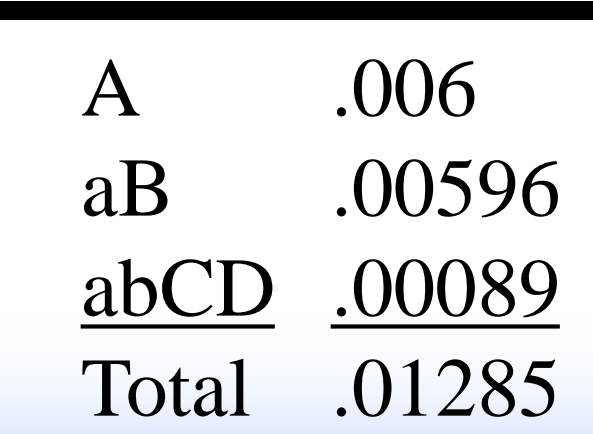

Idaho National Laboratory 


\section{HRA Strengths and Limitations}

- Major Strength: HRA identifies areas where improvements may be made in training, procedures, and equipment to reduce risk

- Limitations:

- Lack of consensus as to which modeling and quantification approach to use (several exist)

- Lack of data on human performance forces reliance on subjective judgment

- Skill and knowledge of those performing the HRA

- These limitations result in a wide variability in human error probabilities and make human contribution to risk a principal source of uncertainty 


\section{Uncertainty arises from many}

\section{sources}

- Inability to specify initial and boundary conditions precisely

- Cannot specify result with deterministic model

- Instead, use probabilistic models (e.g., tossing a coin)

- Sparse data on initiating events, component failures, site conditions and human errors

- Lack of understanding of phenomena

- Modeling assumptions (e.g., success criteria)

- Modeling limitations (e.g., inability to model errors of commission)

- Incompleteness (e.g., failure to identify certain failure modes) 


\section{Key Terminology: \\ Frequentist Interpretation of Probability}

$\operatorname{Pr}\left(\mathbf{N}_{1}\right)=\lim \mathbf{N}_{1} / \mathbf{N}$ $\mathbf{N} \rightarrow \infty$

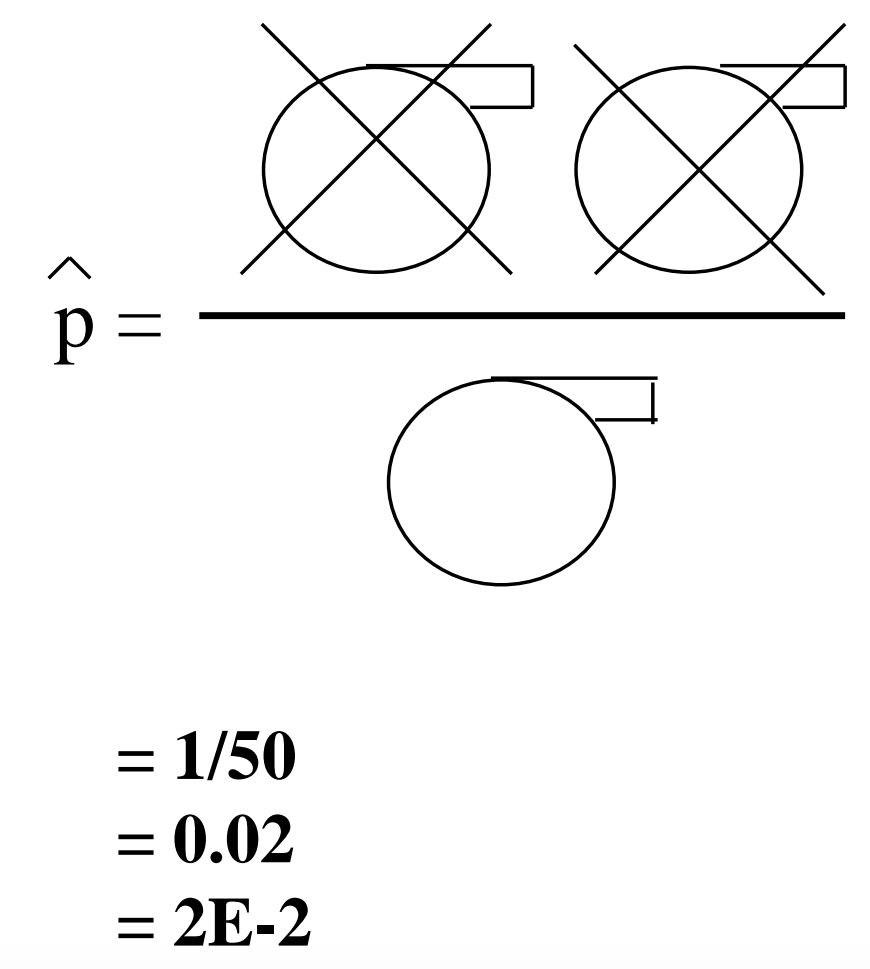

(2)

(100)

\section{Idaho National Laboratory}




\section{Key Terminology: Subjectivist (Bayesian) Interpretation of Probability}

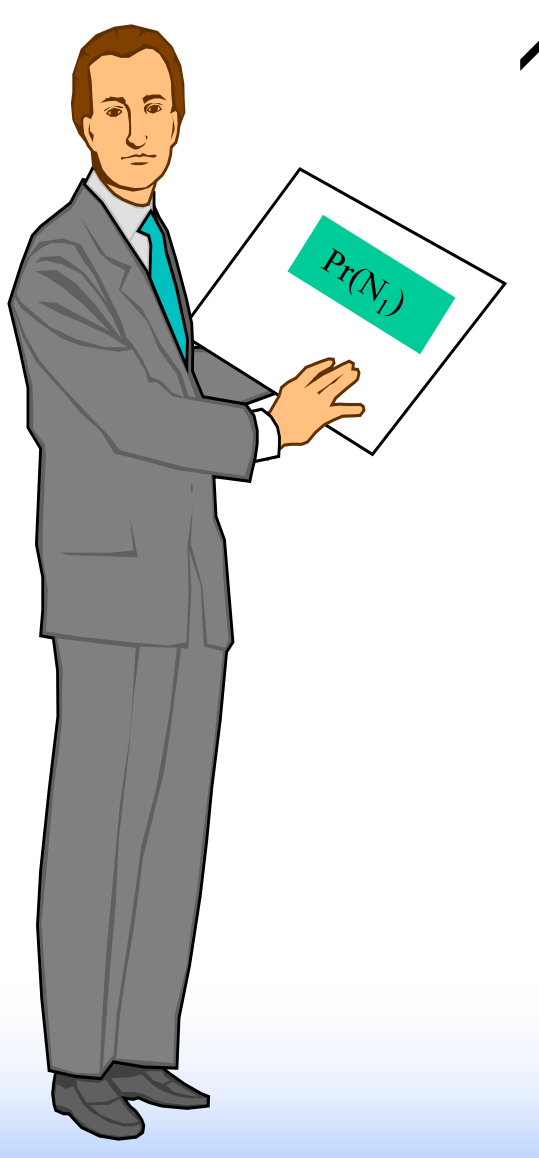

$\uparrow \operatorname{Pr}\left(N_{1}\right)$ is the degree of belief or knowledge the analyst holds about the likelihood of event $\mathrm{N}_{1}$ occurring 


\section{Two Types of Uncertainty}

- Distinction between aleatory and epistemic uncertainty:

- "Aleatory" of or relating to random or stochastic phenomena. Also called "random uncertainty or variability." [From Latin alea, dice].

- "Epistemic" of, relating to, or involving knowledge; cognitive. Also called "state-of-knowledge uncertainty." [From Greek episteme, knowledge]. 


\section{Aleatory Uncertainty}

- Variability in or lack of precise knowledge about underlying conditions makes events unpredictable. Such events are modeled as being probabilistic in nature. These include initiating events, component failures, environmental factors, and human errors.

- For example, initiating events are typically modeled as a Poisson process, similar to the decay of radioactive atoms

- Poisson process characterized by frequency of initiating event, usually denoted by parameter $\lambda$ 


\section{Epistemic Uncertainty}

- Value of $\lambda$ is not known precisely

- Could model uncertainty in estimate of $\lambda$ using statistical confidence interval

- Can't propagate confidence intervals through models

- Can't interpret confidence intervals as probability statements about value of $\lambda$

- Lack of knowledge about value of $\lambda$ is typically modeled by assigning (usually subjectively) a probability distribution to $\lambda$

- Probability distribution for $\lambda$ can be generated using Bayesian methods 


\section{Epistemic Uncertainty (continued)}

- Advantages to Bayesian Approach

- Allows uncertainties to be propagated easily through PRA models

- Allows probability statements to be made concerning $\lambda$ and outputs that depend upon $\lambda$

- Provides unified, consistent framework for parameter estimation 


\section{Uncertainty in $\lambda$ Expressed as Probability Distribution}

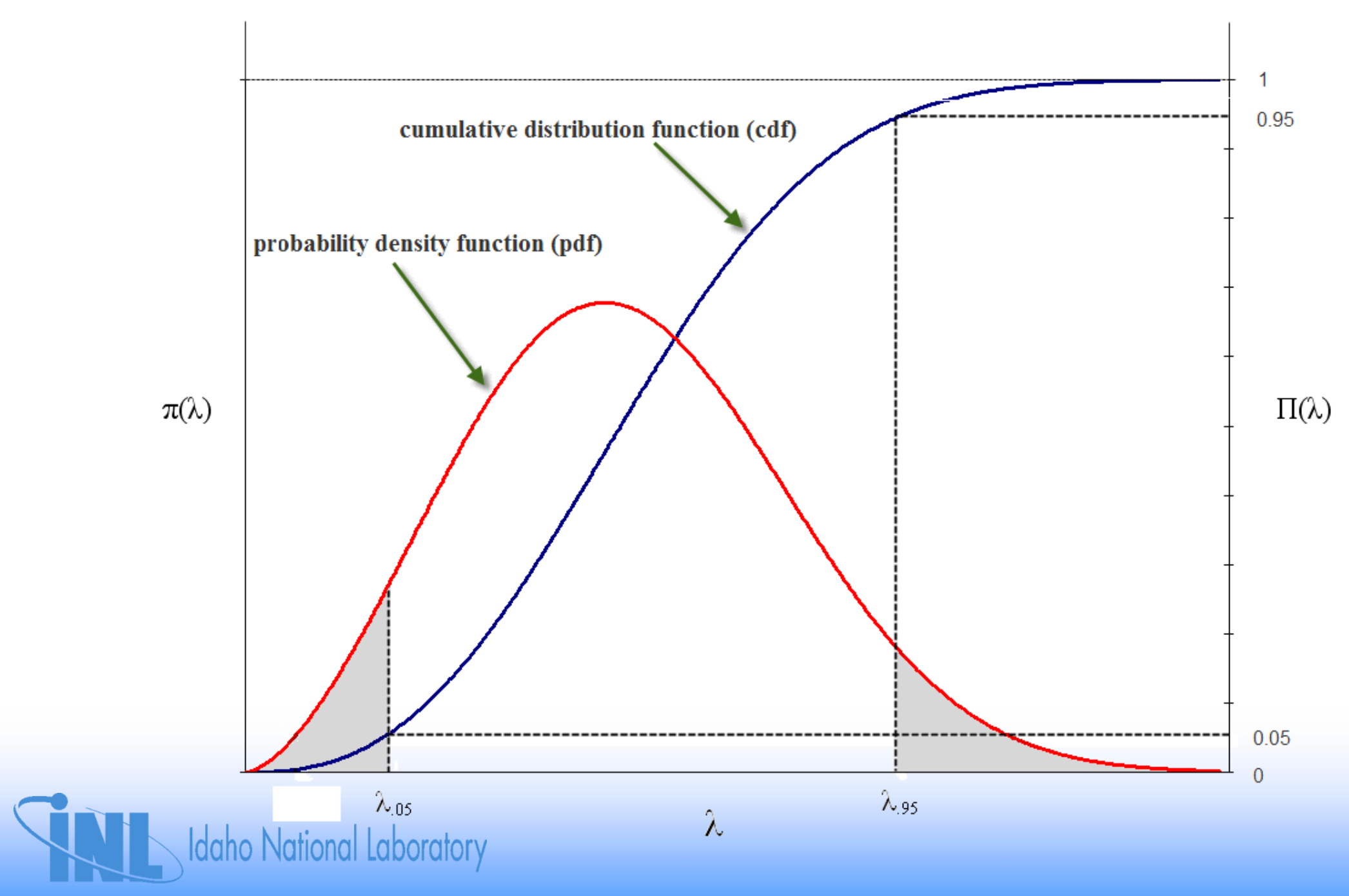




\section{Uncertainty Propagation}

- Uncertainties propagated via Monte Carlo sampling

- In this approach, output probability distribution is generated empirically by repeated sampling from input parameter distributions 


\section{Uncertainty Propagation through Model}

A single distribution for IE

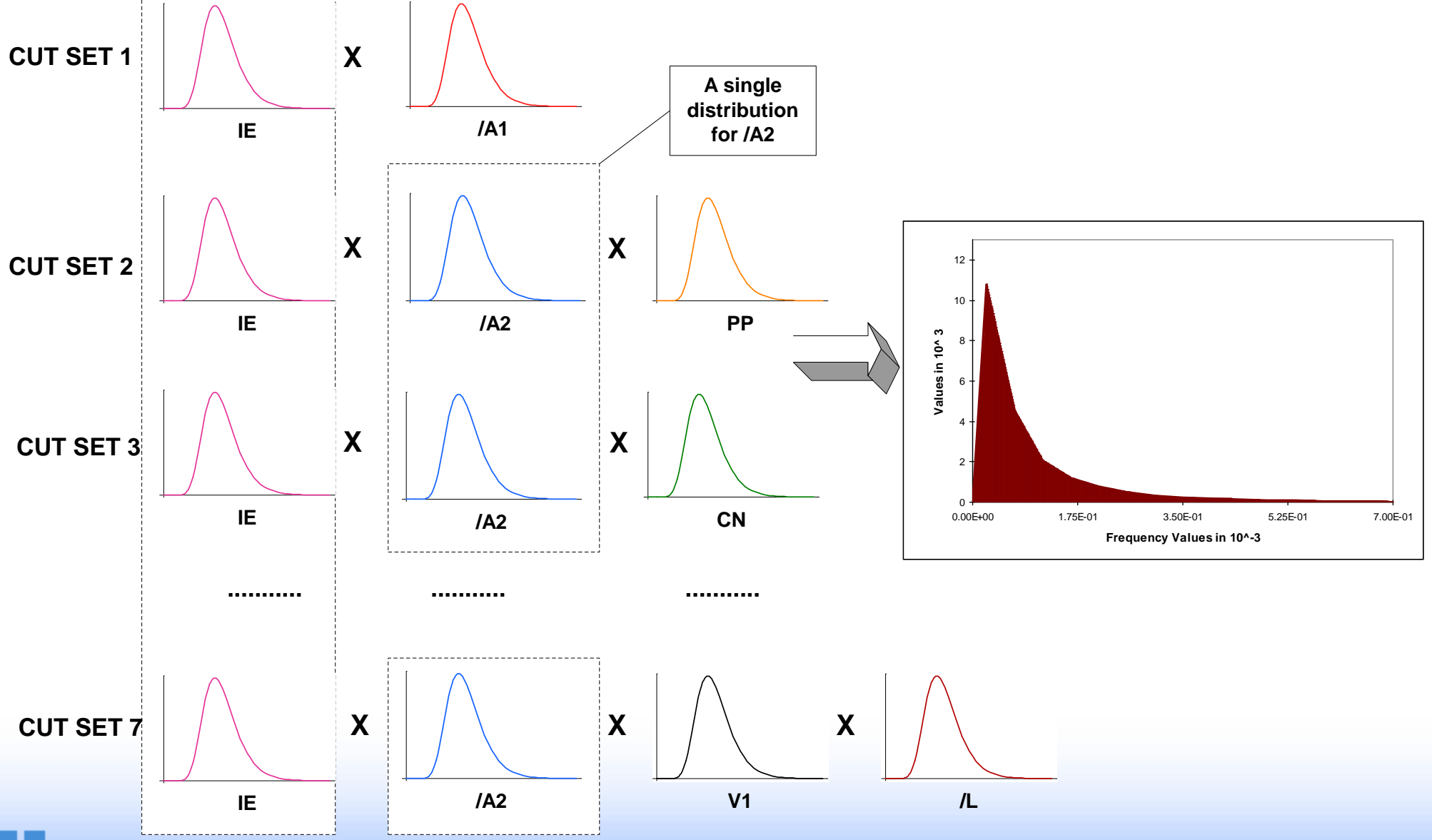




\section{Other Epistemic Uncertainties}

- Modeling uncertainty

- System success criteria

- Accident progression phenomenology

- Health effects models (linear versus nonlinear, threshold versus nonthreshold dose-response model) 


\section{Other Epistemic Uncertainties (continued)}

- Completeness

- Complex errors of commission

- Design and construction errors

- Unexpected failure modes and system interactions

- All modes of operation not modeled 


\section{Other Epistemic Uncertainties (continued)}

- Errors in analysis

- Failure to model all SSCs of a system

- Data input errors

- Analysis errors 


\section{Addressing Epistemic Uncertainties}

- Modeling uncertainty usually addressed through sensitivity studies

- Research ongoing to examine more formal approaches

- Completeness addressed through comparison with other studies and peer review

- Some issues (e.g., design errors) are simply acknowledged as limitations

- Other issues (e.g., errors of commission) are topics of ongoing research

- Analysis errors may be difficult to catch; addressed through peer review 


\section{Principal Steps in Risk Assessment Process}

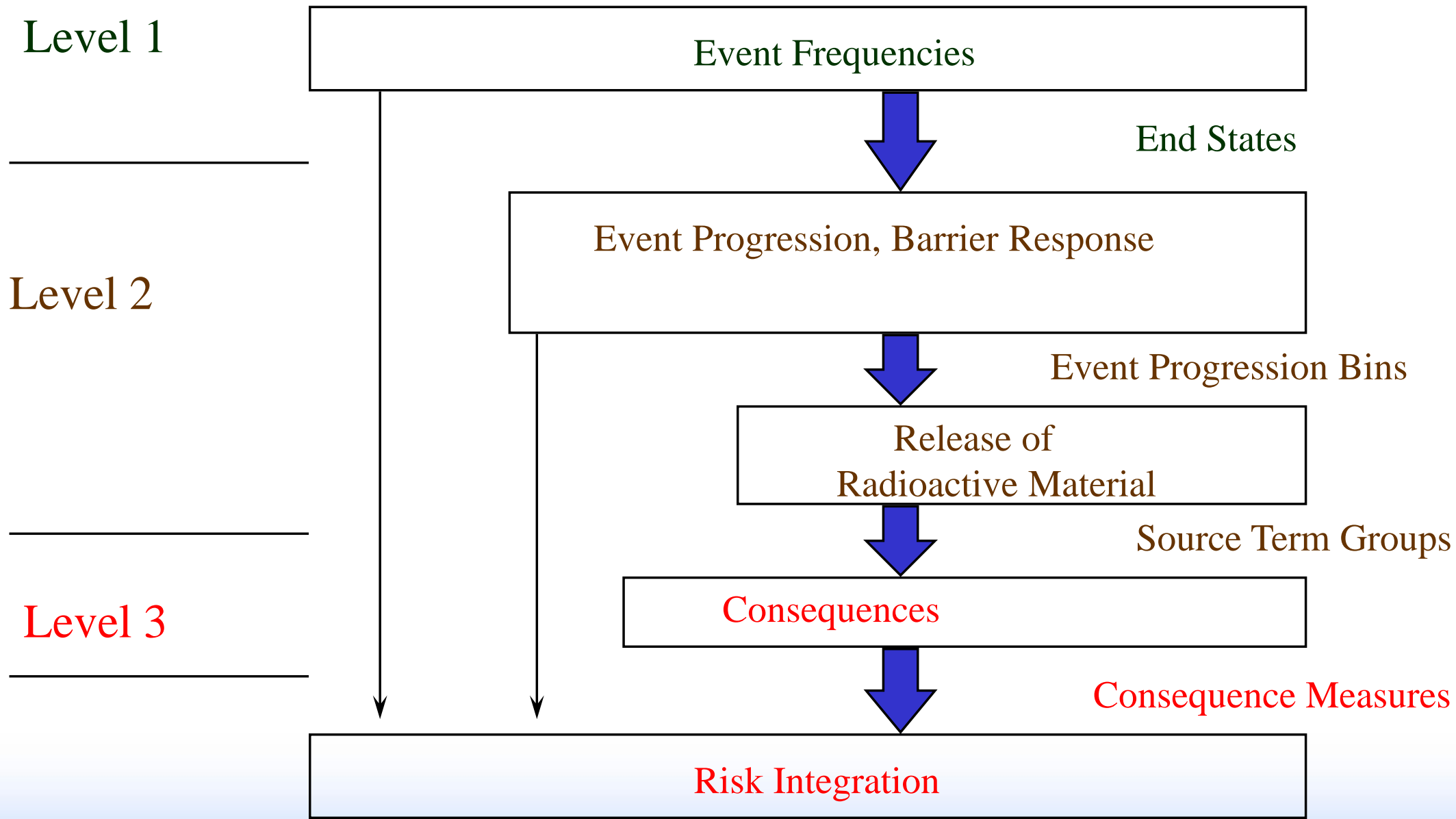




\section{Event Progression Analysis}

- Major steps in event progression analysis

- Develop progression event trees

- Perform analysis of barriers

- Quantify issues from progression event trees

- If warranted, group progression event tree results into bins for further evaluation 


\section{Components of a Consequence Model}

- Transport and diffusion model

- Pathways models

- Dosimetry models

- Health effects model

- Other models:

- Evacuation

- Interdiction

- Decontamination

- Economic effects 


\section{Pathways to People}

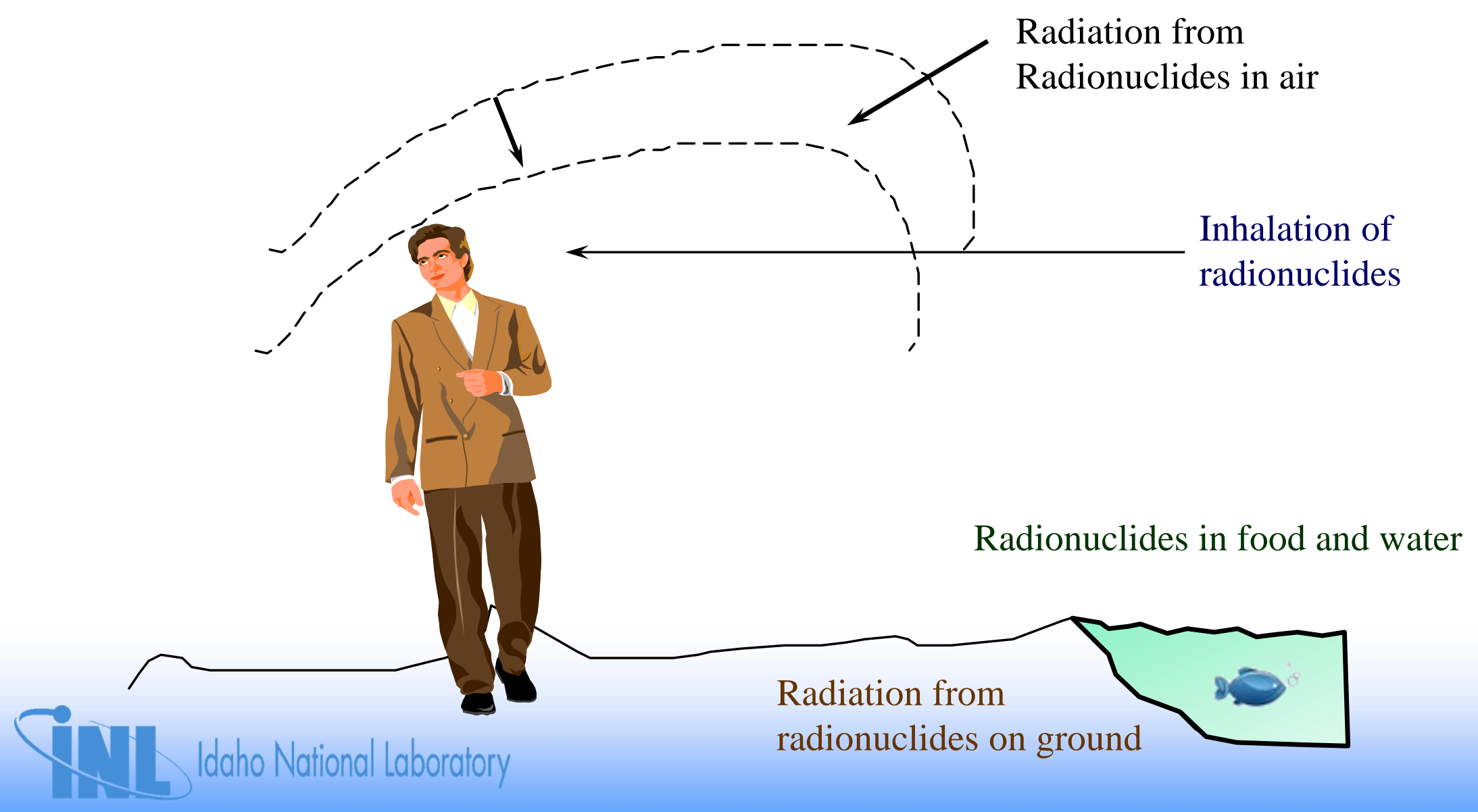




\section{Consequences}

- Population dose

- Acute effects

- Number of fatalities, injuries, and illnesses occurring within one year due to initial exposure to radioactivity; nonlinear with dose equivalent

- Latent effects

- Number of delayed effects and time of appearance as functions of dose for various organs; linear, nothreshold model typically used

- Property damage and/or loss 


\section{Probability and Frequency Questions}

- 1. An event occurs with a frequency of 0.02 per year.

- 1.1. What is the probability that at least one event will occur within a given year?

- $P\{$ event $<1$ year $\}=1-\mathrm{e}^{-(2 \mathrm{E}-2)(1)}=1-0.9802=0.0198=1.98 \mathrm{E}-2$

- Or $\mathrm{P}\{$ event $<1$ year $\} \approx \lambda \mathrm{t} \approx(2 \mathrm{E}-2)(1) \approx 2 \mathrm{E}-2$

- 1.2. What is the probability that at least one event will occur within 50 years?

- $P\{$ event $<50$ years $\}=1-\mathrm{e}^{-(2 \mathrm{E}-2)(50)}=1-\mathrm{e}^{-1}=1-0.3679=0.6321=6.321 \mathrm{E}-1$

- 2. Event $A$ occurs with a frequency of 0.1 per year. Event $B$ occurs with a frequency of 0.3 per year.

- 2.1. What is the probability that at least one event (either A or B) will occur within a given year?

- $P(A)=1-e^{-(\lambda A) t}=1-e^{-(0.1) 1}=1-0.9048=0.0952$

- $P(B)=1-e^{-(\lambda B) t}=1-e^{-(0.3) 1}=1-0.7408=0.2592$

- $P(A+B)=P(A)+P(B)-P(A B)=0.0952+0.2592-[(0.0952)(0.2592)]=0.3543-0.0247=0.3297$

- Or $P(A+B)=P(A)+P(B)-P(A B)=1-e^{-(\lambda A+\lambda B) t}=1-e^{-(0.1+0.3) 1}=1-0.6703=0.3297$

- 2.2. What is the probability that at least one event (either $A$ or $B$ ) will occur within 5 years?

- $P(A)=1-e^{-(\lambda A) t}=1-e^{-(0.1) 5}=1-0.6065=0.3935$

- $P(B)=1-e^{-(\lambda B) t}=1-e^{-(0.3) 5}=1-0.2231=0.7769$

- $P(A+B)=P(A)+P(B)-P(A B)=0.3935+0.7769-[(0.3935)(0.7769)]=1.1703-0.3057=0.8647$

- $\operatorname{Or} P(A+B)=P(A)+P(B)-P(A B)=1-e^{-(\lambda A+\lambda B) t}=1-e^{-(0.1+0.3) 5}=1-0.1353=8.647 E-1$ 


\section{Probability and Frequency Questions}

- 3. An experiment has a probability of 0.1 of producing a failure.

- 3.1. What is the probability of observing exactly one failure if the experiment is repeated 4 times?

- $P$ [exactly 1 failure in 4 trials $\mid 0.1]=$

$$
=\frac{4 !}{1 !(4-1) !} 0.1^{1}(1-0.1)^{4-1}=\frac{4 !}{13 !} 0.1^{1} 0.9^{3}=(4)(0.1)(0.729)=0.2916
$$

- 3.2. What is the probability of observing at least one failure if the experiment is repeated 4 times?

- $P$ [at least 1 failure in 4 trials $\mid 0.1]=$

- $P[1]+P[2]+P[3]+P[4]=$

- $1-P[0$ failures in 4 trials $\mid 0.1]=$

$=1-\frac{4 !}{0 !(4-0) !} 0.1^{0}(1-0.1)^{4-0}=1-\frac{4 !}{0 ! 4 !} 0.1^{0} 0.9^{4}=1-(1)(1)(0.6561)=0.3439$ 


\section{Probability and Frequency Questions}

- $P$ [exactly 0 failures in 4 trials $\mid 0.1]=$

- $=\frac{4 !}{0 !(4-0) !} 0.1^{0}(1-0.1)^{4}=(1)(1)(0.6569)=0.6569$

- $P$ [exactly 1 failure in 4 trials $\mid 0.1$ ] =

- $=\frac{4 !}{1 !(4-1) !} 0.1^{1}(1-0.1)^{3}=(4)(0.1)(0.729)=0.2916$

- $P$ [exactly 2 failures in 4 trials $\mid 0.2$ ] =

- $=\frac{4 !}{2 !(4-2) !} 0.1^{2}(1-0.1)^{2}=(6)(0.01)(0.81)=0.0486$

- $P$ [exactly 3 failure in 4 trials $\mid 0.2$ ] =

- $=\frac{4 !}{3 !(4-3) !} 0.1^{3}(1-0.1)^{1}=(4)(0.001)(0.9)=0.0036$

- $P$ [exactly 4 failures in 4 trials $\mid 0.2$ ] =

$\cdot=\frac{4 !}{4 !(4-4) !} 0.1^{4}(1-0.1)^{0}=(1)(0.0001)(1)=0.0001$ 


\section{Application of Risk Insights to Regulatory Decision Making Activities}




\section{Page Intentionally Left Blank}




\section{Application of Risk Insights to Regulatory Decision Making Activities}

- Purpose: Provide a summary of;

- where risk assessment methods were applied for several examples from NMSS activities

- how the risk insights from these examples were used for regulatory decision making

- where risk assessment methods or a risk informed approach may be applied in NMSS activities for regulatory decision making for these examples 


\section{Application of Risk Insights to Regulatory Decision Making Activities}

- Objectives: To have an understanding of the following:

- Risk assessment methodology utilized

- Key assumptions made in the risk assessment

- Data used for the risk assessment

- Results of the risk assessment

- Risk insights used for decision making 


\section{Transportation Example}

Trojan Reactor Vessel Package 


\section{Safety Evaluation Report, Trojan Reactor Vessel Package (TRVP)}

- Risk assessment and deterministic engineering analysis of TRVP performed by Portland General Electric Company (PGE) reviewed by NRC to ensure

- TRVP satisfies regulatory requirements, and approve PGE's request for an exemption to package testing regulations

- Existing transportation regulations are adequate for protecting public health and safety, and the environment during TRVP transportation 


\section{References}

- Available under Docket 71-9271

- PGE application dated March 31, 1997

- Supplements dated August 8, August 13, and September 23, 1998

- Reactor Vessel and Internals Removal Project, Transportation Safety Plan, PGE-1077, Rev. 0 


\section{Background}

- TRVP transported by barge on the Columbia River from the Trojan Site to the Port of Benton (270.8 miles)

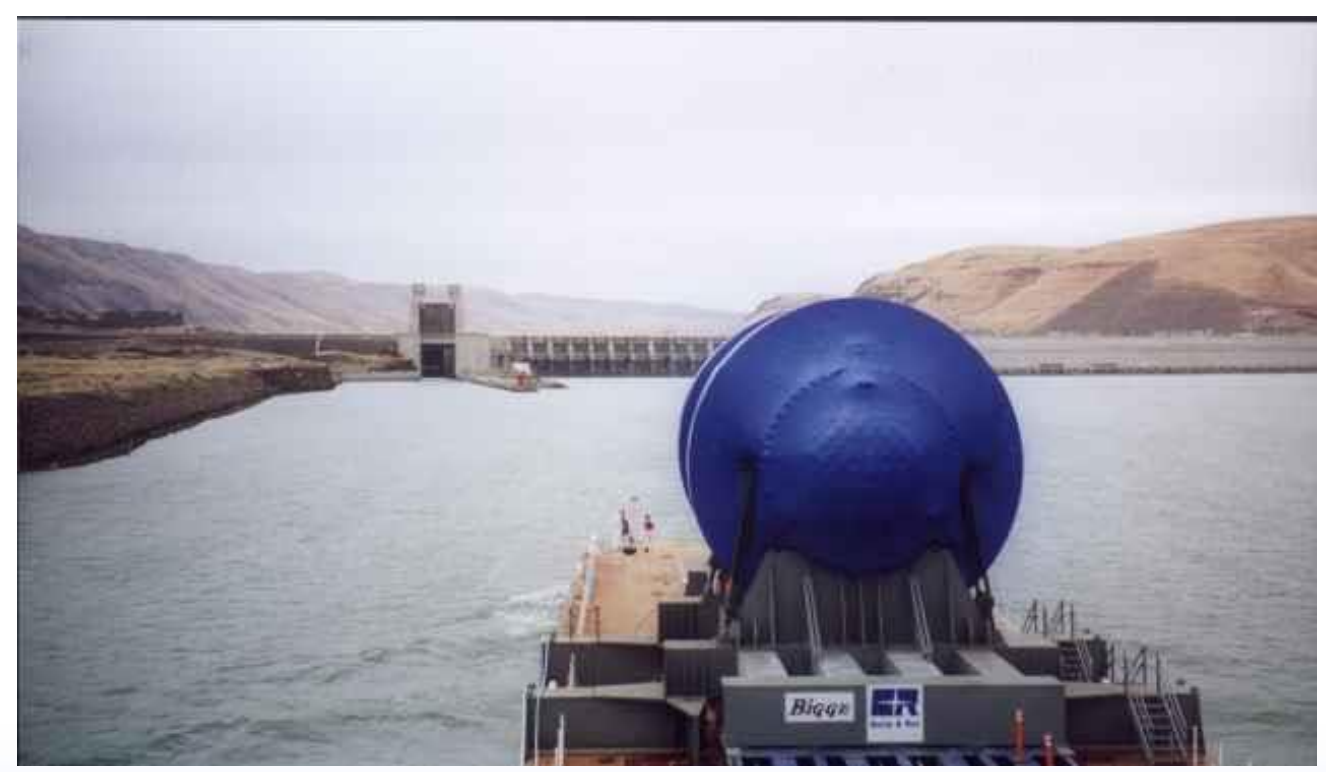




\section{Background}

- TRVP transported by a transporter overland from the Port of Benton to the U.S. Ecology facility on public roads and Hanford Reservation highways (two routes considered 20 miles or 30 miles)

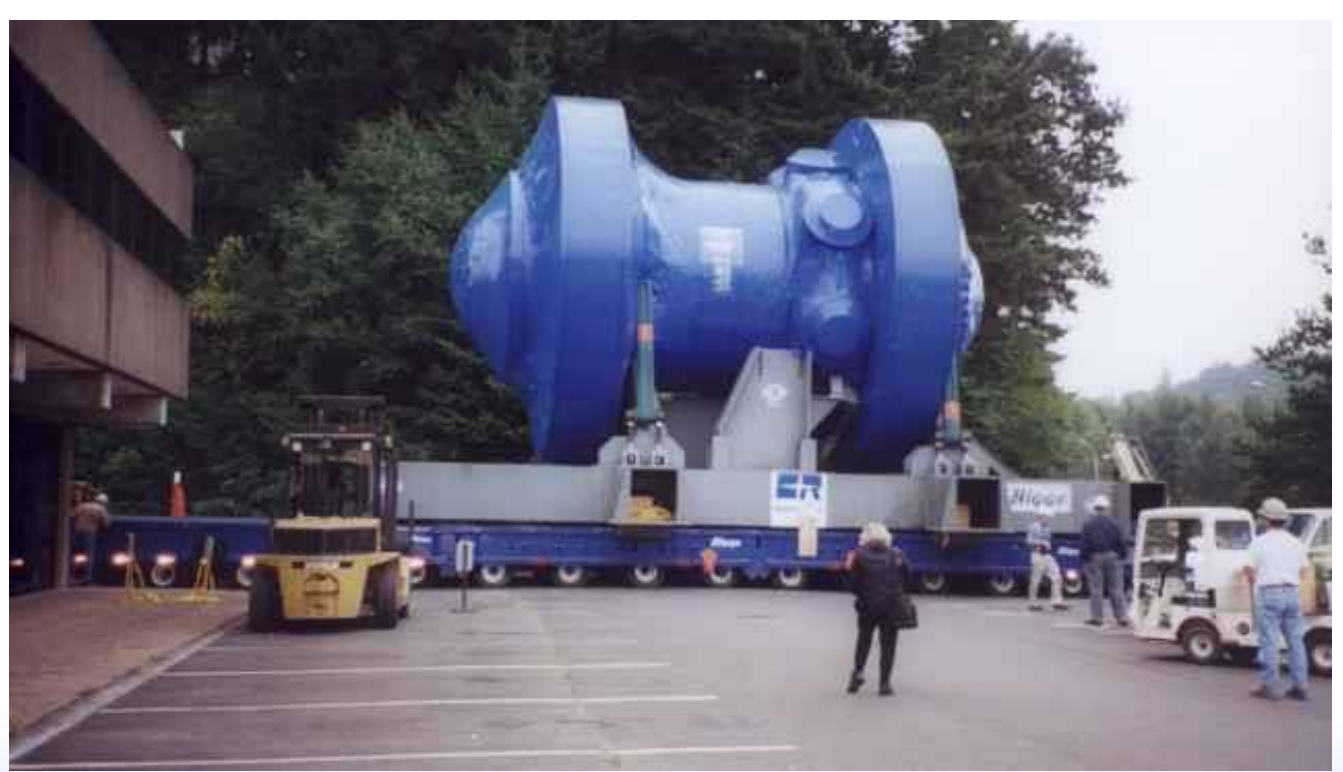




\section{Background (continued)}

- By application dated March 31, 1997, as supplemented, PGE requested approval of the TRVP as a Type $B$ transportation package

- As part of application, PGE requested exemptions, pursuant to 10 CFR 71.8, from the requirements of 10 CFR 71.71(c)(7) and 10CFR 71.73(c)(1) 


\section{Background (continued)}

- 10 CFR 71.71(c)(7) - Requires an evaluation of the package design under normal conditions of transport, and that includes a free drop of the specimen through a distance of 1 foot (for a package weighing more than 33,100 pounds) "onto a flat, essentially unyielding, horizontal surface in a position for which maximum damage is expected." 


\section{Background (continued)}

- 10CFR 71.73(c)(1) - Concerns tests for hypothetical accident conditions and requires: "A free drop of the specimen through a distance of $9 \mathrm{~m} \mathrm{(30} \mathrm{ft)} \mathrm{onto}$ a flat, essentially unyielding, horizontal surface, striking the surface in a position for which maximum damage is expected."

- 10CFR 71.73(b) requires that the ambient air temperature must remain constant during testing at the value between $-29 \mathrm{C}(-20 \mathrm{~F})$ and $+38 \mathrm{C}(+100 \mathrm{~F})$ which is most unfavorable for the feature under consideration. 


\section{Normal and Accident Conditions}

Reviews

- Structural

- Thermal

- Containment

- Shielding

- Criticality

- Operating Procedures

- Acceptance Tests and Maintenance Program 


\section{Probabilistic Safety Studies Conducted}

- TRVP transportation by barge on the Columbia River

- TRVP transportation overland

- External events 


\section{TROJAN BARGE SHIPMENT EVENT TREES}

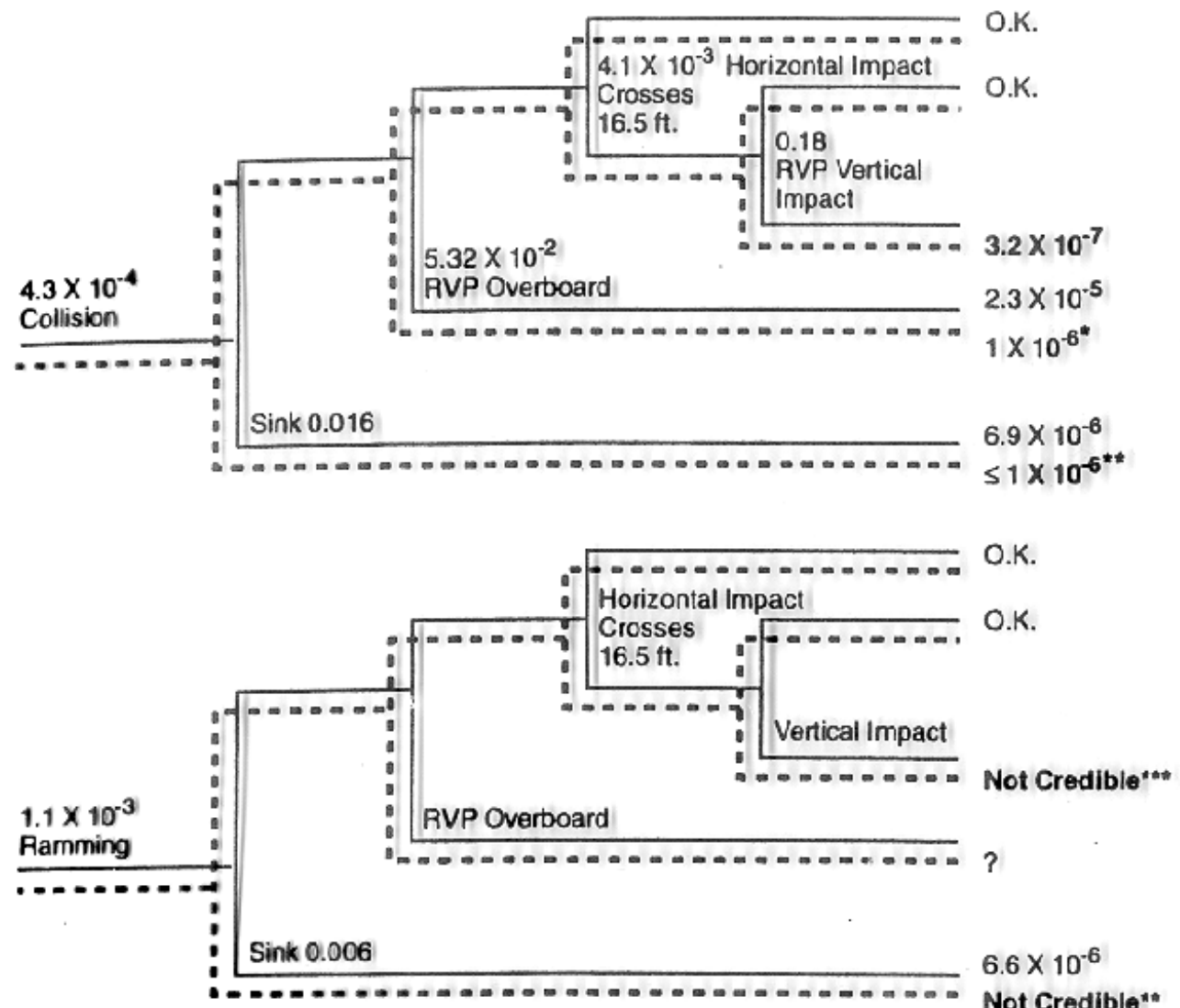

\section{— From data of typical barges}

Trojan barge will have a cargo securing arrangement designed to maintain control of RVP package under exposure to a peak transverse acceleration of $1.60 \mathrm{~g}$

". Trojan barge will have 2 longitudinal watertight bulkheads and six transverse watertight internal bulkheads resulting in 19 walertight compartments

-. Based on a maximum speed of 10 knots

*** Poor maintenance dismissed because barge Is to be certified by a marine suneyor. Heavy weather $d$ 'smissed because of procedures to hold barge below dam if wave height becomes $>6.5$ it.
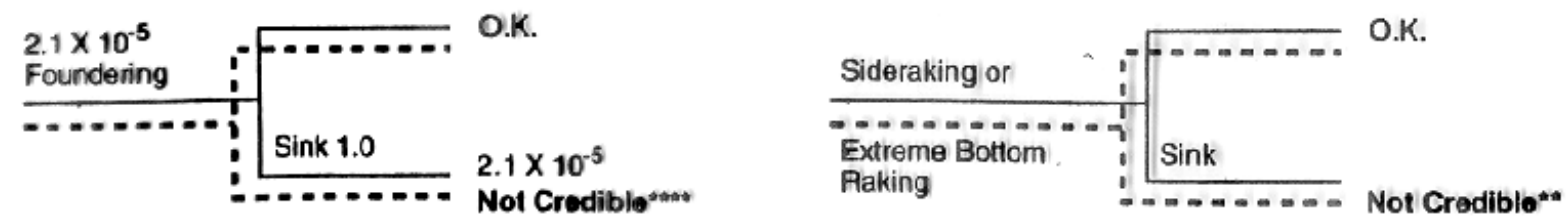


\section{Results of Deterministic and Probabilistic Studies}

- Results of studies indicated;

- Existing transportation regulations were adequate for protecting public health and safety, and the environment.

- Package testing requirements were not met for the particular radioactive materials shipment in a cask, but additional safety measures which were above and beyond regulatory requirements provided equivalent safety. 


\section{Conditions for Authorization to Transport}

- TRVP configuration to be as analyzed

- TRVP transported in compliance with specific exemption issued by U.S. DOT

- TRVP transported in accordance with PGE's Transportation Safety Plan

- TRVP prepared for shipment and operated in accordance with application dated March 31, 1997, as supplemented on August 8, August 13, and September 23, 1998 


\section{Final Result}

- NRC granted a one-time exemption for shipment based on the risk analysis and deterministic engineering analysis submitted as part of request. 


\section{Relative Risk Analysis in Regulating the Use of Radiation-Emitting Medical Devices}

Gamma Knife Example 


\section{Gamma Knife* Example}

( ${ }^{*}$ The Gamma Knife is a registered trademark of Elekta Instruments, Inc.)

- NUREG/CR-6323, Relative Risk Analysis in Regulating the Use of Radiation-Emitting Devices, September 1995

- Study conducted to develop risk analysis approach for evaluating the use of radiationemitting medical devices

- Study represented an initial step in an NRC plan to evaluate the potential role of risk analysis in developing regulations and quality assurance requirements in the use of nuclear medical devices 


\section{Gamma Knife Example (continued)}

- NUREG/CR-6323, Relative Risk Analysis in Regulating the Use of Radiation-Emitting Devices, September 1995 (continued)

- Risk analysis approach initially applied to evaluate the use of the Gamma Knife

- Commercially available external beam radiation therapy device used to deliver radiation to precisely defined intracranial targets

- Analysis approach identified and assessed the most likely risk contributors (both human-initiated actions and equipment failure modes) and their relative importance in the use of the Gamma Knife 


\section{Background}

- NRC has authority to regulate the medical use of nuclear byproduct material or radiation from byproduct material to protect the health and safety of patients, while recognizing that physicians have the primary responsibility for the protection of their patients

- Gamma Knife involves irradiation of brain lesions by 201 stationary cobalt-60 sources geometrically arranged to converge into a precise dose volume 


\section{Objective}

- Identify the likely contributors to risk and their relative importance in the use of the Gamma Knife.

- Involves the assessment of:

- What can go wrong in the process of using a Gamma Knife

- Relative likelihood of undesired events

- Mis-delivery of radiation dose associated with an undesired event 


\section{Approach}

- Selected approach to include, as much as is reasonable, the input of the regulated community

- Device manufacturer

- Medical practitioners

- Review of misadministration events abnormal occurrences indicated risk analysis should be balanced between

- Equipment failures

- Human errors

- A relative risk profiling technique was selected for analysis of the Gamma Knife. 


\section{Risk Definition Used}

- Risk = Error Probability $\times$ Error Consequence

- Error Probability - Probability of an undesired event, which is an unintended dose. Unintended dose depends on;

- Absolute dose (dose rate multiplied by exposure time)

- Volume of brain tissue receiving the radiation (treatment position/volume)

- Error Consequence - Magnitude of the error (deviation from expected) associated with an unintentional exposure or unintended deviation from the prescribed dose.

- However, a dose error and a volume error are not equal consequences. Equation for dose/volume relationship used

- If the magnitude of a dose error was $5 \%$, it was given a 0.075 consequence measure.

- If the magnitude of a volume error was $5 \%$, it was given a 0.05 consequence measure. 


\section{Key Assumptions}

- A relative risk profiling technique was selected for analysis of the Gamma Knife because;

- limited data base for Gamma Knife did not permit accurately estimating individual contributor risk values

- absolute values were not necessary for an effective understanding and regulation of the system

- To minimize intrusion into medical judgements affecting patients and into other areas traditionally considered part of the practice of medicine, it is assumed that properly trained and adequately informed physicians will make decisions in the best interest of their patients 


\section{Relative Risk Analysis Process used in the Gamma Knife Application}

- Review Gamma Knife equipment, functions and operations

- Identify risk contributors through modified task analysis

- Identify high risk contributors and tasks through expert screening process

- Assess high risk tasks through relative ranking and profile analysis

- Estimate the importance and uncertainties of high risk tasks 


\section{Review Gamma Knife Equipment, Functions and Operations}

- The Gamma Knife is a gamma radiation device designed to perform stereotactic radiosurgery of the brain

- The U.S. Gamma Knife model consists of a radiation unit, four interchangeable collimator helmets, a patient treatment table, a hydraulic system, a control console and a treatment planning computer system

- The radiation unit has 201 stationary cobalt-60 sources that are arranged in a large, heavily shielded $(18,000 \mathrm{~kg})$ sphere 


\section{NMSS Activities (continued)}

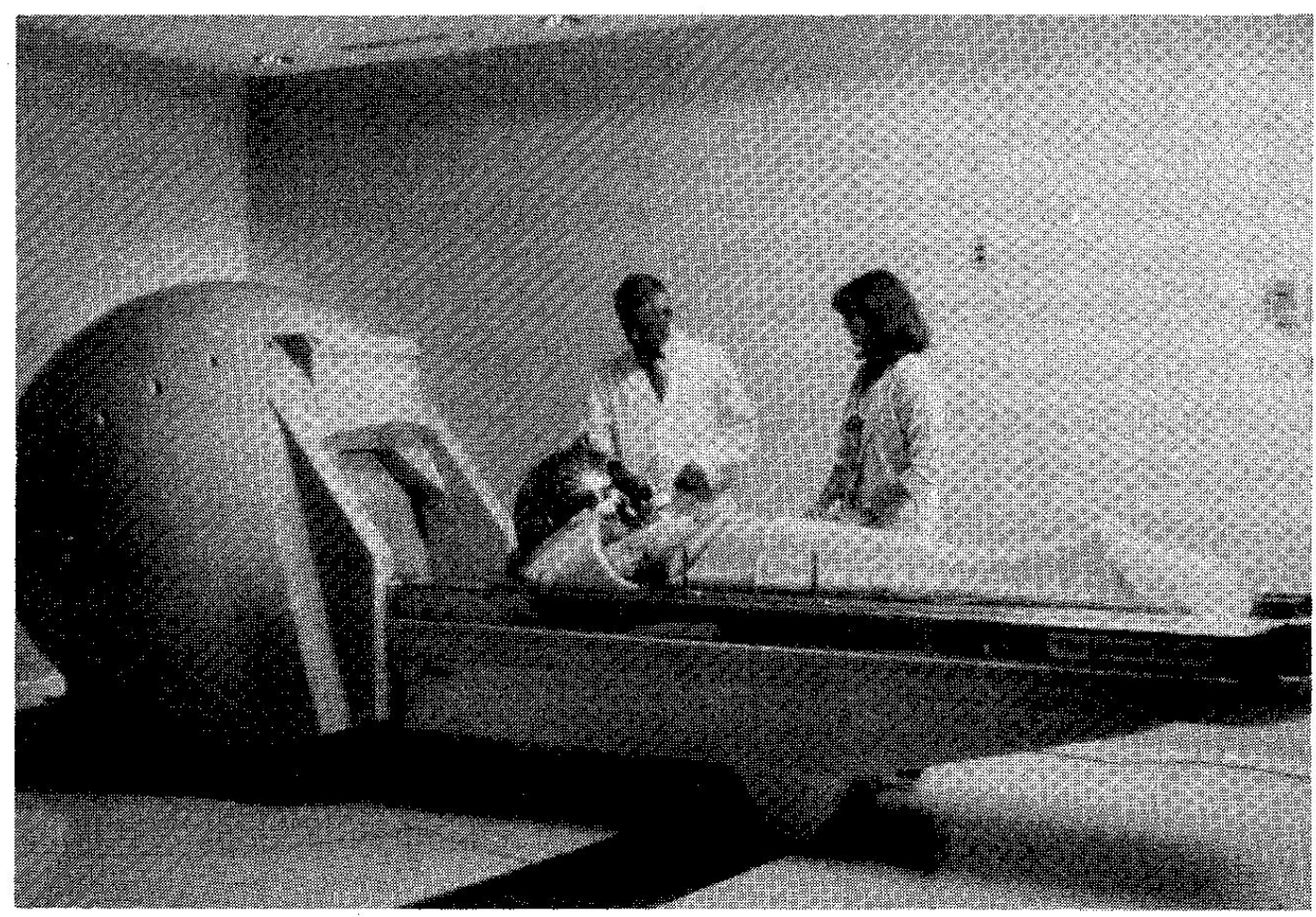

The Gamma Knife 


\section{NMSS Activities (continued)}

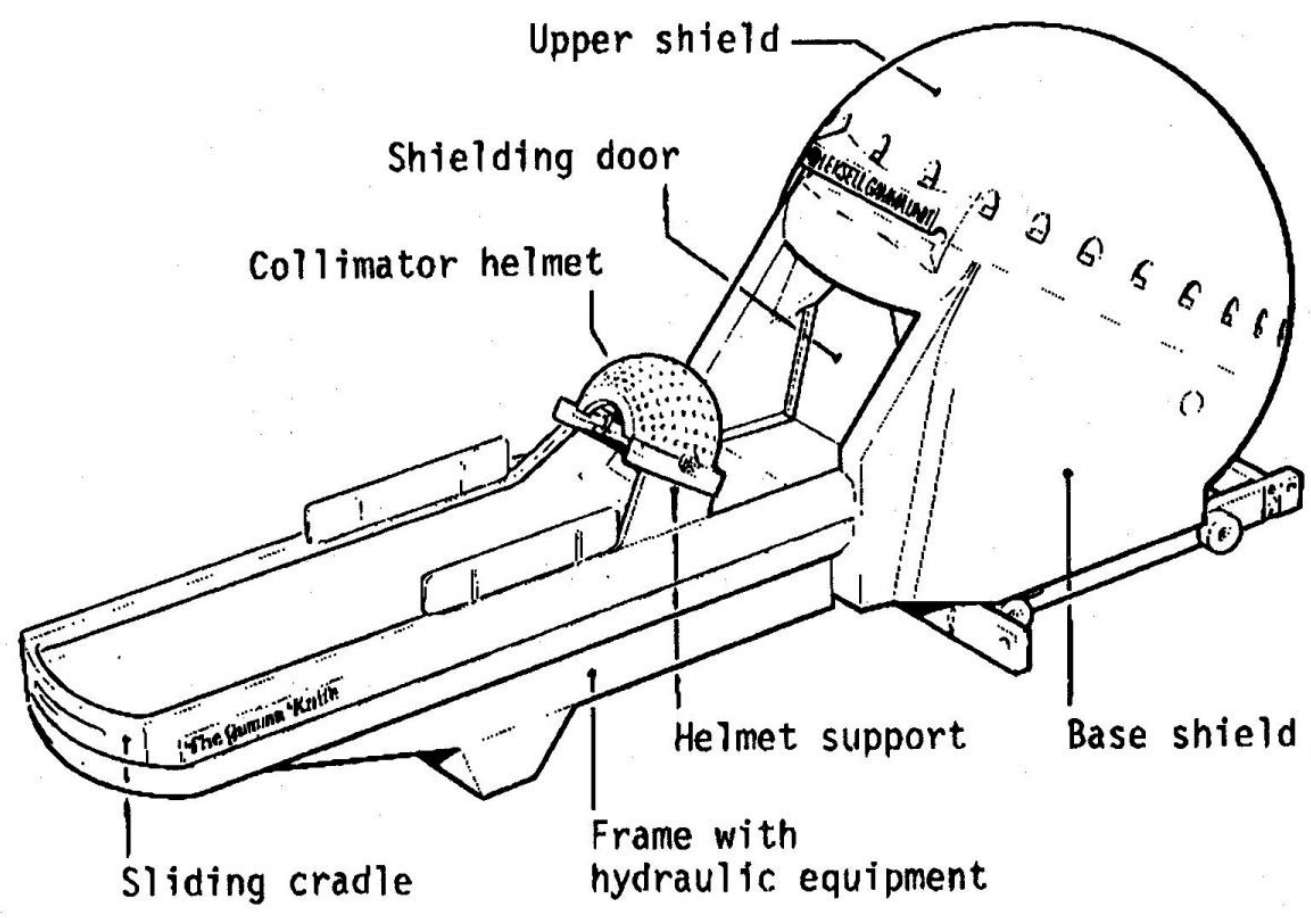

Major components of the Gamma Unit 


\section{Review Gamma Knife Equipment, Functions and Operations (continued)}

- Radiation from each cobalt-60 source is collimated into narrow beams that focus at the center of the sphere

- A movable external collimator device or helmet is moved hydraulically to align with fixed internal collimators inside the sphere

- The beams diameter can be varied by changing the size of circular apertures in the helmet or they can be blocked by using plugs 


\section{Review Gamma Knife Equipment,}

Functions and Operations (continued)

- For each helmet, a pair of trunnions serve as fixation points for the stereotactic frame, which in turn is attached by four pins to the outer surface of the patient's skull

- The cumulative radiation from 201 beams results in a concentrated dose at the center of the sphere while sparing tissue along the 201 individual beam paths

- The gamma unit is isolated in a shielded treatment room with a shielded door interlock system

- Exposure rates are limited to $2 \mathrm{mR} / \mathrm{hr}$ in both controlled and non-controlled areas 


\section{Review Gamma Knife Equipment, Functions and Operations (continued)}

- Patient lays on treatment table with the stereotactic frame attached by trunnions to collimating helmet

- Personnel leave patient in treatment room and engage the door interlock

- Counters are set at control console before starting

- Hydraulic system opens the shield door of the gamma unit and the table is moved into the sphere until the collimator helmet is aligned

- After the prescribed amount of time the table is withdrawn and the shield door closes 


\section{Identify Risk Contributors through Modified Task Analysis}

- Based on observations, interviews and questions answered by medical experts and engineers, a comprehensive set of scenarios were identified which constituted abnormal operating modes and human errors

- These were evaluated using task analysis to determine task sequences and critical human failures

- Task lists were developed for each treatment path

- A total of 102 tasks (tasks and sub-tasks) and 23 equipment failures with potential consequences were postulated 


\section{Identify potentially high risk contributors through expert screening process}

- Probability Estimates

- Users asked how often they experienced undesired events associated with the identified task and equipment. No scale provided in this initial elicitation.

- Based on initial elicitation, the following template or metric for estimating event probabilities established:

- 1 in 1000 (0.001)

- 1 in 500 (0.002)

- 1 in $100(0.01)$

- 1 in 50 (0.02)

- 1 in $10(0.1)$ 


\section{Identify potentially high risk contributors through expert screening process (continued)}

- Consequence Estimates

- To establish a metric for the error consequence experts were asked: If a certain undesired event occurred, how large of an unintended radiation exposure would result?

- Unplanned personnel exposures

- time

- distance

- Unintended dose to patient

- Dose

- Treatment position/volume 


\section{Identify potentially high risk contributors through expert screening process (continued)}

- Consequence Estimates (continued)

- The following template or metric for magnitude of the error;

- $2 \%(0.02)$

- $5 \%(0.05)$

- $10 \%(0.1)$

- $20 \%(0.2)$

- $50 \%(0.5)$

- However, for patient consequence estimates, magnitudes of dose and position/volume errors may not be rationally compared, if dose and volume effects are independent. But dose and volume radiobiological responses appear to obey a power law relationships for volume elements in radiosurgical treatments. Dose value has a 1.5 weighting factor

- volume error $5 \%$, consequence measure 0.05

- dose error $5 \%$, consequence measure 0.075 


\section{Identify potentially high risk contributors through expert screening process (continued)}

- Metrics used in formal expert elicitations

- Individual interviews

- Group interviews

- Questions asked of the experts:

- Is this task pertinent to risk?

- Is this task substantially a matter of medical practice?

- What are the potential errors associated with this task?

- What are the probabilities of these errors occurring?

- What is the likely magnitude of these errors?

- Estimates checked against patient treatments

- In general, observed likelihoods higher than experts estimates

- Relative values though seemed to be consistent 
Identify potentially high risk contributors through expert screening process (continued)

- Some tasks were eliminated because they did not impact risk or they only involved medical practice. Others were combined or subsumed by others.

- A total of 24 tasks (tasks and sub-tasks) were on the consolidated tasks list.

- Fault trees were developed for each primary task showing the logical relationships of its subtasks errors (i.e., its contributing fault events). 
Identify potentially high risk contributors through expert screening process (continued)

- The expert estimation data assimilated into discrete distributions for each event contributing to each task

- discrete distribution for error likelihood

- discrete distribution for error magnitude

- Distribution showed percentage of experts that chose particular values of error probability and error consequence 


\section{Consolidated Primary Tasks}

- Process 1.0: Imaging and Localization

1.1 Identify correct patient (also used for 2.1 and 3.2)

1.2 Affix stereotactic frame

1.3 Set up CT, MR, Angiography

1.3.3 Films not Labeled correctly

1.5 Center correctly deposited on CT, MR films 


\section{Consolidated Primary Tasks (continued)}

- Process 2.0: Treatment Planning

2.3 Check treatment planning equipment

2.6 Take skull measurements

2.7 Enter skull data into computer

2.8 Enter gamma angle

2.9 Geometric determinations from films

2.12 Select calculation mode

2.14 Determine isocenter coordinates

2.15 Enter shot parameters

2.17 Plot isodose curves

2.18 Overlay isodose plots

2.19 Enter prescribed dose

2.20 Produce prescription 


\section{Consolidated Primary Tasks (continued)}

- Process 3.0: Patient Positioning and Treatment

3.3 Choose collimating helmet

3.4 Set plug pattern

3.5 Set isocenter coordinates and gamma angle

3.6 Perform final checks

3.8 Set treatment time

3.9 Monitor treatment

3.10 Check isocenter settings after treatment 


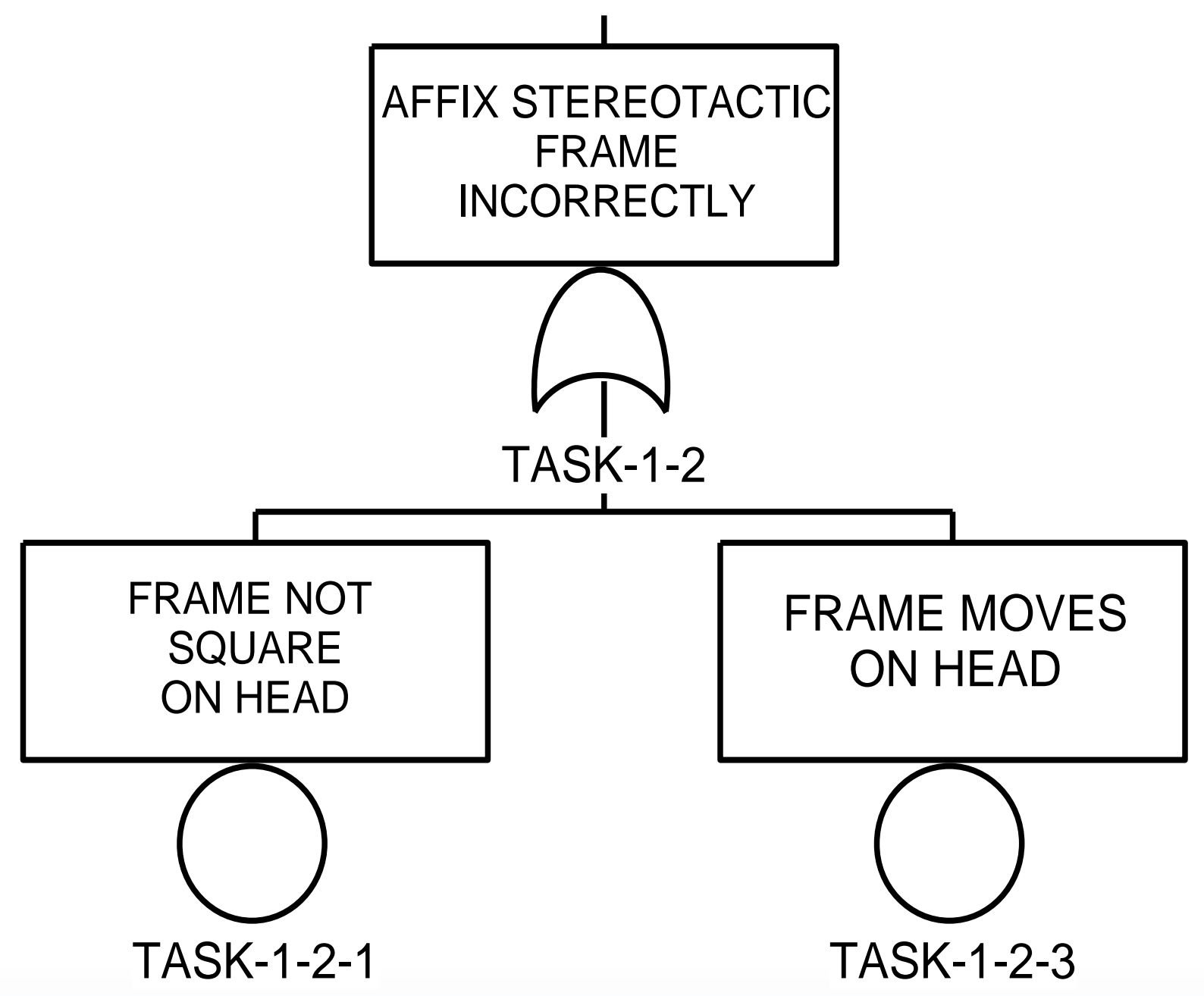


TASK ID NUMBER: 1.2 (1.2.1, 1.2.3) - Affix stereotactic frame

\begin{tabular}{|c|c|c|c|c|c|c|c|c|c|c|}
\hline \multirow{2}{*}{ Most Likely Errors } & \multicolumn{5}{|c|}{ Error Likelihoods } & \multicolumn{5}{|c|}{ Error Magnitudes } \\
\hline & 0.001 & 0.002 & 0.01 & 0.02 & 0.1 & 0.02 & 0.05 & 0.1 & 0.2 & 0.5 \\
\hline \multirow{2}{*}{$\begin{array}{l}\text { Task 1.2.1 - Frame not } \\
\text { "square" (e.g., screws not } \\
\text { tightened properly) }\end{array}$} & \multirow{2}{*}{0} & \multirow{2}{*}{0.6} & \multirow{2}{*}{0.4} & \multirow{2}{*}{0} & \multirow{2}{*}{0} & \multicolumn{5}{|c|}{ _Dose _ X Pos.Nol. __ Other } \\
\hline & & & & & & 0.8 & 0.2 & 0 & 0 & 0 \\
\hline \multirow{2}{*}{$\begin{array}{l}\text { Task 1.2.3 - Frame not } \\
\text { immovable on head and } \\
\text { patient treated }\end{array}$} & \multirow{2}{*}{0} & \multirow{2}{*}{0.7} & \multirow{2}{*}{0.3} & \multirow{2}{*}{0} & \multirow{2}{*}{0} & \multicolumn{5}{|c|}{ _ Dose_X Pos.Nol. __ Other } \\
\hline & & & & & & 0.8 & 0.2 & 0 & 0 & 0 \\
\hline
\end{tabular}




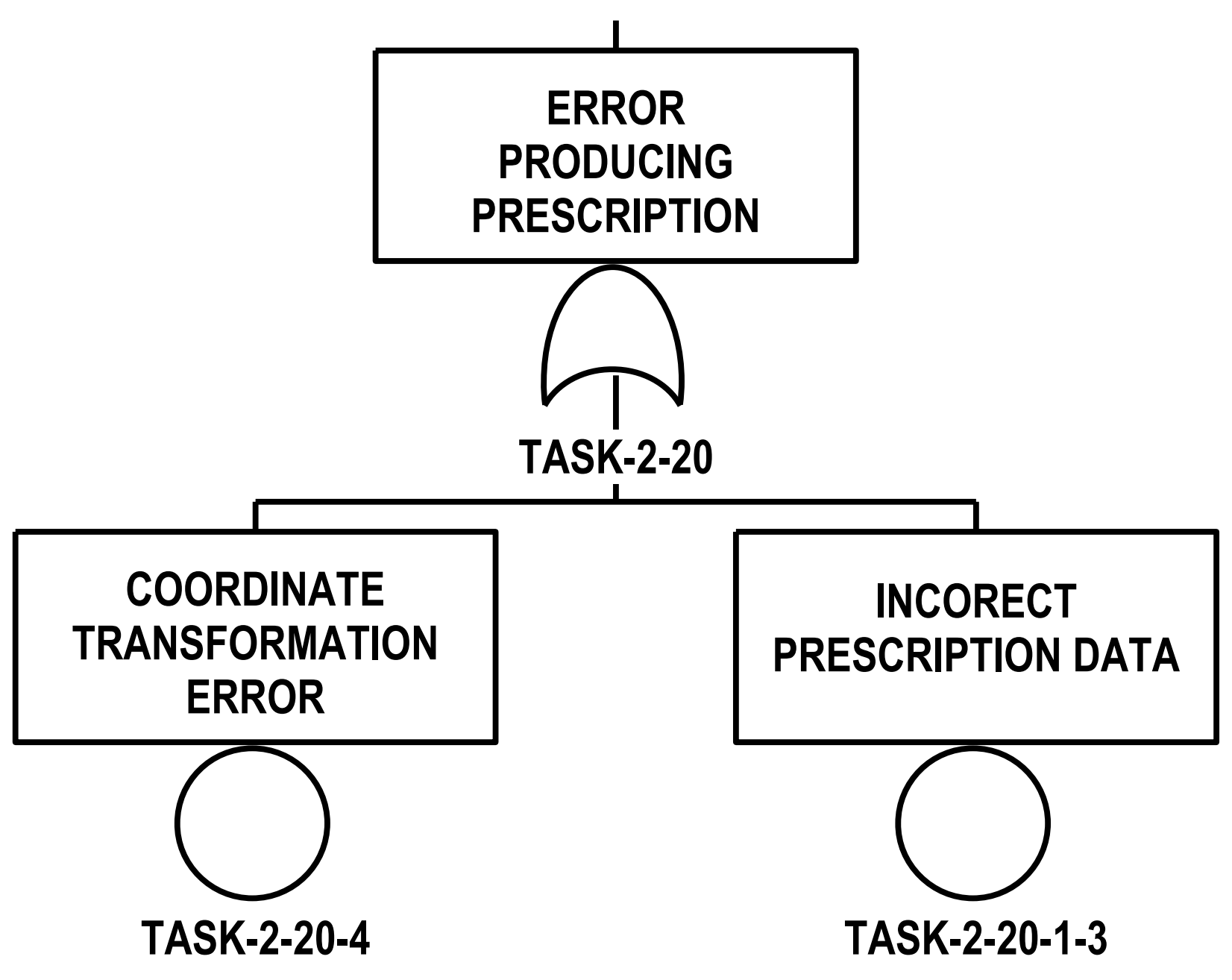


TASK ID NUMBER: 2.20 - Produce prescription

\begin{tabular}{|c|c|c|c|c|c|c|c|c|c|c|}
\hline \multirow{2}{*}{ Most Likely Errors } & \multicolumn{5}{|c|}{ Error Likelihoods } & \multicolumn{5}{|c|}{ Error Magnitudes } \\
\hline & 0.001 & 0.002 & 0.01 & 0.02 & 0.1 & 0.02 & 0.05 & 0.1 & 0.2 & 0.5 \\
\hline \multirow{2}{*}{$\begin{array}{l}\text { Tasks } 2.20 .1 \text { - } 2.20 .3 \text { - } \\
\text { Prescription not correct (e.g., } \\
\text { used wrong parameters or } \\
\text { patient file) }\end{array}$} & \multirow[b]{2}{*}{0.7} & \multirow[b]{2}{*}{0.3} & \multirow[b]{2}{*}{0} & \multirow[b]{2}{*}{0} & \multirow[b]{2}{*}{0} & \multicolumn{5}{|c|}{$\underline{X}$ Dose $\underline{X}$ Pos.Nol. __ Other } \\
\hline & & & & & & 0 & 0 & 0 & 0 & 1.0 \\
\hline \multirow{2}{*}{$\begin{array}{l}\text { Task } 2.20 .4 \text { - Make error in } \\
\text { coordinate transformation } \\
\text { calculation (supine to prone) }\end{array}$} & \multirow{2}{*}{0} & \multirow{2}{*}{0} & \multirow{2}{*}{0.6} & \multirow{2}{*}{0.4} & \multirow{2}{*}{0} & \multicolumn{5}{|c|}{ _ Dose _ X_ Pos.Nol. ___ Other } \\
\hline & & & & & & 0 & 0 & 0 & 0.3 & 0.7 \\
\hline
\end{tabular}




\section{Assess High Risk Tasks through Relative Ranking and Profile Analysis}

- A discrete distribution propagation method was used to obtain aggregated error probability and consequence distributions for each primary task

- Mean values of the aggregated distributions were used as point estimates of their error probability and consequence

- Comparisons of risks from the plots of the relative point estimates for the tasks are referred to as risk profiles 


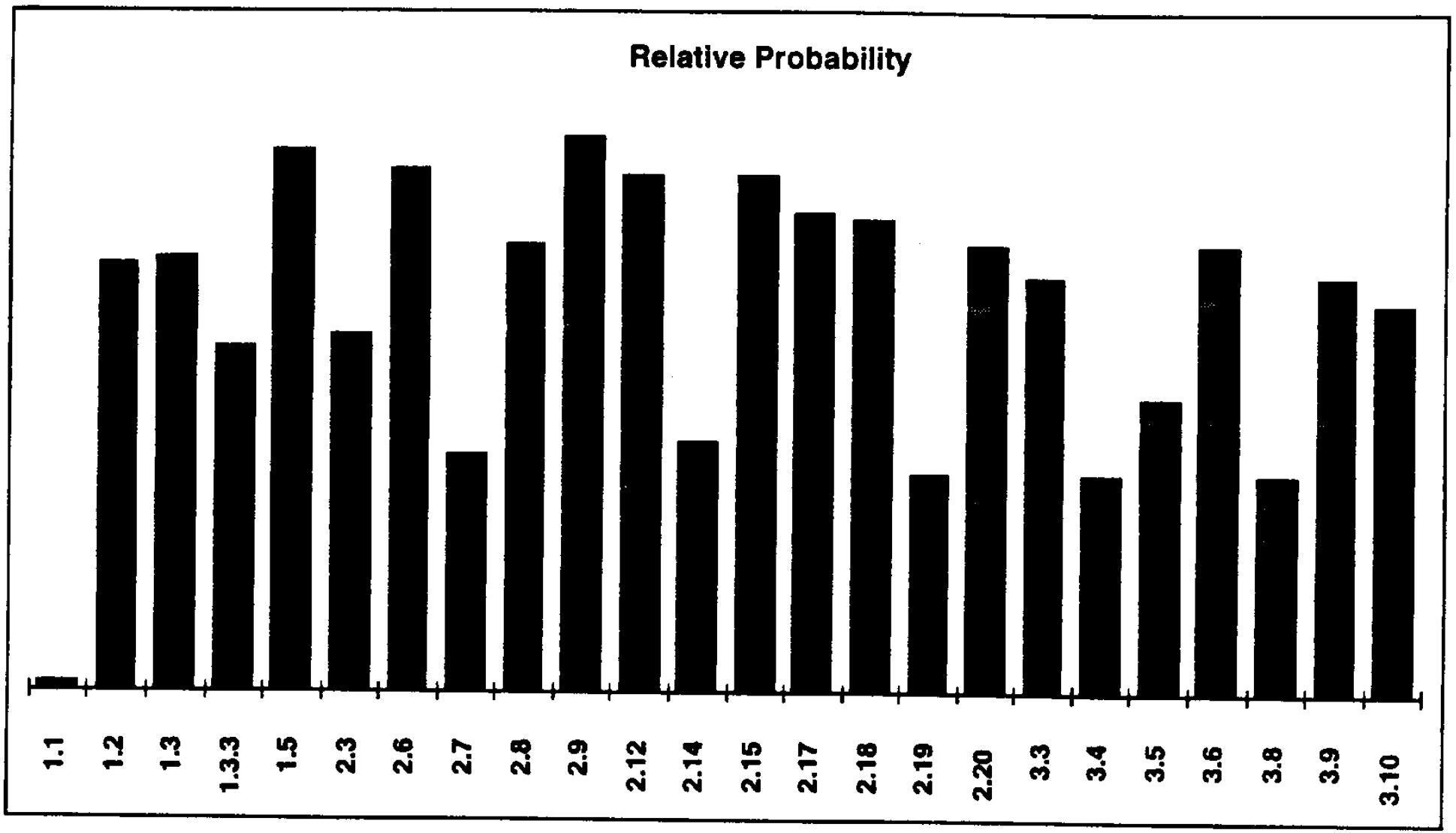

Task

Figure 6-1 Relative probability (logarithmic scale) profile for Gamma Knife tasks.

The numerals along the abscissa are task identification numbers. 


\section{Relative Consequence}

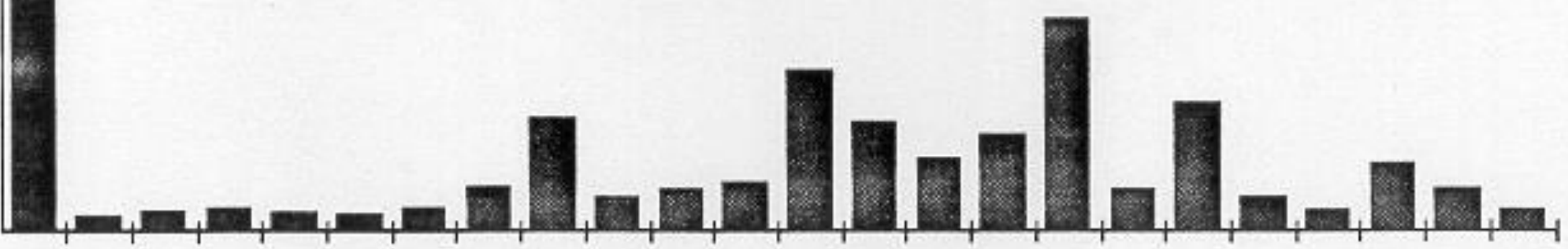
$\mp \div 9$
ำ ำ
กั
त)

\section{Task}

Figure 6-2 Relative consequence (linear scale) profile for Gamma Knife tasks The numerals along the abscissa are task identification numbers. 


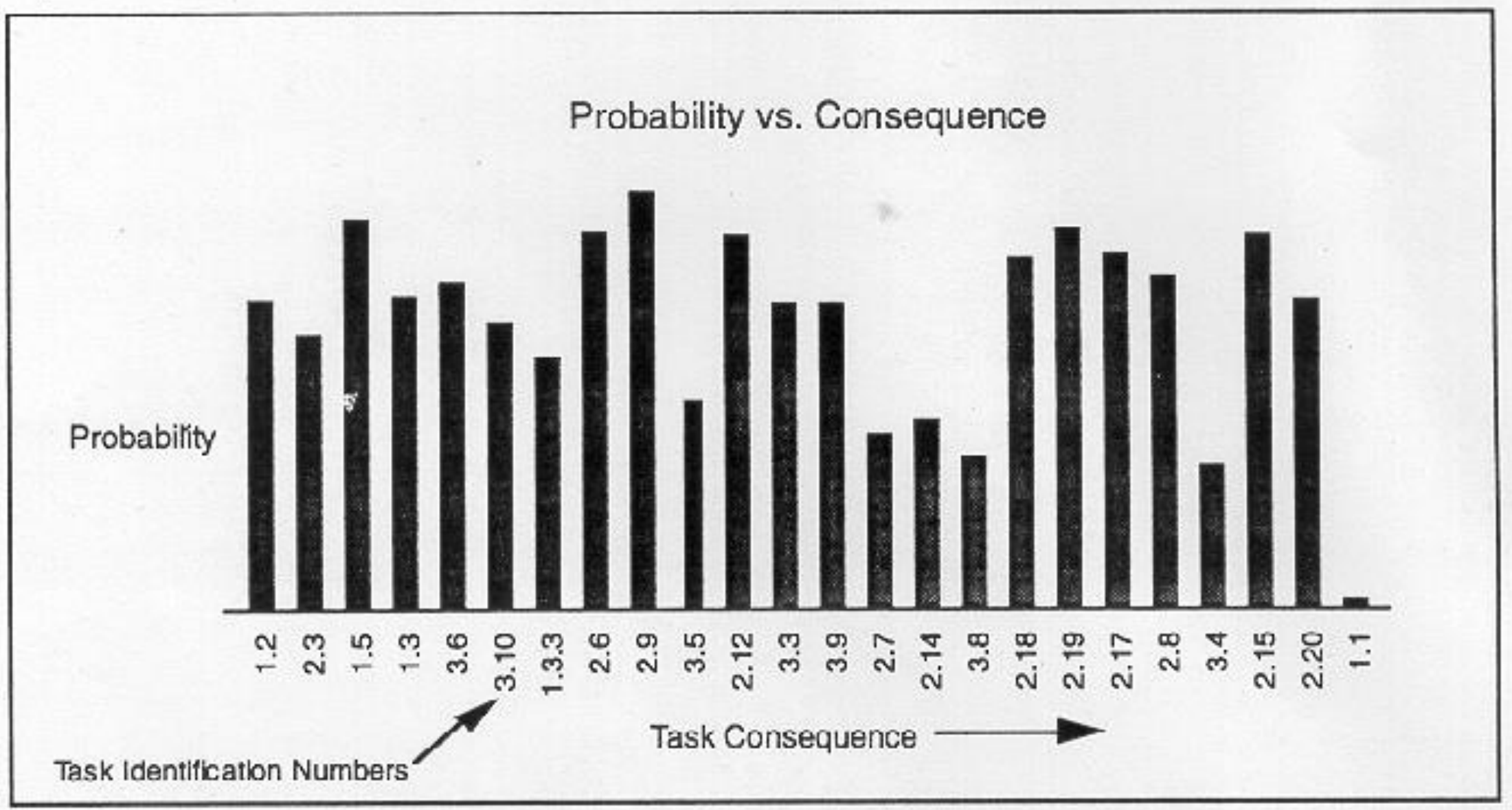

Figure 6-3 A risk domain profile for Gamma Knife tasks.

The probability of an error occurring (logarithmic scale) is along the ordinate, and the tasks are arranged by increasing consequence along the abscissa. The numerals along the abscissa are task identification numbers. 


\section{Relative Risk}

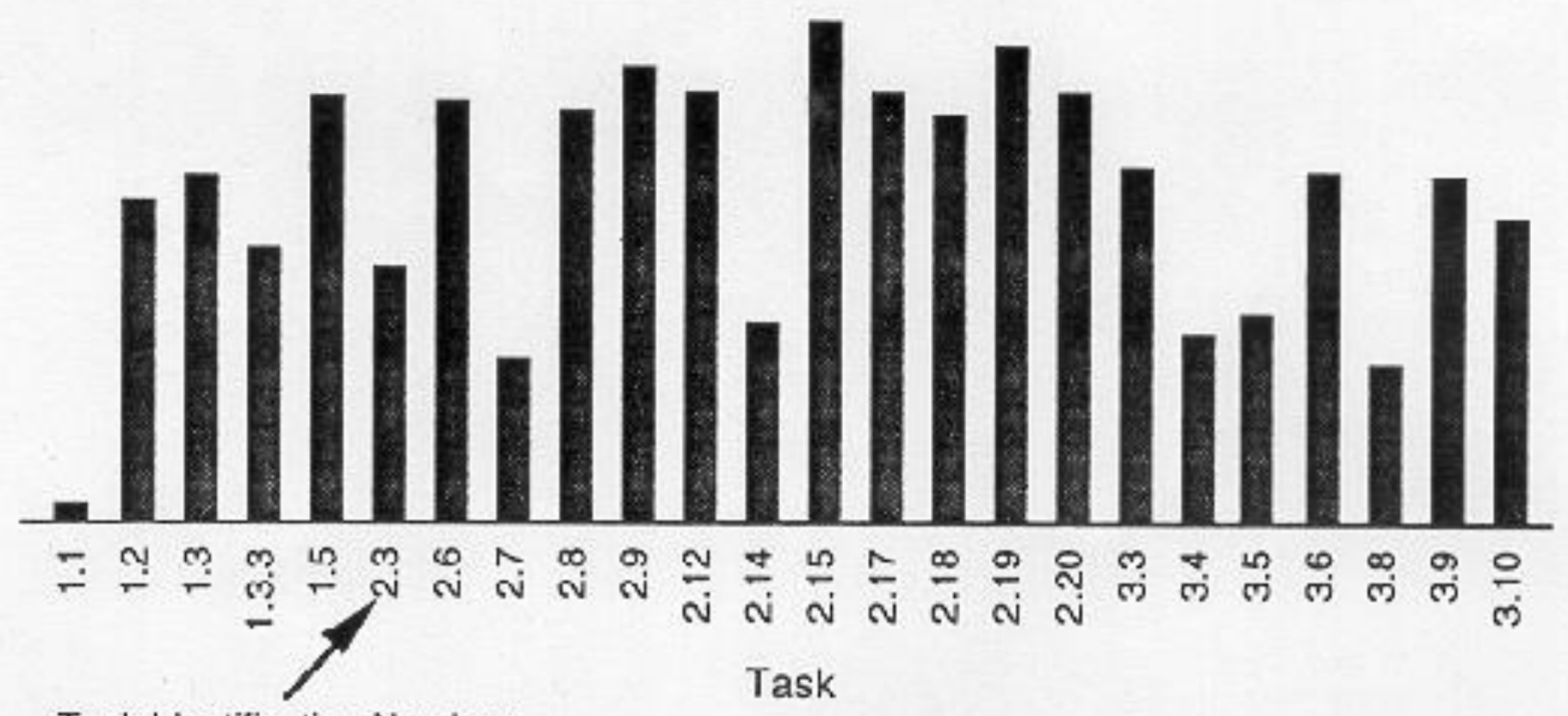

Task Identification Numbers

Figure 6-4 Relative risk (logarithmic scale) profile for Gamma Knife tasks. The numerals along the abscissa are task identification numbers. 


\section{Estimate the Importance and Uncertainties of High Risk Tasks}

- A Monte Carlo code was developed that modeled the propagation of uncertainties in the error rate and error magnitude for each task

- Risk uncertainty was then estimated by calculating coefficient of variation (ratio of standard deviation over the mean) 


\section{Risk Uncertainty}

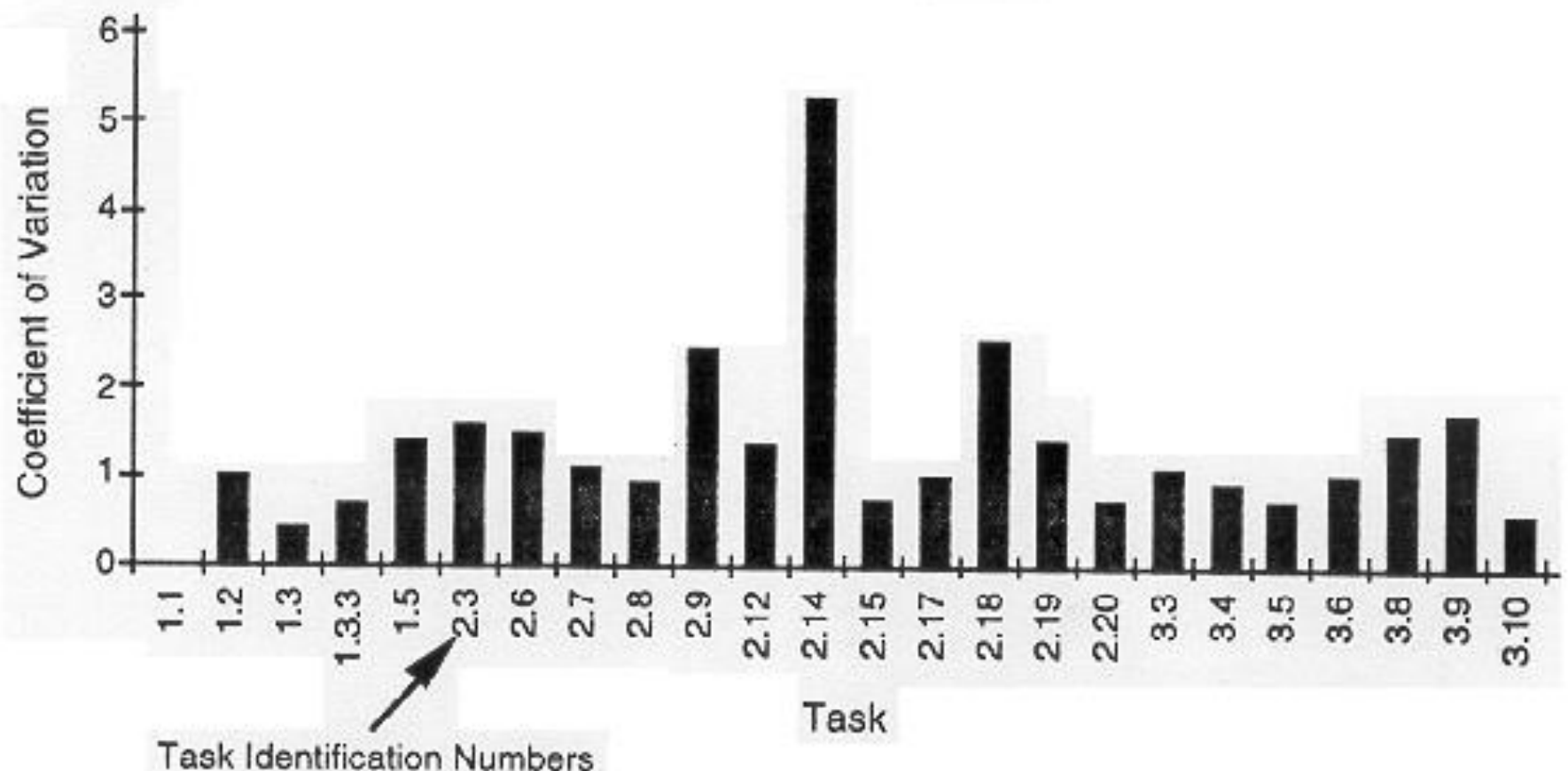

Figure 7.1 Risk uncertainty for Gamma Knife tasks.

The coefficient of variation is the ratio of the standard deviation over the mean. The numerals along the abscissa are task identification numbers. 


\section{Cumulative Distribution of Scenarios with Respect to Risk (Before Strategy)}

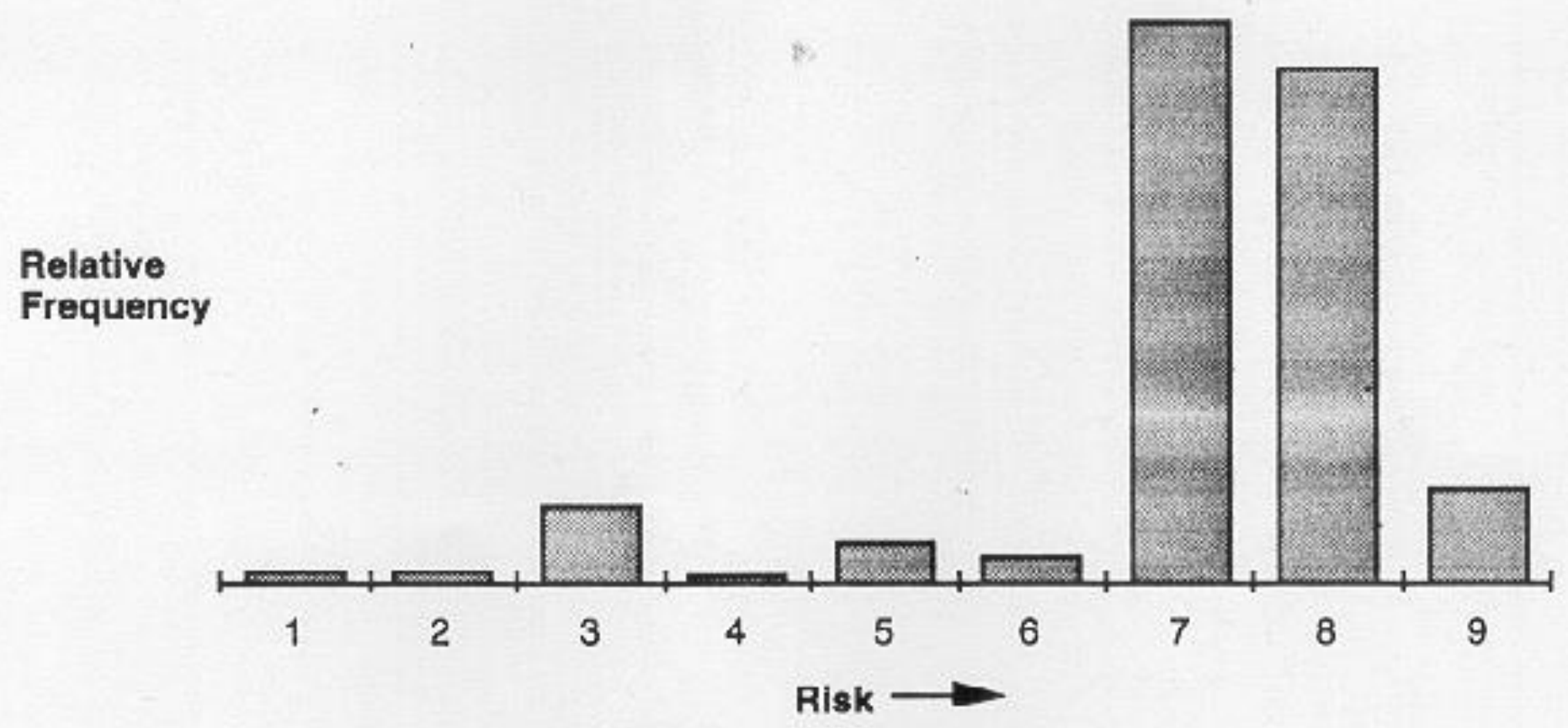

Figure 7-12 Relative frequency of Gamma Knife scenarios as a function of risk. 


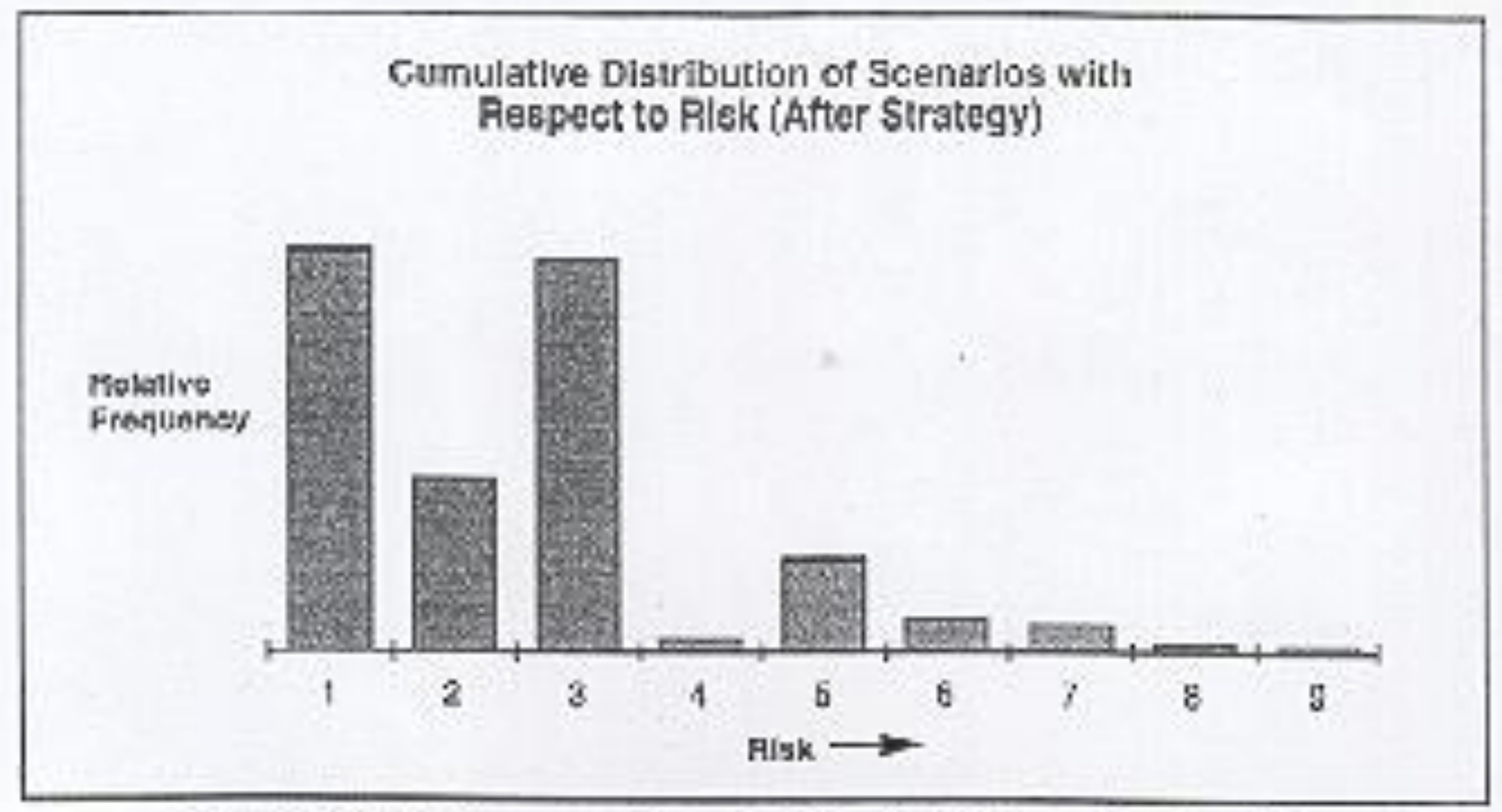

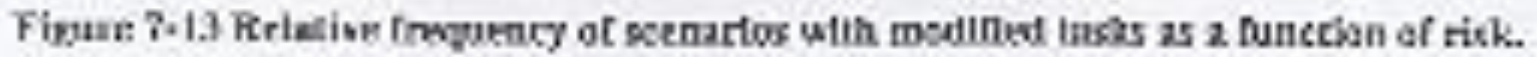




\section{Results and Findings}

- The relative risk profiles showed that several of the highest-risk tasks are from the treatment planning

- The uncertainty and importance analyses indicated that tasks 2.9 Geometric determinations from Films, 2.12 Selection of calculation mode, 2.15 Enter shot parameters, and 2.19 Enter prescribed dose are particularly critical

- Task 2.9 entails acquiring geometric data from imaging films (CT, MRI, angiography). Subtask error distribution analyses indicated the highest consequences were associated with errors of reversing image orientations and performing coordinated transformations. 


\section{Results and Findings (continued)}

- Sensitivity and risk mitigation studies demonstrated that the mean risk with Task 2.9 could be reduced by $20 \%$ by modifying the task to prevent film reversals, and reduced another $10 \%$ by making the correct coordinate transformations.

- Tasks 2.12, 2.15 and 2.19 concern the accuracy of dose calculations. The simple solution to reduce risk is to require an additional check comparing treatment plan to calculated dose distribution 


\section{Results and Findings (continued)}

- The analysis showed that with the above three procedural changes: 1 Prevent film reversals, 2 Correctly determine coordinate transformations, and 3 Compare post-prescription dose profiles to the treatment plan - the number of incorrect treatments could be reduced by $23 \%$ and dose errors greater than $10 \%$ could be reduced by $66 \%$ 


\section{Insights and Use in Decision- Making}

- The relative risk profiling process can be applied to other radiation-emitting devices where it may be most effective in applications that are not highly structured or have limited experience data bases

- The relative risk profiling process, however, does not provide a quantitative risk of misadministration, nor does it permit comparisons of risk among different medical devices

- These techniques can identify weaknesses in the processes and support development of positive performance measures 


\section{Uranyl Nitrate Bulk Storage System - Integrated Safety Analysis}




\section{Method}

- Process Hazard Analysis

- Fault tree

- Event tree 


\section{The Process}

- Ammonium Diuranate (ADU)

- Uranium bearing clean and dirty scrap

- Dissolved in nitric acid producing uranyl nitrate

- Eventually converted to uranium oxide powder using the same ADU process

- Stored in 6 - 7800 gallon tanks 


\section{Controls}

- Free Acid $>4 \%$ in feed concentrator, SOLX I, dissolver

- $\mathrm{pH}<2$ in feed concentrator, SOLX I, dissolver

- Verify no organic material in UN

- House keeping to limit fires

- Emergency action at >8 gU235/liter

- Sample to assure < 5 gU235/liter

- Cutting/welding work permit

- Manual initiated agitation

- Maintain temperature above freezing 


\section{Controls (continued)}

- Heat tracing

- Tank high level alarm

- Gamma detectors in recirculation line and alarm

- SOLX I gamma detectors close discharge valve to storage tanks if $>5 \mathrm{gU} 235 / \mathrm{liter}$

- Dissolver gamma monitors close discharge valve to storage tanks if $>5 \mathrm{gU} 235 / \mathrm{liter}$ 


\section{Controls (continued)}

- Feed Concentrator gamma detectors close discharge valve to storage tanks if $>5 \mathrm{gU} 235 / \mathrm{liter}$

- Passive engineering controls - guard posts, tank wall, diked pad 


\section{Consequence Study}

- Criticality dose

- Release of $25 \%$ of I, 100 liters of solution with $0.05 \%$ of salts

- $0.8 \mathrm{~km}$ to $5 \mathrm{rem}$ total effective dose equiv.

- $6.2 \mathrm{~km}$ to $0.1 \mathrm{rem}$ tede. 


\section{Process Hazard Analysis (PHA)}

- Component Control

- Accident prevented

- Action Expected

- Procedure number

- Maintenance/calibration/periodic test

- Consequence level/discipline (C-Crit Safety) 


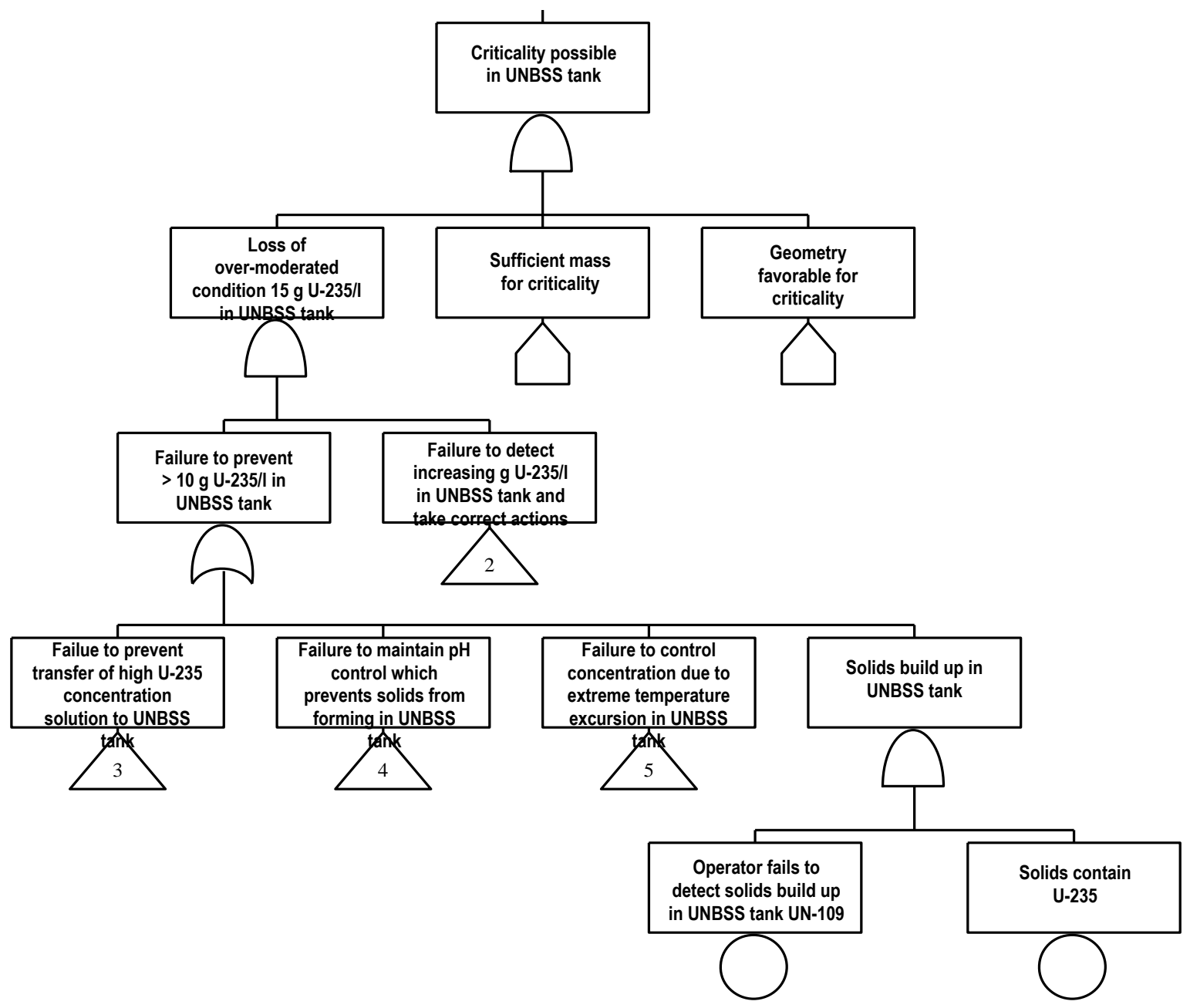

NCS - CRITICALITY POSSIBLE IN UNBSS TANK 


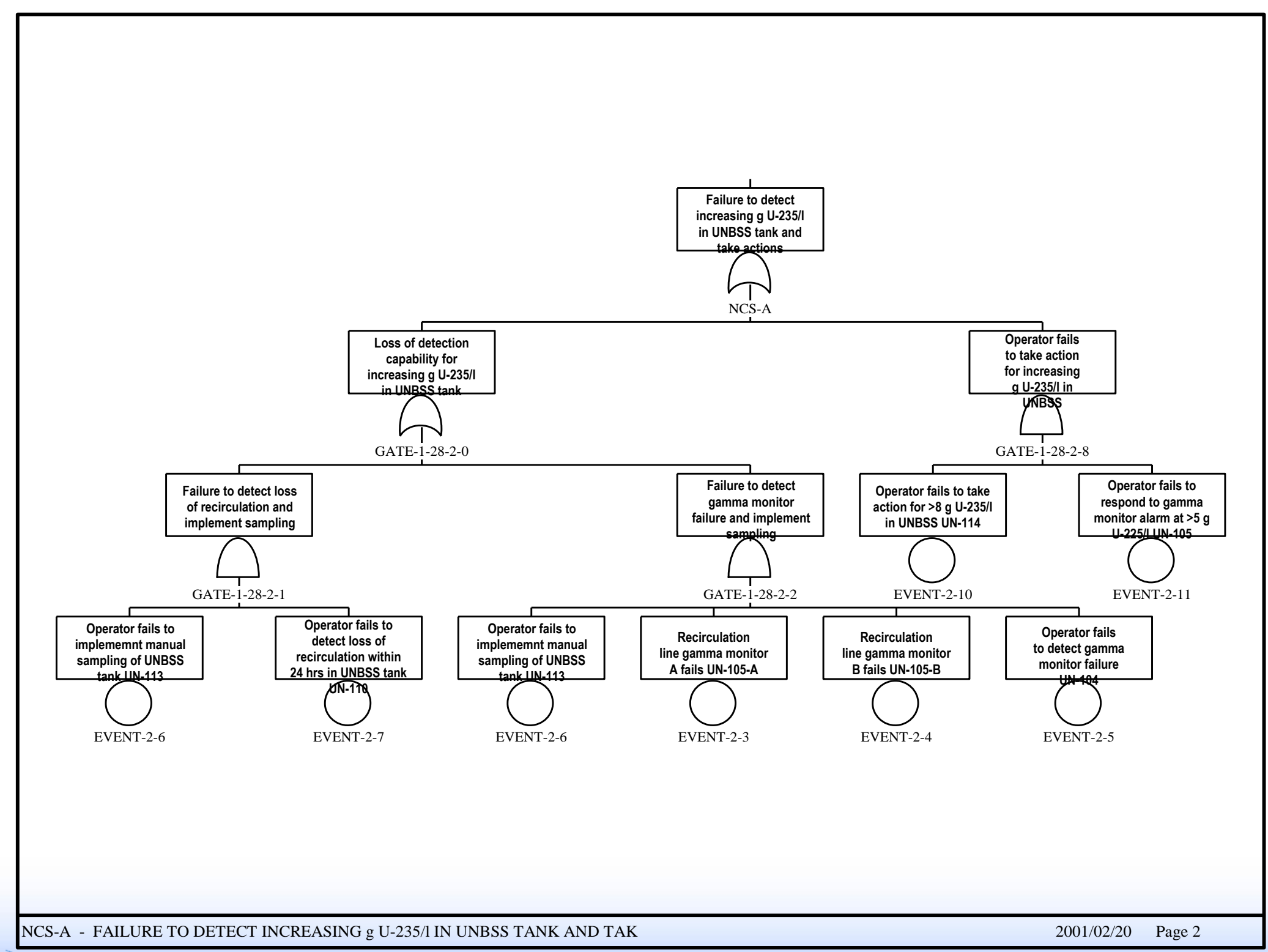

Idaho National Laboratory 


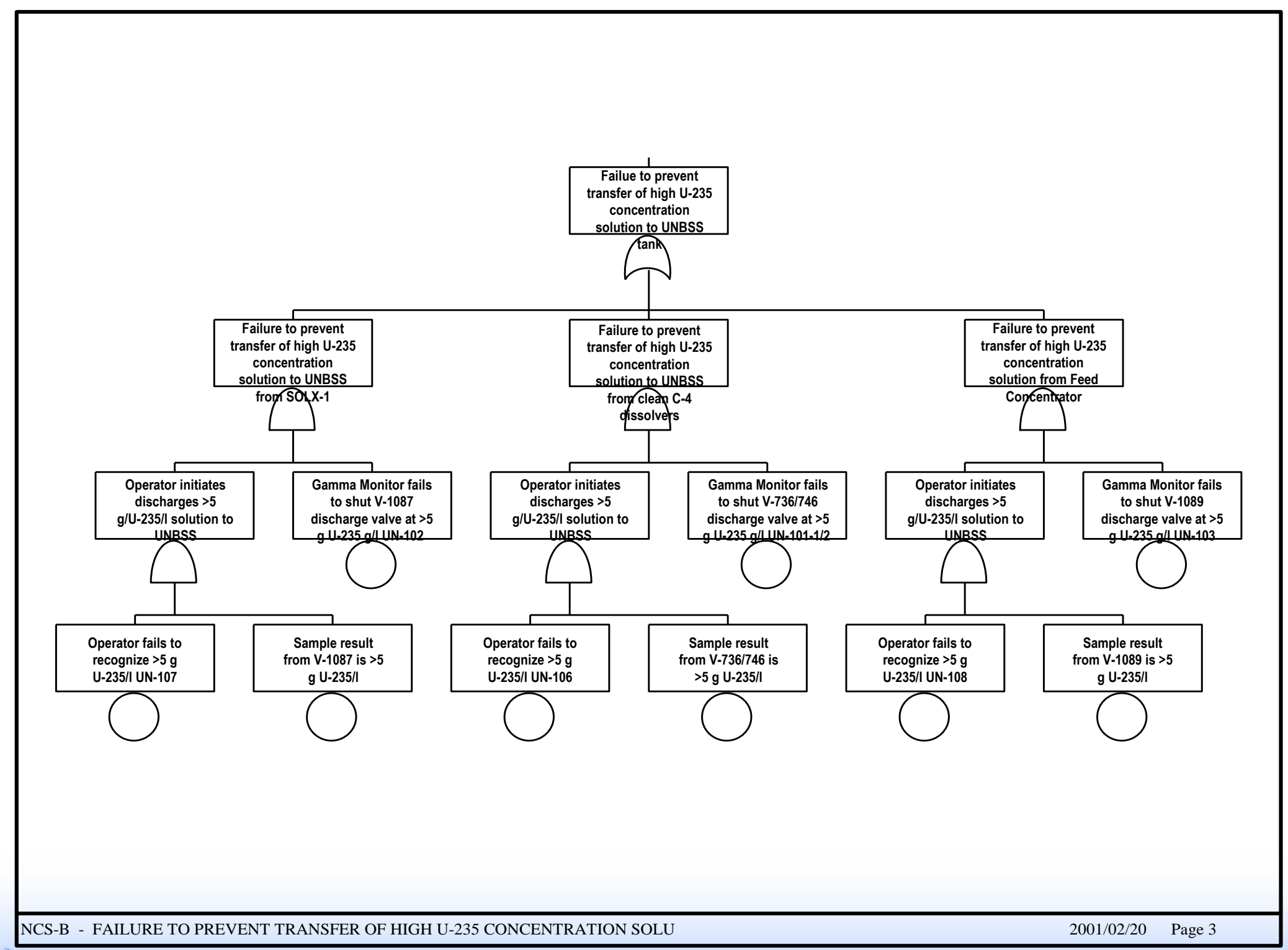

Idaho National Laboratory 


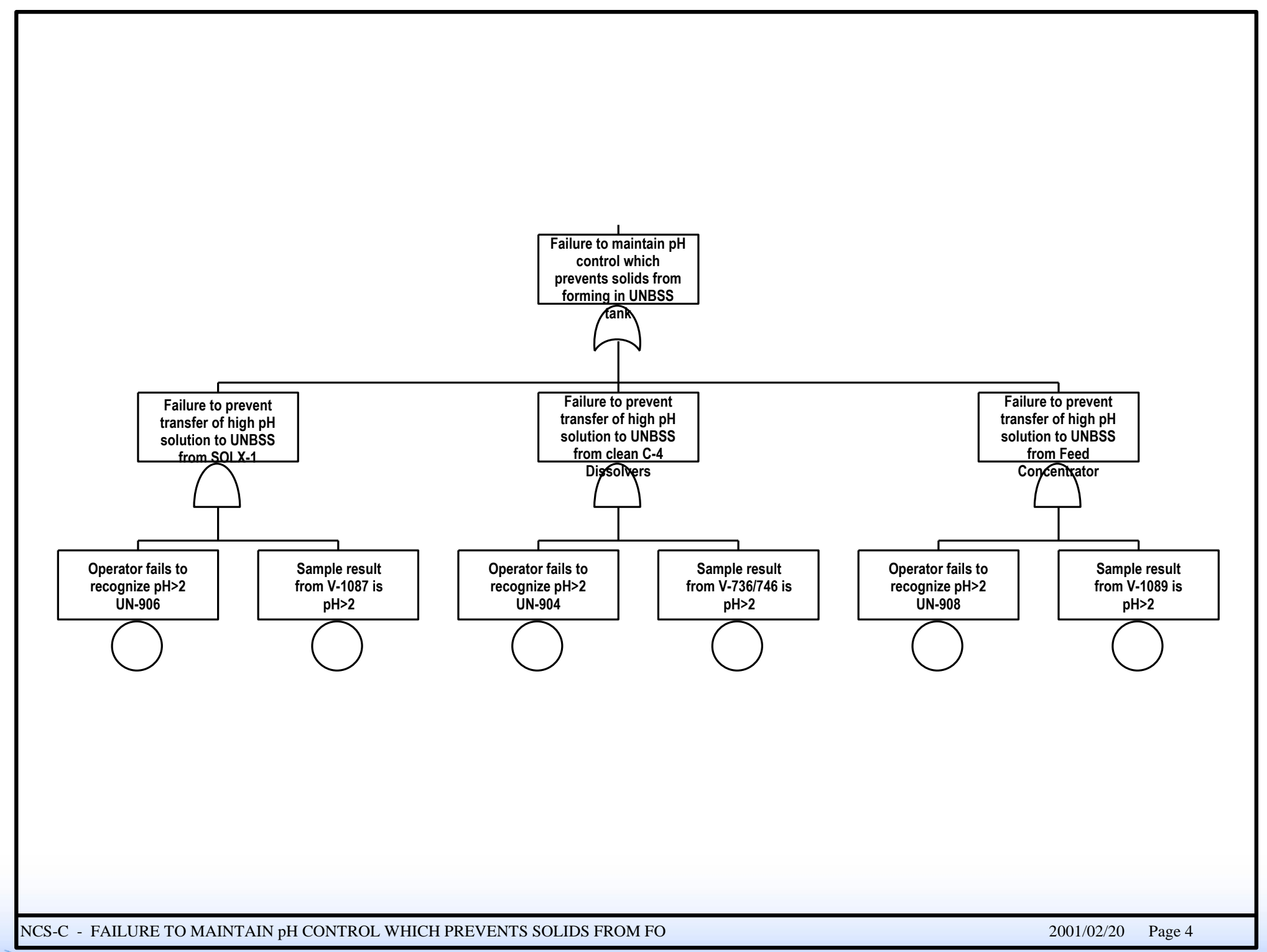

Idaho National Laboratory 


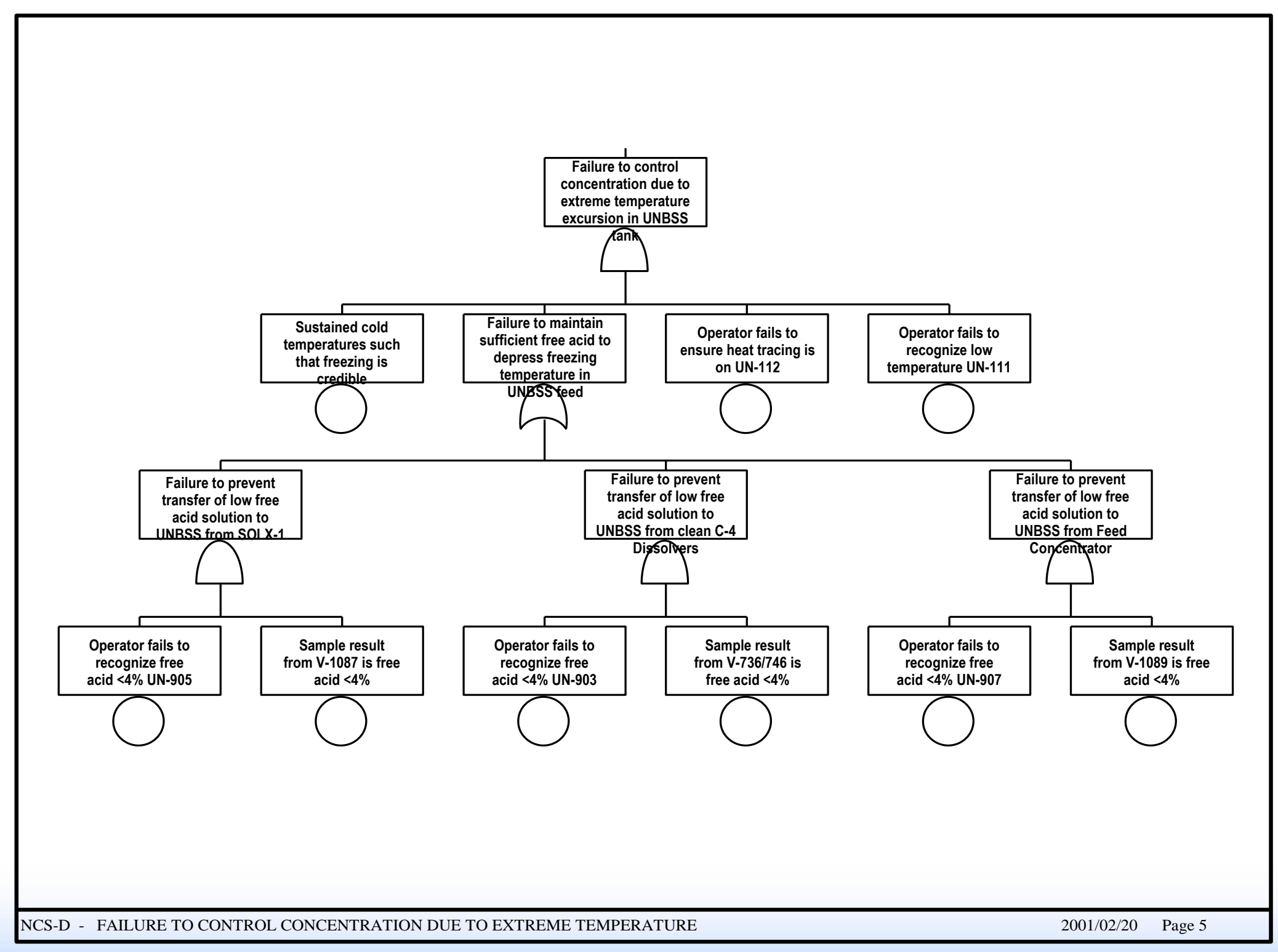




\section{LIQUID SYSTEM CRITICALITY, CONSEQUENCE BASIS EVENT TREE}

\begin{tabular}{|c|c|c|c|c|c|c|}
\hline INITIATING EVENT & $\begin{array}{c}\text { URANIUM SAV } \\
\text { PROGRAM DETECTS } \\
\text { HIGH } \\
\text { CONCENTRATION; } \\
\text { NO FEED TO } \\
\text { TANK STARTED }\end{array}$ & $\begin{array}{c}\text { IN-LINE URANIUM } \\
\text { MONITOR DETECTS } \\
\text { HIGH } \\
\text { CONCENTRATION; } \\
\text { FLOW INTERLOCK } \\
\text { ACTIVATED }\end{array}$ & $\begin{array}{c}\text { TANK URANIUM } \\
\text { MONITORS DETECT } \\
\text { HIGH } \\
\text { CONCENTRATION; } \\
\text { ALARM ACTIVATES; } \\
\text { OPERATIONS } \\
\text { RESPONDS }\end{array}$ & $\begin{array}{l}\text { URANIUM LEVELS } \\
\text { LESS THAN } \\
\text { MAXIMUMM } \\
\text { CRITICAL } \\
\text { CONCENTRATION }\end{array}$ & $\begin{array}{c}\text { URANIUM } \\
\text { CONCENTRATION } \\
\text { REMEDIAL } \\
\text { ACTIONS APPLIED; } \\
\text { HIGH LEVELS } \\
\text { REDUCED OR TANK } \\
\text { DUMPED TO PAD }\end{array}$ & $\begin{array}{l}\text { REGULATORY } \\
\text { RESPONSE }\end{array}$ \\
\hline
\end{tabular}

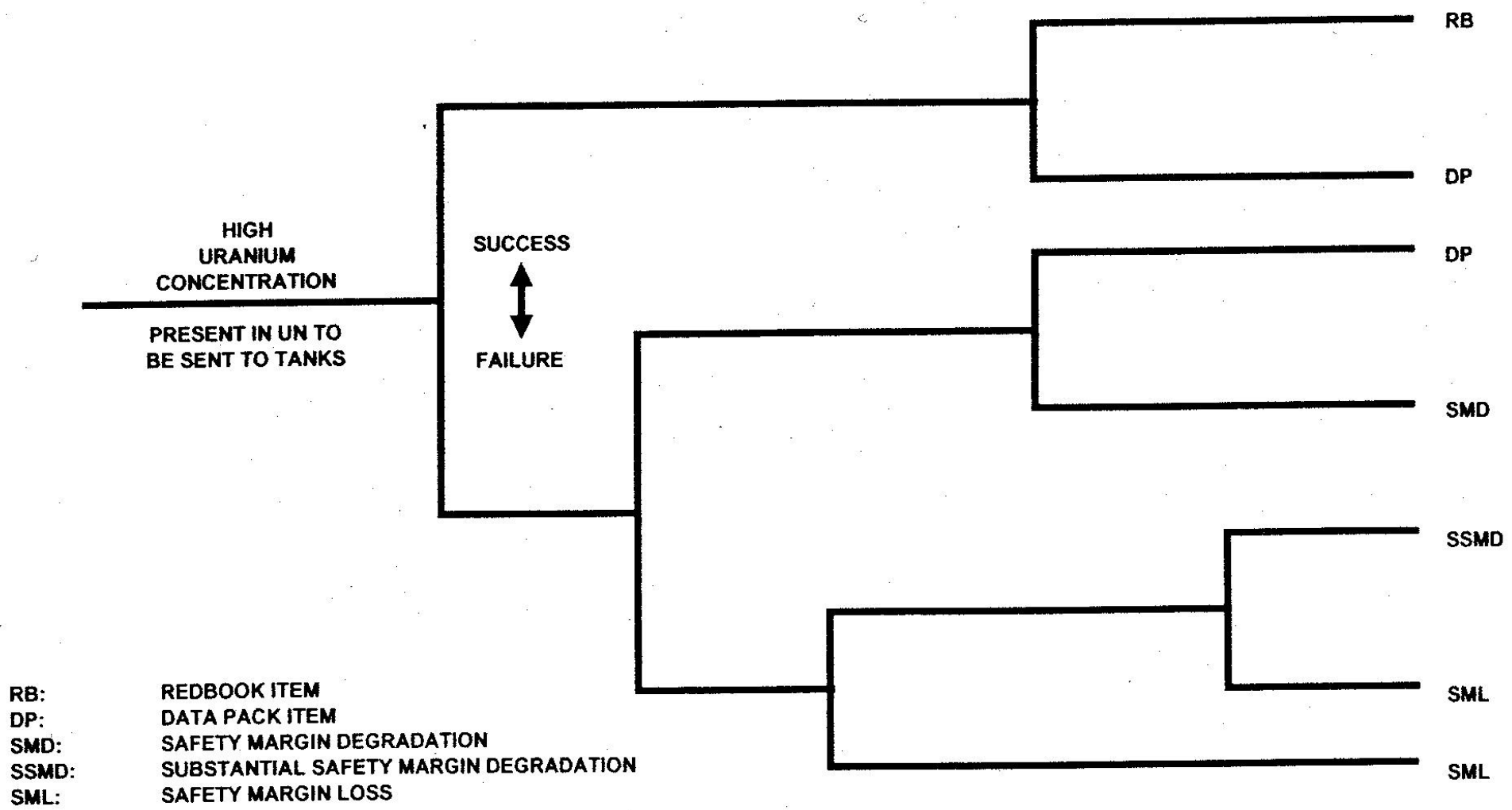




\section{Observations}

- Which actions are independent (i.e., sampling pH and \% acid)

- Cutsets would be worth while

- Quantification could be used to determine which cutsets are most likely.

- Look at cutsets that depend only on human 


\section{Irradiators - Example Study}




\section{Reference}

- International Irradiator Incidents and Their Root Causes, Contract No. NRC-02-00-010, Task Order 5, November 20, 2000

- An Evaluation of the Risk to Workers from Irradiator Operators Being Located Offsite, No. NRC-02-00010, Task Order 5, November 30, 2000

- Extension of NUREG/CR-6642 analysis. 


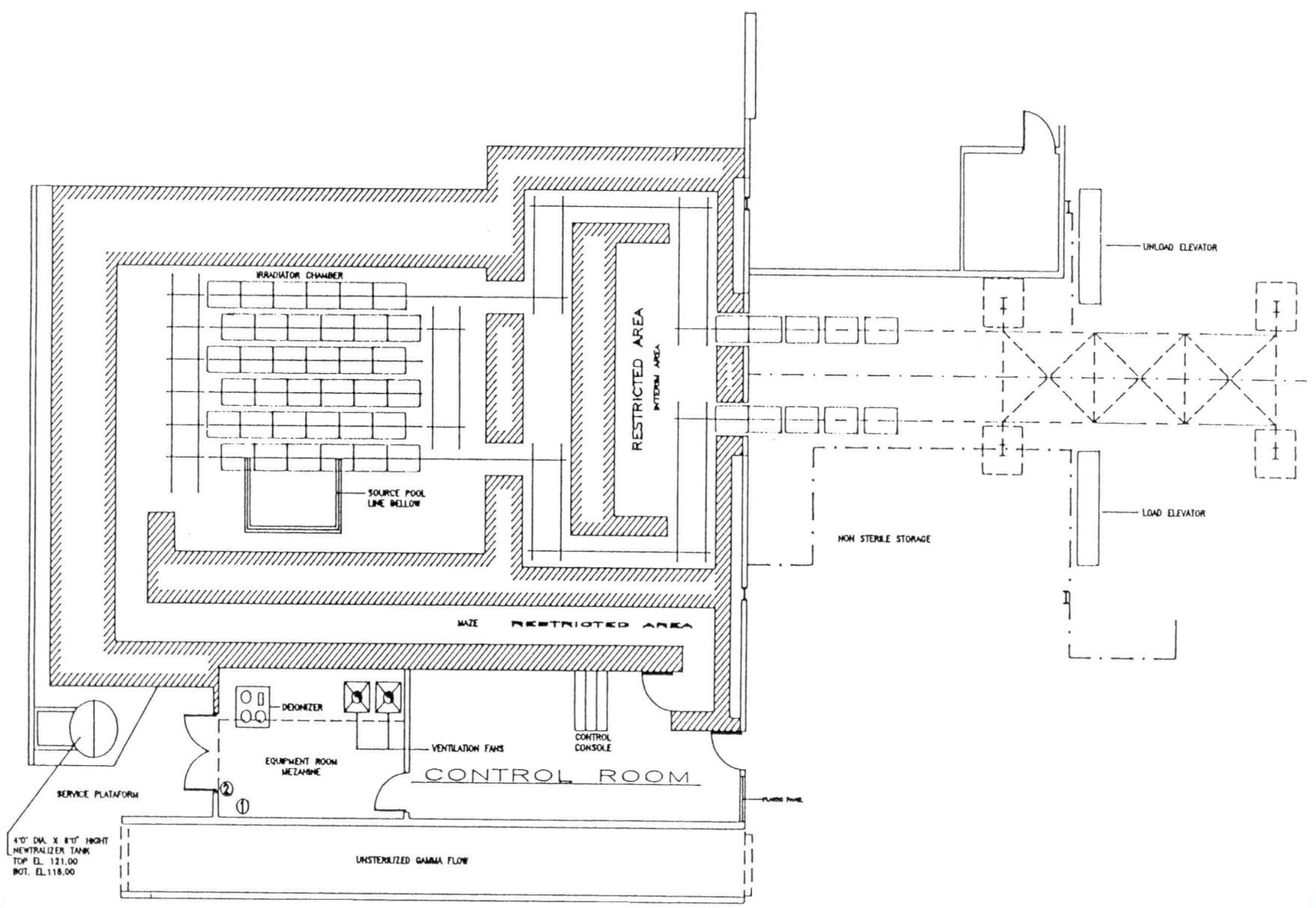

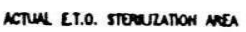




\section{Purpose}

- Evaluate proposed ANSI petition

- Change 10CFR Part 36.65 (a) and (b)

- (a) Both an irradiator operator and at least one other individual, who is trained on how to respond and prepared to

- promptly render or summon assistance if the access control alarm sounds, shall be present onsite:

- (1) Whenever the irradiator is operated using an automatic product conveyor system; and

- (2) Whenever the product is moved into or out of the radiation room when the irradiator is operated in a batch mode.

- (b) At a panoramic irradiator at which static irradiation's (no movement of the product) are occurring, a person who has received the training on how to respond to alarms described in $\$ 36.51(\mathrm{~g})$ must be onsite.

- Change \$36.51(g)

- Allow automatic remote means of communication from the irradiator control system if individual is off site. 


\section{Purpose (continued)}

- Petition: Allow operator or trained responder to be off site when irradiator is in use with a remote alarm indicator.

- Petition basis: According to ANSI - modern irradiators are designed to require minimal or no operator intervention during operation. 


\section{Evaluation}

- Impact the operator has on the risk to workers who have not been trained in facility operation and operation safety

- Risk when jams occur, compounded with failure of source to retract and workers try to fix problem 


\section{Evaluation (continued)}

- Risk during normal operation not an issue since workers have no reason to enter irradiator

- Risk due to maintenance, inspection, replacement not an issue since operator will be available.

- Modified fault trees in NUREG/CR-6642 


\section{Irradiator Description}

- Sealed sources

- Two types

- Pool type - source hoisted out of water or product is lowered into water

- Dry type - source or shielding is moved

- Co-60, Cs-137

- 10,000 to several million curies gamma

- Maze for product transport and maze for personnel access 


\section{Irradiator Description (continued)}

- About 3000 square foot

- 10 CFR 36.2 defines an "irradiator" as a facility with doses exceeding 5 gray (500rad) per hour at one meter from sealed source in air or water.

- Lethal dose in short time (seconds to few minutes) 


\section{Safety Features}

- Barrier door interlocks to place source in safe location if tripped

- Radiation area monitors (RAM) in irradiation room

- RAM in product and personnel maze

- Backup access barrier

- RAM in at product exit to detect radiation in the product (broken source parts)

- Others possibly 


\section{Discussion of Incidents}

- 5 fatalities in 160 facilities

- Foreign facilities with different regulator practice

- Several where operator bypassed interlocks

- Large human error uncertainties in any analysis 


\section{Fault Tree Analysis}

- See handout.

- Fault tree changes 


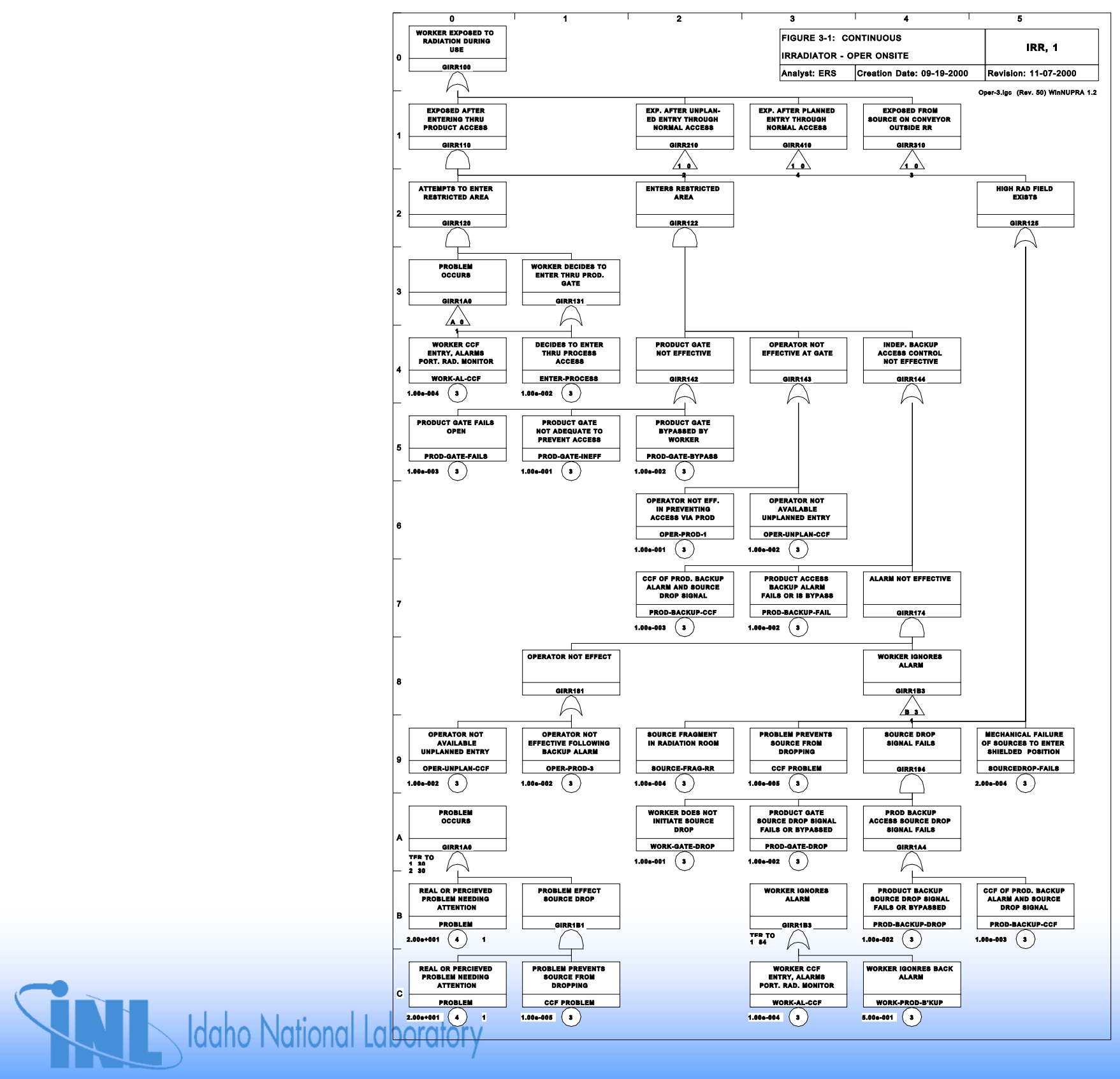




\section{Conclusions}

- Continuous Irradiator Facility - Risk of death increase of 72 to about 3.9E-6 per year.

- Batch Irradiator Facility - Risk of death increase of 11 to about 1E-6 per year 


\section{Status of Petition}

- On August 18, 2006, the NRC published a document in the Federal Register (71 FR 47751), that denies a petition for rulemaking submitted by the American National Standards Institute N43.10 Committee (PRM-36-01). The petitioner requested that the NRC amend its regulations governing the operation of panoramic irradiators to ease the requirements for adequate coverage. The petition was denied because the petitioner did not provide a sufficient basis for the NRC to conclude that the requirements could be eased and still maintain reasonable assurance that common defense and security and public health and safety would be adequately protected. 


\section{PRA of Spent Fuel Dry Storage Cask}

Example Study 


\section{Objectives}

- Determine leak probability of welds during normal conditions

- Determine probability of a through wall crack during a bottom end drop accident

- Determine the probability that a leak below the technical specifications limit will grow to exceed the limit. 


\section{Reference}

- Simonen, F.P. and Klymyshym, N.A., Estimated Flaw Frequencies and Failure Probabilities for Welds in the HISTORM Multi-Purpose Cask, June 14, 2000 


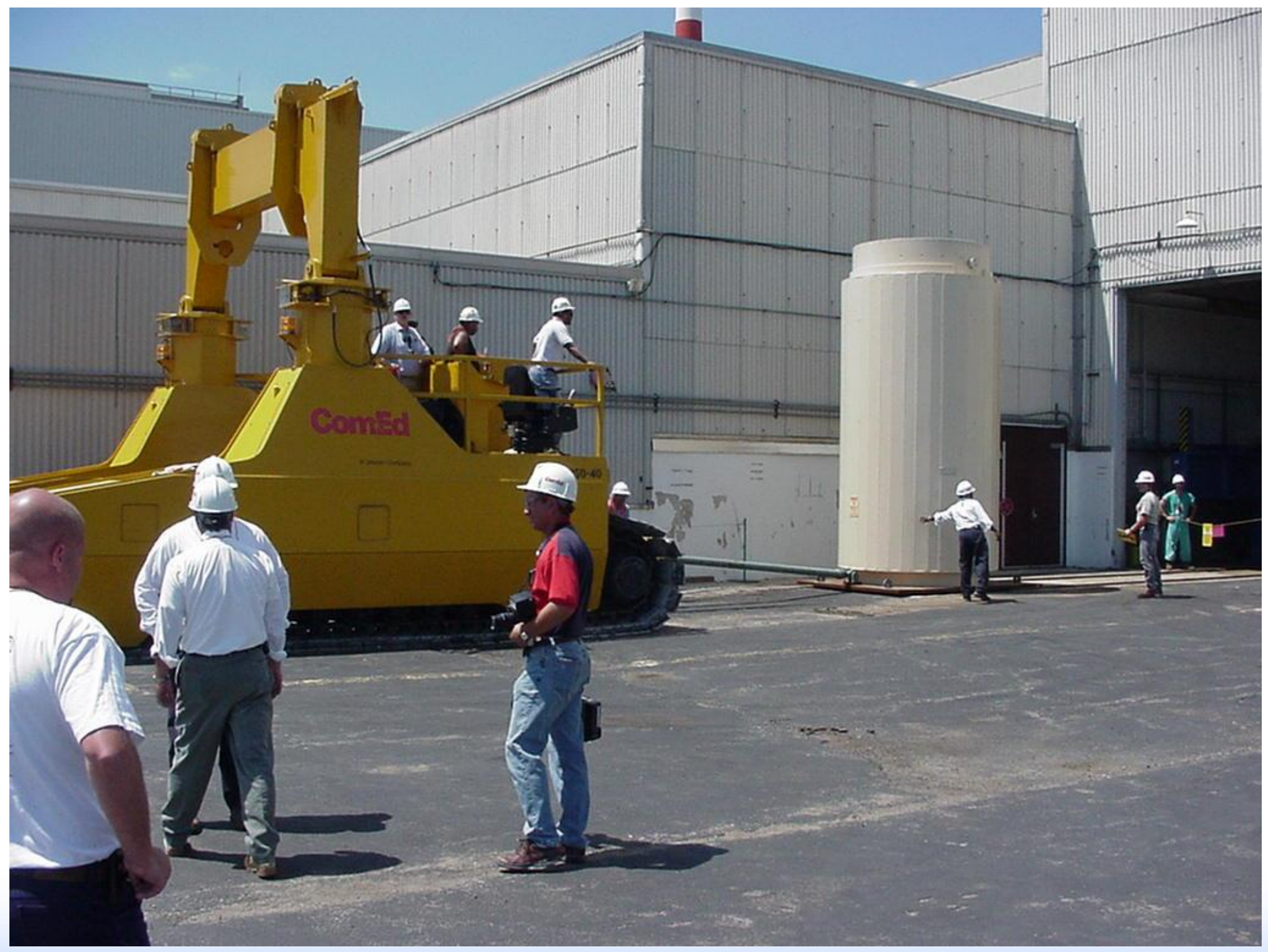

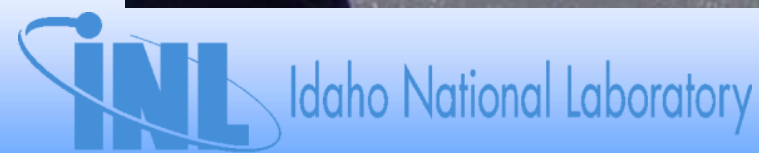




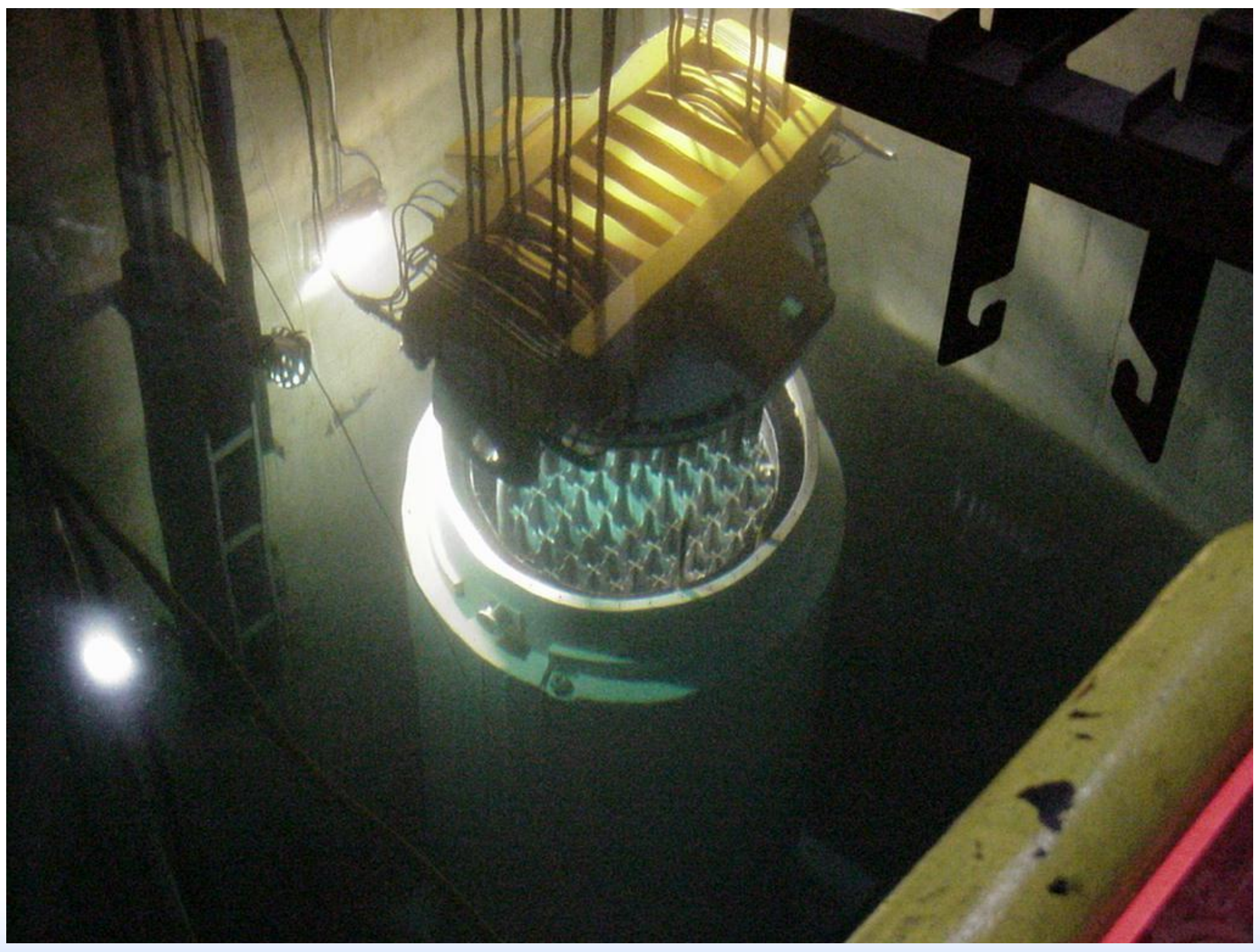

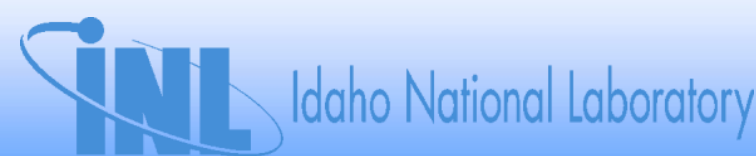




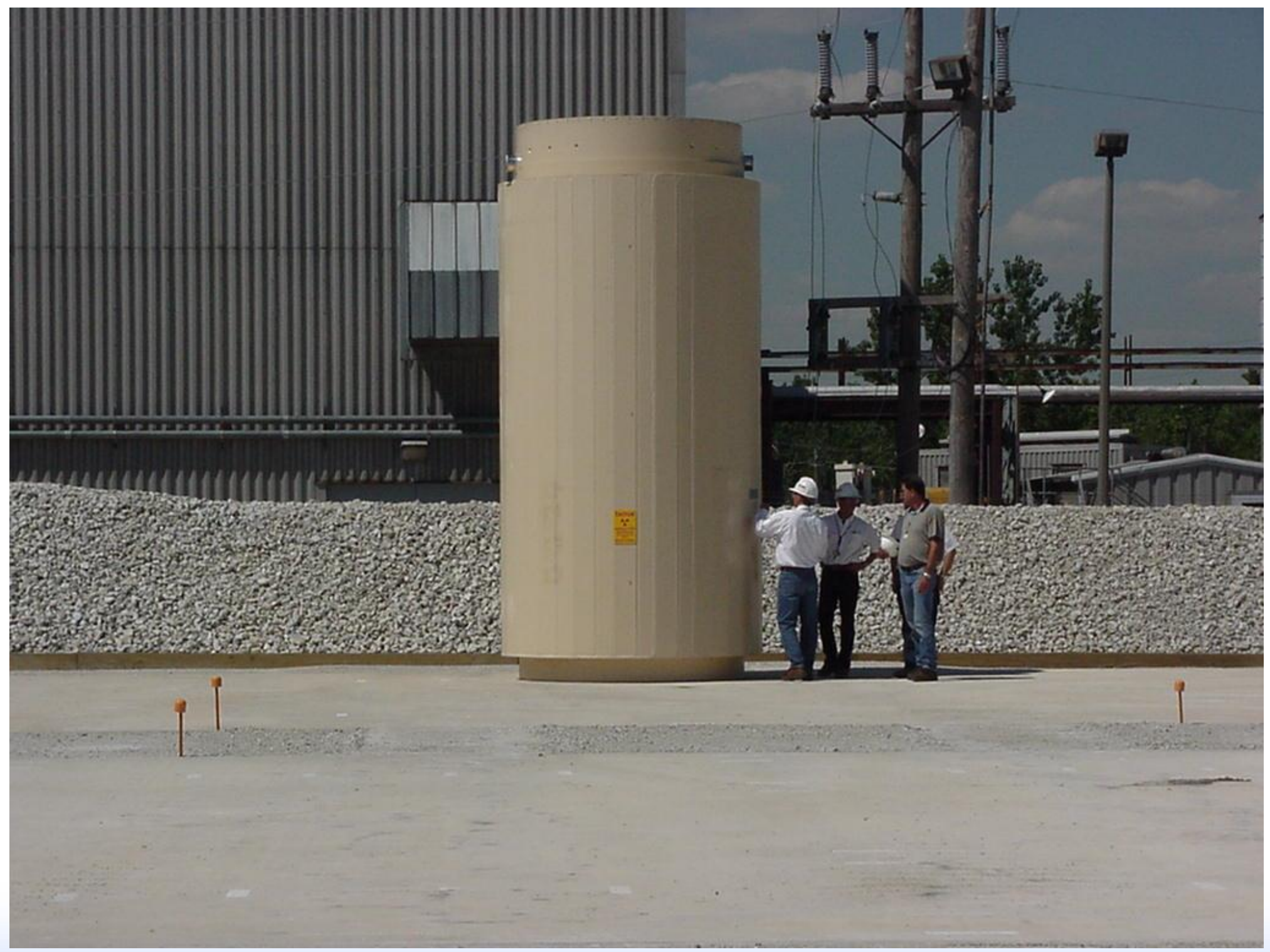

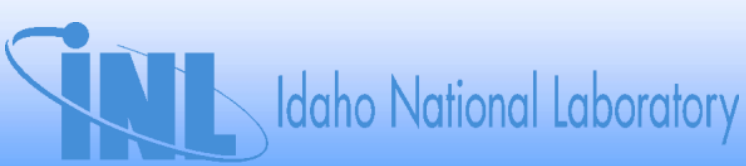




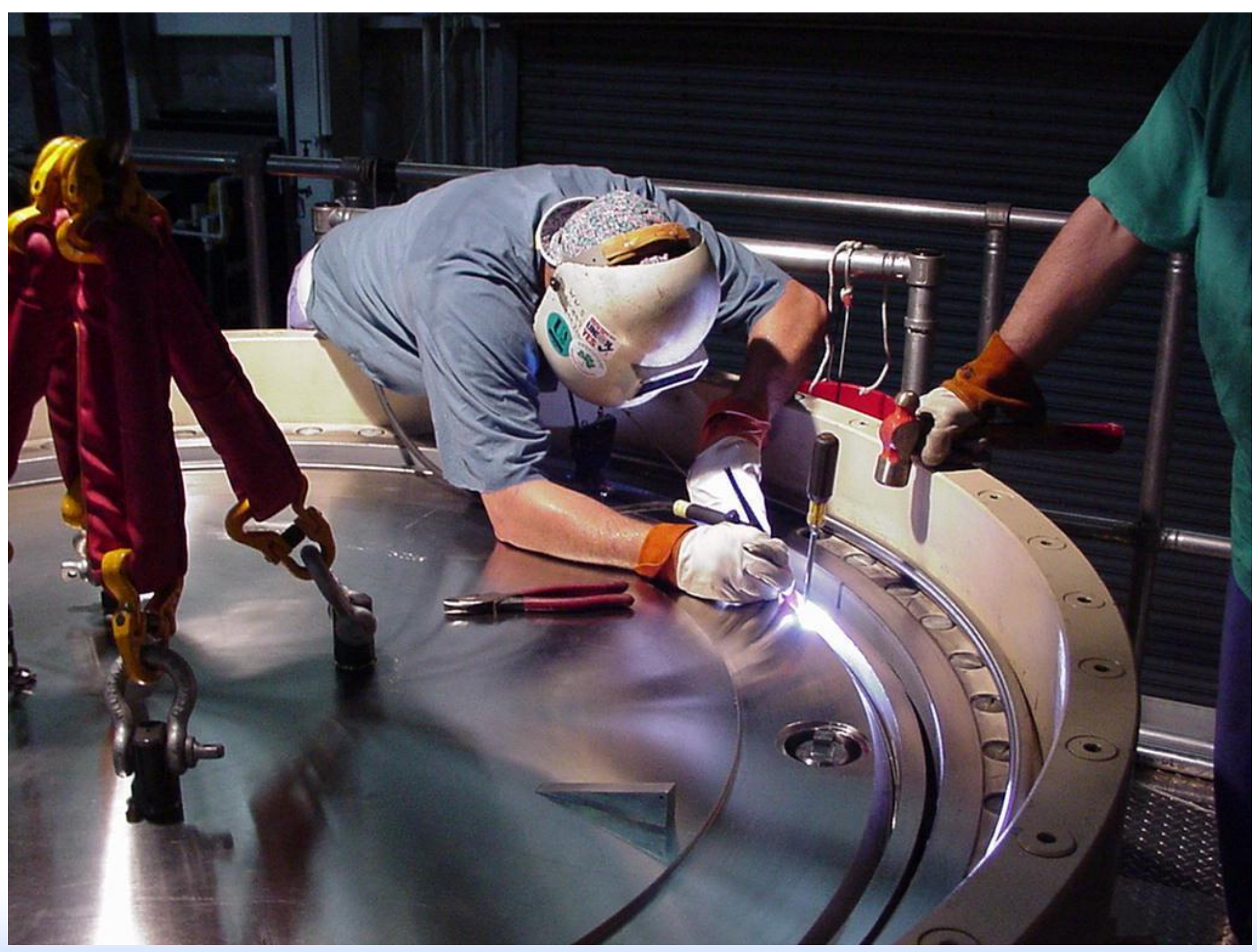

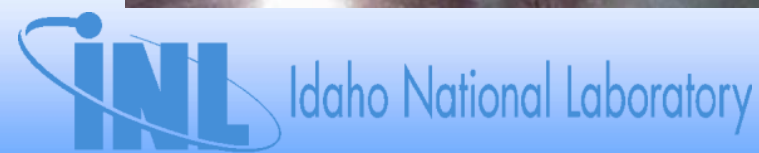




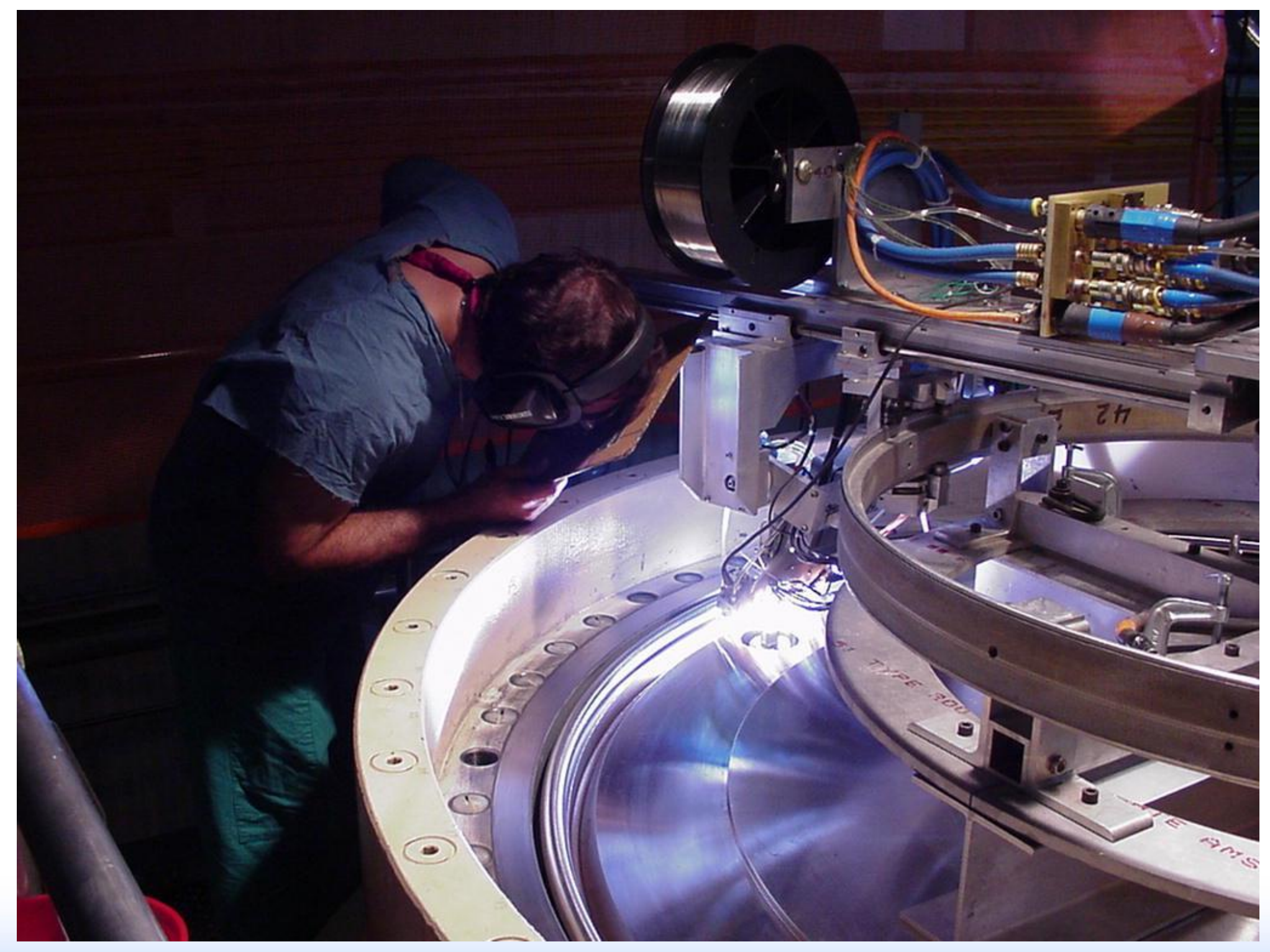

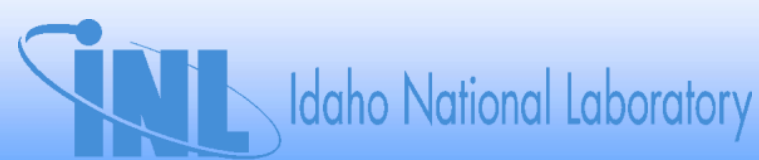




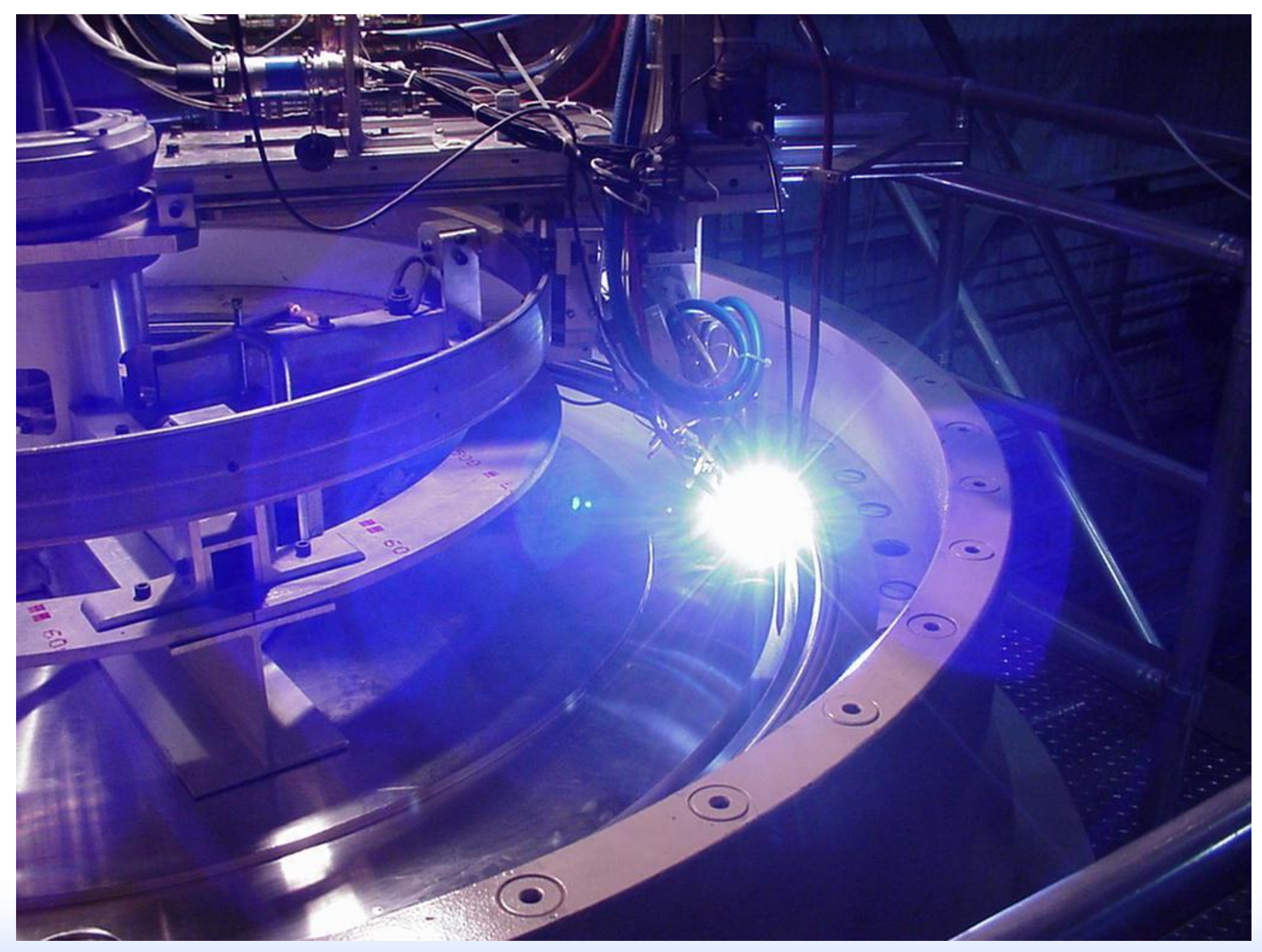

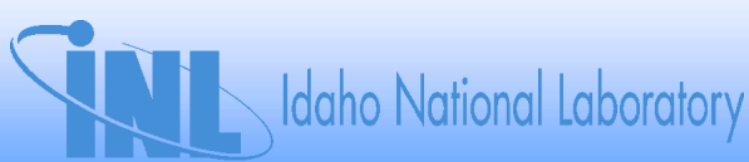




\section{Cask Circumferential Weld Seam - Black "X" \\ CASK / DSC ANNULUS SEAL INSTALLATION}






\section{Approach}

- PRODIGAL Computer code to simulate flaw distributions.

- Probabilistic Fracture Mechanics (PFM) to estimate probability of weld failure

- Uncertainty analysis 


\section{Cask Welds Evaluated}

- Circumferential and axial weld - shop

- Shell to base weld - shop

- Closure weld lid to shell - field

- Closure ring to shell - field

- Closure ring to lid - field 


\section{PRODIGAL Code}

- Expert system model and probabilistic fracture mechanics (PFM)

- expert system for flaw distribution

- PFM for failure probability

- Simulates occurrence of flaws during multi-pass welding beads

- Takes into account radiographic inspection (RT), and die penetrant inspection (PT)

- Spent Fuel Project Office (SFPO) said they rely on NDE 


\section{PRODIGAL CODE (cont.)}

- Code written by Rolls-Royce for risk-informed inspection of plant piping welds

- Determine number, length, and depth distribution of weld flaws

- Developed by extensive discussion with welding experts 


\section{Probabilistic Fracture Mechanics Calculations}

- Uses deterministic equations for fracture mechanics

- Distributions for critical parameters

- Uncertainty on distributions

- Monte Carlo to determine failure rate 
Monte Carlo Technique

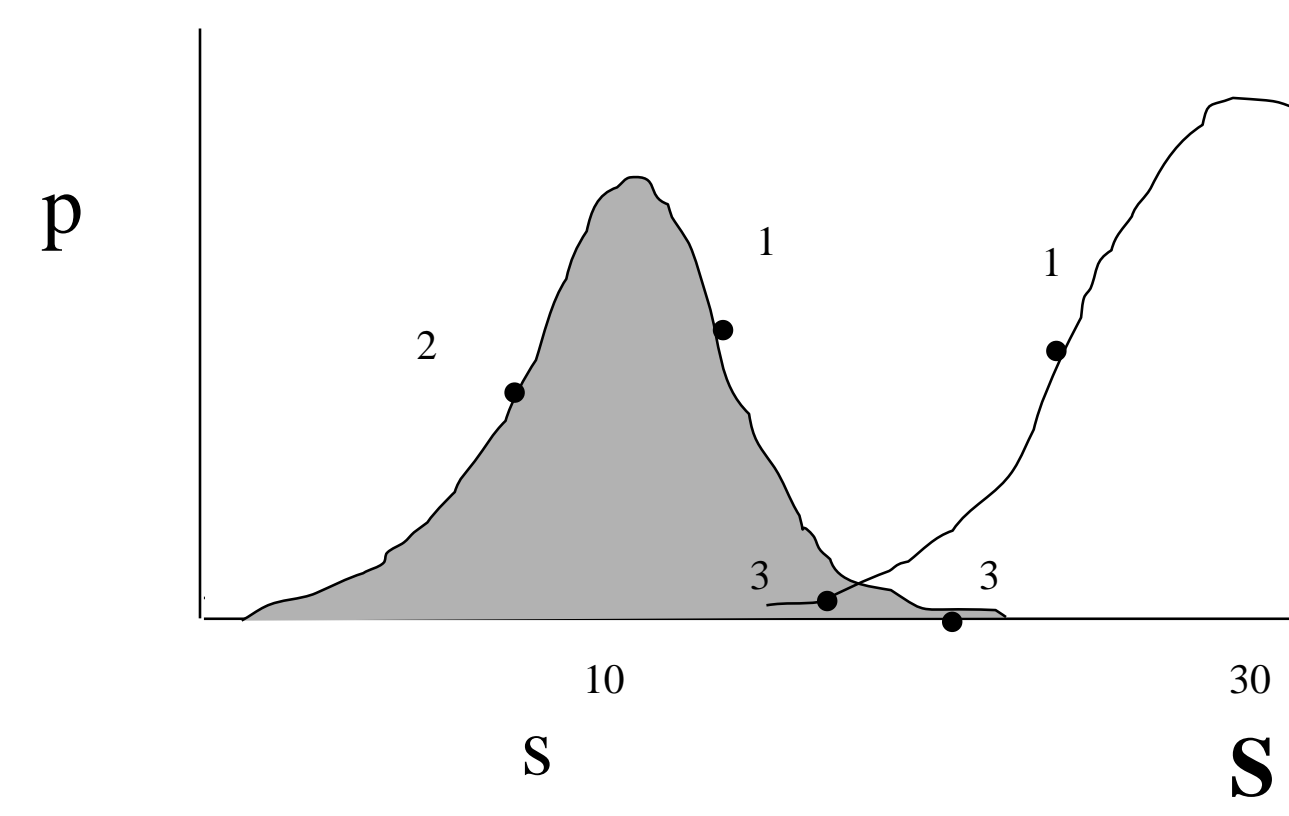

Thousand pounds per square inch (KSI)

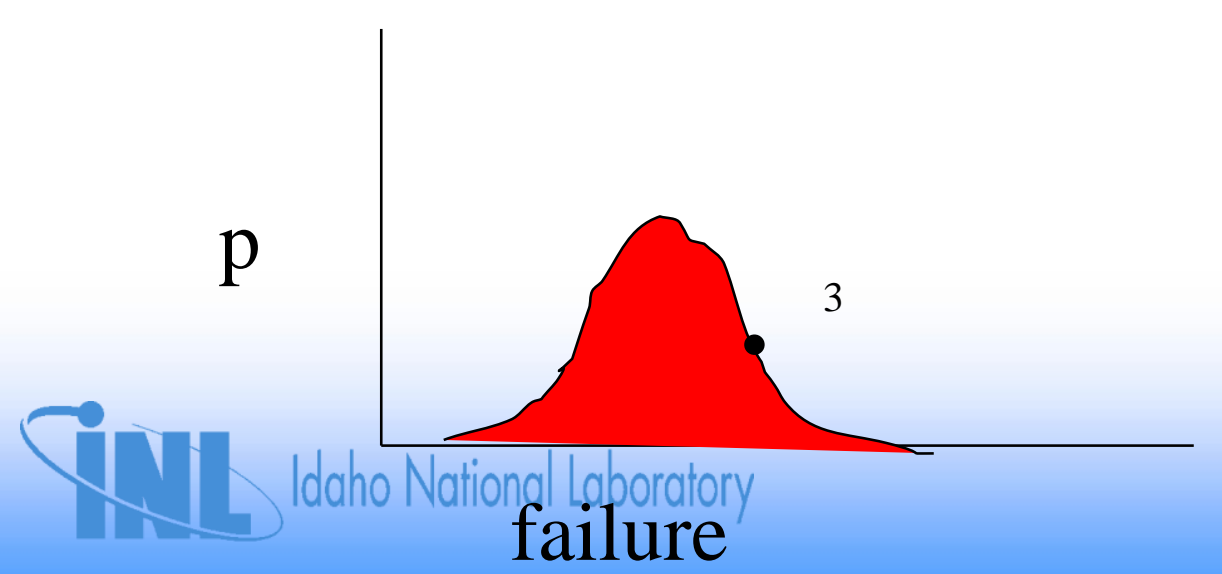

$\mathbf{S} / \mathrm{s}=3$ Safety factor

$\mathbf{S} / \mathrm{s}<1 \quad$ Fails

Where

$\mathbf{S}$ is Strength

$\mathrm{s}$ is stress
1. $20 / 15>1$ ok

2. $38 / 8>1$ ok

3. $18 / 25<1$ failure

$\mathbf{N}$

$\mathbf{P}($ failure $)=$ failures $/ \mathbf{N}$

Example:

10 failures $/ 10,000$ trials $=1 \mathrm{E}-3$ 


\section{Monte Carlo Technique (Continued)}

- Distributions are sampled using a random number generator

- Deterministic equation is used for

- stress < strength, and

- stress intensity < toughness

- Distributions are sampled thousands to millions of times

- Failure is recorded when

- stress is greater than strength, or

- stress intensity is greater than toughness

- Failure probability is

- $\mathbf{P}($ failure $)=$ number of failures $/$ number of trials

- Failure distribution is created 


\section{Results}

- Only 60 g drop loads cause cracks to grow

- Cracks must be greater than $90 \%$ through wall to grow

- SFPO thinks size should be 50 to $60 \%$ 


\section{Conclusion}

- No stresses but $60 \mathrm{~g}$ drop would cause leakage beyond technical specification limits

- Cyclic stresses are very small or non existent - no fatigue 


\section{Conclusion (cont.)}

- Experiencing a leak under normal conditions is equal to or less than the probability of a through wall crack or a best estimate probability of 5.8E-9 failures per weld.

- If credit taken for secondary barrier cover plate, best estimate probability reduced to $3.7 \mathrm{E}-12$ failures per weld. 


\section{Conclusion (cont.)}

- The $60 \mathrm{~g}$ bottom end drop accident best estimate conditional probability is $4.0 \mathrm{E}-8$ failures per weld if the accident occurs.

- If credit is taken for the secondary barrier cover plate, the best estimate probability reduced to 2.6E-11.

- Note: these are the conditional probability if the accident occurs - thus, the probability does not account for the accident probability. 


\section{Additional Information on NMSS Risk-Informing Applications}




\section{Additional Potential Applications}

- RTG worked with the divisions and conducted a survey of division activities that could be amenable to a riskinformed approach

- RTG applied screening considerations to the activities and developed a list of potential activities where risk assessment methods could be applied

- Documented findings in Risk-Informing the Materials and Waste Arenas: Phase 2 Report (ML021210081) 


\section{Potential Future FCSS Risk-Informed Initiatives and Activities}

- Develop guidance on risk significance of inspection findings and operational events

- Develop guidance for risk-informed inspections of fuel cycle facilities

- Reevaluate the uranium recovery licensing and inspection program 


\section{Potential Future IMNS Risk-Informed Initiatives and Activities}

- Develop an assessment of vulnerabilities for materials licensees

- Reevaluate the sealed source and device review process to consider the radiological risk of the device

- Reevaluate the licensing and device review process for radiography licensees to reflect insights from recent radiography risk studies

- Reevaluate the license renewal process for medical licensees to reflect risk and past licensee performance 


\section{Potential Future SFPO Risk-Informed Initiatives and Activities}

- Review and update risk estimates for transportation of radioactive materials other than spent nuclear fuel

- Risk-informed review of licensing and certification process for transportation of non-spent fuel radioactive materials

- Risk-informed review of licensing and certification process for dry cask storage systems and ISFSIs

- Risk-informed review of inspection process for transportation and spent fuel storage 


\section{Potential Future DWM Risk-Informed Initiatives and Activities}

- Integrate preliminary results of the Dry Cask Storage System PRA study with the Repository Preclosure Safety Analysis

- Develop Total System Performance Assessment code sensitivity and uncertainty analyses to support risk-informed licensing and inspection

- Develop human reliability analyses capabilities for preclosure safety analysis 


\section{Potential Future DWM Risk-Informed Initiatives and Activities (continued)}

- Develop Pre-Closure Safety Assessment code sensitivity and uncertainty analyses to support riskinformed licensing and inspection programs

- Develop a risk-informed licensing process for the high-level waste program

- Use risk insights to resolve Key Technical Issues

- Develop a risk-informed inspection program for the high-level waste program 


\section{Workshops}




\section{Page Intentionally Left Blank}




\section{Fault Tree Model Problem}




\section{Radioactive lodine Tank Problem}

- What is the probability of a release from the tank per day based on the following information?

- A release is defined as an undesired "open" tank boundary which includes the relief valve being open.

- The tank is an older design with a single wall construction. Based on an analysis of the tank, the failure rate of the tank due to corrosion was estimated to be 1E-6 per hour.

- The tank has a relief valve that is designed to remain closed except in very limited situations (e.g., overfilling and high temperatures). The tank relief valve spurious failure rate is $1 \mathrm{E}-5$ per hour.

- Radioactive waste is added to the tank once a day. The transfer operation takes two hours. An operator must start a transfer pump and then stop the transfer pump prior to overfilling the tank. Overfilling the tank would cause the tank relief valve to open. Based on previous experience, the pump failing to stop on demand failure rate is 1E-5 per demand.

- A level indicator on the tank is monitored by the operator during filling operations. An analysis was done on collected level indicator data and a failure rate of 1E-4 per hour was estimated.

- An HRA estimated the human failure rate of 1E-2 per transfer for the operator actions required during the filling operations.

- The tank and pump also have an interlock system, completely separate from the level indicator monitored by the human. The interlock system will stop the transfer pump when the tank level is at $90 \%$ of the overfill-capacity. Collected data indicates that the interlock failure rate is 1E-3 per demand. 
TI. Idaho National Laboratory

5 
TI. Idaho National Laboratory 
TI. Idaho National Laboratory 
TI. Idaho National Laboratory 


\section{Dispersion Risk Problem}




\section{Problem}

- Estimate the risk to a person at $100 \mathrm{~m}$ and $200 \mathrm{~m}$ from a high rad waste tank containing radioactive iodine.

- The most likely scenario is the failure of a relief valve, which has a failure probability of 1E-3.

- A dispersion analysis and a distance calculation indicated that a person at $100 \mathrm{~m}$ will get a dose of $10 \mathrm{rem}$ and a person at 200 $\mathrm{m}$ will get a dose of $7 \mathrm{rem}$.

- The gaussian plume calculation was based on $10 \mathrm{mph}$.

- The likelihood of a fatality is estimated to be $5 \mathrm{E}-4 / \mathrm{rem}$. (Recommended by ICRP 60 cited in Reg Guide 8.29)

- Determine risk plots for the events at the maximum dose location. 
Whole Body

10 Rem

100 meters

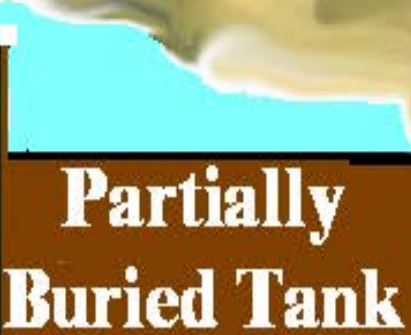

Whole Body

7 Rem

200 meters 

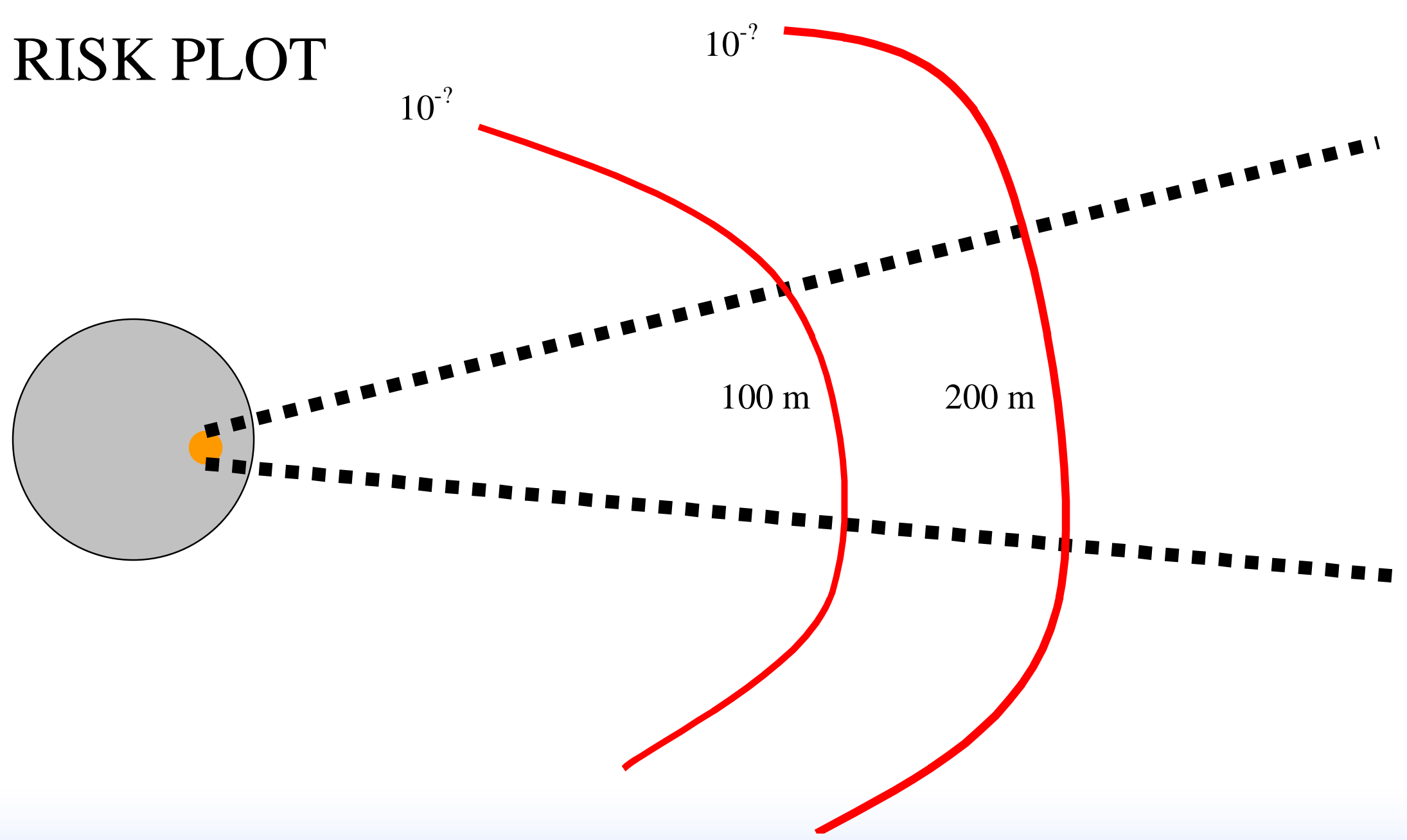
TI. Idaho National Laboratory 
TI. Idaho National Laboratory 


\section{Bracytherapy Example}




\section{Bracytherapy Example}

- Initiating Event \& Event Tree Workshop

- Objective: To identify questions that must be raised when first formulating a problem. Practice identification of potential sequences-of-events; organization of an analysis and selection of an analysis method.

- Problem: In very simple terms, identify information needed to quantify the risk from misadministration of brachytherapy treatments in the U.S. Outline an approach for estimating the risk. In particular,

- List the potential undesired consequences associated with brachytherapy treatments.

- Identify what you would use as the initiating event and describe how you might quantify it (be brief).

- Identify and list aspects and issues to consider in solving the problem.

- Develop a model. 


\section{Bracytherapy Example (continued)}

- Brachytherapy is a procedure of temporarily implanting a set (about 6 to 12) small "seeds" of radioactive material (typically cesium-137 or iridium-192) into cancerous tissue via a catheter. Treatments can last from a few hours to a few days. The general process is as follows:

- 1. Physician identifies the need for a treatment and writes a prescription (radiation dose to a particular reference point in the patient's body).

- 2. Under the supervision of a medical physicist, the dosimetrist (technician) plans treatment using X-rays and a computerized treatment planing system.

- 3. Medical Physicist verifies treatment plan.

- 4. Physician and Physicist initiate treatment:

- insert catheters

- remove radioactive seeds from storage and insert them in the catheters

- 5. After prescribed time, Physician and Physicist terminate treatment:

- remove seeds from patient and put them back into storage. 
TI. Idaho National Laboratory 
TI. Idaho National Laboratory 


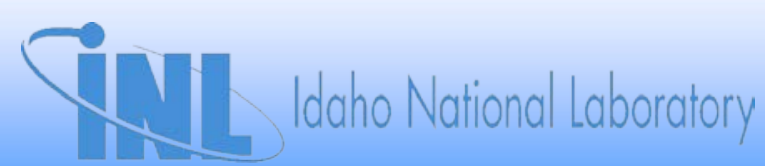

20 


\section{Workshops Solutions}




\section{Page Intentionally Left Blank}




\section{Fault Tree Model Problem Solution}

\section{Probability of Various Failures}

Tank corrosion

Relieve valve failure

Pump fails to stop when demanded

Level indicator fails during transfer

Operator fails to stop pump

Interlock fails
1E-6/hour x 24 hours $=2.4 \mathrm{E}-5$

1E-5/hour x 24 hours $=2.4 \mathrm{E}-4$

1E-5 per demand $x 1$ demand $=1 E-5$

1E-4/hour x 24 hours $=2.4 E-3$

1E-2/transfer $\times 1$ transfer $=1 \mathrm{E}-2$

1E-3 per demand $\times 1$ demand $=1 E-3$ 


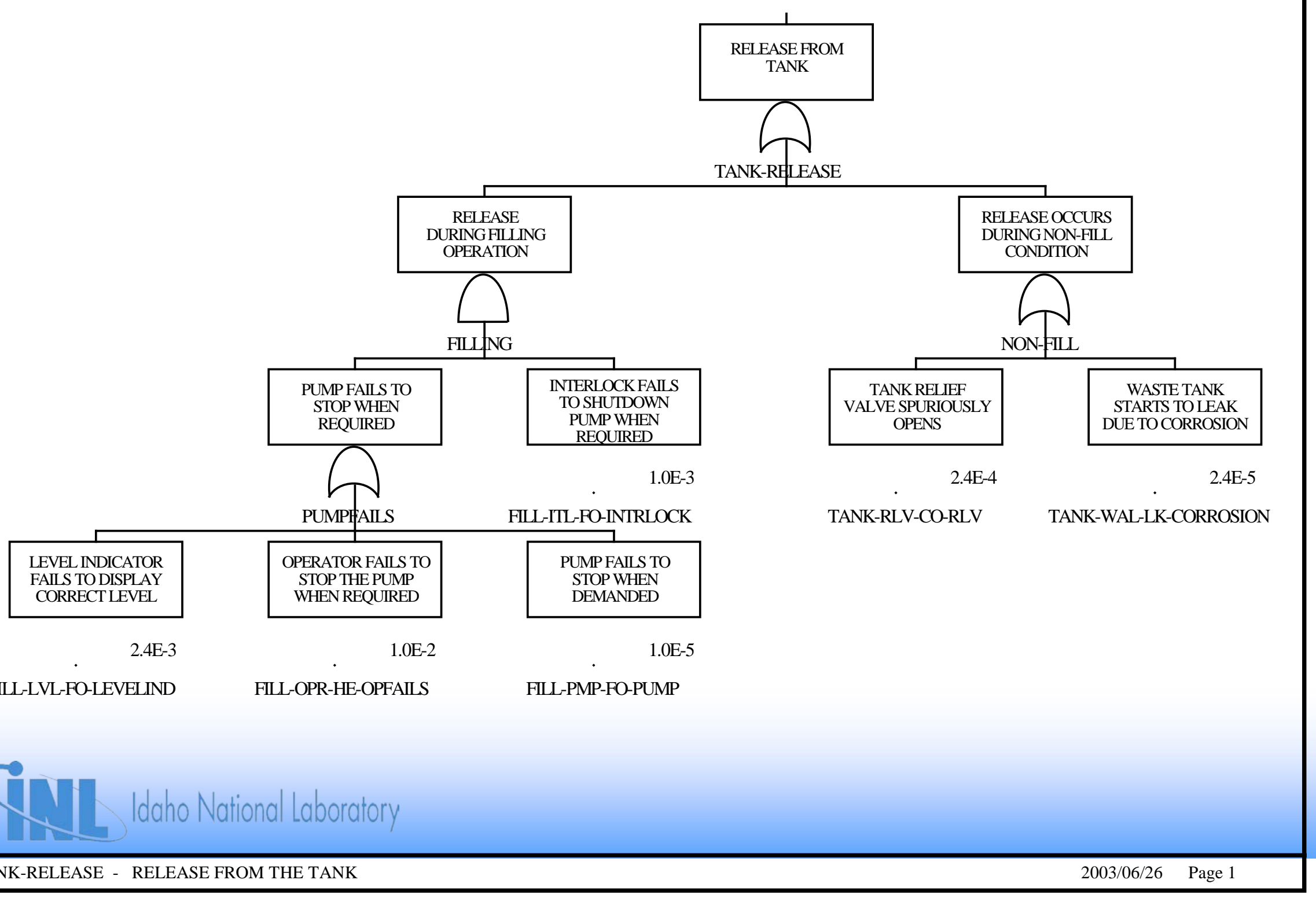




\section{Tank Release Cut Sets}

Sort/Slice Cut Set Report

Project-> NMSS-EXAMPLES

Mincut Upper Bound -> 2.764E-๑๑4

Fault Tree-> TANK-RELEASE

This Partition -> 2.764E-004

$\begin{array}{ccccc}\text { Cut } & \% & \% \text { Cut } & \\ \text { No. Total } & \text { Set } & \text { Frequency cut sets }\end{array}$

$1 \quad 86.8 \quad 86.8 \quad 2.400 \mathrm{E}-004$ TANK-RLV-CO-RLV

$2 \quad 95.5 \quad 8.7 \quad 2.400 E-005$ TANK-WAL-LK-CORROSION

$3 \quad 99.2 \quad 3.6 \quad 1.000 \mathrm{E}-005$ FILL-ITL-FO-INTRLOCK, FILL-OPR-HE-OPFAILS

$4 \quad 100.0 \quad 0.9 \quad 2.397 E-006$ FILL-ITL-FO-INTRLOCK，FILL-LVL-FO-LEVELIND

$5 \quad 100 . \odot \quad 0.0 \quad 1.000 \mathrm{E}-008$ FILL-ITL-FO-INTRLOCK, FILL-PMP-FO-PUMP 


\section{Probability of a Release from Tank per day?}

Relief valve failure

2.4E-4

Tank corrosion

2.4E-5

Operator error and interlock 1E-2 x 1E-3 =

1E-5

Level indicator and interlock 2.4E-3 x 1E-3 =

2.4E-6

Pump and interlock

$1 E-5 \times 1 E-3=$

1E-8

Probability of release from tank per day =

2.764E-4 


\section{Dispersion Risk Problem Solution}

- Risk to an individual at $100 \mathrm{~m}$ ? $200 \mathrm{~m}$ ?

- Conditions:

- Gaussian Plume

- Calm - 10 mph wind

- Other Information:

- Probability of relief valve failure $=1.0 \times 10^{-3}$

-1 rem $=5 \times 10^{-4}$ fatality

- $100 \mathrm{~m}$ dose is $10 \mathrm{rem}$

- $200 \mathrm{~m}$ dose is 7 rem

- 100 meter risk

- Risk = $\left(1.0 \times 10^{-3}\right) \times\left(5 \times 10^{-4}\right.$ fatalities $\left./ \mathrm{rem}\right) \times(10 \mathrm{rem})=5 \times 10^{-6}$

- 200 meter risk

- Risk $=\left(1.0 \times 10^{-3}\right) \times\left(5 \times 10^{-4}\right.$ fatalities $\left./ \mathrm{rem}\right) \times(7 \mathrm{rem})=3.5 \times 10^{-6}$ 

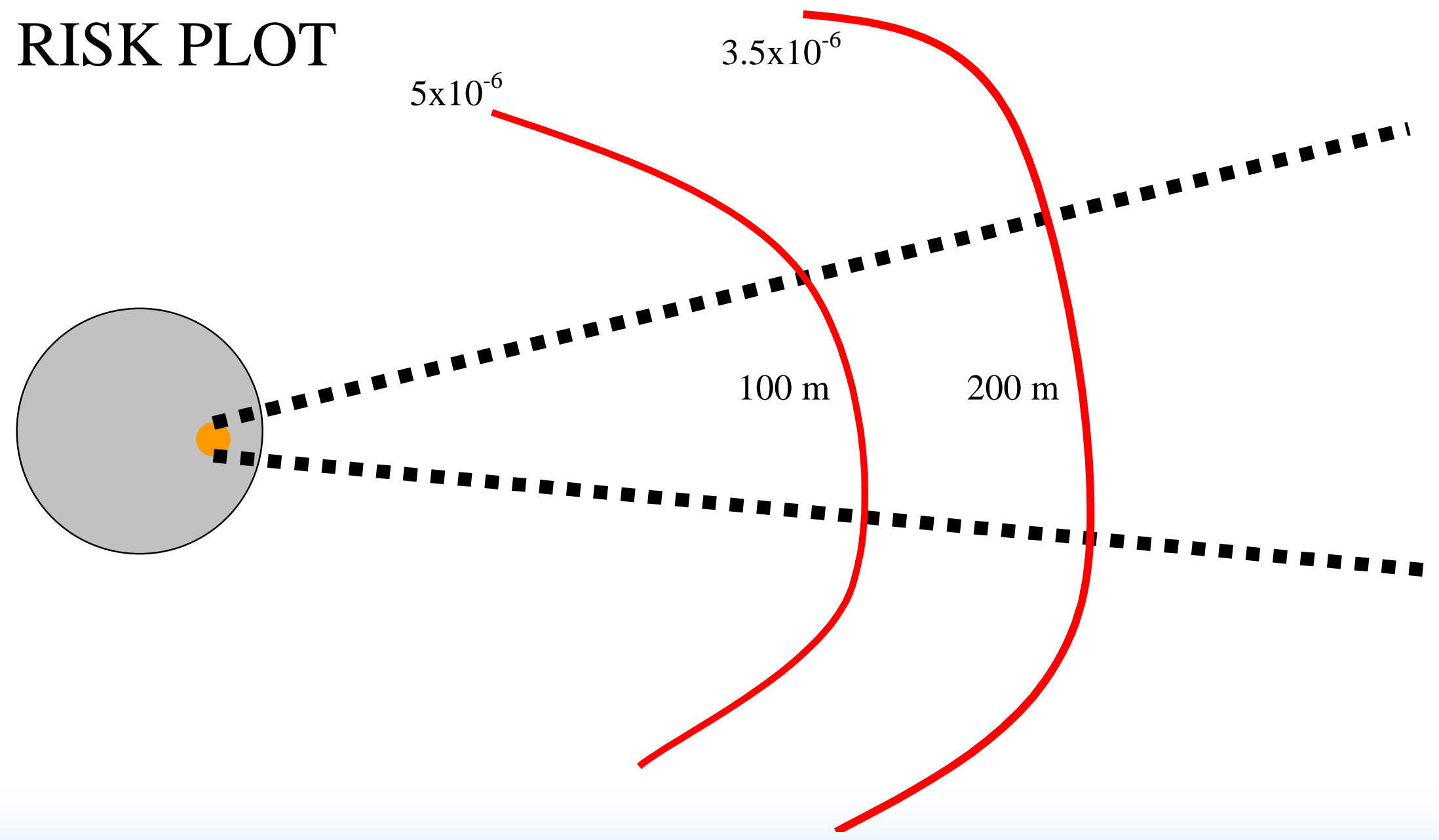


\section{Case Studies and Reference Documents}




\section{Page Intentionally Left Blank}




\section{Objectives of the Case Studies}

- Test draft screening considerations and produce a final version

- Examine the feasibility of developing risk guidelines

- Gain insights on the risk-informing process

- Identify tools, data, and guidance needed 


\section{Insights from Case Studies - Value of Using Risk Information}

- Helped to make decisions that were consistent with agency's current strategic goals

- Can be useful in identifying shortcomings in our regulations or regulatory processes

- To realize benefits of risk-informed approach:

- Continue with staff training

- Introduce risk-informed guidance on rulemaking, licensing, inspection and enforcement

- Recognize that "zero" is impossible in the real world

- Address human reliability in a consistent and credible approach 


\section{Insights from Case Studies - Risk Guidelines}

- Development of risk guidelines is feasible

- Implicit risk guidelines existed in case study areas

- Decision-making could be facilitated if clear set of risk guidelines existed

- Draft guidelines have been proposed:

- Establish thresholds for determining when riskinformed decisions result in insignificant or tolerable levels of risk 


\section{Insights from Case Studies - Information, Tools, Methods, Guidance}

- Exist in varying degrees

- Sufficient in some areas to support risk-informed decision making

- Could use NRR data/models for consistency in some generic case

- Models of processes provide consistent set of assumptions for generic cases

- Share weakness of the human factor 


\section{Insights from Case Studies - Process Improvements}

- Risk information has been/can be used to:

- Reduce burden and improve efficiency without a reduction in safety

- Promote regulatory consistency (e.g., generally licensed, specifically licensed, and exempt)

- Indicate where increased regulatory oversight may be warranted

- Indicate where resources should be focused in proportion to risk

- Identify the significance of nonradiological risk

- Facilitate the certification process of a facility

- Illuminate options for long-term disposal of a facility

- Support granting an exemption

- Highlight the need to revise regulations 


\section{Insights from Case Studies - Process Improvements}

- Identified considerations for how to risk-inform

- Identified what needed to be done to realize benefits of risk-informed approach

- Gave preliminary perspective on risks in the materials and waste arenas 


\section{RISK INFORMING THE MATERIALS AND WASTE ARENAS: Integration of Case Studies and Related Risk Assessments}

- RISK INFORMING THE MATERIALS AND WASTE ARENAS:

Integration of Case Studies and Related Risk Assessments, Volume 1: Main Report, December 2001, Revised February 2002 (ML013610447)

- RISK INFORMING THE MATERIALS AND WASTE ARENAS:

Integration of Case Studies and Related Risk Assessments, Volume 2: Case Study Plan and Case Study Reports, December 2001, Revised February 2002 (ML013620070)

- Appendix A - ML010040111 - Case Study Plan

- Appendix B - ML012960268 - A Case Study on the Regulation of Gas Chromatographs

- Appendix C - ML012960555 - A Case Study on the Regulation of Static Eliminators

- Appendix D - ML012960172 - A Case Study on the Regulation of Fixed Gauges

- Appendix E - ML013200060 - A Case Study on Risk Informing Uranium Recovery

- Appendix F - ML013050332 - A Case Study of Risk Informing 10 CFR Part 76: Seismic Issues at Paducah Gaseous Diffusion Plant

- Note: Not Available to the Public

- Appendix G - ML013050324 - A Case Study on Risk Informing Site Decommissioning

- Appendix H - ML012970156 - A Case Study on the Transportation of the Trojan Reactor Vessel Package

- Appendix I - ML013030006 - A Case Study on the Seismic Exemption for the DOE/INEEL Three Mile Island - Unit 2 Fuel Debris Independent Spent Fuel Storage Installation 
RISK INFORMING THE MATERIALS AND WASTE ARENAS:

INTEGRATION OF CASE STUDIES AND RELATED RISK ASSESSMENTS

Volume 1: Main Report

Prepared By:

Risk Task Group

Office of Nuclear Materials Safety and Safeguards

U.S. Nuclear Regulatory Commission

and

Brookhaven National Laboratory

December 2001

Revised February 2002 


\section{Principal Contributors:}

Ms. Marissa Bailey, NRC/NMSS/RTG

Dr. Robert Bari, Brookhaven National Laboratory

Dr. Dennis Damon, NRC/NMSS

Mr. James Danna, NRC/NMSS/Risk Task Group

Mr. Edward Grove, Brookhaven National Laboratory

Mr. Lawrence Kokajko, NRC/NMSS/Risk Task Group

Ms. Christiana Lui, NRC/NMSS/Risk Task Group

Dr. Vinod Mubayi, Brookhaven National Laboratory

Ms. Raeann Shane, NRC/NMSS/Risk Task Group

Ms. Jessica Shin, NRC/NMSS/Risk Task Group

Mr. James Smith, NRC/NMSS/Risk Task Group

Dr. Patricia Rathbun, NRC/NMSS/IMNS

Dr. James Xu, Brookhaven National Laboratory
Sr. Project Manager

Sr. Advisor for Energy, Science and Technology

Sr. Level Advisor for Risk

Assessment

Systems Performance Analyst

Research Engineer

Section Chief

Sr. Risk Analyst

Physicist

Health Physicist

Intern

Health Physicist

Technical Assistant -

Communications

Scientist 


\begin{abstract}
The U.S. Nuclear Regulatory Commission's Office of Nuclear Materials Safety and Safeguards (NMSS) is moving towards increasing the use of risk insights and information (i.e., risk informing) in the nuclear materials and waste arenas, where appropriate. As part of this effort, case studies were conducted by the NMSS Risk Task Group between September 2000 and December 2001. The purpose of the case studies was (1) to illustrate what has been done and what could be done in the materials and waste arenas to alter the regulatory approach in a risk-informed manner and (2) to establish a framework for using a risk-informed approach in the materials and waste arenas by testing a set of draft screening criteria and determining the feasibility of safety goals. In addition to the case studies, the Risk Task Group has also engaged in other activities to advance the use of risk information in NMSS. This included assisting the NMSS Divisions and Regions in various risk-related initiatives and developing training on risk assessment methods and risk communications.

The objective of this report is to integrate the results of the eight case studies. The insights gleaned from the other risk-related activities in the materials and waste arenas have also been factored into the case study integration. This report finalizes a set of screening considerations and begins the process of developing safety goals. The results of the eight case studies, along with the other risk-informing activities and studies, demonstrate how risk information can be valuable and beneficial to the regulatory process and informs the need for methods, data, and guidance in this area. Although more work needs to be done, there are no fundamental impediments to the expansion and broader application of risk information across the spectrum of NMSS-regulated activities. This report provides a basis for beginning to identify materials and waste areas that are amenable to risk-informed regulation.
\end{abstract}




\section{EXECUTIVE SUMMARY}

\section{OBJECTIVES}

The objective of this report is to integrate the results of eight case studies that were performed by the Risk Task Group (RTG) of the Office of Nuclear Material Safety and Safeguards (NMSS) of the U.S. Nuclear Regulatory Commission (NRC). Insights gathered from the other risk-related activities in the materials and waste arenas were also factored into this integration. The purpose of the case studies was (1) to illustrate what has been done and what could be done in the materials and waste arenas to alter the regulatory approach in a risk-informed manner, and (2) to establish a framework for using a risk-informed approach in the materials and waste arenas by testing a set of draft screening criteria and determining the feasibility of safety goals. The NRC policy on implementing risk-informed regulation was expressed in the 1995 Policy Statement on the use of probabilistic risk assessment (PRA) methods in regulatory activities. This statement called for the increase in the use of PRA technology in all regulatory matters consistent with the state-of-the-art in PRA methods and data in a manner that complements the NRC's deterministic approach and supports the NRC's traditional defense-in-depth philosophy. The Commission recognized that a single approach for incorporating risk analyses into the regulatory process would not be appropriate given the nature and consequences of the use of nuclear materials in reactors, industrial applications and waste disposal facilities.

Accordingly, a framework for risk-informed regulation to NMSS activities was developed by the staff in 1999, in SECY-99-100. In approving the staff's proposal, the Commission stated that the staff should develop appropriate material safety goals analogous to the reactor safety goal, to guide the NRC and to define what safety means for the materials program. The first part of this framework defines the areas in which risk assessment methods can play a role in the NRC decision-making process. This is done by identifying candidate regulatory applications that are amenable to expanded use of risk assessment and identifying responsible staff organizations. A set of screening criteria have been formulated to identify candidate NMSS regulatory application areas suitable for risk-informing. These screening criteria were issued in draft form in 2000 and subsequently tested against selected case studies.

\section{APPROACH}

The case studies were performed using a standardized approach, described in the Case Study Plan. Each case has been studied by a member of RTG or a contractor with risk expertise. Advisors include subject matter experts from the NRC staff who have knowledge of the particular case. The reviewers also consulted with licensees and other stakeholders having knowledge of the particular case, through a series of public workshops. Visits were made, as appropriate, to the sites of the facilities related to the case studies. Also, the NRC historian and other individuals (NRC and non-NRC) were interviewed for perspectives and insights on the materials and waste regulatory history, safety goal development, radiation protection standards, and public confidence and communications.

The basis for each case study has been the review of information from NRC and licensee source documentation, through which the staff answered a standardized list of questions. After the investigative phase of the study, the NMSS staff (and its contractor) generated a set of preliminary 
conclusions based on the answers to these questions. The staff then presented its preliminary conclusions at public workshops in which all stakeholders were invited to participate. After incorporating information and ideas that emerged from these meetings, the NMSS staff produced reports documenting each case study.

This approach was developed using information received during two public workshops/meetings. The first public workshop was held in April 2000. The purpose of that workshop was to solicit public comment on the draft screening criteria and their application and on development of safety goals for nuclear materials and waste applications. The consensus among participants at the workshop was that case studies of specific areas would be useful to test the screening criteria, to show how the application of a risk approach has or could affect a regulatory decision or process, and, if feasible, to develop safety goal parameters and a first draft of safety goals for each area. The purpose of the case studies was to illustrate and highlight, if possible, the explicit or implicit riskinformed nature of previous regulatory approaches or decisions in specific applications, and to establish a framework for using a risk-informed approach in different materials and waste arenas by testing the draft screening criteria and determining the feasibility of safety goals.

A second public meeting was held in September 2000 to solicit public comment on a draft Case Study Plan for carrying out the case studies. The draft plan contained the case study objectives, the draft screening criteria, the measures of success used to gauge the case studies, the case study outline, including the specific areas and applications that would be evaluated in the case studies, and the structure of each case study. The final Case Study Plan was issued on October 27,2000

Four broad objectives were identified for the case studies:

(1) Test the draft screening criteria and produce a final set of screening criteria.

(2) Gain insights into risk-informing NMSS regulatory processes by illustrating how the application of risk information has improved or could improve a particular area of the NMSS regulatory process.

(3) Determine the feasibility of safety goals in a particular area; if feasible, develop safety goal metrics and a first draft of the goals, otherwise, document the reasons for infeasibility.

(4) Identify the gaps in the tools, methods, data, and guidance that are required to risk-inform NMSS.

The measure of success would be to evaluate how well the case studies met these objectives. The case studies were not intended to reopen or reassess any previous decisions made by the Commission, but rather to elicit information that may or could impact future decisions by the staff and the Commission. Eight case study areas were identified as follows:

- Regulation of Fixed Gauges

- Regulation of Static Eliminators

- Regulation of Gas Chromatographs 
- $\quad$ Site Decommissioning of the Trojan Nuclear Power Plant (TNPP)

- $\quad$ Transportation of the Trojan Reactor Vessel Package (TRVP)

- Uranium Recovery

- $\quad$ Seismic Exemption for Dry Cask Storage of Three Mile Island Unit 2 fuel debris at the U.S. Department of Energy's Idaho National Engineering and Environmental Laboratory

- $\quad$ Paducah Gaseous Diffusion Plant Seismic Upgrade

Each of these cases were selected to test the applicability of the draft screening criteria, and extract risk insights related to NMSS activities or decisions made by the Commission in each specific area that could have a bearing on safety goals. The case studies began in November 2000. Five case studies, transportation of the TRVP, gas chromatographs, static eliminators, fixed gauges, and dry cask storage were done by NMSS staff. Studies of the TNPP site decommissioning, uranium recovery, and Paducah gaseous diffusion plant seismic upgrade were done by Brookhaven National Laboratory in collaboration with the RTG staff.

As the case studies progressed, several meetings were held to inform stakeholders about the status of the individual case studies and solicit input on the preliminary results. Finally, a public meeting was held on October 25, 2001 at NRC headquarters. During this meeting, the RTG staff reported on the integration of all the case studies, the screening criteria (now renamed screening considerations), the draft safety goals, and further plans for risk informing.

\section{INFORMATION FROM OTHER RISK-RELATED ACTIVITIES}

The use of risk information in the materials and waste arenas is not limited to the regulatory applications addressed by the case studies. Risk information has been used in other materials and waste regulatory areas as well. Some of these activities were completed and documented before the case studies began. Others were ongoing while the case studies were being conducted, and RTG actively assisted the NMSS Divisions and Regions in several of those ongoing activities. Concurrent with the case studies, RTG also assisted in developing and providing training on risk assessment methods and risk communications. It should be noted that information and insights from these other (past and ongoing) risk-related activities illuminated the case studies and influenced the conclusions.

\section{FINDINGS}

A well-defined procedure for identifying candidate applications in NMSS for risk-informing has been successfully tested and has been finalized as a set of screening considerations. Overall, the case studies demonstrated that the screening considerations contained all the relevant elements needed for risk-informing and can be a useful decision-making tool. However, the application can be subjective, so guidance is needed. The experience of carrying out the case studies also indicated that the draft "screening criteria" should be more properly identified as screening considerations. They are a set of factors that encompass the relevant questions that are needed for risk-informing, but they do not have just yes/no answers. 
The case studies have collectively illustrated that risk information has been used for some time in making regulatory decisions. The case studies were effective in indicating where decisions or processes are consistent with the Agency's strategic goals. Furthermore, they have helped to highlight some of the areas in which there are shortcomings in the regulations or regulatory process.

The studies also showed that safety goals are feasible and decision-making and risk management can be facilitated if a clear set of safety goals existed. A proposed first draft of safety goals have been developed which now need to be tested and refined. Risks to the workers have been found to be significant in comparison to public risks. For some facilities, chemical risks have been found to be comparable to or greater than the radiological risks.

Information, tools, methods, and guidance needs have been identified and the necessary tools can be assembled to make the risk-informing process more effective in NMSS. There is a fairly significant application of risk methods and applications in some areas and somewhat less experience in other areas. One of the major gaps in the methods is the identification and development of a robust and simple method for incorporating human factors and estimating human reliability in the very wide range of situations and activities encountered and performed by NMSS licensees.

The development of guidance on the level of detail and complexity required in the risk methods for various activities should be helpful to staff in future plans for risk-informing materials and waste arenas. Furthermore, the existing risk training program will be updated periodically to make available to the staff the latest applications, data and tools to further advance staff's knowledge and capability in implementing the risk-informed approach.

The case study program has been responsive to the requirements set forth by the Commission. The staff has developed a proposed first draft of materials and waste safety goals analogous to the reactor safety goal, to guide the NRC and to define what safety means for the materials program. Taken together, the reactor goal and the nuclear materials use and waste goals can become a comprehensive set of goals for the entire agency.

The conclusions of the case studies with regard to the value of risk information give several examples of how the information supported the NRC strategic goals on safety issue elucidation, regulatory efficiency, unnecessary burden reduction, and improved risk communication.

\section{CONCLUSIONS}

Risk-informing NMSS activities has been occurring in specific areas and to varying degrees over a number of years. Although more work needs to be done, as discussed in the next section, there are no fundamental impediments to the expansion and broader application of risk information across the spectrum of NMSS-regulated activities.

Risk information can be valuable as an additional input to decisions that NMSS must make. It can complement the more familiar information that is derived from consideration of the existing regulatory framework. It can help to make that framework more rational. An integrated and balanced risk management program would recognize both public and worker risks as well as radiological and nonradiological risks at the regulated facilities. 
An important adjunct to risk information when used for managing risks, is a set of safety goals that assist the decision maker in determining whether safety objectives will be achieved. If safety goals are to move forward, then risk information can be readily compared with these goals to guide and inform regulatory issue resolution.

The case studies illustrated that the seven factors that constitute the screening considerations can be a very useful decision-making tool but their application can be subjective, hence guidance is needed. The seven factors are one important tool in the management decision to risk-inform a specific activity or process. The screening considerations not only lead to a decision whether to risk-inform or not, they also begin to formulate what the issues involved in the decision are and what information and methods are needed to address them. Risk informing in this context implies a commitment to use a set of formal methods or approaches such as PRA in the regulatory decision-making process.

\section{FUTURE PLANS}

As specific applications for risk-informing nuclear materials use and waste arenas progresses, further development of the preliminary safety goals will occur. These two activities will be mutually supportive and synergistic. Safety goals will help to guide and inform regulatory issue resolution and exploration of the issues will provide insights to the refinement and further development of the safety goals. Particular attention will be given to risks to the workers and the presence of nonradiological risks.

Data availability suitable for the needs of risk assessment is another area that should be explored in greater detail. In some case studies, there is a fair amount of good quality data that can be used for risk purposes, while in some other cases, comparatively less information is available.

NMSS is following a general, three-phase plan to implementing the framework described in SECY99-100. The first phase focused on developing a systematic approach for identifying candidate NMSS regulatory applications that may be amenable for increased use of risk information. A important part of Phase 1 was the case studies. The second phase focuses on applying the systematic approach, developed through the first phase, to identify the candidate NMSS regulatory applications. Finally, the third phase focuses on the actual modification of the identified regulatory applications to make them more risk-informed.

Phase 1 has been completed. Phase 2 begins upon finalization of the screening considerations. Phase 2 will focus on the systematic review of NMSS materials and waste regulatory applications, to identify those that would be amenable to an increased consideration of risk insight and information. The product of the screening activity in Phase 2 is expected to be a set of potential future risk-informed activities and initiatives for the various NMSS regulatory areas. 


\section{ACKNOWLEDGMENTS}

We thank several members of the staff of the U.S. Nuclear Regulatory Commission, representatives of the facilities and activities that comprised these eight case studies, other professionals in the nuclear materials use and waste arenas, and members of the interested stakeholder community for helpful guidance, information, comments and suggestions.

In particular, we would like to thank the following NRC staff members who served as subject matter experts for the case studies: Michelle Burgess, Earl Easton, Yawar Faraz, Michael Layton, John Lusher, Jack Parrott, Andrew Persinko, Brian Smith, Mahendra Shah, and Michael Waters. 


\section{TABLE OF CONTENTS}

\section{VOLUME 1: MAIN REPORT}

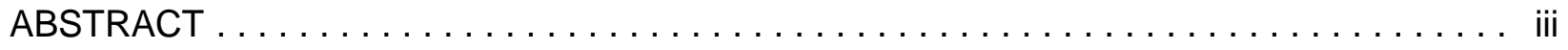

EXECUTIVE SUMMARY $\ldots \ldots \ldots \ldots \ldots \ldots \ldots \ldots \ldots \ldots \ldots \ldots$ iv

ACKNOWLEDGMENTS $\ldots \ldots \ldots \ldots \ldots \ldots \ldots \ldots \ldots \ldots \ldots \ldots \ldots \ldots \ldots \ldots \ldots$

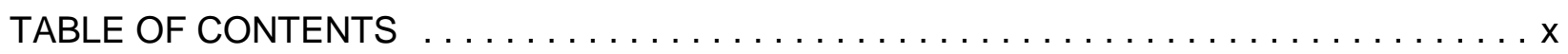

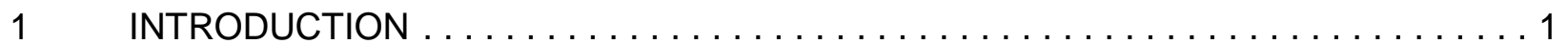

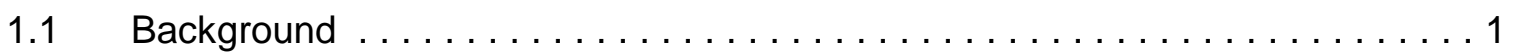

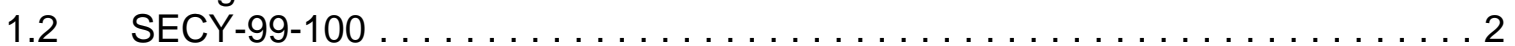

1.3 Staff Requirements Memorandum on SECY-99-100 $\ldots \ldots \ldots \ldots \ldots \ldots 2$

1.4 Draft Screening Criteria and the Case Study Plan $\ldots \ldots \ldots \ldots \ldots \ldots$

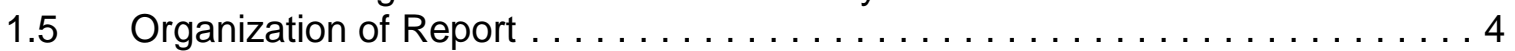

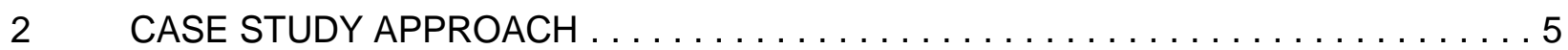

$2.1 \quad$ Capsule Summaries of Case Studies $\ldots \ldots \ldots \ldots \ldots \ldots \ldots \ldots \ldots \ldots$

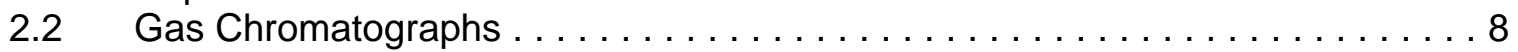

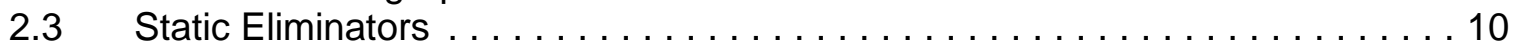

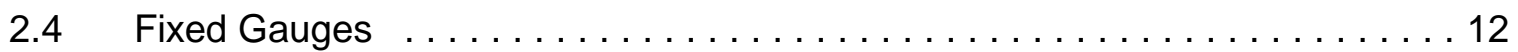

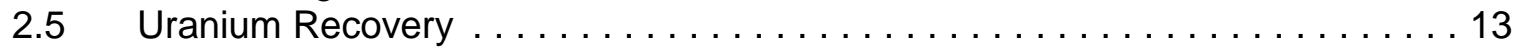

2.6 Paducah Gaseous Diffusion Plant Seismic Upgrades ................ 14

2.7 Trojan Nuclear Power Plant Decommissioning . . . . . . . . . . . . . . 15

2.8 Transportation of the Trojan Reactor Vessel Package . . . . . . . . . . . . 16

2.9 Seismic Exemption for the DOE/INEEL TMI-2 ISFSI $\ldots \ldots \ldots \ldots \ldots \ldots \ldots$

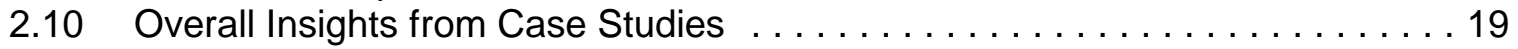

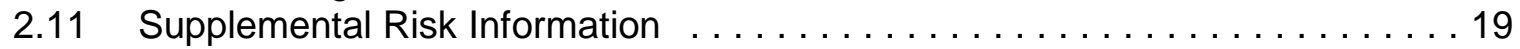

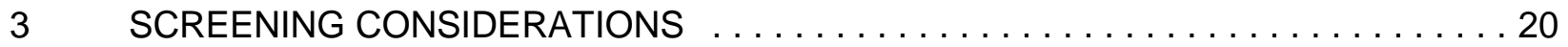

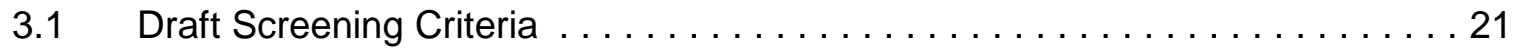

3.1.1 Screening Considerations Based on Performance Goals

in NRC Strategic Plan .......................... 21

3.1.2 Screening Considerations Based on Feasibility $\ldots \ldots \ldots \ldots \ldots 22$

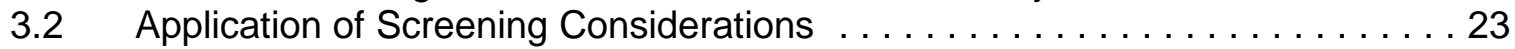

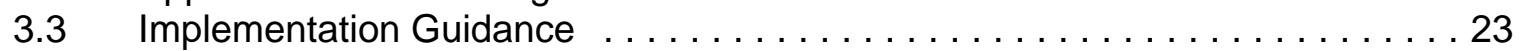

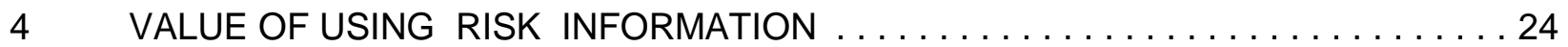

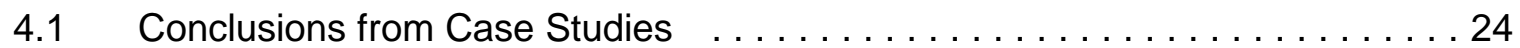

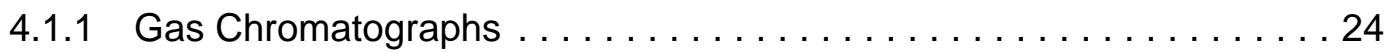

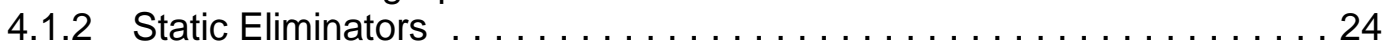

4.1 .3 Fixed Gauges . . . . . . . . . . . . . . . . . . . . 24

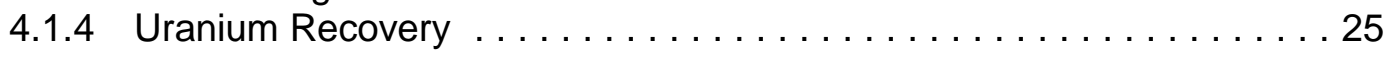




\section{TABLE OF CONTENTS (continued)}

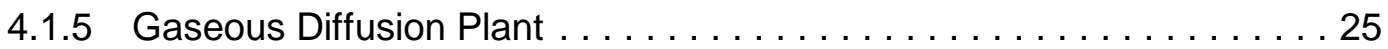

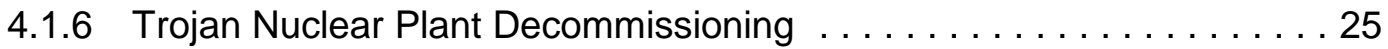

4.1.7 Transportation of the Trojan Reactor Vessel Package ........... 25

4.1.8 Seismic Exemption for the DOE/INEEL TMI-2 Fuel Debris ISFSI . . . . . 25

4.1.9 General Conclusions from Case Studies . . . . . . . . . . . . 26

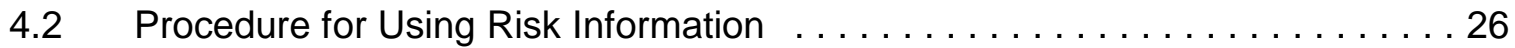

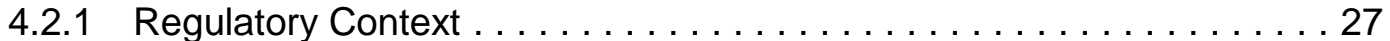

4.2.2 Recipients of Risk: The Exposed Population $\ldots \ldots \ldots \ldots \ldots \ldots 27$

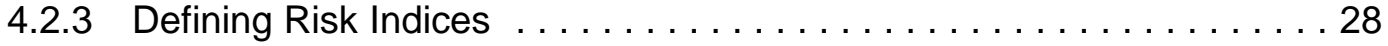

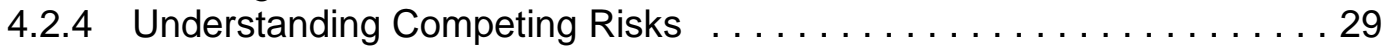

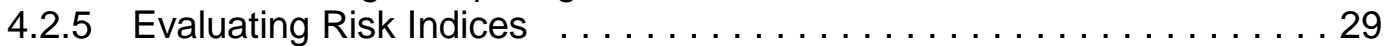

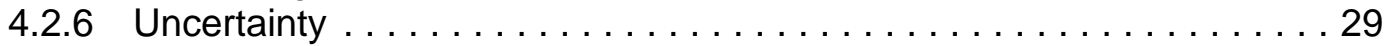

4.2.7 Insights from Risk Information $\ldots \ldots \ldots \ldots \ldots \ldots \ldots \ldots \ldots \ldots \ldots$

4.2.8 Information from Similar Situations $\ldots \ldots \ldots \ldots \ldots \ldots \ldots \ldots \ldots$

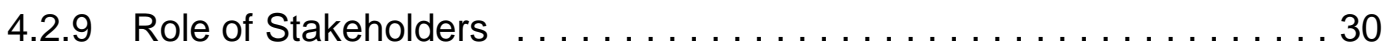

4.3 Activities to Realize Benefits of the Risk Informed Approach . . . . . . . . . 30

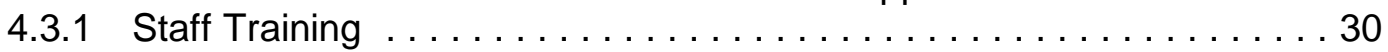

4.3.2 Risk-Informed Guidance on Rulemaking, Licensing, Inspection and Enforcement ........................ 30

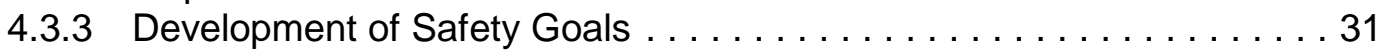

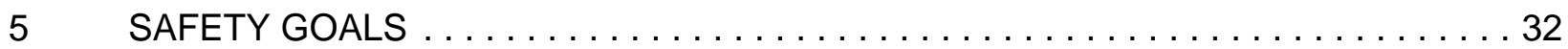

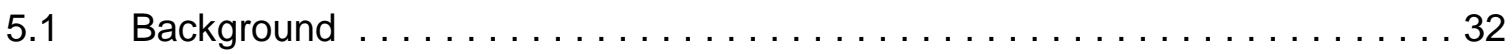

5.2 Implicit Safety Goals in the Case Studies and Related Documents ........ 33

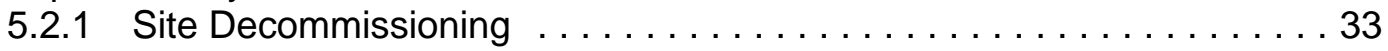

5.2.2 Transportation of Trojan Reactor Vessel Package . . . . . . . . . . 33

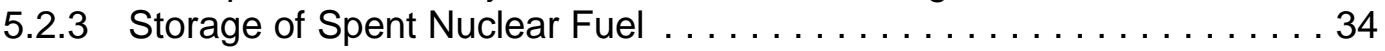

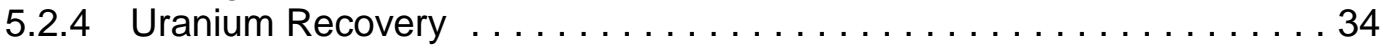

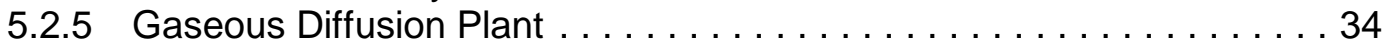

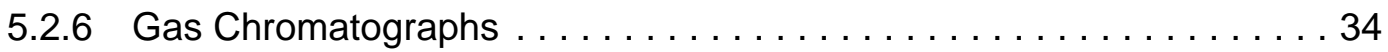

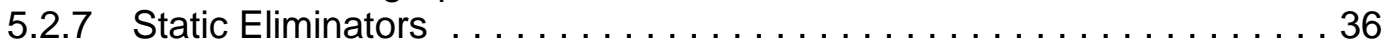

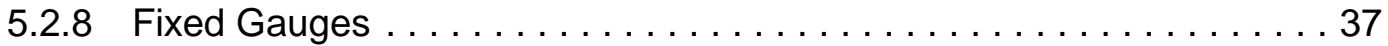

$5.3 \quad$ Feasibility of Developing Safety Goals $\ldots \ldots \ldots \ldots \ldots \ldots \ldots \ldots \ldots \ldots \ldots$

$5.4 \quad$ Approaches to Developing Safety Goals . . . . . . . . . . . . . . . . 38

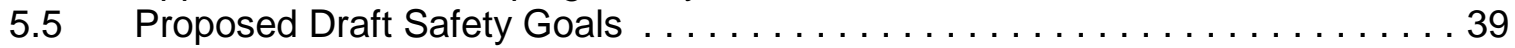

5.5 .1 Qualitative Safety Goals ........................ 39

5.5.2 Quantitative Objectives for Gauging Achievement of the Goals . . . 40

5.5 .3 Subsidiary Objectives ........................ 43

5.6 Responses to Case Study Questions on Safety Goals . . . . . . . . . . 47

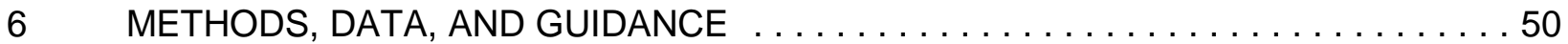

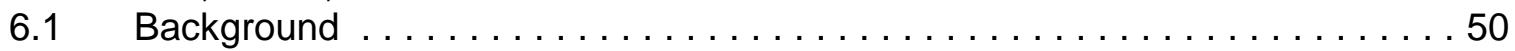

6.2 Outline of Risk Methodologies in the Materials and Waste Areas . . . . . . . 51

6.2.1 Performance Assessment . . . . . . . . . . . . . . . . . . . . 51

6.2 .2 Probabilistic Risk Assessment $\ldots \ldots \ldots \ldots \ldots \ldots \ldots \ldots \ldots \ldots \ldots 2$

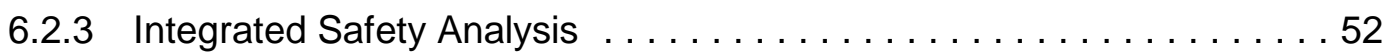

6.2 .4 Barrier/Hazard Method . . . . . . . . . . . . . . . . . . . . . . 52 


\section{TABLE OF CONTENTS (continued)}

6.3 Examples of the Use of Risk Methods $\ldots \ldots \ldots \ldots \ldots \ldots \ldots \ldots \ldots$

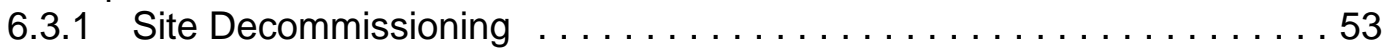

6.3.2 Byproduct Nuclear Material Risk Assessment . . . . . . . . . . 54

6.3.3 Focused/Screening Risk Assessments . . . . . . . . . . . . . . . 55

6.4 Preliminary Identification of Gaps in the Methods, Tools,

Data, and Guidance . . . . . . . . . . . . . . . . . . . . . 56

$7 \quad$ FINDINGS, CONCLUSIONS, AND FUTURE PLANS $\ldots \ldots \ldots \ldots \ldots \ldots \ldots \ldots$

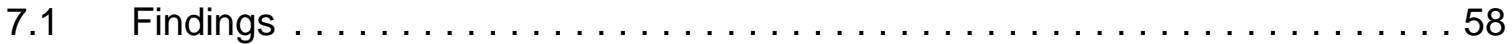

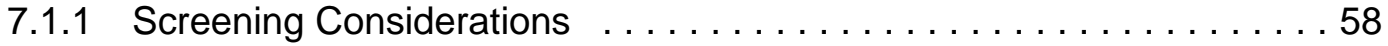

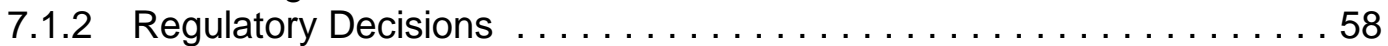

7.1 .3 Safety Goals . . . . . . . . . . . . . . . . . . . . . 59

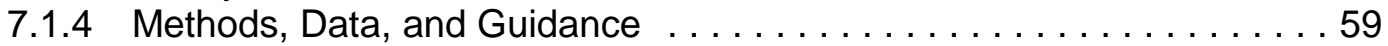

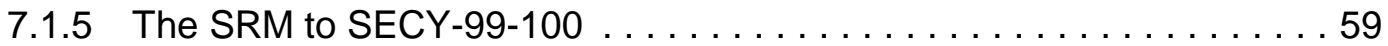

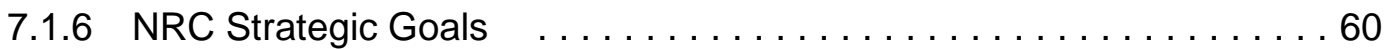

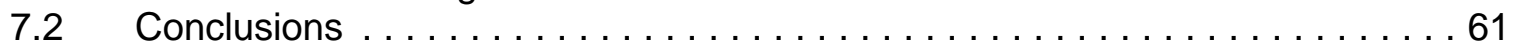

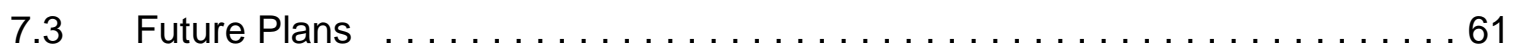

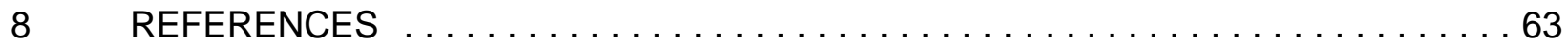

APPENDIX A: Related Risk Documents and Studies . . . . . . . . . . . . . A1

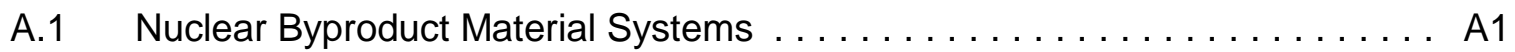

A.2 Spent Fuel Transportation . . . . . . . . . . . . . . . . . . A1

A.3 Dry Cask Storage Probabilistic Risk Assessment $\ldots \ldots \ldots \ldots \ldots \ldots \ldots \ldots$ A2

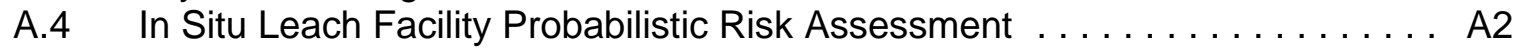

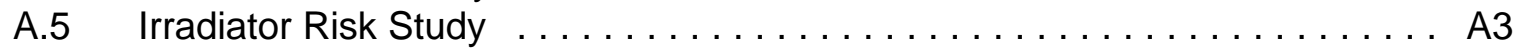

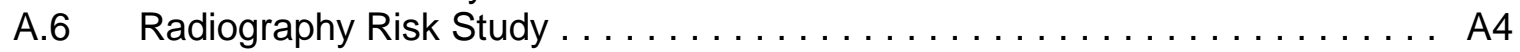

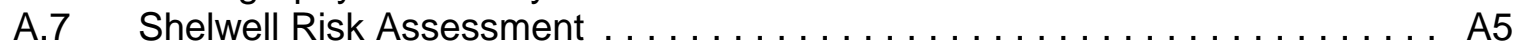

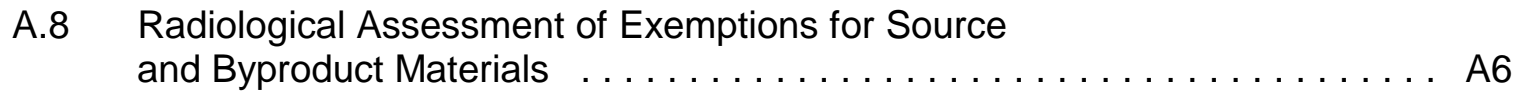

A.9 Risk Analysis of Fixed Nuclear Gauges . . . . . . . . . . . . . . A6

A.10 Risk Analysis in Regulating the Use of Radiation-Emitting

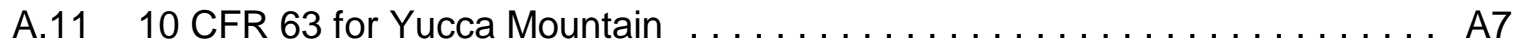

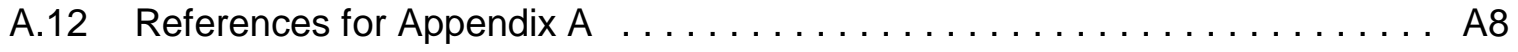

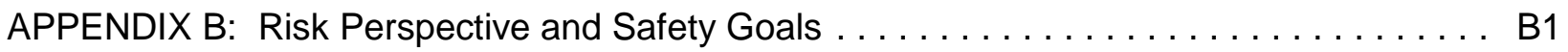

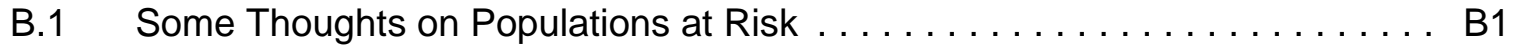

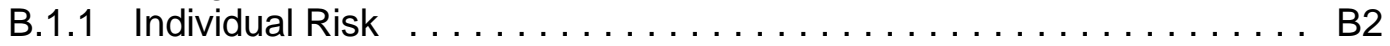

B.1.2 Collective Risk . . . . . . . . . . . . . . . . . . . B3

B.1.3 Safety Goals . . . . . . . . . . . . . . . . . . . . . B3

B.2 Risk Perspective in the Materials Use and Waste Areas . . . . . . . . . B3

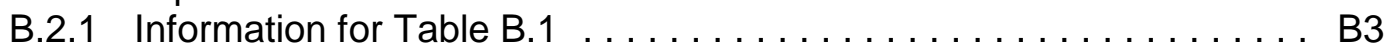

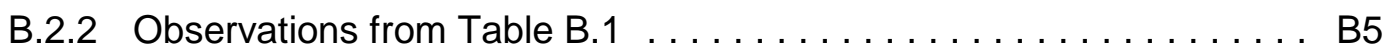

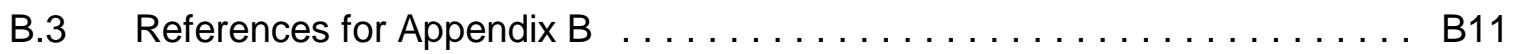




\section{TABLE OF CONTENTS (continued)}

\section{TABLES}

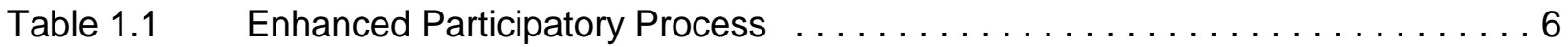

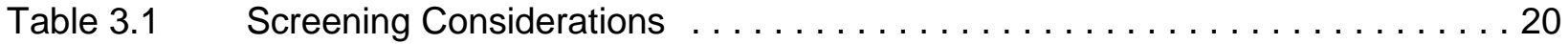

Table $5.1 \quad$ Three-Tier Safety Goal Structure . . . . . . . . . . . . . . . . . . . 44

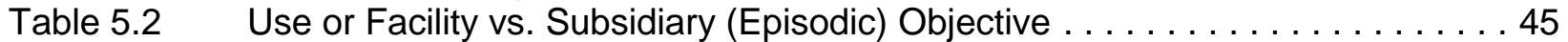

Table B.1 Preliminary Annual Risk Estimates - For Perspective . . . . . . . . . . B B7

\section{FIGURES}

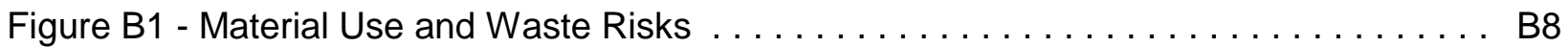

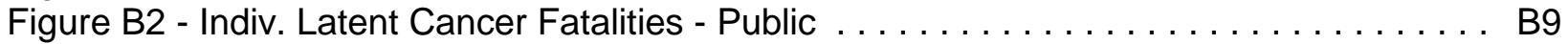

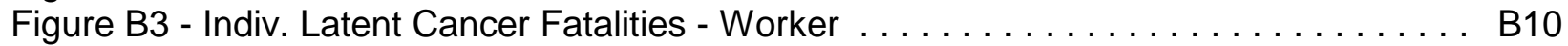

VOLUME 2: CASE STUDY PLAN AND EIGHT CASE STUDIES 
The objective of this report is to integrate the results of eight case studies that were performed by the Risk Task Group (RTG) of the Office of Nuclear Material Safety and Safeguards (NMSS) of the U.S. Nuclear Regulatory Commission (NRC). The purpose of the case studies was (1) to illustrate what has been done and what could be done in the materials and waste arenas to alter the regulatory approach in a risk-informed manner, and (2) to establish a framework for using a riskinformed approach in the materials and waste arenas by testing a set of draft screening criteria and determining the feasibility of safety goals. This report finalizes a set of screening considerations and begins the process of developing safety goals. The results of the eight case studies, along with related studies, show how risk information is valuable and beneficial to the regulatory process and inform the need for methods, data, and guidance in this area. Finally, this report provides a basis for beginning to identify materials and waste areas that are amenable to risk-informed regulation.

\title{
1.1 Background
}

The NRC policy on implementing risk-informed regulation was expressed in the 1995 Policy Statement [1] on the use of probabilistic risk assessment (PRA) methods in regulatory activities. This statement called for the increase in the use of PRA technology in all regulatory matters consistent with the state-of-the-art in PRA methods and data in a manner that complements the NRC's deterministic approach and supports the NRC's traditional defense-in-depth philosophy. The concept of "risk-informed" is the one advanced in the NRC White Paper on the subject [2]. For the convenience of the reader we excerpt some of the key elements of the NRC definition of "riskinformed" from Reference [2] and present them here.

\begin{abstract}
A "risk-informed" approach to regulatory decision-making represents a philosophy whereby risk insights are considered together with other factors to establish requirements that better focus licensee and regulatory attention on design and operational issues commensurate with their importance to public health and safety. Where appropriate, a risk-informed regulatory approach can also be used to reduce unnecessary conservatism in purely deterministic approaches, or can be used to identify areas with insufficient conservatism in deterministic analyses and provide the bases for additional requirements or regulatory actions. "Risk-informed" approaches lie between the "risk-based" and purely deterministic approaches. The details of the regulatory issue under consideration will determine where the risk-informed decision falls within the spectrum.
\end{abstract}

The Commission recognized that a single approach for incorporating risk analyses into the regulatory process would not be appropriate given the nature and consequences of the use of nuclear materials in reactors, industrial applications and waste disposal facilities. In SECY-98-138 [3], the staff presented a plan to develop a framework for increased use of risk-informed, performance-based approaches in NMSS regulation. This plan noted the differences between applying PRA methods to reactors and to the nuclear materials and waste program that regulates many different activities, devices, and systems. 


\subsection{SECY-99-100}

Further development of the framework for risk-informed regulation to NMSS activities was provided in SECY-99-100 [4] that addressed the commitments made by the staff in SECY-98-138. A fourpart framework was identified. The first part defines the areas in which risk assessment methods can play a role in the NRC decision-making process. The second part entails an evaluation of the current considerations underlying an application area, including codes and standards, regulatory limits, current risk considerations such as use of performance assessment in licensing the geologic repository, and institutional considerations such as Agreement State issues. The third part involves an evaluation of new risk considerations in support of the proposed regulatory action or decision, including the scope of the risk assessment, sensitivity and uncertainty analyses, and technical quality. The fourth part integrates current considerations and new risk considerations to ensure that the regulatory process is consistent and scrutable. To implement this framework, SECY-99100 identified a five-step plan for moving towards risk-informed regulation within NMSS as follows:

(1) Identify candidate regulatory applications that are amenable to expanded use of risk assessment and identify responsible staff organizations,

(2) Decide how to modify current approaches through interactions with stakeholders and staff,

(3) Change the current approach by making appropriate changes to the rules and regulations, staff review plans and regulatory guides,

(4) Implement a risk-informed approach including training of staff to assure consistent implementation of the risk-informed approaches, and

(5) Develop or adapt tools and techniques for risk analysis of NMSS activities including, as appropriate, risk assessment methods, computer codes, etc. The five steps are not meant to be strictly sequential. Some regulatory areas and applications are further along the path of risk-informing than others.

The first step of the five-step process identified in SECY-99-100 is accomplished by applying screening criteria to regulatory application areas within NMSS as a way of identifying candidate application areas. To be a candidate for risk-informing in NMSS, regulatory application areas must meet the screening criteria. Seven draft screening criteria (now identified as screening considerations, see Chapter 2 below) were published in a Federal Register Notice [5] and revised draft screening criteria were also published in a Federal Register Notice [6]. These criteria will be discussed in Chapter 3.

\subsection{Staff Requirements Memorandum on SECY-99-100}

In a Staff Requirements Memorandum (SRM) [7] approving the staff's proposal in SECY-99-100, the Commission stated that the staff should develop appropriate material safety goals analogous to the reactor safety goal, to guide the NRC and to define what safety means for the materials program. In addition, the Commission requested:

(1) that the staff should develop these goals through an enhanced participatory process including broad stakeholder participation, 
(2) that the NMSS framework should include as a goal the avoidance of property damage and the staff should develop appropriate metrics for it,

(3) that the staff consider whether critical groups can be defined for classes of material use, consistent with Commission decisions in the License Termination Rule (10 CFR Part 20) and on high-level waste disposal at Yucca Mountain (proposed 10 CFR Part 63),

(4) that the staff give due consideration to existing radiation protection standards in 10 CFR 20,

(5) that new standards should allow for equivalent levels of reasonable assurance of adequate protection across the spectrum of regulated materials activities and should be consistent with risk-informed practices being applied to nuclear power plant regulation.

Finally, the Commission noted that the Agreement States component must be factored into the foregoing for the materials program.

\subsection{Draft Screening Criteria and the Case Study Plan}

In response to the Commission's SRM, the staff held a public workshop [8 ] on April 25-26, 2000, in Washington, DC. The purpose of the first part of the April 2000 workshop was to solicit public comment on the draft screening criteria and their application. The goal of the second part of the workshop was to solicit public input on developing safety goals for nuclear materials and waste applications.

The consensus among participants at the workshop was that case studies of specific areas would be useful to test the screening criteria, to show how the application of a risk approach has or could affect a regulatory decision or process, and, if feasible, to develop safety goal parameters and a first draft of safety goals for each area. The purpose of the case studies was to illustrate and highlight, if possible, the explicit or implicit risk-informed nature of previous regulatory approaches or decisions in specific applications, and to establish a framework for using a risk-informed approach in different materials and waste arenas by testing the draft screening criteria and determining the feasibility of safety goals.

A second public meeting [9] was held on September 21, 2000 at the NRC headquarters to solicit public comment on a draft Case Study Plan for carrying out the case studies. A Federal Register Notice [6] (65 FR 54323, September 7, 2000) announced the meeting and included the draft plan. The draft plan contained the case study objectives, the draft screening criteria, the measures of success used to gauge the case studies, the case study outline, including the specific areas and applications that would be evaluated in the case studies, and the structure of each case study. The final Case Study Plan was issued on October 27, 2000 [10 ].

Four broad objectives were identified for the case studies:

(1) Test the draft screening criteria and produce a final set of screening criteria.

(2) Gain insights into risk-informing NMSS regulatory processes by illustrating how the application of risk information has improved or could improve a particular area of the NMSS regulatory process. 
(3) Determine the feasibility of safety goals in a particular area; if feasible, develop safety goal metrics and a first draft of the goals, otherwise, document the reasons for infeasibility,

(4) Identify the gaps in the tools, methods, data, and guidance that are required to risk-inform NMSS.

The measure of success would be to evaluate how well the case studies met these objectives. The case studies were not intended to reopen or reassess any previous decisions made by the Commission, but rather to elicit information that may or could impact future decisions by the staff and the Commission.

\subsection{Organization of Report}

Chapter 2 of this report provides a chronology of public meetings, site visits, interviews, and key events related to the eight case studies. Chapter 2 also describes the approach taken in conducting the case studies as defined in the Case Study Plan [10 ]. Chapters 3-6 describe how each of the four broad objectives, presented above, have been met by the case study program. Specifically, Chapter 3 discusses the screening criteria and how they were finalized as screening considerations, Chapter 4 discusses how risk information has and could be valuable in the regulatory process, Chapter 5 discusses the feasibility of developing safety goals and makes an initial step in that direction, and Chapter 6 identifies current and future methods, data, and guidance needs for risk-informing the materials use and waste arenas. Chapter 7 presents findings and conclusions and discusses future plans. Appendix A contains discussion of other risk studies and documents that pertain to this case study program and were integrated into the report where applicable. Finally, Appendix B provides supporting information on safety goals and a risk perspective for the materials use and waste arenas.

The eight case studies are contained in Volume 2 of this report and these contain extensive (181) references that were used in the course of performing the case studies. 


\section{CASE STUDY APPROACH}

The objectives of the case studies were to (1) Test the draft screening criteria and produce a final set of screening criteria, (2) Gain insights into risk-informing NMSS regulatory processes by illustrating how the application of risk information has improved or could improve a particular area of the NMSS regulatory process, and (3) Determine the feasibility of safety goals in a particular area; if feasible, develop safety goal metrics and a first draft of the goals, otherwise, document the reasons for infeasibility, and (4) identify the gaps in the tools, methods, data, and guidance that are required to risk-inform NMSS.

Eight case study areas were identified as follows:

- Regulation of Fixed Gauges

- Regulation of Static Eliminators

- Regulation of Gas Chromatographs

- $\quad$ Site Decommissioning of the Trojan Nuclear Power Plant (TNPP)

- Transportation of the Trojan Reactor Vessel Package (TRVP)

- Uranium Recovery

- Seismic Exemption for Dry Cask Storage of TMI-2 fuel at DOE/ldaho National Engineering and Environmental Laboratory

- Paducah Gaseous Diffusion Plant Seismic Upgrade

The case studies began in November 2000. Five case studies, transportation of the TRVP, gas chromatographs, static eliminators, fixed gauges, and dry cask storage were carried out by NMSS staff. Studies of the TNPP site decommissioning, uranium recovery, and Paducah gaseous diffusion plant seismic upgrade were carried out by Brookhaven National Laboratory in collaboration with the NRC staff. Several meetings [11 - 15] were held to inform stakeholders and the public, more generally, about the progress of the individual case studies and solicit input on the preliminary results. Also, the NRC historian and other individuals (NRC and non-NRC) were interviewed for perspectives and insights on the materials and waste regulatory history, safety goal development, radiation protection standards, and public confidence and risk communications. Table 1 provides a chronology and summary of all the interview and public meetings held on the case studies. 
Table 1.1: Enhanced Participatory Process

\begin{tabular}{|c|c|c|c|}
\hline Date/Location & Objective & Participation (approx.) & Outcome/Comments \\
\hline $\begin{array}{l}\text { April 25-26, } 2000 \\
\text { Washington, DC }\end{array}$ & $\begin{array}{l}\text { Solicit comment on draft } \\
\text { screening criteria and } \\
\text { application }\end{array}$ & $\begin{array}{l}30 \text { Persons from NRC } \\
\text { staff, industry, Agreement } \\
\text { States, public, DOE }\end{array}$ & $\begin{array}{l}\text { - Case study approach } \\
\text { needed } \\
\text { - Develop parameters for } \\
\text { screening criteria and } \\
\text { safety goals }\end{array}$ \\
\hline $\begin{array}{l}\text { September 21, } 2000 \\
\text { Rockville, MD }\end{array}$ & $\begin{array}{l}\text { Solicit comment on draft } \\
\text { case study plan and } \\
\text { objectives }\end{array}$ & $\begin{array}{l}20 \text { Persons from NRC } \\
\text { staff, industry, Agreement } \\
\text { States, public, DOE }\end{array}$ & $\begin{array}{l}\text { - Develop success } \\
\text { measures } \\
\text { - Evaluate case studies } \\
\text { against objectives }\end{array}$ \\
\hline $\begin{array}{l}\text { December 21, } 2000 \\
\text { Rockville, MD }\end{array}$ & $\begin{array}{l}\text { Meeting with Dr. David } \\
\text { Kocher on EPA-NRC risk } \\
\text { harmonization }\end{array}$ & NMSS staff & $\begin{array}{l}\text { Recognize that NRC and } \\
\text { EPA have different } \\
\text { approaches to regulating } \\
\text { radiation protection, but in } \\
\text { practicality, both are } \\
\text { regulating to about the } \\
\text { same level of risk }\end{array}$ \\
\hline $\begin{array}{l}\text { January 9, } 2001 \\
\text { Rockville, MD }\end{array}$ & $\begin{array}{l}\text { Interview Sam Walker, } \\
\text { NRC Historian, for a } \\
\text { historical perspective on } \\
\text { risk-informed regulation in } \\
\text { NRC }\end{array}$ & RTG and IMNS staff & $\begin{array}{l}\text { - NRR experience in } \\
\text { developing safety goal may } \\
\text { provide useful lessons } \\
\text { - Keep stakeholders } \\
\text { informed }\end{array}$ \\
\hline $\begin{array}{l}\text { January 16, } 2001 \\
\text { Rockville, MD }\end{array}$ & $\begin{array}{l}\text { Interview representative } \\
\text { from Union of Concerned } \\
\text { Scientist, to gain public } \\
\text { perspective on risk- } \\
\text { informed regulation in NRC }\end{array}$ & RTG staff & $\begin{array}{l}\text { - NRC can do better with } \\
\text { regulating nuclear safety } \\
\text { and public communications } \\
\text { and participation } \\
\text { - Uncertainty is a concern } \\
\text { with risk-informed } \\
\text { regulation } \\
\text { - Public acceptance of risk- } \\
\text { informed regulation will be } \\
\text { difficult to achieve }\end{array}$ \\
\hline $\begin{array}{l}\text { January 17, } 2001 \\
\text { Bethesda, MD }\end{array}$ & $\begin{array}{l}\text { Interview Dr. Charles } \\
\text { Meinhold, NCRP, for } \\
\text { perspectives on risk from } \\
\text { radiation }\end{array}$ & RTG staff & $\begin{array}{l}\text { Safety goal to establish a } \\
\text { de minimus dose }\end{array}$ \\
\hline $\begin{array}{l}\text { February 9, } 2001 \\
\text { Rockville, MD }\end{array}$ & $\begin{array}{l}\text { Provide information and } \\
\text { obtain input on case } \\
\text { studies of } \\
\text { - Gas chromatographs } \\
\text { - Static eliminators } \\
\text { - Fixed gauges }\end{array}$ & $\begin{array}{l}25 \text { Persons from NRC } \\
\text { staff, industry, Agreement } \\
\text { States, public, DOE }\end{array}$ & $\begin{array}{l}\text { Need for more interactions } \\
\text { with stakeholders }\end{array}$ \\
\hline $\begin{array}{l}\text { March 13, } 2001 \\
\text { Rockville, MD }\end{array}$ & $\begin{array}{l}\text { Interview Joseph Murphy } \\
\text { for perspectives on reactor } \\
\text { safety goal development } \\
\text { and application }\end{array}$ & RTG staff & $\begin{array}{l}\text { Background information on } \\
\text { how reactor safety goals } \\
\text { were developed and how } \\
\text { they are used; applicability } \\
\text { of reactor safety goals to } \\
\text { materials and waste } \\
\text { arenas }\end{array}$ \\
\hline
\end{tabular}


Table 1.1: Enhanced Participatory Process

\begin{tabular}{|c|c|c|c|}
\hline Date/Location & Objective & Participation (approx.) & Outcome/Comments \\
\hline $\begin{array}{l}\text { May 11, } 2001 \\
\text { Rockville, MD }\end{array}$ & $\begin{array}{l}\text { Provide information and } \\
\text { obtain input on case } \\
\text { studies of } \\
\text { - Trojan reactor vessel } \\
\text { package shipment } \\
\text { - Trojan decommissioning } \\
\text { and License Termination } \\
\text { Plan }\end{array}$ & $\begin{array}{l}25 \text { Persons from NRC } \\
\text { staff, industry, Agreement } \\
\text { States, public, DOE }\end{array}$ & $\begin{array}{l}\text { Risk trade-offs: impact of } \\
\text { remediation on land }\end{array}$ \\
\hline $\begin{array}{l}\text { May } 23-24,2001 \\
\text { Rockville, MD }\end{array}$ & $\begin{array}{l}\text { Consultations with Dr. } \\
\text { Peter Sandman on risk } \\
\text { communications }\end{array}$ & NRC staff & $\begin{array}{l}\text { Risk includes both hazard } \\
\text { and outrage; to decrease } \\
\text { public concern about small } \\
\text { hazards, work to diminish } \\
\text { outrage }\end{array}$ \\
\hline $\begin{array}{l}\text { June } 13,2001 \\
\text { Denver, CO }\end{array}$ & $\begin{array}{l}\text { Provide information and } \\
\text { obtain input on case study } \\
\text { of } \\
\text { - Uranium recovery }\end{array}$ & $\begin{array}{l}50 \text { Persons (including } \\
\text { some attending the NRC/ } \\
\text { National Mining } \\
\text { Association Workshop, } \\
\text { held at same location, } \\
6 / 13-14 / 01 \text { ) }\end{array}$ & $\begin{array}{l}\text { Value of risk-informed } \\
\text { approaches for a } \\
\text { financially-strained industry }\end{array}$ \\
\hline $\begin{array}{l}\text { July } 31,2001 \\
\text { Rockville, MD }\end{array}$ & $\begin{array}{l}\text { Provide information and } \\
\text { obtain input on case } \\
\text { studies of } \\
\text { - Paducah GDP seismic } \\
\text { upgrade } \\
\text { - Seismic exemption TMI-2 } \\
\text { ISFSI at DOE/INEEL }\end{array}$ & $\begin{array}{l}35 \text { persons including NRC } \\
\text { staff, DOE, industry, and } \\
\text { public interest groups }\end{array}$ & $\begin{array}{l}\text { Discussion of benefits of } \\
\text { doing risk assessments for } \\
\text { specialized facilities }\end{array}$ \\
\hline $\begin{array}{l}\text { September 10, } 2001 \\
\text { Washington, DC }\end{array}$ & $\begin{array}{l}\text { Interview with } \\
\text { representatives from NIRS } \\
\text { and Public Citizen }\end{array}$ & RTG and IMNS staff & $\begin{array}{l}\text { - Concern that risk- } \\
\text { informed regulation means } \\
\text { unclear and, therefore, } \\
\text { unenforceable regulations } \\
\text { - Lack of public confidence } \\
\text { in NRC }\end{array}$ \\
\hline $\begin{array}{l}\text { October 25, } 2001 \\
\text { Rockville, MD }\end{array}$ & $\begin{array}{l}\text { Provide information and } \\
\text { obtain input on } \\
\text { - Integration of case } \\
\text { studies } \\
\text { - Screening considerations } \\
\text { - Development of Safety } \\
\text { Goals } \\
\text { - Future plans }\end{array}$ & $\begin{array}{l}35 \text { persons including NRC } \\
\text { staff, DOE, industry, and } \\
\text { public interest groups }\end{array}$ & $\begin{array}{l}\text { General agreement by } \\
\text { participants to develop } \\
\text { safety goals }\end{array}$ \\
\hline
\end{tabular}

In conducting the case studies, several site visits were made to elicit information from the licensees and relevant stakeholders. These visits included:

(1) A two-day visit by an NRC-BNL team to the Trojan nuclear power plant in Rainier, Oregon. The team held discussions with the licensee's staff and with the State of Oregon regulator on the decommissioning of the plant and the shipment of the Trojan Reactor Vessel Package. A walk-down of the facility was also conducted. 
(2) A visit by NRC-BNL team to the Gaseous Diffusion Plant in Paducah, Kentucky.

(3) Visits by a NRC-BNL team to the White Mesa conventional uranium mill in Utah and to the Smith Ranch in-situ leaching facility in Wyoming to review uranium recovery operations.

(4) A visit to the Phillip Morris facility in Richmond, Virginia, to gain insights on how fixed gauges are used in industry.

(5) A visit to DOE's INEEL facility, in Idaho Falls, Idaho, to gain insights on the storage of the dry case storage of the TMI-2 fuel debris, the licensing process for the dry cask storage facility, and the associated seismic exemption. NRC staff also met with local reporters during the visit to gain insights on the public's attitude toward the TMI-2 fuel debris storage facility and associated fuel shipments.

The case studies were not meant to reconsider any of the regulatory actions that the NRC took in the case being studied. They were a retrospective look at a spectrum of activities or actions made in the materials use and waste arenas to achieve the objectives stated above.

The case studies were carried out using a standardized approach, described in the "Plan for Using Risk Information in the Materials and Waste Arenas"[16]. Each case has been studied by a member of the NMSS Risk Task Group or a contractor with risk expertise. Advisors include subject matter experts from the NRC staff who have knowledge of the particular case. The reviewers also consulted with licensees, experts in risk assessment, and other stakeholders having knowledge or interest in the areas studied.

The basis for each case study has been the review of information from NRC and licensee source documentation, through which the staff answered a standardized list of questions that address aspects of the four objectives listed above. After the investigative phase of the study, the NMSS staff generated a set of preliminary conclusions on the basis of the answers to these questions. The staff then presented its preliminary conclusions at a public workshops in which all stakeholders were invited to participate. After incorporating information and ideas that emerged from these meeting, the NMSS staff produced a report for each case study.

\subsection{Capsule Summaries of Case Studies}

Brief summaries of each of the eight case studies are presented below. Each case study summary identifies the reason why the topic was selected and a brief assessment of how it relates to the four objectives identified above.

\subsection{Gas Chromatographs}

Gas chromatographs are used to separate a gas mixture in order to identify its components and their concentrations. These devices are employed in industrial and laboratory settings to detect small quantities of organic compounds ( 1 part in $10^{14}$ to $10^{16}$ ). Modified versions of this device known as Chemical Agent Monitors are used by the military to detect poisonous chemical gases in the field. Portable versions are being developed to assist forensic investigators determine time and cause of death. Electron capture detectors are employed to enhance sensitivity in the analysis of molecules in the effluent stream. The electrons are provided by low-energy beta decay sources 
such as tritium or Ni-63. Typical material activity levels in the devices are $300 \mathrm{mCi}$ of $\mathrm{H}-3$ and 20 $\mathrm{mCi}$ of $\mathrm{Ni}-63$.

Gas Chromatographs are regulated by NRC under the requirements specified in 10 CFR Part 20, "Standards for Protection Against Radiation," 10 CFR Part 30, "Rules of General Applicability to Domestic Licensing of Byproduct Material," 10 CFR Part 31, "General Domestic Licenses for Byproduct Material," and 10 CFR Part 32, "Specific Domestic Licenses to Manufacture or Transfer Certain Items Containing Byproduct Material." They are used under a general license granted under Part 31.5 or a specific license under Part 30. The general license includes requirements for leak testing and proper storage and disposition of the device and the licensee is also subject to Parts 20.2201 and 2202 for reporting theft or loss of licensed material. Specific license holders are required to follow the regulations in Parts 19, 20, and 21, submit to periodic inspections, employ a radiation safety officer, provide training in radiation safety if workers are likely to receive an annual dose exceeding 100 mrem, and implement a radiation safety program.

Manufacturers of generally licensed chromatographs have to comply with the design criteria of Part 32.51. For generally licensed devices the basic design requirements in addition to those of specifically licensed devices are: the device can be safely operated by persons without radiation protection training, under routine operation the radioactive material will not be released and it is unlikely that any person will receive an annual dose in excess of the limits in 20.1201(a), and that under accident conditions (e.g., fire or explosion) it is unlikely that any person would receive a dose $>15$ rem whole body, $>200$ rem to the hands or feet, or $>50$ rem to any other organ. Specifically licensed devices have to meet the requirements of Part 32.210.

The risks associated with use of gas chromatographs under normal operations are very small. One risk study calculated a maximum dose of 12 mrem under accident conditions for several low probability accidents. A worst case consequence from highly unlikely events was estimated in another study to be 200 mrem to users of $\mathrm{H}-3$ devices and 300 mrem to users of Ni-63 sources.

\section{Reason for Choosing this Topic as a Case Study}

The line between general licenses and specific licenses for almost identical devices is unclear. The case study could illustrate how the application of risk information could improve a particular area of the regulatory process.

\section{Relation to Study Objectives}

The case study showed that a risk-informed approach would maintain safety, reduce burden commensurate with risk presented by the devices, potentially eliminate unnecessary inspections, and improve NRC's regulatory efficiency. Thus the screening considerations appear useful in deciding whether to use risk information in regulatory activities. However, questions related to public acceptance of the use of risk information can only be guessed a priori although, in principle, a risk-informed approach could allow a better understanding of decisions regarding licensing of gas chromatographs.

There are implicit safety goals for exempt distribution products within the approval policy for consumer products. The table of exposure limits in Part 32.28 and the accompanying footnote that provides guidance on the meaning of a "low probability" of exposure and a "negligible probability" 
of exposure is a potential safety goal. Other implicit safety goals are given by the normal occupational and public dose limits in 10 CFR Part 20. Possible accident doses in extremely unlikely circumstances must meet the applicable safety criteria in 10 CFR 32.23, 32.24, 32.26, \& 32.27 .

Sufficient studies of gas chromatographs have been performed to determine the possible consequences and their likelihoods to make a technical decision as to whether regulatory oversight of these devices could be reduced commensurate with their low level of risk.

\subsection{Static Eliminators}

Static eliminators are devices that contain a sealed source of radioactive material for the purpose of reducing electric charge buildup on equipment and materials. The radiation from the radioactive source produces ions in air, which neutralize the static charges in their vicinity. As a consumer product, static eliminators may be used to reduce static charges on photographic film and lenses, and the static charges that can hinder the delicate operation of precision balances. Commercial applications for static eliminators include the following: (1) to reduce the risk of fire or explosion due to static charge buildup and discharge in volatile and explosive environments (e.g., paint shops), (2) to reduce the buildup of static charges that can damage electronic circuits and hard drives during assembly and repair of personal computers, (3) to reduce the buildup of dust on surfaces to be electroplated or painted, and (4) to reduce the static cling of processed material on sheet-fed webs and rollers (e.g., print shops).

Consumer and commercial use of static eliminators is regulated under by NRC under the requirements specified in 10 CFR Part 20, "Standards for Protection Against Radiation," 10 CFR Part 30, "Rules of General Applicability to Domestic Licensing of Byproduct Material," and 10 CFR Part 31, "General Domestic Licenses for Byproduct Material." Manufacture and transfer is regulated under Part 32 "Specific Domestic Licenses to Manufacture or Transfer Certain Items Containing Byproduct Material." Static eliminators used for consumer and commercial applications under a Part 31.3 general license contain a sealed source with a maximum of $500 \mu \mathrm{Ci}$ of Po-210. Devices licensed under this regulation are not subject to any explicit requirements for design, testing, installation, or maintenance, however, the sealed source is specifically licensed and subject to safety evaluation and registration requirements. Devices used under a Part 31.5 general license are subject to requirements for labeling, leak testing, record keeping, maintenance, failure reporting, abandonment, transfer, and disposal.

Manufacture of static eliminators requires a specific license under Parts 30 and 32, in particular, 32.51 and 32.52. Part 32.51 requires an applicant to submit information related to the design, testing, and hazards posed by the device that must meet the following criteria: the device can be safely operated by persons without radiation protection training, under routine operation the radioactive material will not be released and it is unlikely that any person will receive an annual dose in excess of the limits in 20.1201(a), and that under accident conditions (e.g., fire or explosion) it is unlikely that any person would receive a dose $>15 \mathrm{rem}$ whole body, $>200 \mathrm{rem}$ to the hands or feet, or $>50$ rem to any other organ.

The case study indicates that under the sealed source and device registry maintained by the NRC there are eight certificates, seven that use Po-210 as the radiation source and one that uses $\mathrm{Kr}-85$, for static eliminator devices intended for use under a general license. The activity of Po-210 in 
these devices ranges from $5 \mathrm{mCi}$ to $324 \mathrm{mCi}$. The $\mathrm{Kr}-85$ source ranges from 1 to $10 \mathrm{mCi}$. There are, in addition, three certificates for static eliminators that may only be used under a specific license. These employ Am-241 sources and the activity ranges from $0.4 \mu \mathrm{Ci}$ per linear inch to 8.35 $\mathrm{mCi}$ per linear inch depending on the application.

The risks of static eliminator devices are generally low, but studies have been carried out only for the Po-210 sources. Under routine operations, the risks are only to those who come in close contact, i.e., users or workers in commercial applications and the persons involved with transporting devices. In accidents, other personnel such as firefighters could be exposed. In cases of loss or theft, the general public could be at risk of exposure.

\section{Reason for Choosing this Topic as a Case Study}

The line between general licenses and specific licenses, for almost identical devices, appeared inconsistent. This case evaluates the regulatory framework underlying the general and specific licenses with regard to risk.

\section{Relation to Study Objectives}

The first four draft screening considerations are adequate to demonstrate that increasing the use of risk information in the regulation of static eliminators would support one or more of the Agency's four strategic and performance goals in the Materials Safety Arena. Of the remaining three draft screening considerations, the case study suggests that risk-informing static eliminator regulation would be technically feasible as there are a number of existing risk studies in the area that provide technical information. While risk information has the potential to reduce burden and increase staff efficiency in making regulatory decisions the extent to which there would be a net benefit remains undetermined. The case study indicated that the risks associated with individual models of static eliminators are evaluated on a case-by-case basis. There may be a potential for increasing the efficiency of the regulatory process by making more general regulatory decisions based on isotope and activity, or sealed source and device design. Also, the regulation under 10 CFR 31.3 may be better integrated with the static eliminator regulation under 10 CFR 31.5.

Risk insights may be used to make the regulation of static eliminators more consistent with other generally licensed, specifically licensed, and exempt devices, from a risk perspective, thus increasing regulatory effectiveness and efficiency and reducing unnecessary regulatory burden, while maintaining health and safety. The isotope and activity should be limited to meet the occupational dose criteria in 10 CFR Part 20.

The sealed source design should ensure complete containment of the byproduct material (i.e., zero release) under normal conditions of operation and use. The static eliminator design should prevent direct physical contact with the sealed source within the device. Administrative requirements should ensure complete accountability and control of the static eliminators.

Several early studies of risks associated with static eliminators were based on a sealed source design (i.e., micro spheres) that is no longer being used; however, the more recent studies are based on the current sealed source design, which is a laminated foil. The recent risk studies consider only polonium-210 as a source; however, other isotopes are being used as the source in generally licensed and specifically licensed static eliminators. Each static eliminator design that 
is specifically licensed, or generally licensed under 10 CFR Part 31.5, undergoes an independent safety evaluation by the responsible regulatory agency prior to approval for distribution. Current information regarding the distribution of static eliminators, such as the quantity of each type of device distributed per year, should be compiled to support risk estimates.

\section{$2.4 \quad$ Fixed Gauges}

Fixed gauges are instruments containing radioactive materials such as gamma-emitters or betaemitters that are most often used as a way of monitoring a production process or insuring quality control. These devices are used in all types of processing environments, including harsh or hazardous environments. The types of fixed gauges regulated by NRC are primarily thickness gauges, density gauges, level gauges, insertion gauges, and volumetric flow gauges that contain gamma or beta radiation sources. The most common radioactive materials used in fixed gamma gauges are cobalt-60, cesium-137, and americium-241. In fixed beta gauges, the most commonly used radioactive materials are krypton-85, strontium-90, promethium-147, and thallium-204.

Use of fixed gauges is regulated by NRC under the requirements specified in 10 CFR Part 20, "Standards for Protection Against Radiation," 10 CFR Part 30, "Rules of General Applicability to Domestic Licensing of Byproduct Material," 10 CFR Part 31, "General Domestic Licenses for Byproduct Material," and 10 CFR Part 32, "Specific Domestic Licenses to Manufacture or Transfer Certain Items Containing Byproduct Material." Fixed gauges can be used under a general license or under a specific license, depending, in part, on whether the device meets certain manufacturing and dose criteria in 10 CFR 32.51. Thus similar devices can be controlled under different regulatory schemes. General licensees who use fixed gauges are subject to Part 31.5 "Certain Measuring, Gauging, or Controlling Devices" and are required to appoint a responsible individual and register their device if they contain the following minimum amounts of material: $10 \mathrm{mCi}$ of Cs137, $1 \mathrm{mCi}$ Co-60, Am-241 or other transuranics, $0.1 \mathrm{mCi}$ Sr-90. Licensees are also required to comply with Part 20.2201 and 2202 for reporting radiation incidents and any theft or loss of licensed material. Specific licensed gauge users are required to obtain a license under Part 30 and to follow the regulations of Parts 19, 20 and 21, employ a radiation safety officer, and provide training in safety if workers are likely to receive doses exceeding 100 mrem annually, among other requirements.

Manufacturers of generally licensed gauges are subject to the design and dose requirements of Part 32.51 that could expose users with no training in radiological protection to $10 \%$ of the annual limits to workers under routine conditions. The current public dose limit is $2 \%$ of the worker limit but Part 32.51 has not been updated as yet. Specific licensed devices are required to meet Part 32.210. Both types of gauges must undergo a sealed source and device review before they are approved to be distributed to general or specific licensees. Design requirements for devices that are approved for distribution to a general licensee are: the device can be safely operated by persons without radiation protection training, under routine operation the radioactive material will not be released and it is unlikely that any person will receive an annual dose in excess of the limits in 20.1201(a), and that under accident conditions (e.g., fire or explosion) it is unlikely that any person would receive a dose $>15$ rem whole body, $>200$ rem to the hands or feet, or $>50$ rem to any other organ.

The risks associated with fixed gauges include: routine and accident doses to workers, and public exposures from gauges that have been lost, stolen, or improperly disposed. Contamination of 
metals processing facilities and disposal of radioactive waste during cleanup is another risk. Incidents and events of contamination and exposure from loss or improper disposal have occurred in the past.

\section{Reason for Choosing this Topic as a Case Study}

The regulatory criteria for classifying general versus specific licenses are not based on risk. The case study could illustrate how the application of risk information could improve a particular area of the regulatory process; also, this could be a test case for a safety goal on property damage.

\section{Relation to Study Objectives}

The screening considerations indicated a path to follow when attempting to make a decision about whether risk-informing the regulation of fixed gauges is feasible and/or desirable. They also appeared to contain all the relevant considerations for making decisions as to whether to pursue risk-informing a proposed regulatory action. Application guidance will be an important tool for the staff to use when applying the screening considerations to future decisions.

The case study demonstrated that using risk information can provide burden reduction and improve efficiency in decision making. It also pointed out that increased regulatory oversight may be warranted in some cases. Using risk information could benefit NRC, licensees, and the public by providing for more regulatory controls on devices which are more likely to cause harm. The approach would allow resources to be focused in proportion to the risk a device presents. Staff would be given the tools needed to make a clear safety argument for their licensing and inspection decisions, and efficiency and effectiveness would be improved by reducing the review time necessary for special cases in licensing and device approvals.

Safety goals for fixed gauges would be beneficial. They would enable the staff to make licensing and inspection decisions which are more consistent and defensible. There appears to be no reason why safety goals could not be developed for occupational and accident risks. Previous risk-informed staff decisions pertaining to approval of generally licensed devices, as well as staff decisions regarding clean up of sites contaminated by breaches of sealed sources, provide reference points for safety goals on accident risks. If safety goals had existed then, both licensees and staff would have benefitted from a reduction in the time needed to make a decision and an enhancement in the defensibility of the decision.

Several risk studies have been done for fixed gauges, and other similar devices, which use sealed sources of radioactivity. Compilation and comparison of these studies should result in a useable source of information to risk-inform the regulation of fixed gauges. Inferences may need to be made for the risk-informed regulation of fixed gauges from risk studies for other similar devices.

\subsection{Uranium Recovery}

The uranium recovery process primarily consists of the milling and disposal aspects of uranium recovery after the uranium ore is removed from the ground. In a conventional mine, either deep mining or shallow open pit, the rock containing the uranium ore is removed and processed at a uranium mill, where an extraction process concentrates the uranium into yellow cake. Uranium can also be leached out of the ground by pumping a water solution through wells to dissolve the 
uranium in the ore. The uranium is then pumped to the surface in a liquid solution, and then processed. Waste from milling operations are disposed of in a tailings pile. Mill tailings are fine-grained sand-like waste materials left over from uranium processing. Wastes from in-situ leach (ISL) facilities may be disposed of in several ways, including release to surface water, evaporated from lined ponds, onsite applications (irrigation) or returned to the aquifers via deep well injection.

The NRC does not regulate mining operations (deep well or surface), and its regulations only apply to the ISL process and subsequent milling processes. NRC efforts for the uranium recovery program are governed by the Uranium Mill Tailings Radiation Control Act of 1978, as amended, and the applicable regulations of 10 CFR Part 40.

\section{Reason for Choosing this Topic as a Case Study}

Gaps in the regulations may be found; this may be helpful in testing the screening criteria. The case study could also illustrate how the application of risk information has improved or could improve the uranium recovery regulatory process.

\section{Relation to Study Objectives}

The case study revealed that chemical risk is the primary risk in uranium recovery and this is not presently regulated by NRC. The toxic chemicals are only considered in terms of chemical accidents which may induce radiological events. Risk-informing the regulatory process could be beneficial, but is not supported by industry due to the depressed economic state of the uranium recovery industry.

Risk was used to evaluate various disposal options at a mill site. By identifying chemical as a potential risk, operators and regulators can focus resources on this area. The ISL PRA showed the importance of radiological and chemical safety and in maintaining integrity of the aquifer against excursions from the ore bed

There are several implicit safety goals in existing regulatory documents, for example, (1) Prevent significant adverse impacts from radioactive waste to the current/future health of the environment and maintain safety and protection of the environment [17] (NUREG-0706), (2) No significant adverse impact on occupational health from uranium recovery activities (SECY 99-100), (3) Maintain public confidence in the uranium recovery industry [18].

A fairly significant amount of risk-related information is contained in (1) site specific and generic environmental impact statements (EISs), integrated safety assessments (ISAs) and probabilistic risk assessments (PRAs), (2) nuclear materials events database (NMED), and (3) Dose assessment models (RESRAD, MILDOS-AREA). In-situ leach facilities have an option for a performance-based license approach

\subsection{Paducah Gaseous Diffusion Plant Seismic Upgrades}

The Paducah Gaseous Diffusion Plant (GDP) is the only operating uranium enrichment plant in the United States. The facility is owned by the United Stated Enrichment Corporation (USEC), which was created by Congress in the 1992 Energy Policy Act. Under this Act, the oversight 
responsibility for the Paducah GDP is placed on the NRC. It is NRC's responsibility to establish safety, safeguards, and security regulations, and to certify the plant in accordance with 10 CFR Part 76, "Certification of Gaseous Diffusion Plants."

Because of its close proximity to the New Madrid Seismic Zone, seismic safety became an important consideration in the certification of the Paducah GDP. The case study took a retrospective look at the activities undertaken by NRC and USEC to address the seismic issues associated with the plant. The case study examined how, and to what extent, risk information was used to resolve these seismic issues.

\section{Reason for Choosing this Topic as a Case Study}

This study could provide insights on whether the use of risk information could improve the regulatory process for gaseous diffusion plants. This decision-making process will be a good test for the draft screening considerations and will help establish consistency in applying risk information across materials and waste programs. Also, chemical risks could be explored.

\section{Relation to Study Objectives}

The case study clearly showed that risk information was used in a manner applicable to decision making. The study helped to identify chemical risk as the important contributor, established the level of risk for particular facility, provided a basis for Justification for Continuing Operation, and identified and quantified seismic weak links.

Several implicit safety goals were identified, including: no significant impact on public health and safety, no significant impact on worker health and safety, and no significant impact on the environment.

Information and tools are available in several risk studies that were performed for the certification process, in extensions and adaptations of PRA methods, and in 10 CFR 76 that identifies applicable codes and standards.

\subsection{Trojan Nuclear Power Plant Decommissioning}

This case study focuses on the decommissioning of the Trojan Nuclear Power Plant and, more specifically, the License Termination Plan (LTP) proposed by the licensee, Portland General Electric Company, the NRC License Termination Rule, and the review of the licensee's Plan by the NRC.

The Trojan Nuclear Power Plant operated from 1976 to 1992 and shutdown permanently in 1993. The licensee is now in the process of decommissioning the plant. Its objective is to obtain an unrestricted release of the site as per the requirements of 10 CFR 20, Subpart E [19], from its license. The LTP was prepared in accordance with 10 CFR 50.82 and the guidance provided in RG 1.179 [20]. The objective of the LTP is to demonstrate that the remainder of decommissioning activities will be performed in accordance with 10 CFR 50.82, and will not affect public health and safety and the quality of the environment. 


\section{Reason for Choosing this Topic as a Case Study}

Trojan was the first decommissioning plant to submit an LTP under NRC's new License Termination Rule, which is considered to be risk informed.

\section{Relation to Study Objectives}

The case study showed that the License Termination Rule embodies a risk informed approach that is helpful in decision making for evaluating decommissioning options. The License Termination Plan proposed by the licensee demonstrated that the residual risk levels at the site were extremely low. The Trojan decision to go for screening DCGLs reflected a realistic appreciation of site risks.

Both the GEIS and the LTR established the value of a risk approach to decommissioning. The study indicated that a risk informed approach can help in analyzing options for situations where a restricted site release is warranted.

Implicit/Explicit Safety Goals that were identified in the study include: no significant additional impact on public/worker health from decommissioning, no significant additional impact on environment, return site to pre-existing conditions, release site for unrestricted use, and maximize number of sites for unrestricted release.

Information and tools relevant to risk-informing site decommissioning are contained in the provisions of the License Termination Rule, in the Standard Review Plan [21], in the DCGL Screening Values [22], in the DandD [23] and RESRAD [24] codes for dose assessment to member of critical group, and in MARSSIM [25] and NUREG-1549 [26] for assessing compliance with generic or site specific screening concentration levels.

\subsection{Transportation of the Trojan Reactor Vessel Package}

This case study focuses on the shipment of an irradiated nuclear reactor vessel from the Trojan Nuclear Plant in Rainier, Oregon, to a low level waste disposal site in Richland, Washington. The Trojan Reactor Vessel Package (TRVP) consisted of the reactor vessel and the contaminated material contained inside it and was filled with low-density concrete to a weight of approximately 1000 tons. The shipment was one of the decommissioning activities for the Trojan Nuclear Plant, which permanently shutdown in 1993 after approximately seventeen years of operation. Most of the shipment occurred by barge on the Columbia River; a small portion was by land transporter at the Hanford Reservation, where the disposal site was located. The case study identified the risks involved with various options for the removal and transport of the reactor vessel and analyzed how risk information was considered in the NRC approval process.

The NRC approved the shipment based, in part, on probabilistic safety studies of alternative options prepared by the licensee, Portland General Electric. The probabilistic safety studies provided the basis for the NRC granting an exemption to certain design requirements in $10 \mathrm{CFR}$ Part 71, NRC's regulations for packaging and transporting radioactive materials. The exemption allowed the licensee to ship and dispose the Trojan reactor vessel as a whole with internals intact; thus, reducing radiation risk to workers and saving the licensee and area rate payers millions of dollars. 


\section{Reason for Choosing this Topic as a Case Study}

Elements of existing, implicit safety goals may be found in Commission decisions; may also be a good case for examining public confidence and communication issues.

\section{Relation to Study Objectives}

The screening criteria appeared to contain all the relevant considerations for making decisions as to whether to pursue risk-informing a proposed regulatory action. However, clarifying guidance is needed to make their use practical for the staff, and to make their intent clear to stakeholders. The study indicated that the TRVP shipment would have been identified as a case that would benefit from risk information.

The case study showed the potential of risk information to provide for substantial burden reduction and improved staff efficiency in making decisions, at no increase in risk. As illustrated by this case, the alternative shipment method (intact by barge), that was justified by the risk analysis, implied a substantial reduction in risk. Regulations often prescribe just one way to provide and demonstrate safety, but risk analysis can open the path to many more options with equivalent or better safety, along with other benefits such as efficiency.

Implicit/explicit safety goals include several risk metrics involved in the process of preparing, shipping, and disposing of the reactor vessel, including occupational exposure of workers and accident risks. The primary metric that was considered in the decision to permit the shipment was the $10^{-6}$ probability for the most likely accident. Thus, the staff decision that this was an acceptable risk is a reference point for a safety goal on accidental risks with consequence levels similar to these. The licensee was able to calculate the $10^{-6}$ probability, but there was no guidance saying what would be acceptable. Safety goals are needed; licensee uncertainty could be alleviated and staff decision making facilitated if a clear set of safety goals existed.

\subsection{Seismic Exemption for the DOE/INEEL TMI-2 ISFSI}

In 1996, the Department of Energy (DOE) submitted to NRC an application for a license to build and operate an independent spent fuel storage installation (ISFSI) on its Idaho National Engineering and Environmental Laboratory (INEEL) site in Eastern Idaho. The ISFSI would be used to store the Three Mile Island Unit 2 (TMI-2) spent fuel debris which, at the time, was being stored in a spent fuel pool at INEEL. DOE's decision to transfer the TMI-2 fuel debris from wet storage to dry storage was motivated by concerns that, in the event of a leak, the spent fuel pool water could contaminate the nearby underground water sources.

As part of this application, DOE requested an exemption to the seismic design criteria specified in 10 CFR $72.102(f)(1)$. This provision required that ISFSls be designed to withstand an earthquake with peak ground acceleration (PGA) values evaluated by a deterministic method using Appendix A of 10 CFR Part 100, NRC's nuclear reactor site criteria. DOE proposed an alternative lower PGA value for its ISFSI and justified the lower value with results from deterministic and probabilistic seismic hazards analyses. NRC evaluated the results and concluded that the DOE's alternative PGA value provided adequate conservatism. Therefore, NRC granted a seismic exemption to DOE in 1998. The exemption allowed DOE to design the ISFSI based on a design earthquake with a PGA of $0.36 \mathrm{~g}$ (instead of $0.56 \mathrm{~g}$, which was derived by a deterministic method). Cost savings for 
constructing a thinner concrete storage pad with fewer reinforcing bars were estimated to be several million dollars.

Prior to the TMI-2 ISFSI seismic exemption, NRC staff had proposed to revise 10 CFR Part 72 to incorporate the use of probabilistic seismic hazard analysis in the earthquake PGA determination. The TMI-2 ISFSI seismic exemption emphasized the need for revising the 10 CFR Part 72 seismic design criteria for dry-cask ISFSIs. The staff has proposed to lower the design earthquake to a level that is commensurate with the lower risk associated with an ISFSI versus an operating nuclear power reactor.

\section{Reason for Choosing this Topic as a Case Study}

Implicit safety goals may be found in decisions and documents related to the probabilistic hazards analysis exemptions and proposed rulemaking. May also be a good case for examining public confidence issues and burden considerations.

\section{Relation to Study Objectives}

This case study passed all the draft screening criteria. The draft screening criteria appeared to be effective in screening a potential application for risk-informing. To make better use of the screening criteria, it is suggested that the flow chart for criteria 5 and 6 be modified to read: "If the answer to criterion 5 (or 6 ) is yes, proceed to additional criteria; if not, the activity may be screened out pending the outcome of other criteria." Essentially, this modification allows the user to look at the screening criteria in their entirety and make a decision based on all the screening criteria.

Risk information was used successfully by the Agency to support granting the licensee the seismic exemption in their TMI-2 independent spent fuel storage installation (ISFSI) application. This case study highlights the need to revise the 10 CFR Part 72 to accept the use of probabilistic seismic hazard analysis (PSHA) method so it will be consistent with 10 CFR Part 50, "Domestic Licensing of Production and Utilization Facilities." The use of risk information in the seismic areas for future ISFSI applications is feasible. The use of risk information in the other areas of future ISFSI applications was not evaluated in this case study. It could probably be expanded into other areas.

No explicit safety goals are found in the current regulations; however, the Part 72 Statements of Consideration recognized that the risks of dry cask storage were lower than those at an operating nuclear power plant. Hence a different set of risk criteria for the ISFSI are reasonable.

One possible safety goal could be that the human exposure to radionuclides should be lower for more frequently occurring events with smaller magnitudes (e.g., an earthquake with a 2,000-yr return period). Conversely, exposure to radionuclides should be higher for a less frequently occurring event (e.g., an earthquake with a 10,000-yr return period) with a larger magnitude. Regardless of the frequency of an event, all exposures should be less than the regulatory limits.

Both deterministic and probabilistic seismic studies have been performed at various locations throughout the Idaho National Engineering and Environmental Laboratory site. The earlier studies (pre 1990) were of less quality because they were less location specific. Recent studies (post 1990) were of higher quality because they were more site specific and included sensitivity analyses that could isolate the contribution to the total seismic hazard from various potential sources. 
Sophisticated probabilistic hazard analysis tools are available to the practitioners if another ISFSI application is submitted to the NRC for evaluation. However, site-specific data is always necessary before meaningful conclusions can be drawn from the studies.

\subsection{Overall Insights from Case Studies}

On an overall basis, the case studies showed that the screening criteria contained all the relevant considerations needed for risk-informing and can be a useful decision-making tool. However, the application can be subjective so guidance is needed. The experience of carrying out the case studies also indicated that the draft screening criteria should be more properly identified as screening considerations instead of screening criteria. They are a set of factors that encompass the relevant questions that are needed for risk-informing but they do not have just yes/no answers.

The case studies demonstrated that, in several instances, risk information helped the NRC staff to make decisions that were, in retrospect, consistent with the Agency's current strategic goals and can be useful in identifying shortcomings in NRC regulations or regulatory processes.

The studies also showed that safety goals are feasible and decision-making can be facilitated if a clear set of safety goals existed.

Information, tools, methods, and guidance needed for risk-informing exist in some materials and waste program areas, but may need to be developed in others.

\subsection{Supplemental Risk Information}

The case studies provide a broad perspective on the use of risk information in the nuclear materials and waste arenas. However, the use of risk information in these arenas is not limited to the regulatory applications addressed by the case studies; risk information has been used in other materials and waste regulatory areas as well. Some of these have been ongoing for several years, such as the work on performance assessment [27] for the high-level waste repository, while some are more recent, such as the risk assessment for dry cask spent fuel storage [28]. Knowledge of these studies have influenced the case study program in various ways. For example, the risk assessment performed for byproduct materials [29] has a direct bearing on three of the case studies. Similarly, the case study on uranium recovery reviewed the risk assessment for in situ leach extraction of uranium. The risk study for spent fuel transportation [30] broadens our perspective on transportation risks beyond the Trojan reactor vessel shipment case study.

Appendix A of this report contains brief summaries of these studies and documents to enhance the perspective on risk-related activities in the materials use and waste arenas. This is not an exhaustive listing of risk assessments performed within NMSS. 


\section{SCREENING CONSIDERATIONS}

One of the objectives of carrying out the case studies was to test the draft screening criteria and to produce a set of final screening considerations. This chapter discusses how the screening criteria were tested in each case study and how the criteria became considerations.

The final screening considerations, for identifying materials and waste regulatory applications amenable to increased use of risk information, are listed in Table 3.1.

\section{Table 3.1: Screening Considerations}

(1) Could a risk-informed regulatory approach help to resolve a question with respect to maintaining or improving the activity's safety?

(2) Could a risk-informed regulatory approach improve the efficiency or the effectiveness of the NRC regulatory process?

(3) Could a risk-informed regulatory approach reduce unnecessary regulatory burden for the applicant or licensee?

(4) Would a risk-informed approach help to effectively communicate a regulatory decision?

If the answer to any of the above is yes, proceed to additional considerations; if not, the activity is considered to be screened out.

(5) Do information (data) and/or analytical models exist that are of sufficient quality or could they be reasonably developed to support risk-informing a regulatory activity?

If the answer to (5) is yes, proceed to additional considerations; if not, the activity is considered to be screened out.

(6) Can startup and implementation of a risk-informed approach be realized at a reasonable cost to the NRC, applicant or licensee, and/or the public, and provide a net benefit?

If the answer to (6) is yes, proceed to the additional consideration; if not, the activity is considered to be screened out.

(7) Do other factors exist which would limit the utility of implementing a risk-informed approach?

If the answer to (7) is no, a risk-informed approach may be implemented; if the answer is yes, the activity may be given additional consideration or be screened out. 


\subsection{Draft Screening Criteria}

As discussed in Chapter 1, seven draft screening criteria were developed to explore whether a particular area regulated by NMSS would be amenable to the expanded use or application of risk assessment. The first four criteria were related to the NRC's overall strategic goals [18] related to risk-informing, that is, whether risk-informing would (1) maintain or enhance safety, (2) improve efficiency or effectiveness of the regulatory process, (3) reduce burden for the licensee, and (4) help to communicate a regulatory decision. The remaining 3 criteria related to the feasibility of riskinforming, that is, whether (1) data and models of sufficient quality exist or can be reasonably developed to support risk-informing, (2) implementation of risk-informing can be realized at a reasonable cost and provide a net benefit, and (3) other factors such as legislative, judicial, etc. exist that would preclude changing the current approach. Experience of conducting the case studies has provided one important lesson, that the draft screening criteria should be more properly identified as screening considerations rather than as strict criteria. In other words, they are a set of factors that encompass the relevant considerations that will influence the risk-informing of activities and areas within NMSS but they are not pass/fail tests that have a yes or no answer and can thus be considered as criteria in the sense that acceptance have been traditionally regarded within the regulatory arena.

The case studies showed that the seven factors that constitute the screening considerations can be a very useful decision-making tool but their application can be subjective, hence guidance is needed. The seven factors are one important tool in the management decision to risk-inform a specific activity or process. The screening considerations not only lead to a decision whether to risk-inform or not, they are an important communication tool in communicating which areas or factors are most important from the standpoint of risk. They also begin to formulate what the issues involved in the decision are and what information and methods are needed to address them. Risk informing in this context implies a commitment to use a set of formal methods or approaches such as PRA in the regulatory decision-making process.

\subsubsection{Screening Considerations Based on Performance Goals in NRC Strategic Plan}

The first screening consideration is whether risk-informing could help to resolve a question with respect to enhancing or maintaining safety of an activity or regulated area. There is a general presumption that adherence to rules and regulations assures adequate safety of regulated activities, however, there could still be unresolved safety questions in specific areas or there may be unrecognized or unevaluated hazards or accidents. In some areas, there could be new information that indicates that the risk from known hazards is greater than previously assessed or that the uncertainty in risk based on current analyses and information is too large and needs to be reduced. Improved risk assessment, including quantification of uncertainty, may help to resolve these issues.

The second screening consideration relates to whether risk informing could improve the efficiency or effectiveness of the NRC regulatory process. This issue has a number of dimensions that include: streamlining the decision-making process, ensuring consistency in application, and keeping the focus on safety. The case study on the Trojan reactor vessel package shipment showed that risk-informing the approval process by adopting safety goals would have streamlined decision-making by obviating the need to go through the cumbersome process of obtaining an 
exemption from transportation regulations. Risk-informing may help to introduce consistency and maintains a focus on safety by ensuring that decisions are based on an assessment of the underlying risk.

The third screening consideration is whether risk-informing could reduce unnecessary regulatory burden. The qualifier "unnecessary" in this context denotes that the regulations that have to be complied with are incommensurate with the risk posed by the regulated activity or action. This implies, of course, that some kind of a risk assessment, even a simple risk screening, has been carried out and some criterion has been utilized to compare the burden of compliance with the risk to be averted in order to demonstrate the incommensurable nature of the regulation. Implementation of this consideration is really an issue of proper risk allocation, in other words a graded approach that allocates resources to systems, structures, components, and procedures in proportion to the magnitude of the risk averted while maintaining overall safety.

The fourth screening consideration relates to public communication of agency decisions, whether a risk-informed approach would help to effectively communicate a regulatory decision. Generally a risk approach provides data and information about a set of options and an objective basis for choosing a particular option. There is a reasonable assumption here that risk-informing would provide more and better information to support the underlying rationale of an agency decision. In principle it could thus lead to decisions that are more transparent and more defensible.

These four screening considerations are based on the NRC's strategic goals of maintaining safety, increasing regulatory efficiency and effectiveness, reducing unnecessary burden, and improving public communication. Risk-informing has an important role to play in promoting these strategic goals.

\subsubsection{Screening Considerations Based on Feasibility}

The other three considerations relate essentially to the feasibility of risk-informing the regulatory activity carried out by NMSS.

The fifth consideration asks if data and/or analytical models of sufficient quality exist or could reasonably be developed to support risk-informing a particular activity. The sixth screening consideration is whether startup and implementation of a risk-informed approach can be realized at a reasonable cost to NRC, applicant/licensee, and/or the public, and provide a net benefit. These considerations are, in essence, two sides of a coin. Data can always be acquired and analytic models developed if sufficient resources are available. Thus the issue is basically one of net benefit and the approach needs to take into account a number of ways, of varying costs, quality, and feasibility, that could be used to risk-inform a regulatory activity or decision. The long and still ongoing experience of risk-informing regulations and regulatory activities related to power reactors illustrates this point. From the Reactor Safety Study [31] to the Risk Assessment for Five Nuclear Power Plants [32], the Individual Plant Examinations [33] (IPE and IPEEE), and many other risk studies, a large number of risk approaches have been used in support of resolving particular issues. More data and newer models may be needed for specific issues but a scoping risk assessment may suffice for many other activities or decisions. Thus feasibility hinges ultimately, as it should, on resource availability in relation to the decision that has to be taken. 
The seventh and final screening addresses the existence of various other factors that would limit the utility of implementing a risk-informed approach. These include legislation or judicial decisions that might preclude alteration of the current regulatory approach. For example, there may be other agencies such as Agreement States that are involved in regulating the licensees or there could be multiple jurisdictions that would need to be addressed. There could also be issues of agency policy or social considerations in particular jurisdictions that may become an obstacle to risk-informing. These factors would need to be evaluated for their impact on risk-informing NMSS activities.

\subsection{Application of Screening Considerations}

The application of the screening considerations is not only useful in the decision of whether or not to risk-inform a particular activity, the questions posed by the screening considerations also lead to the process of understanding how to risk-inform the activity, i.e., what information is needed, how it should be organized, and what kinds of issues can or need to be addressed by risk-informing. However, the implementation of these screening considerations as one factor in the management decision to risk-inform a specific activity or decision within NMSS requires guidance.

A typical issue may involve a set of proposed changes such as changes in regulatory practice, changes in facility procedures, or a re-interpretation of the scope of a particular rule. It is likely that such proposed changes are motivated by one or more of the NRC strategic goals that are embodied in the first four screening considerations stated above, that is, enhancing or maintaining safety, increasing efficiency, reducing burden or improving risk communication. Risk information would clearly be needed to help evaluate the change, i.e., to assess which of the proposed alternatives are permissible, and which one is preferred, based on the risk assessment.

\subsection{Implementation Guidance}

Regulatory Guide 1.174[34], developed to provide guidance in carrying out risk-informed decisions about changes to the licensing basis for nuclear power plants, contains useful information on how the risk information should be applied in evaluating the proposed changes. The rationale underlying the guidance offered by Regulatory Guide 1.174 is based on the following principles:

(1) If the licensed activity has a risk that is too high, then the alternatives should focus on ways of reducing the risk.

(2) If the proposed changes reduce the risk, there should be no barrier to their implementation unless other impacts such as cost, increase in uncertainty, or loss of defense-in-depth are involved.

(3) If the licensee's overall risk is low and the proposed change may lead to an increase in the risk, the incremental change in risk should be small relative to the subsidiary objectives and the quantitative health objectives derived from the reactor safety goals.

This guidance assumes the existence of safety goals, the quantitative health objectives, and the subsidiary objectives (see Chapter 5 , below) for estimating and comparing risk. Without these goals, it is difficult to make judgements about "low" or "high" risks. Chapter 5 is devoted to an exploration of these issues for NMSS activities. 


\section{VALUE OF USING RISK INFORMATION}

This chapter presents the conclusions of the eight case studies with respect to the second objective of the Case Study Plan [10]: gain insights into risk-informing NMSS regulatory processes by illustrating how the application of risk information has improved or could improve a particular area of the NMSS regulatory process. The following conclusions can be drawn from each of the eight case studies with regard to the value of risk information.

\subsection{Conclusions from Case Studies}

\subsubsection{Gas Chromatographs}

This case study [35] indicated that these devices meet or greatly exceed any implicit safety goal, and are likely to also meet or exceed any reasonable explicit quantitative or qualitative safety goal that may be developed in the future. The case study demonstrated that the use of risk information can provide burden reduction and improved efficiency in decision making, without a reduction in safety. However, the actual risk, consequence times the probability, seems to have little impact on public acceptance.

\subsubsection{Static Eliminators}

This case study [36] showed that risk information may have the potential to reduce regulatory burden and improve the staff's efficiency in making decisions, without increasing risk. The extent to which there may be a net benefit, however, is undetermined.

The case study indicated that, while there are two generic risk studies addressing static eliminators, the risks associated with individual models of static eliminators are evaluated on a case-by-case basis through the sealed source and device registration process. There may be potential for increasing the efficiency of the regulatory process by making more general regulatory decisions based on isotope and activity, or sealed source and device design. Also, the regulation under 10 CFR 31.3 may be better integrated with the static eliminator regulation under 10 CFR 31.5, and some devices may be suitable for exempt status.

Risk insights may be used to make the regulation of static eliminators more consistent with other generally licensed, specifically licensed, and exempt devices, from a risk perspective, thus increasing regulatory effectiveness and efficiency and reducing unnecessary regulatory burden, while maintaining health and safety.

\subsubsection{Fixed Gauges}

This case study [37] demonstrated that using risk information can provide burden reduction and improve efficiency in decision making. It also pointed out that increased regulatory oversight may be warranted in some cases. Using risk information could benefit NRC, licensees, and the public by providing greater controls on devices which are more likely to cause harm. The approach would also allow resources to be focused in proportion to the risk a device presents. Staff would be given the tools needed to make a clear safety argument for their licensing and inspection decisions, and efficiency and effectiveness would be improved by reducing the review time necessary for special cases in licensing and device approvals. 


\subsubsection{Uranium Recovery}

This case study [38] showed how risk concepts were used to evaluate various disposal options at a mill site. It also showed how, by identifying chemical as a potential risk, operators and regulators can focus resources on this area in an efficient way. The in situ leach PRA [39] (NUREG/CR-6733) showed the importance of radiological and chemical safety and in maintaining integrity of an aquifer against excursions from an ore bed. This helped to identify the relative importance of a safety issue

\subsubsection{Gaseous Diffusion Plant}

This case study [40] showed how a level of risk was established for particular aspect of a facility. The risk assessment provided the basis for Justification for Continuing Operation while the seismic upgrade was being performed at Paducah. Hence the risk approach help to support burden reduction and improve efficiency in the certification process. More generally, it served to identify and quantify the risks associated with the seismic vulnerabilities at the facility.

\subsubsection{Trojan Nuclear Plant Decommissioning}

This case study [41] found that the Generic Environmental Impact Statement for site decommissioning established the value of a risk approach to decommissioning. The study also noted that the License Termination Rule (10 CFR Part 20, Subpart E) is risk informed. The study also concluded that a risk-informed approach can help in analyzing options for restricted site release. Specifically, more realistic long-term scenarios and consequences could be analyzed using risk methods.

\subsubsection{Transportation of the Trojan Reactor Vessel Package}

This case study [42] showed the potential of risk information to provide for substantial burden reduction and improved staff efficiency in making decisions, at no increase in risk. As illustrated by this case, the alternative shipment method (intact by barge) that was justified by the risk analysis, was actually a substantial reduction in risk. The case study also revealed the benefits of risk information to communication: the notion of the relative risk of "one barge vs. 44 trucks" was readily understood by the stakeholders in the area. Regulations often prescribe just one way to provide and demonstrate safety, but risk analysis can open the path to many more options with equivalent or better safety, along with other benefits such as efficiency.

\subsubsection{Seismic Exemption for the DOE/INEEL TMI-2 Fuel Debris ISFSI}

This case study [43] showed how risk information was used successfully to support granting the Department of Energy the seismic exemption in their TMI-2 fuel debris independent spent fuel storage installation (ISFSI) license application. It also highlighted the need to revise 10 CFR Part 72 to accept the use of the probabilistic seismic hazard analysis (PSHA) method to be consistent with 10 CFR Part 50, "Domestic Licensing of Production and Utilization Facilities." The use of risk information in the seismic areas for future ISFSI applications is feasible. 


\subsubsection{General Conclusions from Case Studies}

The case studies have collectively shown that risk information has been used in making regulatory decisions. They were effective in indicating where decisions or processes are consistent with the Agency's strategic goals. Furthermore, they have helped to highlight some of the areas in which there are shortcomings in the regulations or regulatory process. Specifically, the case studies illustrated how risk information:

(1) can provide burden reduction and improved efficiency in decision making without a reduction in safety,

(2) can be used to make the regulations more consistent for generally licensed, specifically licensed, and exempt devices,

(3) can indicate where increased regulatory oversight may be warranted,

(4) would allow resources to be focused in proportion to risk,

(5) can identify the significance of nonradiological risks of a facility or activity,

(6) can facilitate the certification process of a facility,

(7) can illuminate options for long-term disposal of a facility,

(8) can support granting an exemption from the existing regulations,

(9) can highlight the need to revise regulations.

\subsection{Procedure for Using Risk Information}

Risk information can be valuable as an additional input to a decision that NMSS must make. It can complement the more familiar information that is derived from consideration of the existing regulatory framework. It can help to make that framework more rational. If safety goals are to move forward, then risk information can be readily compared with these goals to guide and inform regulatory issue resolution.

From these case studies and the final screening considerations, a procedure is beginning to emerge for risk informing specific regulatory issues that NMSS must consider. If a particular regulatory issue is determined to be a candidate for risk informing (by virtue of the screening considerations), then the following questions should be addressed:

(1) What is the current regulatory context for the issue or activity?

(2) Who are the individuals, population, or environment at risk?

(3) What are the risk indices that characterize these risks?

(4) Are there competing risk when alternatives are under consideration? 
(5) Can the risk indices be evaluated by analysis and/or testing?

(6) What are the uncertainty ranges associated with each risk parameter?

(7) Does the risk information provide an additional insight that can inform a decision?

(8) Are there similar situations for which a risk-informed approach has been useful?

(9) Can stakeholders be engaged in a risk-informed decision making process?

\subsubsection{Regulatory Context}

After it is established that an issue or activity is a candidate for being risk-informed, it is important for the regulator to gather up all other pertinent information with regard to this issue or activity. Some of this information will already be identified by the screening considerations. In particular, the broad institutional context for an issue or activity needs to be recognized in the decision process.

\subsubsection{Recipients of Risk: The Exposed Population}

In order to understand the actual risks, an identification must be made of the individuals, population, or environment at risk. What is the size of the potentially affected geographical area? What is the population density of the exposed group? How is the hazard transmitted to the exposed group? Can and should a critical group of potentially most exposed individuals be defined? Is the recipient of risk the physical environment?

In performing a realistic assessment of radiological risk, a model (construct) must be developed to calculate the doses to the individuals and population who have been exposed to the hazard. For the nuclear materials use and waste arenas the target population will vary widely. Spatial and temporal factors will need to be considered in assessing the risks.

In developing rules for verifying compliance with regulations, highly prescriptive algorithms have been developed for defining the critical group of individuals who would receive a dose that would be compared against a criterion. For example, in the License Termination Rule [19], the critical group is the group of individuals reasonably expected to receive the greatest exposure to residual radioactivity for any applicable set of circumstances. The average member of a critical group is an individual who is assumed to represent the most likely exposure. For a residential scenario, this individual is defined to be a resident farmer. Similarly, in the proposed (dated 2/22/99) 10 CFR Part 63, a farming community in the vicinity of Yucca Mountain is identified and the average member of the critical group is based on the mean value of the group's variability range. In the final version of 10 CFR 63 [45], the critical group notion is not used. Rather, the concept of the "reasonably maximally exposed individual," consistent with standards of the Environmental Protection Agency and similar to the average member of the critical group, is used.

These are specific constructs that are structured to assure adequate protection according to the law. When using risk information to gain insights into the actual risk of a particular facility or activity, the models and, thus, the risk assessment should be as realistic as possible. There should be no undue bias in the modeling in either direction. 
The case studies have illustrated that the exposed populations can be quite different among the areas considered. For site decommissioning (long-term site release), radiological hazards are expected to be quite low and localized to the site. This suggests that the population at risk is very small, perhaps on the order of 100 people or less. On the other hand, for the transportation of the Trojan reactor vessel package, the hazard is moved through the vicinities of many local communities, which can involve many thousands of people (albeit to a very low hazard). Spent fuel transportation is an amplification of this, involving approximately one million people along a representative route (with a larger overall hazard). Uranium recovery involves a small onsite work crew, typically 10 s of people, who are subject to chemical hazards at least as much as radiological hazards. The uranium recovery facilities are sited in low population density areas with a few thousand people or less in nearby communities. Realistic population exposures may involve less than one hundred people. Gaseous diffusion plants involve, perhaps a few hundred workers who are subject to chemical hazards more than nuclear hazards. Again, because of the remoteness of the siting of these facilities, collective exposures to the surrounding populations would likely involve on the order of 100 people. Static eliminators, gas chromatographs, and fixed gauges could be hazards to small populations, on the order of five or less, at any given time. Of course, many (ten thousand or more) of these devices have been deployed and thus the collective societal risk will involve an aggregation across the spectrum of these applications, leading to collective risks that can be as much as four orders of magnitude higher than the individual risk. For field radiography, well logging and irradiators the collective industry-wide risk is one-to-three orders of magnitude larger than the individual risks from these enterprises (see Table B.1 for a characterization of individual risks across a spectrum of facilities and activities).

Specific risk assessments, such as the Shelwell study performed by NRC, involved an assessment of doses that would be received from local contamination by a small population due to an accident at that facility. Each risk assessment must be performed to address a specific safety question. This will be needed to define the right questions as "top events" for the analysis.

For perspective, in the reactor arena, the consequence models used in a full-scope probabilistic risk assessment typically calculate offsite doses from severe accidents out to one mile, ten miles, and fifty miles from the reactor. (Doses to larger distances, 500 miles, are also calculated for completeness, but the assumptions and approximations required limit the utility of very large distance calculations). The population potentially exposed and their location is obtained from actual census data on a detailed spatial grid surrounding the reactor site.

\subsubsection{Defining Risk Indices}

Once the recipients of the risk are established, quantitative measures of their risk must be defined. For example, it may be appropriate to measure the likelihood of fatality (prompt or latent) to the individual. An aggregate, societal risk may be important to define. Risks can be cast in monetary terms, where property or environmental damage is of concern. To manage the operation of a facility, it may be useful to have a risk measure that reflects the performance of that facility (e.g. likelihood of a specified radiological release). Risk indices are essential because they help to shape the type of risk assessment that should be performed. Also they are the parameters that would be compared to safety goals, if and when they are established. 


\subsubsection{Understanding Competing Risks}

Often, when a decision is to be made, the alternative choices pose different risks. Sometimes the risk indices for one alternative are different and not as significant as for another alternative. It is important to define the complete set of risk indices for all alternatives at hand so that a comparison can be made with maximum information about each choice. Because there are multiple indices involved, the choices can often be difficult (e.g. weighing a larger number of delayed fatalities for one alternative against a larger number of prompt fatalities for the other alternative).

\subsubsection{Evaluating Risk Indices}

This is the heart of the problem. A risk assessment needs to be performed to determine the risk values of the risk indices. The depth, scope, and completeness of the risk assessment will depend on the complexity of the facility or operation, the questions to be answered, the availability of scientific data that would support the risk assessment, and the resources available to perform the risk assessment. For some cases, a rather elaborate probabilistic risk assessment (PRA) or performance assessment (PA) would be warranted. In other cases, risk studies of reduced scope and depth would be sufficient. Integrated safety assessments would be a reasonable approach if the data is limited and a more qualitative analysis is suggested. For more frequent events, historical data could help to directly form the risk assessment. Experiments or tests could be defined which could also help in the assessment of the risks.

\subsubsection{Uncertainty}

No risk assessment (or other form of scientific analysis) is free of uncertainty. Quantification of the uncertainty in the risk predictions is important because it can help the decision maker understand the robustness of a choice. This is true whether the comparison is to be made to a safety goal or an alternative design or operation approach. Decision makers often make choices on the basis of the mean value (a point value) of an uncertainty distribution. The Safety Goal Policy Statement for the Operation of Nuclear Power Plants [44] notes that the Commission adopted the use of mean estimates of the risk metrics for the purpose of implementing the quantitative objectives. Further, 10 CFR 63 [45] advocates the use of mean values for evaluating the adequacy of Yucca Mountain as a disposal site for high-level wastes. Both documents, and many others, duly note that it is useful to know (however crudely assessed) the width of the uncertainty distributions .

\subsubsection{Insights from Risk Information}

Risk insights are defined in the Commissions's White Paper on Risk-Informed Performance-Based Regulation [2] as the results and findings of risk assessments. These include end results such as public health effects or estimates of core damage frequency or large early release frequency (for nuclear power reactors). In areas and activities regulated by NMSS, these results could include risk curves for radioactive waste disposal facilities, frequency of occupational exposures, predicted dose from decommissioned sites and many others. The analyst and decision maker should decide (both before and after the risk assessment is performed) whether these results would provide fresh insights, beyond the conventional regulatory analysis, into maintaining or enhancing safety, reducing unnecessary burden, and improving regulatory effectiveness. In many cases, insights from risk assessments have unearthed potential vulnerabilities and led to new and improved system and process designs. The White Paper indicates that risk insights have been incorporated 
successfully into several regulatory activities, and have proven to be a valuable complement to the traditional deterministic approaches.

\subsubsection{Information from Similar Situations}

Insights can be obtained by examining the results and conclusion from similar situations. For example, risk assessment results or insights for a reactor site decommissioning may be useful for a non-reactor site decommissioning and vice-versa.

\subsubsection{Role of Stakeholders}

It would be helpful in arriving at a decision by risk information if the stakeholders for the particular issue are involved in the process from the beginning. Results will then not be a surprise and may not be the subject of undue discussion and controversy.

\subsection{Activities to Realize Benefits of the Risk Informed Approach}

In order to realize the benefits of risk-informing issues or activities that NMSS must consider, it is important that NMSS management and staff embark on a path that involves the elements outlined below.

\subsubsection{Staff Training}

NMSS, in coordination with the Technical Training Center and the Regions, has established a risk training program for the staff. This training program consists of three tiers. Two Tier I courses have been designed to provide an overview of risk assessment in NMSS for technical managers and administrative staff, respectively. A Tier II course has been designed to introduce to the staff the various risk assessment concepts and methodologies applicable for NMSS activities, including a discussion of risk assessments and insights gained from several actual examples. The purpose of the Tier I and Tier II training is to equip the staff with a basic familiarity of risk assessment to facilitate the use of a risk-informed approach in regulating the use of nuclear materials and nuclear waste disposal. Tier III courses, currently under development, are intended for specialized training in risk methodology, risk analyst qualification, and risk management. The purpose of Tier III training is to cultivate risk analysts who are capable of performing risk assessments, drawing risk insights, and formulating risk management strategies for the various areas that NMSS regulates. As NMSS continues its work in developing the safety goals and incorporating the risk-informed approach into rulemaking, licensing, guidance development, inspection and enforcement, the curriculum will be updated periodically to make available to the staff the latest applications, data and tools to further advance staff's knowledge and capability in implementing the risk-informed approach.

\subsubsection{Risk-Informed Guidance on Rulemaking, Licensing, Inspection and Enforcement}

A risk-informed approach can support developments and activities in each of these areas. For example, a risk-informed approach could have been helpful in the development of a new 10 CFR Part 41 for the in situ leach method of uranium recovery. Risk methods were useful to the certification process for the gaseous diffusion plants. Risk information may be useful in the determination of whether a class of licensees should be moved from specific to general. 
Application of risk information to inspection and enforcement are potential areas for new development. Lessons can be learned from the application of risk information in the reactor arena.

\subsubsection{Development of Safety Goals}

An important adjunct to risk information when used for managing risks, is a set of safety goals that assist the decision maker in determining whether safety objectives will be achieved. The case studies showed that implicit safety goals already exist in some materials use and waste arenas. This provides encouragement for the feasibility of developing safety goals. Some preliminary ideas are presented in the next chapter of this report. 
This chapter presents the conclusions of the eight case studies with respect to the third objective of the Case Study Plan [10]: determine the feasibility of safety goals in a particular area; if feasible, develop safety goal metrics and a first draft of the goals, otherwise, document the reasons for infeasibility.

\subsection{Background}

Safety goals are objectives designed to guide regulatory requirements and to help regulatory decision-making in a manner consistent with NRC's legal mandate of protection of the public, the workers and the environment from the operation of licensed facilities, activities, and materials. The goals are statements of the NRC philosophy and approach to safety that provide the public with a clear expression of the objectives underlying NRC regulatory actions. However, safety goals are not requirements. They are, instead, indications of "how safe is safe enough" that should be used to guide rulemaking, licensing, inspection, or enforcement actions.

There are currently two safety goals that have been approved by the Commission and both relate to operation of nuclear power plants [44]. These goals are defined by limiting the risk arising from the operation of power plants for two risk measures, early (or prompt) fatalities and latent cancers. The goals are stated in both qualitative and quantitative terms. There are no other formal NRC safety goals that have been explicitly stated in risk language. These approved goals were developed over a six-year period (1980-1986) in which many interested parties were encouraged to provide input to the purpose, character, and formulation of the safety goals. This process included two major workshops which involved representatives of the affected industry, researchers in risk analysis, non-governmental special interest groups, social scientists, ethicists, regulators, and members of nuclear review committees. Several independent versions of safety goals were developed by interested organizations and a multi-year trial use and applications by the NRC followed before the final goals were approved in 1986. The suitability of these goals have been revisited by the Commission, its advisory committees and the NRC at various times over the past 15 years.

In the Framework for Risk-Informed Regulation in the Office of Nuclear Materials Safety and Safeguards, SECY-99-100 [4], it was noted that no policy statement exists for materials use and disposal that would be the counterpart of the Commission's "Safety Goals for the Operations of Nuclear Power Plants Policy Statement". SECY-99-100 further noted that the absence of such a policy statement represented an essential gap in the Commission's plans to develop a risk management foundation in the materials use and disposal areas. Hence, the SECY recommended to the Commission the development of risk metrics and goals.

SECY-99-100 made the following observations with regard to risk management metrics and goals for nuclear materials use and disposal: (1) risks from normal operations and accident conditions should be considered, (2) alternatives to analogues of quantitative health objectives and subsidiary risk goals for power operation must be contemplated, (3) worker protection from accidents must be addressed, (4) NRC must accommodate shared functions with other agencies and standardssetting entities in developing a risk management approach, (5) capability and resources of licensees to participate in a risk-informed regulatory approach must be considered, and (6) a broad 
range of stakeholder input would be needed to effectively expand risk-informed regulatory approaches in this area.

In accordance with the Staff Requirements Memorandum [7] for SECY-99-100, risk metrics and goals should be developed that: (a) define what safety means in the materials area, (b) include a goal on the avoidance of property damage, (c) defines critical groups for classes of materials use, (d) gives due consideration to existing radiation protection standards, (e) allows for equivalent levels of reasonable assurance of adequate protection across the spectrum of regulated materials activities, and ( $f$ ) is consistent with risk-informed approaches to nuclear power plant regulation.

\subsection{Implicit Safety Goals in the Case Studies and Related Documents}

One of the objectives of the case study approach was to determine whether safety goals already appear, at least implicitly, in the particular topics that were chosen in the Case Study Plan. These can be qualitative or quantitative goals, or both. In this subsection, the implicit safety goals for each of the eight case studies is presented.

\subsubsection{Site Decommissioning}

There are implicit goals that are contained in various documents. For example in the Generic Environmental Impact Statement [46], it is stated that regulations require licensees to decommission their facilities so that property can be released for unrestricted use. This can be regarded as a top-level safety (and environmental) goal. It expresses the notion that there are no residual hazardous conditions remaining on the site that would preclude its future use for any purpose. There is also a discussion in the GEIS specifically of returning a site to preexisting background radiation conditions. The GEIS recognizes that there are some facilities for which this goal could be achieved. However, the GEIS also points out that there are some sites (e.g. with contaminated soils and/or structures) for which it is not reasonable to, in terms of costs vs. impacts, to achieve the preexisting background conditions. For those sites, it is argued, there are competing risks associated with doses that would be received during remediation activities and with nonradiological hazards that would weigh against the benefits to be achieved for dose reductions near the background level.

\subsubsection{Transportation of Trojan Reactor Vessel Package}

There was a bounding probability that was used as an acceptance criteria in the NRC's review of PGE's Safety Analysis Report. The probabilistic safety study showed that the most likely of the accident scenarios was a TRVP barge collision with the TRVP lost overboard. PGE developed a recovery plan for this scenario. Consequently the staff concluded "Since the probability of accidents that could damage the package and lead to potential health impacts is less than $10^{-6}$, these accidents were not evaluated by the staff." In addition, the potential consequences associated with the scenarios were anticipated to be low. Therefore, the staff found the probabilistic studies and results to be acceptable. This tends to imply that a $10^{-6}$ probability of health impact to an individual is at or below the safety goal level of risk. 


\subsubsection{Storage of Spent Nuclear Fuel}

No explicit safety goals were found in the current regulation 10 CFR Part 72 . However, the Part 72 Statement of Considerations recognized that a less stringent seismic frequency is appropriate for structures that are rather less massive than nuclear power plants.

\subsubsection{Uranium Recovery}

The Generic Environmental Impact Statement, NUREG-0706 [47], stated that: "Operation of uranium mills and the management of mill tailings... [should] appropriately assure the public health and safety and the preservation of environmental values". Also SECY 99-100 notes that both public and worker risks should be considered. It also provides four strawman safety goals for consideration.

Limits for NRC radiological concentrations and for air and water effluents, the EPA standard for groundwater, and occupational protection guides and standards are suggestive of possible goals in this area.

\subsubsection{Gaseous Diffusion Plant}

The regulation, 10 CFR Part 76, states "protect the public health and safety from radiological hazards and provide for the common defense and security." The Commission framework document for risk-informed regulation in NMSS activities (SECY 99-100) also notes public and worker risk, and provides four strawman risk metrics for safety goals.

The US Enrichment Corporation (USEC) estimated no additional increase of risk to the public heath and safety from a three-month extension period for seismic modifications. Similarly, worker risk increases were predicted to be very low. Based on this risk information and compensatory measures that USEC committed to maintain, the NRC staff concluded that the extension of the seismic modification completion was acceptable because (1) the increased risk to public and workers was not significant, (2) the risk would continue to decrease over time due to increased seismic bracing completions, and (3) the compensatory measures minimized consequences. Clearly, the staff decision implicitly considered that an acceptable level of safety was attained for ensuring health and safety of workers and the public.

The Evaluation Basis Earthquake (EBE) with a 250-year return period was explicitly called for in the Compliance Plan for achieving safety compliance with 10 CFR Part 76 and therefore, can be suggestive of a safety goal.

\subsubsection{Gas Chromatographs}

Products intended to be distributed to persons exempt from licensing (e.g. the general public) must meet specific safety requirements. These specific requirements could be seen as safety goals for these products. The requirements which pertain to smoke detectors, and other gas and aerosol detectors are found in 10 CFR 32.26, this is the category that is most similar to gas chromatographs. These regulations contain safety criteria that the device must meet which include: 
(1) In normal use and disposal of a single exempt unit, and in normal handling and storage of the quantities of exempt units likely to accumulate in one location during marketing, distribution, installation, and servicing of the product, it is unlikely that the external radiation dose in any one year, to a suitable sample of the group of individuals expected to be most highly exposed to radiation or radioactive material from the product will exceed the dose to the appropriate organ as specified in Column 1 of the table in $\S 32.28$ (below).

\begin{tabular}{|l|l|l|l|}
\hline Part of Body & $\begin{array}{l}\text { Column I } \\
\text { (rem) }\end{array}$ & $\begin{array}{l}\text { Column II } \\
\text { (rem) }\end{array}$ & $\begin{array}{l}\text { Column III } \\
\text { (rem) }\end{array}$ \\
\hline $\begin{array}{l}\text { Whole body; head and trunk; } \\
\text { active blood forming organs; } \\
\text { gonads; or lens of eye }\end{array}$ & 0.005 & 0.5 & 15 \\
\hline $\begin{array}{l}\text { Hands and forearms; feet and } \\
\text { ankles; localized areas of skin } \\
\text { averaged over areas no larger } \\
\text { than 1 square centimeter }\end{array}$ & 0.075 & 7.5 & 200 \\
\hline Other organs & 0.015 & 1.5 & 50 \\
\hline
\end{tabular}

(2) It is unlikely that there will be a significant reduction in the effectiveness of the containment, shielding, or other safety features of the product from wear and abuse likely to occur in normal handling and use of the product during its useful life.

(3) In use and disposal of a single exempt unit and in handling and storage of the quantities of exempt units likely to accumulate in one location during marketing, distribution, installation, and servicing of the product, the probability is low that the containment, shielding, or other safety features of the product would fail under such circumstances that a person would receive an external radiation dose or dose commitment excess of the dose to the appropriate organ as specified in Column II of the table in $\S 32.28$, and the probability is negligible that a person would receive and external radiation dose or dose commitment in excess of the dose to the appropriate organ as specified in Column III of the table in $\$ 32.28$.

In addition, the table contains the following explanatory footnote: "It is the intent of this paragraph that as the magnitude of the potential dose increases above that permitted under normal conditions, the probability that any individual will receive such a dose must decrease. The probabilities have been expressed in general terms to emphasize the approximate nature of the estimates which are to be made. The following values may be used as guides in estimating compliance with the criteria:

$\begin{array}{lll}\text { Low } & - & \begin{array}{l}\text { not more than one such failure per year for each } 10,000 \\ \text { exempt units distributed. }\end{array} \\ \text { Negligible } \quad-\quad & \begin{array}{l}\text { not more than one such failure per year for each one million } \\ \text { exempt units distributed." }\end{array}\end{array}$


Thus, for products intended for exempt distribution, there are elements of both quantitative and qualitative safety goals.

\subsubsection{Static Eliminators}

There are both explicit and implicit safety goals embedded in the regulations, guidance documents, and sealed source and device registration certificates. These goals are both quantitative and qualitative.

Static eliminators containing a sealed source of no more than 500 microcuries of Po-210 may be used in both consumer and commercial applications under a 10 CFR 31.3 general license. The device must be manufactured, tested, and labeled by the manufacturer in accordance with the specifications of a specific license. This implies that an acceptable level of safety is provided by the quantity of the particular radionuclide, together with the physical properties of the sealed source and device.

Static eliminators may also be used in the commercial sector pursuant to 10 CFR 31.5 . The regulations and the individual sealed source and device registration certificates for these devices identify several quantitative safety goals. According to 10 CFR 32.51, an applicant for a specific license to manufacture a 10 CFR 31.5 device must submit information that is sufficient to provide reasonable assurance that, under ordinary conditions of handling, storage, and use of the device, the byproduct material contained in the device will not be released or inadvertently removed from the device (i.e., zero release). This is quantified in the regulations through the specific leak test threshold of 0.005 microcuries of removable contamination. Also, the manufacturer must demonstrate that, under ordinary conditions, it is unlikely that any person will receive in 1 year a dose that exceeds $10 \%$ of the annual occupational dose limits for adults specified in 10 CFR 20.1201(a).

Additionally, 10 CFR 32.51 requires that, under accident conditions (such as fire or explosion) associated with handling, storage, and use of the device, it is unlikely that any person would receive an external radiation dose or dose commitment in excess of the dose to the appropriate organ as specified in Column IV of 10 CFR 32.24 (15 rem to the whole body, head and trunk, active blood-forming organs, gonads, or lens of the eye; 200 rem to the hands and forearms, feet and ankles, or localized areas of skin; 50 rem to other organs). A review of the registration certificates for these devices indicates that the reviewer's safety evaluation of each device is based on the applicant's ability to demonstrate conformance to these requirements.

Several qualitative safety goals may also be identified. Review of the registration certificates indicates that the devices should be designed so that the user of the device will not come into direct contact with the sealed source. Also, the registration certificates indicate that the devices should only be used in environments that will not lead to degradation of the containment capability of the sealed source.

In 1988, the NRC issued a series of orders to a particular manufacturer and distributor of static eliminators, Minnesota Mining and Manufacturing Company (3M). The orders required 3M to suspend distribution and to recall static eliminators employing Po-210 in the form of "microspheres" as the source. These devices were being used in commercial manufacturing applications. Evidence indicated that the sealed sources were failing and the microspheres were being released 
from the devices, thereby resulting in contamination of the manufacturing environment, workers and other individuals in the manufacturing environment, and possibly the manufactured products.

A review of the agency's records indicates that the decision to issue the recall orders was based on the evidence of release of the radioactive material from the sealed source device, and the subsequent contamination of the immediate environment, workers and others in the environment, and the products being manufactured. While the risks associated with the contamination are not evident, the chronic failure of the devices and the resulting contamination were sufficient to support the recall orders. A safety goal of zero release from a sealed source may, therefore, be inferred from this decision.

\subsubsection{Fixed Gauges}

There are qualitative safety goals in 32.51 , to the extent that we have been approving gauges for distribution if they meet the safety requirements, i.e. they are safe enough. These requirements are that (1) the device can be safely operated by persons not having training in radiological protection; (2) that under ordinary conditions of handling, storage, and use, it is unlikely that any person will receive a dose in excess of 10 percent of the annual limits specified in 20.1201(a); and (3) that under accident conditions it is unlikely that any person would receive a dose in excess of the dose specified in Column IV of the table in 32.24. However, the term "unlikely" is open to interpretation by the reviewer, and it is left to the individual reviewer to decide what accident scenarios to accept. Whether the dose numbers given in these limits are appropriate as safety goals is not clear at this time, but the idea of considering dose in both normal and accident conditions is consistent with a safety goal.

SECY-00-0137 [48], "Response to Staff Requirements Memorandum Dated December 21,1998-SECY-98-232 -- Seaman Nuclear's Application to Distribute Portable Gauges to General Licensees" [49], documents the staff's use of risk information in deciding the appropriate licensing category for a portable gauge. The staff reviewed NUREG/CR-6642, as well as documented data on events involving portable nuclear gauges, and made a risk informed decision to deny the application. While the device in this case was not a fixed gauge, the case does provide an example of what risk the staff felt was acceptable, and what types of accident scenarios need to be evaluated.

\subsection{Feasibility of Developing Safety Goals}

At the NRC Stakeholder Meeting [15] that was held on October 25, 2001, there was encouragement for the development of safety goals in the nuclear materials use and waste areas. Members of public interest groups and of the nuclear industry both endorsed the development of safety goals. In order to attain acceptance of safety goals, broad stakeholder input and participation must be sought during the development process.

Safety goals are only one element, albeit an important one, in developing a risk-informed framework for nuclear materials use and waste. As suggested in a joint letter from the ACRS and the ACNW to the Commission [50], there is much less experience in the application of probabilistic risk assessment methods to nuclear materials than there is for power reactors. Even in the reactor arena, various compensatory measures, such as defense-in-depth and safety margins, have to be employed to deal with issues of uncertainty and the inability to adequately quantify risk. The 
ACRS/ACNW letter indicates that although materials systems are not as complex as reactors in terms of assessment of risk, there is much greater diversity in materials licensed activities.

The long time periods involved in the some of the materials use and waste areas introduces a different element of uncertainty that perhaps can be compensated for, in part, by defense in depth concepts. In SECY-99-100, the staff addressed issues related to both risk assessment and risk management, i.e., establishment of appropriate goals and metrics for risk to appropriate individuals and groups, for NMSS regulated activities.

In the nuclear materials use and waste area, the risk to the workers involved with these facilities and processes is significant relative to the risks to the general public in the nearby vicinity. In addition, for some of these areas, chemical risks dominate the radiological risk. These factors need to be recognized in the development of an overall risk management program in these areas.

The eight case studies have clearly shown that risk assessment methods have been used in several of the areas (Trojan vessel shipment, seismic upgrade at Paducah, DOE/INEEL TMI-2 fuel debris storage) and that other five are candidates for additional risk-informed decision making. Existing risk assessment methods can be adopted or modified from the reactor area, in some cases, for application to materials use and disposal. The NRC staff has already shown [51] how performance assessment, a form of probabilistic risk assessment, can be used in risk-informing the high level waste, low level waste and decommissioning areas.

The information presented here should be regarded as preliminary. Further progress in this area is anticipated during FY 2002. Some of the issues that will be addressed are:

- Individual and Societal Goals

- $\quad$ Voluntary and Involuntary Risks

- Worker and Public Risks

- $\quad$ Non-radiological Hazards of Facilities and Operations

- $\quad$ Operational-Phase Risk and Long-Term Risk

\subsection{Approaches to Developing Safety Goals}

Safety goals can be either qualitative or quantitative or embody elements of both. Qualitative goals can be posited in a language that is readily understandable by the public. Quantitative goals can be expressed in terms of parameters that are easily understandable by the public (likelihood of an undesirable health effect) or in terms of parameters that relate to engineering features of the technology (likelihood of failure of an engineered barrier). Further, safety goals can be related to natural characteristics of a site and its performance with regard to protection of the public and the environment.

The safety goals developed for nuclear power plants in the 1986 Safety Goal Policy Statement has a hierarchical structure comprised of three tiers: a top, qualitative tier which is followed by a quantitative tier which is, in turn, supported by subsidiary objectives. 
Another, perhaps complementary approach has been advanced by the United Kingdom Health and Safety Executive [52]. In that body of work, quantitative limits and quantitative objectives are put forth for consequences to the public and workers associated with all phases of nuclear power generation. Risk management is implemented by not allowing a licensee to operate if the limit is exceeded and by not requiring further risk reduction if the objective is achieved. Between the limit and the objective the licensee would reduce risk to as low as reasonably practicable.

In Japan, a safety goal program [53] is now underway and it includes activities similar to those that NMSS regulates as well as nuclear power plants. At the time of this writing, that program is in its early stages, but there are indications that the Japanese regulatory body and the NRC are thinking along similar lines.

\subsection{Proposed Draft Safety Goals}

The proposed first draft of safety goals presented here follow the general structure of the safety goals for the operations of nuclear power plants. This is in accord with the NRC objective [54]: to establish goals across the spectrum of regulated materials activities in a manner consistent with acceptable risk in the area of nuclear power plant regulation.

This section presents qualitative safety goals that are supported by quantitative objectives. Further, in order to suggest how to use the proposed goals in regulatory decision-making, subsidiary objectives are defined for the various categories of application in the nuclear materials use and disposal areas. The focus is on the risks to the public and workers from nuclear materials use and disposal and on risks to environmental and property damage.

As previously stated, the safety goals presented here are preliminary. Further development of these goals is necessary.

\subsubsection{Qualitative Safety Goals}

The qualitative safety goals established by the Commission's Safety Goal Policy Statement [44] for the Operation of Nuclear Power Plants are:

- Individual members of the public should be provided a level of protection from the consequences of nuclear power plant operation such that individuals bear no significant additional risk to life and health.

- $\quad$ Societal risks to life and health from nuclear power plant operation should be comparable to or less than the risks of generating electricity by viable competing technologies and should not be a significant addition to other societal risks.

The first goal is based on individual risk while the second goal is societal. As shown below, in the translation of these qualitative goals into quantitative health objectives, the first goal is evaluated through limiting the risk of acute (life threatening) radiation exposure while the second goal is assessed through limiting latent cancer risks. Both goals, however, apply to the general public living in the vicinity of a nuclear power plant. 
In nuclear materials use and disposal, however, the workers are the population that bears a significant portion of the risk and SECY-99-100 has indicated that the risk metrics and goals must address the safety of workers. The SRM [7] to SECY 99-100 also indicates that the "NMSS framework should include as a goal the avoidance of property damage". Additionally, in the area of nuclear materials disposal such as site decommissioning, the Commission has established regulatory limits on exposure based on the notion of a "critical group", i.e., the population living on or in the vicinity of a decommissioned site.

Accordingly, the qualitative safety goals for nuclear materials use and disposal proposed below address both the public and the worker and, to be broadly consistent with the reactor safety goals, are couched in terms of both individual and societal risks. The goals are as follows:

Individual: Nuclear materials use and disposal do not pose a significant additional risk to life and health of individual members of the public, and to workers associated with these activities.

Societal: Societal risks to life and health from nuclear materials use and disposal are not significant additions to other societal risks, and the benefits of the use greatly outweigh the risks.

The property damage goal that also includes an environmental damage goal is expressed qualitatively as follows:

\section{Property/Environmental Damage: Nuclear materials use and disposal should not result in environmental or property damage in excess of other means of achieving a similar end objective that is deemed beneficial to society.}

\subsubsection{Quantitative Objectives for Gauging Achievement of the Goals}

A. Quantitative Health Objectives (QHO)

In the reactor Safety Goal Policy Statement [44], the Commission proceeded to specify the risk measures in which the qualitative safety goals would be couched and then defined what "no significant additional risk" meant in quantitative terms. In so doing, the qualitative safety goals are transformed into quantitative health objectives (QHOs).

The individual risk goal for the public is stated in terms of the risk of prompt fatality due to acute radiation exposure: "The risk to an individual in the vicinity of a nuclear power plant of prompt fatality that might result from reactor accidents should not exceed one-tenth of one percent $(0.1$ percent) of the sum of prompt fatality risks resulting from other accidents to which members of the U.S. population are generally exposed." 
This goal can be taken over directly to the nuclear materials use and disposal area and stated as:

Individual Public Acute (QHO 1): The risk to an individual member of the public in the vicinity of a facility, site, or activity of prompt fatality due to acute radiation exposure that might result from accidents involving nuclear materials use and disposal activities does not exceed one-tenth of one percent (0.1 percent) of the sum of prompt fatality risks resulting from other accidents to which members of the U.S. public are generally exposed.

The 0.1 percent expresses in quantitative terms what is implied by "no significant additional risk" in the qualitative goal.

The societal risk goal for the public from reactors is stated as: The risk to the population in the area near a nuclear power plant of cancer fatalities that might result from nuclear power plant operation should not exceed one-tenth of one percent ( 0.1 percent) of the sum of cancer fatality risks resulting from all other causes. This goal recognizes that the health risk arising from radiation exposures that are below the prompt fatality threshold are latent cancers and that the qualitative goal of no "significant addition to other societal risks" is expressed through the limit of 0.1 percent of cancer fatality risks from all other causes. While this goal is literally an individual risk goal, it has been used a surrogate for a societal goal. Provisionally, this distinction will be recognized here: an individual public latent fatality goal, $\mathrm{QHO} 2$, will be distinguished from a societal goal, identified as QHO 3 (see below).

The individual latent fatality goal, QHO 2, for the public can also be taken over from the second quantitative health objective for reactors to the nuclear materials use and disposal area and expressed as follows:

Individual Public Latent (QHO 2): The risk to an individual in the vicinity of a facility, site, or activity of cancer fatalities that might result from nuclear materials use and disposal does not exceed one-tenth of one percent $(0.1$ percent) of the sum of cancer fatality risks resulting from all other causes.

A societal goal, QHO 3, expresses the cumulative risk to the public in a risk-benefit context. The thoughts presented here are preliminary and additional discussion of this topic can be found in Appendix B of this report.

Societal Public (QHO 3): The cumulative risk (expected value) of acute plus latent fatalities for a nuclear materials application is much less than the benefit of that application.

(Nuclear materials use and disposal also involve transportation of nuclear materials, including spent fuel and waste, and accidents can potentially occur at any point along the transport route. Hence the qualifiers "near" and "in the vicinity" that are applied to the safety goals above will be suitably qualified to reflect the population in the vicinity of the transportation route.)

The QHOs for worker exposure are based on the consideration that the phrase "no significant additional risk" for workers stated in the qualitative safety goal implies a comparison with the risk faced by workers in general in the U.S. Stakeholders should address the determination of an 
appropriate fraction of industrial risks that should be adopted as a goal by the NRC in controlling worker risks in the materials area. There are also jurisdictional issues concerning other agencies such as OSHA. Three strawmen QHOs, one for prompt fatality, one for latent cancer, and one for injuries to workers in nuclear materials use and disposal activities are proposed as follows:

\section{Individual Worker Acute (QHO 4): The risk of prompt fatality to any worker arising from a nuclear materials use and disposal activity does not exceed one percent (1 percent) of the sum of prompt fatality risks that U.S. workers are generally exposed.}

\section{Individual Worker Latent (QHO 5): The risk of latent cancer to workers from nuclear materials use and disposal activities does not exceed a small fraction of the risk of cancer of workers in other hazardous material industries.}

In QHO 4, the use of 1 percent of the sum of prompt fatality risks in U.S. industry generally is believed to represent a compromise between two possible extremes. A very stringent limit such as 0.1 percent might come into conflict with the corresponding public limit of 0.1 percent in QHO 2. On the other hand, a much looser limit such as simply "should not exceed the sum of prompt fatality risks to workers generally" might not adequately reflect the high levels of safety adopted in the nuclear industry. However, this is an area that needs to be further explored. It is also recognized that workers in the nuclear materials use and disposal facilities are potentially exposed to chemical and other hazards in addition to radiation.

Regarding the quantitative aspect of $\mathrm{QHO} 5$, it would be useful to examine data on worker risk from hazardous materials in the chemical industry or in Department of Energy facilities to develop a suitable percentage limit. A quantitative expression of "a small fraction" may be something on the order of 10 percent, reflecting the more rigorous level of safety in the nuclear industry. Another area for stakeholders to explore is whether other chronic disease outcomes besides cancer should be included in the cohort to which the "small fraction" is applied. For example, such diseases include asbestosis, chronic beryllium disease, etc., for which considerable data exists in the public domain.

There is a possibility of a permanent or temporary severe injury to workers from radiation exposure. Such injuries have occurred in the past in licensed activities like field radiography (see Appendix A.6) from exposures that are severe enough to cause radiation burns requiring extensive medical treatment and rehabilitation but are below the threshold for a prompt fatality. These severe exposures may lie in a range from 25 rem to 200 rem whole body and about 300 rem to 1000 rem to an extremity. Thus, a worker severe injury goal is proposed here.

Worker Severe Injury (QHO 6): The risk of severe injury to workers from inadvertent or accidental exposure to nuclear materials is a small fraction of the corresponding risk of severe injury to workers in other hazardous industries. (A quantitative goal is currently under consideration). 


\section{B. Quantitative Environmental Objective (QEO)}

Protection of the environment is an essential requirement in all areas of the nuclear enterprise that are regulated by NRC [55]. Contamination or scarring of land as a result of normal, intended activities or as a result of upset conditions must be minimized. The License Termination Rule [19] for decommissioning of nuclear facilities sets forth clear and stringent requirements for returning land for unrestricted use in the long term. The Uranium Mill Tailings Radiation Control Act of 1978 [56] (PL 95-604) is specifically aimed at preventing or minimizing radon diffusion into the environment and minimizing other environmental hazards from mill tailings. Similarly, the Nuclear Waste Policy Act [57] (PL 97-425) for the disposal of high-level radioactive waste and the LowLevel Radioactive Waste Policy Amendments Act of 1985 [58] (PL 99-240) are structured to assure that the environmental risks from nuclear wastes are minimized. Finally, the National Environmental Policy Act [59] (PL 91-190) is aimed at preventing or eliminating damage to the environment and biosphere and requires NRC and other agencies to use a multidisciplinary approach to decision making and to consider all types of risks and benefits to the environment (and humans).

Accordingly the quantitative environmental objective is as follows:

\section{Environment/Property Damage (QEO): The risk of environmental or property damage that is implied by a particular materials use or disposal activity is clearly less than the sum the risks from all other activities aimed at achieving a comparable societal benefit.}

\subsubsection{Subsidiary Objectives}

A. Introduction

Subsidiary objectives are an essential element of a risk management program because they are the figures of merit that can be most directly estimated with regard to the intention of the overarching safety goals. For example, in the case of nuclear power plant operation, the subsidiary objectives are the core damage frequency (CDF) and the large early release frequency (LERF). These objectives can be estimated by performing a probabilistic risk assessment of the plant in question and then comparing these computed values with the criteria set for these objectives. The numerical criteria for CDF and LERF are selected to be consistent with the safety goals and thus a determination of whether the plant meets the goals can be made by this indirect process.

The safety goals structure that exists for the nuclear power plants is a three-tier paradigm. The first tier is the qualitative statement of the goals, the second tier contains the quantitative health objective and the third tier is represented by the subsidiary objectives that can be computed in a probabilistic risk assessment (PRA). The regulation of power plants is not done via PRA. Rather, it is done at a lower level of aggregation, here termed the "fourth tier" which describes and specifies the rules, regulations, and guidance for systems, structures, components, and operations. These latter entities are more directly measured and verified in the regulatory arena. PRAs are an effective means of aggregating the net result of achieving a given level of performance within the multiplicity of parameters within the fourth tier. They are in fact now being used in a risk-informing process to help guide regulatory decisions. 
For the materials use and disposal areas, PRAs have not yet been performed that provide the same degree of aggregation of fourth tier performance as they do for reactors. In some areas, comprehensive PRAs are not warranted because the overall system structure is not complex enough to require a four-tier structure. For example, in long-term site release of a decommissioned facility, residual concentrations of radionuclides imply a residual dose that, in turn, implies a residual health risk (to a potentially exposed individual). As discussed below, this example can be structured into (at most) a three tier, or even a two-tier paradigm.

\section{B. Proposed Subsidiary Objectives}

In this section, subsidiary objectives are proposed that can be compared with estimates of the risks for the various facilities regulated by the NRC in the materials use and disposal areas. The list of subsidiary objectives presented here is not meant to be complete. In fact, the intention is not to be overly prescriptive. Rather, they are being presented in the spirit of a discussion paper - to be refined and modified by additional examination of the technical areas and of the overall objectives of this activity. Stakeholder input will be sought on this topic in the next phase of this program.

In order to facilitate the presentation of the subsidiary objectives, it is useful to compare the nuclear materials use and disposal area with nuclear power plant operations in the context of the three-tier structure for safety goals. This is illustrated in Table 5.1.

Table 5.1: Three-Tier Safety Goal Structure

\begin{tabular}{|c|c|c|c|}
\hline & Reactor Operations & \multicolumn{2}{|c|}{ Material Use \& Disposal } \\
\hline $\begin{array}{l}\text { Tier I: } \\
\text { Qualitative Goals }\end{array}$ & $\begin{array}{l}\cdot \text { Risk to Individual } \\
\text { - Societal Risk }\end{array}$ & \multicolumn{2}{|c|}{$\begin{array}{l}\text { - Risk to Individual/Society, } \\
\text { including public and workers } \\
------------ \\
\text { - Environmental and Property } \\
\text { Damage Risk }\end{array}$} \\
\hline $\begin{array}{l}\text { Tier II: } \\
\text { Quantitative Goals }\end{array}$ & $\begin{array}{l}\text { - Prompt Fatality Risk } \\
\text { - Cancer Fatality Risk } \\
------\end{array}$ & \multicolumn{2}{|c|}{$\begin{array}{l}\text { - Quantitative Health Objective } \\
\text { (QHOs) } \\
------------- \\
\text { - Quantitative Environmental } \\
\text { Objective (QEO) }\end{array}$} \\
\hline \multirow{2}{*}{$\begin{array}{l}\text { Tier III: } \\
\text { Subsidiary Objectives }\end{array}$} & \multirow{2}{*}{$\begin{array}{l}\text { - Core Damage Frequency } \\
\text { - Large Early Release } \\
\text { Frequency }\end{array}$} & Chronic & Episodic \\
\hline & & ${ }_{-}^{*} \mathrm{mrem} / \mathrm{yr}$ & See Table 5.2 \\
\hline
\end{tabular}

In this table the relevant risk measures are compared for each tier of the three-tier structure. At the third tier, the materials use and disposal area is divided into two components. This is done because the chronic risk due to the residual condition of a facility or use must be distinguished from 
the episodic ("what can go wrong?") risk that arises from potential upset conditions at the facility or for the use in question.

For the chronic subsidiary objective, we have chosen a radiological dose as the figure of merit. The actual numerical value, shown here as * , could be a number in the range (approximately) of 4 to 40 . Note that a chronic dose directly implies risk if one uses the BEIR V conversion factor from radiation dose to cancer fatalities. The choice of $4 \mathrm{mrem} / \mathrm{yr}$ corresponds to a latent cancer risk of one tenth of one per cent of the cancer risk from all causes in the U.S. population (the latent cancer quantitative health objective of the existing safety goal for reactor operations). Similarly, a goal of $40 \mathrm{mrem} / \mathrm{yr}$ would correspond to one per cent of the cancer risk in the U.S. population. The all pathways dose criterion of $25 \mathrm{mrem} / \mathrm{yr}$ for long-term site release in the License Termination Rule [19] and the criterion of $15 \mathrm{mrem} / \mathrm{yr}$ promulgated by the U.S. Environmental Protection Agency are bracketed by this range. The subsidiary objective proposed here is a goal, to be aspired to, and not a criterion to be complied with. If this goal were intended to be consistent with the dose inferred from the quantitative (societal) health objective for nuclear power plants, then a selection of a numerical value close to the low end of the range would be appropriate. This issue would benefit from input from stakeholders.

The subsidiary parameters for the episodic events are presented in terms of upset events for each of the specific areas noted above in terms of engineering or process failures and their corresponding likelihoods. In this draft document, only the qualitative structure of each subsidiary objective is given. In a subsequent draft, trial values will be proposed. In addition, these parameters should be reviewed for their adequacy of embracing the intent of the qualitative and quantitative goals and the practicality of estimating these parameters for specific applications. Hence, they are being presented in the spirit of a "strawman" and are subject to (drastic) revision.

Table 5.2: Use or Facility vs. Subsidiary (Episodic) Objective

\begin{tabular}{|l|l|}
\hline USE OR FACILITY & SUBSIDIARY OBJECTIVE - Likelihood of ... \\
\hline Uranium Milling & Yellowcake and Chemical Release \\
\hline In Situ Leaching & Yellowcake and Chemical Release/Groundwater Excursion \\
\hline Fuel Conversion & Yellowcake Release/ UF6 and other Chemical Release \\
\hline Fuel Enrichment & UF6 and other Chemical Release \\
\hline Fuel Fabrication & Large Radiological and Chemical Release/ Criticality \\
\hline Industrial Uses & Radiation Dose to Workers/Public \\
\hline High Level Waste & Failure of Waste Isolation (also see new 10 CFR 63) \\
\hline Low Level Waste & Release from Waste Disposal Unit \\
\hline Mill Tailings & Release from Impoundment Area \\
\hline Transportation & Loss of containment, shielding, and/or criticality control \\
\hline Decommissioning & Dose \\
\hline Spent Fuel (Pool) & Fuel Damage/ Release \\
\hline Spent Fuel (Dry Storage) & Loss of confinement, shielding, criticality control, and/or fuel retrievability \\
\hline Reactor Operation & Core Damage/ Large Early Release \\
\hline
\end{tabular}


The subsidiary objectives proposed in Table 5.2 should be regarded as the analogues to the core damage frequency or the large early release frequency of the reactor operations area. The objective, in each case of materials use and disposal, is chosen to characterize the engineering or process barrier that must be maintained in order to provide reasonable assurance of adequate protection. The objectives are set at a level that is high enough to allow flexibility to the owners and operators to maintain safety in a performance-based manner. They are also set low enough to capture and manage the risk associated with the particular technology. Each objective is briefly discussed below.

Uranium Milling: The main concerns here are the dispersal of yellowcake powder as a result of an upset condition and the potential release of chemical that are used in the milling process.

In Situ Leaching: The main concern is again the dispersal of yellowcake powder and the potential for release of chemicals used in the leach process. There is also a potential for environmental damage to the aquifer due to an excursion of the extraction solution (lexiviant) from the ore body.

Fuel Conversion: The concern is again with yellowcake, which is the input to this process and with UF6 that may be accidentally released from the storage bottles at the output of this process. Other chemical, used in this process, may serve as risk parameters as well.

Fuel Enrichment: Release of UF6 from storage bottles (both enriched and unenriched) and from the cascades are primary concerns. In addition, chemical releases of HF and UO2F2 must be considered whenever UF6 comes into contact with moist air.

Fuel Fabrication: Radiological release associated with various aspects of the conversion of UF6 to UO2 pellets and chemical releases are the concerns. In addition, there is a potential for criticality here that may warrant special attention.

Industrial Uses: Radiation doses to workers and the public associated with particular industrial processes are the concern.

High Level Waste: The loss of waste isolation is selected as the figure of merit to measure repository performance. For preclosure activities, a radiological release characterization may be more suitable. Note that the new 10 CFR 63 intends to be more performance-based by prescribing dose limits rather than performance requirements related to the engineered and geologic systems at Yucca Mountain. This is not necessarily in conflict with having goals for the engineered and geologic systems. The latter could be helpful in the development of a risk management program for DOE (and NRC). Compliance with the regulations would be achieved at a higher level of performance (i.e. the dose limit).

Low Level Waste: Radiological release from the waste disposal unit is chosen as the parameter to gauge facility performance.

Mill Tailings: Radon release from the impoundment area is the essential hazard for this objective.

Transportation: The potential concerns are: loss of containment of the hazardous material being transported, failure of the shielding to perform its function, or, for certain materials, criticality. 
Decommissioning: Radiological release from a decommissioned site is the concern, particularly for one that has achieved only restricted site release, and thus has the potential for the failure of institutional or physical barriers.

Spent Fuel (Pool): While not categorized with materials use and disposal, it is useful to provide an integral picture across nuclear activities. Here the concerns are with fuel damage and the potential for a radiological release.

Spent Fuel (Dry Storage): As above, this objective is illustrated for cohesiveness of presentation. Breach of the storage cask and potential for radiological release are the concerns.

Reactor Operation: For completeness and perspective, the established objectives for this case are included here.

\subsection{Responses to Case Study Questions on Safety Goals}

These questions are contained in the Case Study Plan [10] and the responses, below, are based on the proposed first draft safety goals that are presented in Section 5.5, above.

\section{Are the current regulations sufficient in that they reflect the objectives of the proposed first draft goals? Would major changes be required?}

From examination of the risks reported in the matrix presented in Appendix B, it can be seen that for prompt fatalities to the public or to the workers, the proposed first draft safety goals would be easily met for most of the nuclear materials use and waste areas. Only the irradiators show a small risk contribution for workers. This risk, however, is a small fraction of occupational risk and thus this safety goal (if a specific numerical value is adopted) is likely to be met. For the gaseous diffusion plant, there is a potential, not assessed here, of prompt fatalities to workers due to a criticality event. For latent cancer risk to individual members of the public, the goal is $2 \mathrm{E}-6$ per year. It can be seen that about half of the entries are below this goal (by an order of magnitude or more) and that half of these entries are above the goal (by up to approximately an order of magnitude). Notably uranium recovery and field radiography are above the goal and gas chromatographs, dry cask storage, and gaseous diffusion plants are below the goal.

Clearly, for those facilities and operations that are below the goal, the objectives of the goals is reflected. For those above the goal, while the residual risk above background (100-300 mrem/yr) is less than the contribution from the latter, areas for possible improvement in the regulatory approach may be suggested.

Draft goals related to the workers do not currently have counterparts in the NRC regulations. The exposures covered under 10 CFR 20 are regulatory limits for determining compliance, not goals. Other-agency jurisdiction for non-radiological accident conditions would need to be examined for consistency with these draft goals.

The environmental goals are new and tentative. As such, they have no direct touchstones with existing regulations. It is worth noting that potential safety goals related to land contamination have been discussed for reactor accidents for some time now. In the Staff Requirements Memorandum 
[55] on SECY-00-0077, the Commission disapproved the NRC staff's recommendation that the Safety Goal Policy Statement include "there be no adverse impact on the environment."

\section{Would the regulations need to be tightened?}

As discussed above, adequate protection appears to be assured for several of the NMSS application indicated in the risk matrix given in Appendix B. Tightening of regulations may be warranted for field radiography on the basis of the comparison with the goals and from the operational history in this area. The regulations for uranium recovery may bear further scrutiny. However, conventional mills are mostly no longer operational and in situ leach facilities tend to be in remote locations (thus limiting the population risk).

If the suggestions for worker protection and environmental protection were to be adopted, then it is possible that an associated regulatory framework would need to be developed.

\section{Are the regulations overly conservative and/or too prescriptive with respect to the goals?}

The current requirement in 10 CFR Part 72 was overly conservative with respect to seismic design. While the conservatism of current regulations in other areas of Part 72 was not evaluated in this case study, preliminary results from the dry cask storage risk assessment may indicate that the risks are reasonably low and that some relaxation of regulations may be warranted.

For conventional uranium mills, the regulation (10CFR 40, Appendix A) is rather prescriptive, yet the risk is on the higher side of the NMSS regulated activities (see Appendix $B$ ).

The case study on the Trojan Reactor Vessel Package pointed out that the Type B package accident requirements in 10 CFR Part 71, for this atypical package, was overly prescriptive. The recent risk assessment for spent fuel transportation (NUREG/CR-6672) indicates relatively low risks, but further review is warranted.

For sealed sources and devices, the regulations are generally not overly conservative. However, the scope of devices reviewed by the staff is broad; therefore, in assessing the conservatism of the regulations, the specific radionuclides and the health risks they pose would need to be considered.

With regard to decommissioning, the License Termination Rule is not prescriptive because it is dose-based and does not set concentration limits. The License Termination Rule is consistent with the proposed draft safety goals.

The current requirement in 10 CFR Part 76 for seismic design was not overly conservative with respect to the goals and was consistent with the proposed safety goals.

\section{If these were the safety goals, what decisions would be made?}

Generally, the case studies indicated that safety goals would be helpful to the staff in making decisions that are consistent and commensurate with the risk that a device, facility, or activity presents. For example, the safety goals could be useful in the case-by-case decisions (in the absence of a 10 CFR 41) being made for in-situ leach facilities. The development of an improved 
risk management program for field radiography may be suggested. Risk management for site decommissioning would proceed unchanged.

\section{Would these goals be acceptable to the public?}

At the Stakeholders Meeting [15] held on October 25, 2001, there was general agreement by the stakeholders that NRC should proceed with development of safety goals in the nuclear materials use and waste area. The format of these goals, as presented in Section 5.5 without specific parameters suggested, was not a point of objection by the stakeholders. These goals are cast in a framework similar to the one that has been in existence for over 15 years for nuclear power plants. However, further stakeholder involvement will be necessary as safety goals are developed and their implications understood. 
This chapter is devoted to the fourth objective of the Case Study Plan, that is, to identify the gaps in the tools, methods, data, and guidance required to risk inform the activities of NMSS.

\subsection{Background}

In order to bring risk insights to a particular assessment or decision, a method is needed to calculate the risk of the condition or activity in question. There are a wide range of activities and conditions for which risk tools have been used to calculate risk. The scope, depth of analysis, end products, and mode of inquiry are essential aspects of a risk assessment that define the particular methodology. For example, in the area of health science (or environmental) risk assessment, the top level approach is to address:

$\begin{array}{ll}\text { - } & \text { Hazard identification } \\ \text { - } & \text { Dose response assessment } \\ \text { - } & \text { Riskosure assessment } \\ & \text { Risacterization }\end{array}$

These four activities are well suited to a situation in which a hazard is continuously present (this could be regarded as a "chronic" risk) and the risk needs to be evaluated.

For engineered systems, the favored top level approach to risk assessment addresses the socalled risk triplet:

- What can go wrong?

- How likely is it?

- What are the consequences?

This approach is naturally suited to "episodic" risks, where something fails or breaks, a wrong action is taken, or a random act of nature (such as a tornado or a seismic event) occurs. This is the approach that has been taken, with much success, in probabilistic risk assessments of nuclear power reactors. The NRC White Paper on Risk-Informed and Performance-Based Regulation, [2], has an evident orientation toward reactor risks that are episodic in origin. The White Paper does note that risk insights are also derived from "predicted dose from decommissioned sites".

The environmental risk assessment methodology and the engineered system methodology do have elements in common, particularly in the dose and exposure areas. Further, in the development of physical and biomedical models in the environmental area, uncertainties in the parameters of the models and the models themselves are expressed probabilistically. This is also sometimes the case in the engineered system area.

Thus, the kind of analytical methodologies that will be most useful for analyzing risk depends on the activity and system under review in the materials and waste areas. As noted above, there is a difference between activities and systems that are operational in which the episodic risk is applicable, i.e., what can go wrong, how likely is it, and what are the consequences, and areas that pertain to post-decommissioned facilities where the risk is due to materials that are incorporated in the background. In operational facilities, probabilistic or quantitative risk assessment is the 
generally the method of choice and the tools such as failure modes and effects analysis (FMEA) are employed along with release and exposure models to estimate risk. A second difference pertains to the likely modes of release and exposure. Different release and exposure models could be required depending on whether the release is to air, water, or land and what the dominant mode of exposure is, inhalation, ingestion, or submergence in a shine mode. For many of the byproduct materials facilities, such as sealed sources, static eliminators, radiography, irradiators, etc., the dominant mode of exposure is due to loss of shielding. A second mode is dispersal of material due to a fire or a mechanical impact. Chemical releases and modes of exposure, ingestion or inhalation, are other important areas of analysis in some NMSS licensed facilities, such as uranium mills and fuel fabrication plants.

\subsection{Outline of Risk Methodologies in the Materials and Waste Areas}

SECY-99-100 classifies the activities of NMSS into four groups and associates various risk assessment methods with each group (see Attachment 2 of the SECY):

(1) Performance assessment (PA) is identified as the method of choice for evaluation of the risk posed by activities that involve long-term commitment of a site or facility to the presence of nuclear material at a planned acceptable level. This group includes a high level waste repository, low level waste disposal, site decommissioning, and uranium mill tailings reclamation. SECY-99-100 defines PA to be a type of systematic safety assessment that characterizes the magnitude and likelihood of health, safety, and environmental effects of creating and using a nuclear waste facility which can be used to show compliance with long-term performance objectives for such facilities.

(2) Probabilistic risk assessment (PRA) can be used for activities that involve the use of engineered systems to isolate nuclear material under normal and off-normal conditions. Spent fuel transport and storage are identified as activities that comprise this group.

(3) Integrated safety assessment (ISA), a technique developed for the chemical process industry, is a hazard identification and assessment methodology that allows for flexibility in the scope and detail of the analyses depending on the magnitude of the hazards and the nature of the system. Fuel fabrication, enrichment, and mining and milling of source material that present both chemical and radiological risks constitute the activities in this group.

(4) Hazard/Barrier analysis as applied in the Nuclear Byproduct Material risk assessment methodology is identified in SECY-99-100 as the method for activities that involve the use of sealed or unsealed byproduct material in industrial and medical applications. These activities include: irradiators, radiography, well logging, static eliminators, medical uses of radiation for diagnosis and therapy, gauges and measuring devices, etc.

\subsubsection{Performance Assessment}

Performance assessment (PA) is the method of choice for evaluation of the risk posed by a high level waste repository. SECY-99-100 defines PA to be a type of systematic safety assessment that characterizes the magnitude and likelihood of health, safety, and environmental effects of creating and using a nuclear waste facility. Upon reviewing some applications of performance assessment, 
PRA and PA appear to be very similar methodologies. In a recent paper, Eisenberg, et. al. [27] state the connection very succinctly and directly: "performance assessment is a probabilistic risk assessment method applied to waste management". Further, in a paper on this subject, Garrick [60], notes that: (PRA) is identified with the risk assessment of nuclear power plants, probabilistic performance assessment (PPA), or just PA, is its counterpart in the radioactive waste field. He adds that in the mid-1990s the USNRC began to equate PRA with PA.

\subsubsection{Probabilistic Risk Assessment}

Probabilistic risk assessment or PRA has been used extensively for risk assessment of nuclear power reactors. In NMSS, PRA has been used for estimating the risk from transportation of spent fuel (NUREG/CR-6672) [30]. A study using PRA is also underway in the Office of Nuclear Regulatory Research [28] for estimating the risk from dry storage casks containing spent fuel. Attachment 1 to SECY-98-138 states that the "staff sponsored a study that applied PRA methods to a new medical technology". This study was a first step in gaining insight into the feasibility of applying PRA technology to medical devices. SECY 99-100 indicates that although the results of this application were positive, the approach was expensive and had some significant limitations.

\subsubsection{Integrated Safety Analysis}

Integrated Safety Assessment (ISA) is a qualitative or semi-quantitative method of risk assessment to identify facility and external hazards and their potential for initiating accident sequences. It focuses on process-specific accident sequences, assigns a qualitative measure of likelihood and consequences, and then identifies the items relied on for safety (i.e., the systems and components and personnel activities that are relied on to prevent accidents at a facility or mitigate their consequences). Descriptions of ISA as applied to NRC regulated facilities are provided in [61] NUREG-1520, "Standard Review Plan for the Review of a License Application for a Fuel Cycle Facility", NUREG-1513, "ISA Integrated Safety Analysis Guidance Document" [62] and in industry guides (e.g., "Industry Guidance Document on Preparation of an ISA Summary" [63]).

\subsubsection{Barrier/Hazard Method}

The barrier/hazard methodology for risk-informing byproduct material systems has been developed in NUREG/CR-6642, "Risk Evaluation and Evaluation of Regulatory Options for Nuclear Byproduct Material Systems". This methodology is based on grouping all byproduct materials into 40 systems (13 medical, 27 non-medical uses) that have features in common. Each system is systematically described in terms of processes/tasks, hazards, barriers, and receptors. The barriers, both physical and administrative, are developed and identified based on the basic safety functions shielding, confinement, and limiting access - taking into account the source strength and nature of the radionuclides involved. Deviations from normal that can cause worker or public radiation exposure were identified. The approach is based on the Hazard and Operability Analysis (HAZOP) procedure similar to that used in the chemical industry.

\subsection{Examples of the Use of Risk Methods}

The risk methodologies discussed above should not be thought of as mutually exclusive, they share a number of common features and attributes, and there is no hard and fast dividing line between them. The differences arise from the level of completeness, the amount of detail, the pedigree of 
the models used, and the standards against which the methods have been evaluated and validated. All of the methods address in one way or another the questions contained in the risk triplet stated earlier; the difference lies in the rigor and completeness with which the answers are given. However, the most rigorous methods, such as PRA or quantitative risk assessment, require the most resources and the appropriateness of their use or application or the use of a less rigorous approach has to be justified in terms of the risks involved.

Below, some methods that were used or referenced in the 8 case studies are discussed briefly. In the case of decommissioning of a nuclear power plant, the Trojan site decommissioning case study discussed a combination of PRA and PA to provide a complete risk profile of the plant and site from the start of decommissioning activity to license termination. The case studies of gas chromatographs, static eliminators and fixed gauges referenced the risk assessment performed in the nuclear byproduct materials risk analysis. Accordingly, the methods used in this analysis are briefly reviewed. The case studies of uranium recovery, the Paducah gaseous diffusion plant seismic upgrade, transportation of the Trojan reactor vessel package, and the seismic exemption of the DOE/INEEL TMI-2 fuel debris ISFSI can be regarded in some cases as highly focused risk assessments that only dealt with one specific issue and not the overall risk profile of the facility. In the uranium recovery case study, the risk assessment of the in-situ leach process is an example of a scoping or screening risk assessment that used the limited data available to reach conclusions about the risk presented by the facility.

\subsubsection{Site Decommissioning}

The case study on site decommissioning of the Trojan plant recognized that PA has been recommended as the methodology for assessing the risks related to residual contamination associated with decommissioning. In order to obtain some insight on how this might proceed, it is worthwhile to briefly review how PA is applied to the repository. In the risk studies described in [27], the probabilistic aspects of the assessment come from two areas: 1) the likelihood of disruption of the repository site, due to natural and man-caused events, at some time after site closure and 2) the uncertainty characterization in the physical models of the transport of radionuclides. The analyses do not provide a probabilistic depiction of habitation of the environs of the repository site at the time of exposure. Further, there is no discussion of the risk during the preclosure phase (a multi year period) of the repository in this reference.

If one now looks to the decommissioning of a nuclear facility in this light, certain parallels can be drawn in connection with the use of PA for decommissioning.

(1) The period from cessation of power operations to site release is analogous to the preclosure operations phase of the repository. There is much activity on both sites during these respective phases. Worker risk can be expected to be dominant from (episodic) accidents (both radiological and nonradiological) and from (chronic) exposure to contamination.

(2) The period from site release to 1000 years for a decommissioned site is analogous to the postclosure 10000-year period for the repository. The radiological source term for the former is much smaller. 
(3) The foregoing suggest that for the 1000 year period of the decommissioned site, the likelihood of stochastic events and their consequences be assessed. Fires and floods are two obvious candidates.

(4) For both the decommissioned site and the repository the long term dose recipient is treated deterministically. This is a potential area for risk-informing the assessment in both situations.

A framework for applying a mix of PA and PRA methods that could be done in the context of the LTR is identified in the Trojan decommissioning case study. We distinguish the two phases of decommissioning that is outlined in item 1 as the pre-release and post-release phases. The postrelease phase includes unrestricted and restricted site release conditions. Pre-release is included in the analysis because there may be some activities that would be carried out during this phase that pose risks for the near term (e.g. to workers) that ought to be weighed, in a risk-informed manner, against the implications of these activities and their alternatives for the longer term postrelease risks. In both the pre-release phase and the post-release phase, it is important to tailor the analysis to the risks posed by the activities and situations to be analyzed. In general, relatively more effort in the analysis should be given to the higher risk areas. Smaller risks should be evaluated with bounding and screening approaches.

A PRA for the pre-release phase is performed. This is based on the operations that are planned for in the licensee's post-shutdown decommissioning activities report (PSDAR) or decommissioning plan. Risks to the public and to the site workers are assessed. For the workers, both nonradiological and radiological risk scenarios are developed. Routine (chronic) and accident (episodic) risk are computed. Risks are expressed in term of health, environmental, and economic impacts.

A PA for the post-release phase is performed. As discussed above, its content will be similar to the PA that is performed for the repository. Chronic doses and their implied health effects are assessed for the 1000-year period. The likelihood of the resident farmer scenario, the building occupancy scenario, and other potential scenarios as well as the nature of the critical group are evaluated probabilistically. It is recognized that there are great uncertainties in this area and these uncertainties will be expressed in the analysis. Model and parameter uncertainties for the dose assessments will also be reflected in the quantitative assessment of risk. The probabilities for the occurrence of natural events that may disrupt the site during this period will be assessed. The consequences of this event in terms of transport of radionuclides to the environment and their potential health effects will be calculated. Human intrusions to the site will also be evaluated.

For sites that have restricted release, scenarios need to be developed that will challenge the engineered and institutional barriers and controls that have been put in place to meet the requirements for restricted site release. The likelihood of these scenarios and their consequence should be quantified, including assessments of uncertainties. Public, worker, radiological, and nonradiological risks would be included in this analysis.

\subsubsection{Byproduct Nuclear Material Risk Assessment}

NUREG/CR-6642 [29] applied a barrier/hazard method based on the HAZOP approach developed in the chemical industry to obtain the risk for 40 systems using nuclear byproduct materials. A 
radiation risk assessment was carried out for each system, determining both the risk of routine operations and of accidents for the workers and the public. For each task, doses and risks (consequences and frequencies) were quantified for sequences that occur routinely or can occur (accident). The risks were then tallied to obtain the risk for each task and the whole system.

Risk is defined as the product of frequency of a particular state occurring and the consequences to a receptor of being in that state. The frequency of being in a particular state is the frequency of a task that can potentially lead to that state multiplied by a set of conditional probabilities; the probability of an initiating event that can lead into that state and the probability of a failure of a preventive or mitigative barrier. The consequence to a receptor (worker or a member of the public) depend on the nuclide and quantity associated with the state, the degree of confinement, the effectiveness of shielding, and the location of and time spent by the receptor in that state. Other factors, such as dispersion of released material, also affect the estimation of consequences. All pathways of exposure, external exposure, inhalation, ingestion, and submersion in a radioactive cloud, were included in the approach.

Event trees based on failure or success of the three basic safety functions, shielding, confinement, and access were constructed for each task and/or initiating event. Given that each safety function can result in success/failure there are thus $2^{3}=8$ outcomes or sequences of each event tree. The information used to characterize the systems was developed using the NRC databases, the General License Database that contains information on approximately 50,000 general licenses and the Licensing Tracking System that tracks 5,900 specific licensees. Additional information was obtained from the Nuclear Materials Event Database, NMED, vendors, licensees, industry reports, $\mathrm{NRC}$ regulations and guidance documents, etc.

The risks obtained were used to develop a set of regulatory options for byproduct material systems based on "public and worker health and safety" ensuring that each option comprised a set of system barriers and regulatory structure that would lead to compliance with guidelines on safe dose limits. The options were developed using a "diamond tree" approach that shows how elements of a system, including safety systems and components, human actions, and training interact and perform together to provide successful system performance.

SECY-00-0048 [64] "Nuclear Byproduct Material Risk Review" provides an overview of the methodology developed in NUREG/CR-6642. It indicates that the study provides a relative risk ranking for purposes of comparison of different activities but does not contain enough information to identify where changes in regulation would be most effective. It also points out that the risk values obtained in the study have uncertainties of one or more orders of magnitude and indicates that this is due to lack of information about activities and uncertainties in available information, human factors and performance, and uncertainties in the models used.

\subsubsection{Focused/Screening Risk Assessments}

The case studies of the Paducah gaseous diffusion plant seismic upgrade, the DOE/INEEL TMI-2 ISFSI seismic exemption, and the transport of the Trojan reactor vessel package are examples of focused or partial risk assessments where the techniques of PRA were applied to estimate the risk due to one specific hazard or one specific system. In such applications, there is an issue of the possible neglect of system interactions or of synergy among various hazards in the estimate of risk. Moreover, fragmented risk assessments tend to not provide an overall picture of the contributors 
to risk. The case study of uranium recovery referenced the risk assessment of in-situ leach (ISL) facilities. This risk is both chemical and radiological and the ISL risk assessment can be regarded as a scoping or screening type of risk study based on the small amount of available data.

\subsection{Preliminary Identification of Gaps in the Methods, Tools, Data, and Guidance}

The brief survey of methods used in various areas of NMSS activity indicates that there is a fairly significant application of risk methods and applications in some areas and somewhat less experience in other areas. The application of performance assessment for the waste repository is well-advanced from the risk standpoint and can be considered a reasonably developed technology for application to other areas such as site decommissioning or other long-term risks that arise from material in the background. PRA is a mature technology for power reactors and systems. Its application to specific NMSS activities is limited mostly by data and experience and a judgement on whether the resources needed for its application would be justified by the risks involved. ISA is relatively newer as compared to PRA. Some issues have been raised in ACRS meetings on the relative merits of ISA and PRA as applied to relatively complex facilities such as fuel fabrication facilities or enrichment plants. The ACNW stated in a letter to the NRC Chairman that ISA has not been sufficiently tested on issues critical to nuclear regulation, such as applicable standards, peer review, quality control, and validity of databases [65]. Completeness of the list of accident scenarios and the analysis of uncertainty have also been cited [66] as possible shortcomings of this method compared to PRA. The barrier/hazard method developed for the byproduct nuclear materials is a comparatively recent development and more experience and guidance on its use is needed.

One of the major gaps in the methods is the identification and development of a robust and simple method for incorporating human factors and estimating human reliability in the very wide range of situations and activities encountered and performed by NMSS licensees. These situations range from the extremely procedure-based methods encountered in medical technology to the relative absence of any procedures for devices such as general-purpose gauges. SECY 99-100 pointed out that in the case of the gamma knife risk study [67], although PRA correctly predicted human error to be the principal accident initiator, the fault tree event tree methodology was an inadequate tool for analyzing such accidents. Similarly, in the area of industrial radiography, where very serious radiation injuries have occurred in the past [68], human errors coupled with mechanical failures appear to be the main cause. The nuclear byproduct material risk review in SECY-00-0048 [64] also identifies uncertainties in human factors and performance as being one of the principal contributors to uncertainty in the risk estimates.

Data availability suitable for the needs of risk assessment is another area that should be explored in greater detail. In some case studies, such as Trojan site decommissioning, there is a fair amount of good quality data that can be used for risk purposes. In some other cases, such as insitu leach facilities, comparatively less information is available.

Overall, the experience of conducting the case studies has shown that there has been a fairly significant application of risk assessment methods in various activities regulated by NMSS that provides a good foundation on which future development can occur. The adoption of safety goals for materials use and waste disposal as envisaged in the Commission's SRM on SECY-99-100 is a necessary step in the process of risk-informing. In addition, the development of guidance on the 
level of detail and complexity required in the risk methods for various activities should be helpful to staff in future plans for risk-informing NMSS. 


\section{$7 \quad$ FINDINGS, CONCLUSIONS, AND FUTURE PLANS}

\subsection{Findings}

Sections 7.1.1-7.1.5 summarizes how the objective of the Case Study Plan [10 ] have been met. Section 7.1.5 shows how the Staff Requirements Memorandum [7 ] for SECY-99-100 have been addressed.

\subsubsection{Screening Considerations}

A well-defined procedure for identifying candidate applications for risk-informing has been successfully tested and has been finalized as a set of screening considerations. Overall, the case studies demonstrated that the screening considerations contained all the relevant elements needed for risk-informing and can be a useful decision-making tool. However, the application can be subjective so guidance is needed. The experience of carrying out the case studies also indicated that the draft screening criteria should be more properly identified as screening considerations instead of criteria. They are a set of factors that encompass the relevant questions that are needed for risk-informing and do not have just yes/no answers.

\subsubsection{Regulatory Decisions}

The case studies have collectively illustrated that risk information has been used in making regulatory decisions. They were effective in indicating where decisions or processes are consistent with the Agency's strategic goals. Furthermore, they have helped to highlight some of the areas in which there are shortcomings in the regulations or regulatory process. Specifically, the case studies illustrated how risk information:

(1) provides burden reduction and improved efficiency in decision making without a reduction in safety,

(2) can be used to make the regulations more consistent for generally licensed, specifically licensed, and exempt devices,

(3) can indicate where increased regulatory oversight may be warranted,

(4) would allow resources to be focused in proportion to risk,

(5) can identify and highlight the significance of non-radiological risks of a facility or activity,

(6) can facilitate the certification process of a facility,

(7) can illuminate options for long-term disposal of a facility,

(8) can support granting an exemption from the existing regulations,

(9) can highlight the need to revise regulations. 


\subsubsection{Safety Goals}

The studies also showed that safety goals are feasible and decision-making and risk management can be facilitated if a clear set of safety goals existed. A proposed first draft of safety goals have been developed which now need to be tested and refined. Risks to the workers have been found to be significant in comparison to public risks. For some facilities, chemical risks have been found to be comparable to or greater than the radiological risks.

\subsubsection{Methods, Data, and Guidance}

Information, tools, methods, and guidance needs have been identified and the necessary informational tools can be assembled to make the risk-informing process more effective in NMSS. There is a fairly significant application of risk methods and applications in some areas and somewhat less experience in other areas. Tools for risk-informing exist in some materials use and waste areas, but would need to be developed in others. One of the major gaps in the methods is the identification and development of a robust and simple method for incorporating human factors and estimating human reliability in the very wide range of situations and activities encountered and performed by NMSS licensees.

The development of guidance on the level of detail and complexity required in the risk methods for various activities should be helpful to staff in future plans for risk-informing materials and waste arenas. NMSS has a program in place to train its staff in the methods and applications of risk information.

\subsubsection{The SRM to SECY-99-100}

The results of the case study program can now be assessed relative to the Staff Requirements Memorandum [7] for SECY-99-100. The specific points of the SRM are presented here (in italics) along with the specific findings. Overall the case studies show that the staff has been responsive to the requirements set forth by the Commission.

- $\quad$ The staff should develop appropriate material safety goals analogous to the reactor safety goal, to guide the NRC and to define what safety means for the materials program.

The staff has determined that safety goals are feasible for the materials and waste arenas. A proposed first draft of safety goals have been develop (Chapter 5) that parallel the reactor safety goal. These goals will need to be further refined and subsidiary objectives need to be developed. Ultimately, taken together, the reactor goal and the nuclear materials use and waste goals can become a comprehensive set of goals for the entire agency.

- $\quad$ The staff should develop these goals through an enhanced participatory process including broad stakeholder participation.

Several stakeholder meetings were held (see Chapter 2) over a two-year period. A broad and inclusive representation of interested stakeholders was sought and strongly encouraged to attend these meetings. Written comments were encouraged as well. It is anticipated that as the safety goal development continues, broad stakeholder participation will occur. 
- $\quad$ The NMSS framework should include as a goal the avoidance of property damage and the staff should develop appropriate metrics for it.

The preliminary goals presented in Chapter 5 include a qualitative goal as well as a quantitative metric. Further work needs to be done on the development of this goal.

- The staff should consider whether critical groups can be defined for classes of material use, consistent with Commission decisions in the License Termination Rule (Part 20) and on high-level waste disposal at Yucca Mountain (Part 63).

In the development of the risk characterization to the individual that is presented in Appendix $B$, the notion of the group that is exposed was used. This will help to test and refine the concept of critical groups in the further development of safety goals.

- $\quad$ The staff give due consideration to existing radiation protection standards in 10 CFR 20.

In the consideration of safety goals, 10 CFR 20 was assumed to be the standard for worker protection from routine radiological exposures. A subsidiary objective is proposed for chronic exposures ("incident-free" exposures) such as those the may occur in the proximity of a decommissioned reactor, a mill tailing pile, or transported spent fuel.

- New standards should allow for equivalent levels of reasonable assurance of adequate protection across the spectrum of regulated materials activities and should be consistent with risk-informed practices being applied to nuclear power plant regulation.

The qualitative and quantitative goals presented in Chapter 5 are specifically designed to achieve this purpose. Subsidiary objectives (Chapter 5.5.3), that are specific to the particular regulatory activities, will now have to be quantified to assure that this equivalence is promulgated to the third tier of the safety goal structure.

- $\quad$ The Agreement States component must be factored into risk-informing for the materials program.

As noted above, stakeholders meetings were held over the course of this program and some Agreement States have sent representatives to provide input to various topics. As the safety goal work progresses, continued and focused attention will be given to areas appropriate to Agreement States.

\subsubsection{NRC Strategic Goals}

The conclusions of the case studies with regard to the value of risk information (Chapter 4.1), give several examples of how the information supported the goals of safety issue elucidation, regulatory efficiency, undue burden reduction, and communication. As discussed in Chapter 5 , the first four screening considerations for determining whether to risk-inform are based on the NRC's strategic goals. 


\subsection{Conclusions}

Risk-informing NMSS activities has been occurring in specific areas and to varying degrees over a number of years. Although more work needs to be done, as discussed in Section 7.3, there are no fundamental impediments to the expansion and broader application of risk information across the spectrum of NMSS-regulated activities.

Risk information can be valuable as an additional input to decisions that NMSS must make. It can complement the more familiar information that is derived from consideration of the existing regulatory framework. It can help to make that framework more rational. An integrated and balanced risk management program would recognize both public and worker risks as well as radiological and nonradiological risks at the regulated facilities.

An important adjunct to risk information when used for managing risks, is a set of safety goals that assist the decision maker in determining whether safety objectives will be achieved. If safety goals are to move forward, then risk information can be readily compared with these goals to guide and inform regulatory issue resolution.

The case studies illustrated that the seven factors that constitute the screening considerations can be a very useful decision-making tool but their application can be subjective, hence guidance is needed. The seven factors are one important tool in the management decision to risk-inform a specific activity or process. The screening considerations not only lead to a decision whether to risk-inform or not, they also begin to formulate what the issues involved in the decision are and what information and methods are needed to address them. Risk informing in this context implies a commitment to use a set of formal methods or approaches such as PRA in the regulatory decision-making process.

The application of the screening considerations is not only useful in the decision of whether or not to risk-inform a particular activity, the questions posed by the screening considerations also lead to the process of understanding how to risk-inform the activity, i.e., what information is needed, how it should be organized, and what kinds of issues can or need to be addressed by risk-informing. However, the implementation of these screening considerations as one factor in the management decision to risk-inform a specific activity or decision within NMSS requires guidance.

\subsection{Future Plans}

As specific applications for risk-informing nuclear materials use and waste arenas progresses, further development of the proposed first draft safety goals will occur. These two activities will be mutually supportive and synergistic. Safety goals will help to guide and inform regulatory issue resolution and exploration of the issues will provide insights to the refinement and further development of the safety goals. Particular attention will be given to risks to the workers and the presence of nonradiological risks.

The existing risk training program will be further developed to cultivate risk analysts who are capable of performing risk assessments, drawing risk insights, and formulating risk management strategies for the various areas that NMSS regulates. As NMSS continues its work in developing the safety goals and incorporating the risk-informed approach into rulemaking, licensing, guidance development, inspection and enforcement, the curriculum will be updated periodically to make 
available to the staff the latest applications, data and tools to further advance staff's knowledge and capability in implementing the risk-informed approach.

Data availability suitable for the needs of risk assessment is another area that should be explored in greater detail. In some case studies, such as Trojan site decommissioning, there is a fair amount of good quality data that can be used for risk purposes. In some other cases, such as insitu leach facilities, comparatively less information is available.

NMSS is following a general, three-phase plan [69] to implementing the framework described in SECY-99-100. The first phase focuses on developing a systematic approach for identifying candidate NMSS regulatory applications that may be amenable for increased use of risk information. The second phase focuses on applying the systematic approach, developed through the first phase, to identify the candidate NMSS regulatory applications. Finally, the third phase focuses on the actual modification of the identified regulatory applications to make them more riskinformed.

Phase 2 is expected to begin upon finalization of the screening considerations, described above. Phase 2 will focus on the systematic review of NMSS materials and waste regulatory applications, to identify those that would be amenable to an increased consideration of risk insight and information. Specific Phase 2 activities are not yet defined; however, a general approach has been formulated and is described below.

The product of Phase 2 is expected to be a set of potential future risk-informed initiatives and activities for various NMSS regulatory areas. Staff will provide the supporting justification for the activities by documenting the application of the screening considerations. The activities will then be prioritized through the normal PBPM prioritization process. 


\section{REFERENCES}

1. US NRC, "Use of Probabilistic Risk Assessment in Nuclear Regulatory Activities: Final Policy Statement," Federal Register, Vol. 60, No.158, August 16,1995.

2. US NRC "Staff Requirements - SECY-98-144 - White Paper on Risk-Informed and Performance Based Regulation”, March 1,1999.

3. US NRC, SECY-98-138, "Risk-Informed, Performance-Based and Risk-Informed, LessPrescriptive Regulation in the Office of Nuclear Material Safety and Safeguards," June 11, 1998.

4. US NRC, SECY-99-100, "Framework for Risk-Informed Regulation in the Office of Nuclear Material Safety and Safeguards," March 11, 1999.

5. US NRC, Draft Screening Criteria, Federal Register, 65 FR 14323, March 16, 2000.

6. US NRC, Case Study Plan and Revised Draft Screening Criteria, Federal Register, 65 FR 54323, September 7, 2000.

7. US NRC, "Staff Requirements Memorandum - SECY-99-100 - Framework for RiskInformed Regulation in the Office of Nuclear Material Safety and Safeguards," June 28, 1999.

8. US NRC, "Transcript of the Public Workshop on Risk-Informing NMSS," April 25-26, 2000, Washington, DC..

9. US NRC, "Transcript of the Public Meeting on the Draft Case Study Plan," September 21, 2000, Rockville, MD.

10. US NRC, "Plan for Using Risk Information in the Materials and Waste Arena," Case Studies Plan, prepared by the Risk Task Group, ADAMS Ascension Number ML0110040111, October 27, 2000.

11. US NRC, "Transcript of the Public Meeting on the Case Studies of Gas Chromatographs, Static Eliminators, and Fixed Gauges," February 2, 2001, Rockville, MD.

12. US NRC, "Transcript of the Public Meeting on the Case Studies of the Trojan Site Decommissioning and the Trojan Reactor Vessel Shipment," May 11, 2001, Rockville, MD.

13. US NRC, "Transcript of the Public Meeting on the Case Study of Uranium Recovery," June 13, 2001, Denver, CO.

14. US NRC, "Transcript of the Public Meeting on the Case Studies of the DOE/INEEL TMI-2 Fuel ISFSI Seismic Exemption and the Seismic Modifications to the Paducah Gaseous Diffusion Plant," July 31, 2001, Rockville, MD.. 
15. US NRC, "Transcript of the Public Meeting on Integration of Case Studies," October 25, 2001, Rockville, MD.

16. Reference 10, op.cit.

17. US NRC, "Final Generic Environmental Impact Statement on Uranium Milling," NUREG0706, September 1980.

18. US NRC, “NRC Strategic Plan FY 2000-2005”, NUREG-1614, October 19, 2000.

19. US NRC "Radiological Criteria for License Termination" 10 CFR 20, Subpart E.

20. US NRC "Standard Format and Content of License Termination Plans for Nuclear Power Reactors," Regulatory Guide 1.179, January 1999.

21. US NRC, "Decommissioning Standard Review Plan,” NUREG-1727, September 2000.

22. US NRC "Screening Values of Derived Concentration Guideline Levels," Federal Register, 63 FR 64134, November 18, 1998, and 64 FR 68396, December 7, 1999.

23. Kennedy, W.E. Jr., and D.L. Strenge, "Residual Radioactive Contamination from Decommissioning," NUREG/CR-5512, 1992.

24. Kamboj, S. et al. "Probabilistic Dose Analysis using RESRAD and RESRAD-BUILD Codes," NUREG/CR-6676, July 2000.

25. US NRC, "Multi-Agency Radiation Survey and Site Investigation Manual (MARSSIM)," NUREG-1575, December 1997.

26. US NRC, "Decision Methods for Dose Assessment to Comply with Radiological Criteria for License Termination,” NUREG-1549, July 1998.

27. Eisenberg, N.A. et al. "Development of a Performance Assessment Capability in Waste Management Programs at the US NRC", Risk Analysis, Vol. 19, pp. 847-875, 1999.

28. US NRC, Office of Nuclear Regulatory Research, "Dry Cask Storage PRA Status and Initial Assessments", Briefing to the SFPO, July 20, 2001.

29. Schmidt, E.R., et al. "Risk Analysis and Evaluation of Regulatory Options for Nuclear Byproduct Material Systems," NUREG/CR-6642, Scientech, Inc., February 2000.

30. Sprung, J.L. et al., Re-examination of Spent Fuel Shipment Risk Estimates," NUREG/CR6672, Sandia National Laboratories, March 2000.

31. US NRC, "Reactor Safety Study, An Assessment of Accident Risks in U.S. Nuclear Power Plants," WASH-1400, NUREG-75/014, October 1975

32. US NRC, "Severe Accident Risks: An Assessment for Five U.S. Nuclear Power Plants," NUREG-1150, December 1990. 
33. US NRC, "Individual Plant Examination Program," NUREG-1560, November 1996.

34. US NRC, "An Approach for Using Probabilistic Risk Assessment in Risk-Informed Decisions on Plant-Specific Changes to the Licensing Basis," Regulatory Guide 1.174, July 1998.

35. Smith, J.A., "Using Risk Information in the Nuclear Materials and Waste Arenas: A Case Study on the Regulation of Gas Chromatographs", US NRC, December 2001.

36. Danna, J.G., "A Case Study on the Regulation of Static Eliminators," US NRC, December 2001.

37. Shane, R.M., "A Case Study on the Regulation of Fixed Gauges," US NRC, December 2001.

38. Bari, R.A. and E. Grove, "Risk Informing Uranium Recovery," Brookhaven National Laboratory, December 2001.

39. Mackin, P. et al., "A Baseline Risk-Informed Performance-Based Approach for In Situ Leach Uranium Extraction Licensees," Center for Nuclear Waste Regulatory Analyses, NUREG/CR-6733, June 2001.

40. Bari, R.A. and J. Xu, "A Case Study of Risk Informing 10 CFR Part 76: Seismic Issues at the Paducah Gaseous Diffusion Plant," Brookhaven National Laboratory, December 2001.

41. Bari, R.A. and V. Mubayi, "Risk Informing Site Decommissioning," Brookhaven National Laboratory, December 2001.

42. Drummond, C.M. and D.R. Damon,"A Case Study on Transportation of the Trojan Reactor Vessel Package," US NRC, December 2001.

43. Wong, A., et al., "A Case Study on the Seismic Exemption for the DOE/INEEL TMI-Unit 2 Fuel Debris Independent Spent Fuel Storage Installation," US NRC, Draft, December 2001.

44. US NRC, "Safety Goals for the Operation of Nuclear Power Plants: Policy Statement," Federal Register, Vol. 51, No. 149, August 1986.

45. US NRC, "Disposal of High-Level Radioactive Wastes in a Proposed Geologic Repository at Yucca Mountain, Nevada; Final Rule, 10 CFR Parts 2, 19, 20, 21, 30, 40, 51, 60, 61, 63, 70, 72, 73, and 75," Federal Register, Vol. 66, No. 213, pp 55731-55816, November 2, 2001.

46. USNRC, "Final Generic Environmental Impact Statement on Decommissioning of Nuclear Power Reactors," NUREG-0586, August 1988.

47. Reference 17, op.cit. 
48. US NRC, SECY-00-0137, "Response to Staff Requirements Memorandum Dated December 21, 1998 -- SECY-98-232-- "Seaman Nuclear's Application to Distribute Portable Gauges to General Licensees," June 2000.

49. US NRC, SECY-98-232, "Seaman Nuclear's Application to Distribute Portable Gauges to General Licensees," 1998.

50. U.S. Nuclear Regulatory Commission, "Use of Defense in Depth in Risk-Informing NMSS Activities", ACRS/ACNW Letter to the Chairman, May 25, 2000.

51. 51. Reference 27, op.cit.

52. United Kingdom Health and Safety Executive, "Safety Assessment Principles for Nuclear Plants", ISBN 011882043 5, 1992, http://www.hse.gov.uk/nsd/saps.htm.

53. Matsuura, S. "Action of Nuclear Safety Commission of Japan", AESJ/ANS Joint Meeting on Safety Goals and Safety Culture, Milwaukee WI, June 18, 2001.

54. Reference 18, op.cit.

55. US NRC, "Staff Requirements Memorandum - SECY-00-0077 - Modifications to the Reactor Safety Goal Policy Statement”, June 27, 2000.

56. US Congress, “Uranium Mill Tailings Radiation Control Act (UMTRCA)”, PL 95-604, 1978.

57. US Congress, "Nuclear Waste Policy Act”, PL 97-425, 1982.

58. US Congress, "Low-Level Radioactive Policy Amendments Act of 1985, PL 99-240, 1985.

59. US Congress, "National Environmental Policy Act", PL 91-190, 1969.

60. B.J. Garrick, "Radioactive Waste Disposal," Proc. Of the Workshop on Promotion of Technical Harmonization of Risk-Based Decision-Making, European Commission, Stresa, Italy, May 22-24, 2000.

61. US NRC, "Standard Review Plan for the Review of a License Application for a Fuel Cycle Facility," Draft NUREG-1520, May 11, 2000.

62. US NRC, "ISA Integrated Safety Analysis Guidance Document,"NUREG-1513, Draft, 1999.

63. Nuclear Energy Institute, "Industry Guidance on Preparation of an ISA Summary," September 2000.

64. US NRC, SECY-00-0048 "Nuclear Byproduct Material Risk Review," February 24, 2000.

65. US NRC, "Development of Risk-Informed Regulation in the Office of Nuclear Material Safety and Safeguards," Letter from ACNW to NRC Chairman, July 27, 2000. 
66. US NRC, "Implementing a Framework for Risk-Informed Regulation in the Office of Nuclear Material Safety and Safeguards," ACRS/ACNW Letter to Chairman, November 17, 1999.

67. Jones, E.D., et al., "Relative Risk Analysis in Regulating the Use of Radiation-Emitting Medical Devices," NUREG/CR-6323, Lawrence Livermore National Laboratory, 1997.

68. US NRC, "Working Safely in Gamma Radiography," NUREG/BR-0024, September 1982.

69. US NRC, "Risk-Informed Regulatory Implementation Plan 2001" 


\section{APPENDIX A: Related Risk Documents and Studies}

\section{A.1 Nuclear Byproduct Material Systems}

A number of risk studies of nuclear byproduct material systems were carried in NUREG/CR-6642 [A1]. The goal of these studies was to identify risk-informed regulatory options for byproduct materials that are currently regulated under 10 CFR Parts 30 through 36 and Part 39 . The process involved (1) organization of nuclear byproduct material, as used, into 40 systems, (2) identification of existing and potential physical and procedural barriers that limit dose to workers and the public, (3) risk analysis of each system under normal operation and off-normal (accident) conditions, (4) consideration of regulatory options for each system, and (5) comparison of regulatory options to current regulatory barriers. A graded approach, based on comparison of risk analysis results with dose screening guidelines, is used. Options considered ranged from those that would provide a high level of assurance that doses exceeding guidelines would be prevented, through those where performance-based approaches would assure prevention of doses near the guidelines, to those where little appears necessary to assure doses well below the guidelines.

The non-medical applications analyzed in NUREG/CR-6642 included well logging (tracers and field flooding), well logging (sealed sources), irradiators (pool and self-shielded), and radiography (field and shielded room). NUREG/CR-6642 also reviewed several waste disposal practices including incineration, compacting, packaging, and solidification.

Well logging in the oil and gas industry through use of radioactive tracers is practiced on a large scale. Solid, liquid, and gaseous tracers are employed by injected into a single well (regulated under 10 CFR 39) or into or more wells, a practice called field flooding that is regulated under 10 CFR 30. Single well applications use the isotopes Sc-46, Ir-192 and Sb-124 in solid form. Field flooding employs gaseous tracers such as $\mathrm{H}-3, \mathrm{C}-14, \mathrm{Xe}-133$ or $\mathrm{Kr}-85$ and liquid solutions of I-131 or HTO (tritiated water). Potential accidents that can occur during receipt, storage, preparation, use (both above ground and subsurface), and recovery and disposal include the failure of access controls, dropping of a container, a fire leading to failure of shielding and source confinement, operator failure to observe procedures leading to excessive exposure, spill of the material, inadvertent injection into a fresh water aquifer. The annual worker dose from normal operations is estimated at between 1 and 2 rem, dominated by the large number of solid tracer injection operations during aboveground activities at the well site. Public (the public in this case consists of other workers in the vicinity of well logging operations) doses from normal operations are stated to be a factor of about 6 lower. The accident risk in terms of expected value of dose is much smaller compared to the risk from normal operations. However, the maximum exposures of workers in accidents where gaseous tracers are involved are stated to approach the range where health effects could be observed.

\section{A.2 Spent Fuel Transportation}

The risk study reported in NUREG/CR-6672 [A2] updates an earlier generic environmental impact statement, "Final Environmental Statement on the Transportation of Radioactive Material by Air and Other Modes", NUREG-0170 [A3]. NUREG-0170 provided the regulatory basis for issuance of general licenses for transportation of radioactive material under 10 CFR 71. NUREG/CR-6672 estimates the radiological and nonradiological, routine and accident transportation risks based on updated methodology for estimating risks and on updated plans and cask designs for spent fuel 
shipments. It concluded that incident-free population doses involving shipments by truck or rail were somewhat (but not greatly) lower than those estimated in NUREG-0170. It was also concluded that the cask failure criteria in NUREG-0170 led to conservatively large radioactive releases and thus to conservative predictions of accident risk.

\section{A.3 Dry Cask Storage Probabilistic Risk Assessment}

The Office of Research of NRC is performing a probabilistic risk assessment [A4] for dry cask storage. There is no formal documentation of this study at this time, but there have been briefings on the progress of this work. The study follows the structure of a Level 3 PRA and thus include frequency of fuel damage, assessment of physical processes associated with radiological releases, and health risks to the public. This PRA focuses on handling, transfer, and storage of the spent fuel for 20 years. It does not consider fabrication of the casks, off-site transportation, or sabotage. The study considers a spectrum of initiating events including accidental aircraft crashes, tornadoes, and lightning strikes. Other initiating events, are being screened in accordance with sitespecific characteristics. Issues under consideration include fuel misloadings, criticality, and inadequate preparation of the spent fuel package in the cask. Human actions related to the latter as well as transfer activities are being studied. Mechanical and thermal loads (including fires) are being evaluated to obtain cask failure probabilities. Radiological release fractions from the spent fuel are being guided by the NUREG/CR-6672 analysis as well as a calibration against NUREG1150 [A5] release characteristics for the Surry plant. Consequence analysis is being performed with the MACCS code [A6]. Initial and preliminary results of this study indicate that the off-site risks are very low.

\section{A.4 In Situ Leach Facility Probabilistic Risk Assessment}

"A Baseline Risk-Informed, Performance-Based Approach for In Situ Uranium Extraction Licensees", NUREG/CR-6733 [A7] was performed by the Center for Nuclear Waste Regulatory Analyses (CNWRA) for NMSS. Its purpose is to provide a risk-informed, performance-based foundation for regulating in situ leach (ISL) facilities. 10 CFR 40 applies broadly to facilities related to source and byproduct material and has been used for the licensing uranium recovery facilities. Appendix A of 10 CFR 40 provides criteria for conventional uranium mills and for the disposition of their wastes and tailings. However, there are no specific regulations that address ISL activities that are not also common to conventional uranium mills (e.g. yellowcake drying is addressed by contamination of groundwater by ISL activities is not addressed). These exceptional situations for ISLs are addressed by the imposition of license conditions on the licensees. NUREG/CR-6733 provides a risk perspective for ISL operations that could lead to a more predictable and stable regulatory process.

The study addressed both radiological and chemical risks on the surface environment and in the groundwater. The authors determined that it was not practical to do a conventional PRA for the hazards involved. In performing this study, the authors realized that the conventional (reactor-type) probabilistic risk analysis approach would need to be modified for the ISL application. They noted that it had to be tailored to the nature of the specific materials, activities, and regulatory requirements associated with ISL facilities. Based on the hazards that come under NRC purview for ISL facilities, CNWRA defined three top-level categories for further analytical decomposition. They are: 
- Surface environmental chemical hazards

- Surface environmental radiological hazards

- Groundwater chemical and radiological contamination hazards.

The authors noted that NRC considers chemical mishaps only to the extent that they could imply radiological releases.

CNWRA examined the Nuclear Materials Events Database (NMED) [A8] and determined that release of radioactive material and contamination of groundwater occurred with relatively high frequency (within the lifetime of an ISL facility). Thus they focused on the evaluation of the consequences of these accidents. They also assessed the consequences of various accidents in a conservative way. If they found that the consequences were unacceptable from a regulatory standpoint, they explored mitigation actions. They wanted to avoid dealing with the uncertainties and difficulties associated with calculating the likelihood of occurrence with a small amount of data available.

The foregoing is one approach to risk management. It avoids the development of uncertainty distributions by eliminating, or minimizing the impact, of the source of the uncertainty. However, in some instances this may not be practical or cost-effective. Even if probabilities are very low and have large uncertainties associated with them, methods exist to characterize these uncertainties. This alternative approach would allow a balancing of consequence against probability and thus provided a relative risk perspective for the various events considered in the CNWRA study. It would help to prioritize the sundry recommendations provided in that study. In order to do this, risk would have to be expressed in common units (or a valuation would have to be placed on risk parameters in different units).

NUREG/CR-6733 is a good starting point for a more complete probabilistic risk assessment for ISL's. Facility-specific studies would help to reveal and correct weaknesses and vulnerabilities in facility design and/or operation.

\section{A.5 Irradiator Risk Study}

Irradiators are devices that use sealed gamma sources to irradiate and disinfect food products, sterilize medical products and cosmetics, and to conduct research on the effects of gamma rays on organic and inorganic materials. Dry source irradiators are licensed under 10 CFR 32.210. In pool irradiators, the sources, mainly Co-60, are stored in a pool of water 10 to 30 feet deep inside a shielded room or cell. Access to the room is controlled through a system of interlocks and alarms. The sources are raised out of the pool to deliver the required dose or the material may be submerged in the pool. In other irradiators, the sources are stored dry inside a depleted uranium or lead shield and then are moved or the shielding is removed to give the required dose. Some pool irradiators have large sources (exceeding $1 \mathrm{MCi}$ ) and the dose rate in air about $1 \mathrm{~m}$ from the source can exceed 500 rads per hour so failure of access controls with the source exposed could lead to a severe injury or even fatality. Another potential accidental exposure can occur if a portion of the source is carried outside the cell on the conveyor which transports the material to be irradiated. Risk studies of these facilities that are licensed under 10 CFR 36 are reported in ICRP 
Publication 76, NUREG/CR-6642 and in PRM 36-1 [A9], the petition for rulemaking requesting amendment of 10 CFR 36.65 as described below.

PRM-36-1 requested that NRC amend 10 CFR 36.65 to provide relief from the requirement that an operator and at least one other individual, who is trained to respond to access control alarms, must be present onsite, whenever the irradiator is operated using an automatic product conveyor system, and whenever the product is moved into or out of the radiation room when the irradiator is operated in a batch mode. Staff commissioned a risk study to assess the impact of the proposed rule changes using NUREG/CR-6642 as the basis and expanding upon it. The study used fault tree models to assess risk to irradiator operation when operators are located offsite. The risk analysis estimated the current frequency of a life-threatening exposure of a worker to be about $5 \times 10^{-8}$ per year for a continuous facility and about $9 \times 10^{-8}$ per year for a batch facility, based on a model facility developed with the assumption that the facility would generally meet the requirements of NRC's current regulations. The basic risk results for not having the operator onsite would increase the risk of an accidental irradiation of a worker at a continuous irradiator by a factor of about 70 , to approximately $4 \times 10^{-6}$ per year. For a batch irradiator, the risk would increase by a factor of about 10, to approximately $1 \times 10^{-6}$ per year. Based on Table 710, "Statistical Abstract of the United States 2000," U.S. Census Bureau, the risk of occupational fatality for all U.S. workers in 1998 was $4.5 \times 10^{-5}$ per year. For manufacturing workers, it was somewhat less, $3.3 \times 10^{-5}$ per year. Excluding falls, homicide, and transportation accidents, the remaining process-related manufacturing fatalities were only 53 percent of this, or a risk of $1.7 \times 10^{-5}$ per year. Thus, the irradiator risk of $4 \times 10^{-6}$ per year is about 20 to 25 percent of this rate for process-related manufacturing fatalities. No changes are anticipated in the risk to the public because sealed sources are contained in the radiation room, and irradiator facilities have security systems and access control to the radiation room. While the staff, based on this comparison, viewed a fatality risk of $10^{-6}$ per year range to be generally acceptable, the Commission was not informed of the proposed petition response due to emerging events.

\section{A.6 Radiography Risk Study}

Risks of industrial radiography operations have been reported in several studies. NUREG/BR-0024 "Working Safely in Gamma Radiography" [A10] published in September 1982 reported on several accidents in the 10-year period from 1971-1980. The study revealed that industrial radiographers suffer a major portion of the overexposures among workers employed by NRC licenses. Over the time period of the study, there were 600 over exposures reported by all licensees and one-quarter of these were industrial radiographers although they made up only a few percent of people working with radiation at NRC-licensed facilities. Even more important, there were 21 serious overexposures reported over the 1971-80 period (exceeding 25 rem whole body or 375 rem to an extremity) and 15 of these were radiographers with some suffering permanent injury. NUREG1631 [A11] published in 1998 reviewed radiography camera system failures and their implications for exposing radiography workers. NUREG-6642 evaluates the risks of both field and sealed room radiography systems. The dominant mode of exposure is when the radiation source is left exposed due to failure of the equipment to retract the source back to its shielded position or to human error (forgetting to retract or secure the source). Failure to perform a radiation survey or perform it adequately compounds the risk.

A petition for rulemaking, PRM-34-1, requested that the NRC clarify Part 34.20 to remove the associated equipment from the rule and continue to perform source and devices reviews only. In 
addition, the petitioner requested that Part 34.28 be amended to reflect appropriate inspection and maintenance requirements for all of the radiography equipment including associated equipment. In response to this petition, staff commissioned a risk study using NUREG/CR-6642 as the basis and expanding upon it. The risk assessment evaluated the change in risk to the workers and the public from radiography operations if the petition was granted. In performing the evaluation of the petition, available data on radiography events, exposure history, and self-certification in other industries were included where possible. The overall conclusion of the assessment is that the adverse risk impact of granting the petition is expected to be very small. Another risk study of radiography is the petition for rulemaking PRM 34-5 [A12] that requests NRC to clarify the requirements of Part 34.20 related to the scope of equipment for industrial radiography operations that is covered under the rule. It concluded that improvements in radiography equipment and performance standards to address the human error and equipment deficiencies that are the dominant contributors to risk would do more to reduce risk than any potential increases due to granting the petition.

\section{A.7 Shelwell Risk Assessment}

Shelwell, located in Hebron, Ohio, was licensed to use sealed sources and unsealed radioactive material in well logging and tracer studies of oil and gas wells. In 1983, the license accidentally drilled into a 2-curie, cesium-137 sealed source, which caused the spread of radioactive contamination. The site was substantially decontaminated following this incident. The licensee completed additional decontamination, and requested release for unrestricted use. However, elevated radiation was caused by very small, discrete particles containing Cs-137. The particles appeared to be insoluble, with minimal leaching to surrounding soil. Contamination was also identified on surfaces inside a building. The building contamination was also in the form of very small particles. The initial analysis of the soil samples collected from the elevated areas, and the review of the building surface contamination measurements, indicated that the contamination levels significantly exceeded NRC criteria for unrestricted use. The NRC staff would approve termination of the Shelwell license if the staff determined that the site had been adequately decontaminated, and the site was suitable for release for unrestricted use in accordance with 10 CFR 30.36, 10 CFR Part 20, Subpart E, and other applicable requirements.

The fact that the contamination identified was in the form of discrete, very small, particles made comparison with those guidelines difficult. The unrestricted-use guidelines for both building surfaces and soil apply to average contamination levels and assume that the contamination is uniformly distributed and relatively widespread. However, calculating average levels to determine compliance for the Shelwell site had limited usefulness. For example, using conservative assumptions, it could be demonstrated that the average Cs-137 concentration in the soil at the Shelwell site was less than the applicable guideline. However, individual soil samples were identified that contained over 70 times the guideline level. The high activity levels were caused by the presence of one, or perhaps a few, discrete particles in the soil samples. Therefore, to determine the risk to the public at the Shelwell site, the individual particles had to be evaluated, in addition to the average contamination level.

In 1998, the staff performed a risk assessment which was reported in SECY-98-117 [A13]. Mechanistic doses from these particles were calculated for inhalation and ingestion related to both the soil and the building. The probabilities of incurring these doses were also estimated and 
expected annual doses were obtained. These were found to be well within the dose criterion of the License Termination Rule criterion ( $25 \mathrm{mrem} / \mathrm{yr}$ ) for unrestricted release of a site.

The staff considered the PRA in SECY-98-117 to be the "NRC-approved decommissioning plan" which eliminated the need for a formal submittal by the licensee for license termination. The license was terminated in 1999. Thus, in the Shelwell licencing action NRC has not only been riskinformed, it has been risk-based. The EPA concurred with NRC's analysis and issued a Finding of No Significant Impact [A14].

\section{A.8 Radiological Assessment of Exemptions for Source and Byproduct Materials}

In NUREG-1717, "Systematic Radiological Assessment of Exemptions for Source and Byproduct Materials" [A15], an assessment was made of potential radiation doses associated with the current exemptions for byproduct and source material in Title10 of the Code of Federal Regulations. Doses were estimated for the normal life cycle of a particular product or material, covering distribution and transport, intended or expected routine use, and disposal using dose assessment methods consistent with the current requirements in 10 CFR Part 20. In addition, assessments of potential doses due to accidents and misuse were estimated. Also presented is an assessment of potential radiological impacts associated with selected products containing byproduct material which currently may only be used under a general license and may be potential candidates for exemption from licensing requirements.

\section{A.9 Risk Analysis of Fixed Nuclear Gauges}

Fixed nuclear gauges containing the radionuclides Cs-137, Co-60, or Am-241 are used in many industries to improve the quality and lower the costs of products for industrial, commercial, and private uses. However, gauges that are improperly controlled during use and transfer can expose people to radiation and, upon entering the stream of recycled steel, can cause steel mills to spend millions of dollars to decontaminate equipment and dispose of contaminated materials. The risk to licensees and the recycling industries that nuclear gauges pose is incompletely understood. In NUREG-1669, "Risk Analysis of Fixed Nuclear Gauges" [A16], an analysis of fixed gauges was performed to study the risk to life and property, from facilities where the gauges are used to steel mills where the gauges might be melted. This risk analysis should be of interest to all stakeholders--agencies that promulgate regulations, licensees who must comply with the regulations, and the recycling industries who use scrap steel as a resource for making products. Although risk could not be estimated because data are lacking, observations and insights were made that can be used by all stakeholders to reduce their risk, even if the extent of the reduction is unknown.

\section{A.10 Risk Analysis in Regulating the Use of Radiation-Emitting Medical Devices}

NUREG/CR-6323, "Relative Risk Analysis in Regulating the Use of Radiation-Emitting Medical Devices" [A17], describes a preliminary application of an analysis approach for assessing relative risks in the use of radiation-emitting medical devices. Results are presented on human-initiated actions and failure modes that are most likely to occur in the use of the Gamma Knife, a gamma irradiation therapy device. This effort represents an initial step in an NRC plan to evaluate the potential role of risk analysis in regulating the use of nuclear medical devices. For this preliminary application of risk assessment, the focus was to develop a basic process using existing techniques 
for identifying the most likely risk contributors and their relative importance. The approach taken developed relative risk rankings and profiles that incorporated the type and quality of data available and presented results in an easily understood form. This work was performed by the Lawrence Livermore National Laboratory for the NRC.

\section{A.11 10 CFR 63 for Yucca Mountain}

While 10 CFR 63 [A18] is not itself a risk study, it does suggest a risk-informed approach to the licensing of high-level radioactive waste at Yucca Mountain. In the new 10 CFR 63, the Commission seeks to establish a coherent body of risk-informed, performance-based criteria for Yucca Mountain that is compatible with its other efforts in this area. The Commission advocates that compliance with its performance objectives be demonstrated through 1) an integrated safety analysis of preclosure operations and 2) a performance assessment for long-term, post-closure performance.

For preclosure activities, NRC advocates protection to the workers and public through maintaining exposure limits given in 10 CFR 20 and, for operational occurrences requiring that for any member of the public beyond the site boundary that the dose would not exceed $25 \mathrm{mrem} / \mathrm{yr}$. This latter value is consistent with other NRC regulations in the area of waste management (e.g. low level waste, decommissioning).

For post-closure, the Commission proposes an individual dose limit, rather than an explicit individual risk limit with the understanding that a dose/risk equivalence is understood on the basis of a constant total effective dose equivalent to health risk coefficient. Further, the Commission advocates an individual dose limit because it believes that the public would readily understand this limit and that it would be in a form more frequently used to regulate nuclear activities. The final standard issued by the Environmental Protection Agency [recently set at $15 \mathrm{mrem} / \mathrm{yr}$ ] has been adopted by NRC in the final version of 10 CFR 63. The expected annual dose is recognized by $\mathrm{NRC}$ to be probabilistic in the sense that it incorporates the probability that the estimated dose will occur. Further this is recognized to be the expected annual dose to the reasonably maximally exposed individual. The Commission now considers that probabilistic risk assessment (or performance assessment for the repository is sufficiently mature (15 year of experience) to allow it to be the sole quantitative method to be used to demonstrate compliance with the post-closure individual dose limit. The Commission recognizes the importance of defense-in-depth and of the multiple (engineered and geologic) barriers of the repository system. However it does not believe that it should prescribe which barriers are important to waste isolation or the methods to describe their capability to isolate waste. 


\section{A.12 References for Appendix A}

A1. Schmidt, E.R., et al. "Risk Analysis and Evaluation of Regulatory Options for Nuclear Byproduct Material Systems," NUREG/CR-6642, Scientech, Inc., February 2000.

A2. Sprung, J.L. et al., Re-examination of Spent Fuel Shipment Risk Estimates," NUREG/CR6672, Sandia National Laboratories, March 2000.

A3. US NRC "Final Environmental Statement on the Transportation of Radioactive Material by Air and Other Modes," NUREG-0170, December 1977.

A4. US NRC, Office of Nuclear Regulatory Research, "Dry Cask Storage PRA Status and Initial Assessments", Briefing to the SFPO, July 20, 2001.

A5. US NRC, "Severe Accident Risks: An Assessment for Five U.S. Nuclear Power Plants," NUREG-1150, December 1990.

A6. Chanin, D. and M.L. Young, "Code Manual for MACCS2," NUREG/CR-6613, SAND970594, Sandia National Laboratories, May 1998.

A7. Mackin, P. et al., "A Baseline Risk-Informed Performance-Based Approach for In Situ Leach Uranium Extraction Licensees," Center for Nuclear Waste Regulatory Analyses, NUREG/CR-6733, June 2001.

A8. US NRC, "The Nuclear Materials Events Database (NMED)," http://nmed.inel.gov.

A9. Advanced Technologies and Laboratories International, Inc., "An Evaluation of the Risk to Workers From Irradiator Operators Being Located Offsite," Evaluation of the Petition for Rulemaking 36-1, Prepared for the U.S. NRC, Office of Nuclear Material Safety and Safeguards, November 30, 2000.

A10. US NRC, "Working Safely in Gamma Radiography," NUREG/BR-0024, September 1982.

A11. Camper, L.W., et al., "Source Disconnects Resulting From Radiography Drive Cable Failures,” NUREG-1631, United States Nuclear Regulatory Commission, June 1998.

A12. Advanced Technologies and Laboratories International, Inc., "Risk Assessment of the Petition for Rulemaking Petition PRM-34-5," Prepared for the U.S. NRC, Office of Nuclear Material Safety and Safeguards, July 12, 2001.

A13. US NRC, "Shelwell Services, Inc., Risk Assessment," SECY-98-117, Memorandum from L.J. Callan to the Commissioners, May 27, 1998.

A14. US EPA, Federal Register, Vol.64, No.36, pp.9181-9182, February 24, 1999.

A15. US NRC, "Systematic Radiological Assessment of Exemptions for Source and Byproduct Materials," NUREG-1717, June 2001. 
A16. US NRC, "Risk Analysis of Fixed Nuclear Gauges," NUREG-1669, March 2000.

A17. Jones, E.D., et al., "Relative Risk Analysis in Regulating the Use of Radiation-Emitting Medical Devices," NUREG/CR-6323, Lawrence Livermore National Laboratory, 1997.

A18. US NRC, "Disposal of High-Level Radioactive Wastes in a Proposed Geologic Repository at Yucca Mountain, Nevada" Code of Federal Regulations Title 10 Part 63. 


\section{APPENDIX B: Risk Perspective and Safety Goals}

\section{B.1 Some Thoughts on Populations at Risk}

The following is a discussion which raises some issues in the identification of risk metrics for safety goals in the nuclear materials and waste arenas. This area warrants further exploration in the development of safety goal guidance.

Before one can decide what level of risk is safe enough, one must identify what types of consequences are being addressed and who is the population at risk. There are many potential adverse consequences of nuclear hazards including prompt fatality, latent fatality, injury, and other health detriments. Safety goals for the general public living in the vicinity of nuclear power plants have been adopted by the Commission [B1]. Safety goals may be needed for each type of consequences, or they may be combined as in the concept of serious detriments discussed in the 1990 Recommendations of the International Commission on Radiological Protection (ICRP 60) [B2]. The focus of this section is the consideration of populations at risk. These concepts are also discussed in Section 4.2 in relation to the insights gained from the case studies. In particular, Subsection 4.2.2 discusses populations at risk.

The phrase "population at risk," as used here, does not refer to those persons most at risk. It refers, instead, to the concept that there are different populations in terms of the acceptability of risk to them. The differences of interest are those which might influence the answer to the question: Is this group of persons safe enough? One example of different populations at risk is the distinction between radiation workers and members of the general public. In order to identify all the risk metrics needed to address safety goals, one must identify all the populations at risk. Populations at risk can be differentiated from one another as being individuals, special groups, or all exposed persons. Each category possesses properties which influence the acceptability of risk to the members in that category.

A number of such risk-acceptability factors were considered in relation to safety goals. The properties that appeared most important were the following three: a) control, b) benefit, and c) individual vs. collective. One can identify general categories of "populations at risk" by forming combinations of these properties. In order to clarify this idea, the meaning of these three properties will be discussed below. The implication of this idea is that there may be a need for a risk metric and safety goal for each such general category. The acceptability of risk will, in principle, differ among them, as it does between workers and the general public.

\section{$\underline{\text { Control }}$}

Control refers to the degree of choice that the population has as to whether to be exposed to the risk or not. The degree of control which a person has over a risk affects the level of risk which that person will accept. The usual distinction is that between radiation workers and members of the offsite public. The public in the vicinity of a nuclear facility may be exposed to risks from that facility sited near them, but has no control over this risk. Radiation workers at the facility have the choice whether to engage in radiation-related work and thus have some degree of control over the exposure. There are degrees and types of control other than these two classic cases. Examples of other degrees of control include: non-radiation workers employed by the licensed facility; workers of other companies co-located at the site of the hazard; other workers who use a nuclear 
device; and members of the public who use a nuclear device for their benefit. The Health and Safety Executive in the United Kingdom provides different risk limits and goals for some of these different categories [B3]. NRC generally limits its categorization to just the basic two, workers and general public.

\section{Benefit}

Benefit refers to the amount of benefit that the population at risk derives from the regulated activity. Workers derive the benefits of employment. The acceptability of risk may be greater to a population at risk which makes the choice to accept a risk-benefit trade-off. It is important to remember that, in addition to the classic grouping of radiation worker and offsite public, there are special categories of persons whose situation is different with respect to benefit. These special cases include nonradiation workers and users of nuclear devices. As discussed previously, these two categories also differ with respect to degree of control.

\section{Individual vs. Collective (Societal) Risk}

The distinction being made here is between the individual risk to an average member of the critical group (see the discussion of "critical group" in the next section) versus the total risk summed over all persons. In one sense the "populations" here are the same, namely, all those at risk; but the risk metrics are different. This distinction needs to be considered in defining "populations at risk" because individual risk and societal risk are different metrics with different criteria for what is safe enough. In general, both types of risk metrics need to be considered in judging the safety of a situation. A situation which meets an individual risk goal, however, might not sufficiently minimize the societal risk. Avoidance of unnecessary societal risk appears to be the objective of certain regulatory practices. Examples of societal risk limitation include waste disposal at regulated sites and low population siting criteria.

\section{B.1.1 Individual Risk}

There are some technical subtleties and issues in this distinction between individual and societal risk that need to be clarified. The following discussion introduces some of the issues, but further work is needed. A risk evaluation for individual risk, in principle, would evaluate the risk to each individual that might be exposed. The safety goal or quantitative health objective (QHO) would be met if this risk metric were below some goal value. One way of stating it is that the objective would only be met if the risk to every single individual was at or below the QHO value. What is often evaluated as a subsidiary risk metric is the average risk to a potentially highly exposed group. In the case of the reactor safety goals, the groups are defined as those located within a predetermined distance from the nuclear power plant. This approach is closely related to the concept of "critical group" which is used to define design requirements in 10 CFR 20 and elsewhere. The subject has been intensively discussed with respect to various waste disposal and decommissioning safety criteria. A major goal of these criteria appears to be to limit individual risk. Thus, it appears feasible to establish critical groups for calculating individual risk metrics for specific applications in a manner identical, or very similar, to these design requirement critical groups. 


\section{B.1.2 Collective Risk}

The other type of risk metric is referred to here as collective. In the reactor safety goal, the related term used is "societal risk." Collective risk is risk summed over all individuals in a group, and not divided by the number of persons in that group. The population may be all persons exposed, or it may be a subgroup of interest, such as radiation workers at a particular plant. The term "societal risk," properly speaking, is the sum of all risks to all persons; that is, everyone. Collective risk, which could be for any relevant group, is thus the more general term. The difference between collective risk and individual risk is that collective risk is a total, not on a per person basis. An example would be the total person-rem exposure per year to workers at a facility, as opposed to the maximum dose in rem to an individual worker that year.

Collective risk metrics are used in various contexts in the regulation of nuclear materials and waste. Collective dose has been evaluated in transportation risk studies [B4] and in NUREG/CR-6642, the byproduct material risk study [B5]. Waste disposal at selected sites, and remote siting in general, appear to be driven by a goal of limiting both individual and collective risk. Thus it is clear that there are areas where safety goals on collective risk would be applicable. However, not all collective risk metrics are of equal standing. Collective risk to various groups are part of the sum that forms the total societal risk. It may be that only the total societal risk is fundamental, while other collective metrics are essentially subsidiary (tier III) quantitative guidelines that are components of this total. To facilitate optimization and comparison of a collective risk metric, the value of $\$ 2000$ per avoided person-rem is often applied.

\section{B.1.3 Safety Goals}

One product derived from the above considerations was the addition of a societal risk metric to the list of draft safety goal QHOs. With the individual risk metrics addressing the three types of consequences mentioned at the beginning of this section, namely prompt fatality, latent fatality and acute injury, the addition of this societal risk metric appears to form a more complete set of safety goal metrics that address all aspects of safety.

\section{B.2 Risk Perspective in the Materials Use and Waste Areas}

\section{B.2.1 Information for Table B.1}

To gain a perspective on the risks in the various non-reactor areas that are regulated by NRC, a tabulation of radiological risks has been constructed for the eight case studies and a few related areas. This tabulation is found in Table B.1. In this table, both public risk and worker risk to individuals are displayed.

It must be strongly emphasized that the information in Table B.1 should be regarded as very preliminary and is subject to revision as additional information on these risks becomes available. There has been essentially no critical review of the information presented here: it was extracted from the source documents as presented. There may be large uncertainties in some of these numbers. A careful review of this information may yield somewhat different results and other insights. This is a first-look presentation of these risks in a holistic way and it may be useful for developing a relative sense of the risk across a wide range of regulated activities. The risk are presented in terms of the annual likelihood of prompt or latent cancer fatalities. 
The following notes, as annotated in Table B.1, should be considered with regard to the numbers displayed in Table B. 1:

1. All numbers are preliminary rough estimates and are subject to revision. There may be at least an order of magnitude uncertainty for some of these numbers.

2. The notation NC means that no credible mechanism has been identified to exceed the threshold for prompt fatalities for the risk assessed.

3. The pre-exponential numbers shown have been rounded-up to the next whole number from the source information.

4. The risks reported here are due to potential radiological exposures only. In some areas the dominant risks are not radiological. For example, chemical hazards are significant for uranium recovery and for the gaseous diffusion plants. Occupational (nonradiological) risks to workers are not shown in this table and may be comparable to or exceed the radiological risk in some instances.

5. BEIR V [B6] dose conversion factor was used throughout to obtain latent cancer fatalities. The conversion factor is $5 \mathrm{E}-4$ latent cancer fatalities per rem.

6. Trojan Site Decommissioning: Latent cancer fatality risk to the public is based on a 1 $\mathrm{mrem} / \mathrm{yr}$ residual dose to the average member of the critical group. Other facilities may and can have a risk that is 25 times higher (allowed by the License Termination Rule, 10 CFR 20 , Subpart E). Latent fatality risk to the workers is based on the projected worker dose during from decommissioning operations at the Trojan facility. Reported worker doses for the years 1999 and 2000 [B7, B8] were reviewed. The average individual worker LCF/yr risk was found to be $2 \mathrm{E}-4$ and $1.2 \mathrm{E}-4$, respectively for those years. In the early, 1990s, the risk was somewhat higher and for the remainder of the decommissioning period it will become significantly less. We take $1 \mathrm{E}-4$ as the mid-term risk for this 20 year period.

7. Uranium Recovery: This has been separated into conventional mill and in situ leach.

A. For the mill, the Atlas EIS (NUREG-1531) [B9] was used to obtain characteristic doses from mill tailings. The numbers obtained from NUREG-0706 [B10], the GEIS for Uranium Milling are a factor of 2 and 3 lower, respectively, than the Atlas numbers.

B. For the in situ leach facilities, NUREG/CR-6733 [B11] was used to obtain characteristic risk estimates. This assessment process was confirmed with $P$. Mackin, principal author of this report.

The risk estimates presented here are generic. Specific calculations for actual sites may lead to risk estimates that are lower.

8. Paducah Gaseous Diffusion Plant: Latent cancer fatality risk to the public is based on projected exposure to radioactive effluents to the nearest offsite individuals as reported in SECY 98-275 (NRC Report to Congress, 11/24/98) [B12]. Similarly, latent fatality risk to the workers is based on the maximum dose received by a worker. Other sources of 
radiological exposure have not been identified to pose a higher risk. The prompt fatality risk to workers is designated as "NC", however, a probabilistic evaluation of the worker fatalities from a potential criticality event has not been identified. The possibility of a criticality event exists and should be noted. The hypothetical injury risks to the public from the accidents, as reported in the case study are due to chemical hazards.

9. Trojan Reactor Vessel: The vessel shipment is a one-time activity and, thus, is not an annualized risk. Also, values shown in ( ) are risk estimates if 44 truck shipments had been made instead of one barge shipment. [B13]

10. Spent Fuel Transportation: The risk reported here are synthesized from information obtained from NUREG/CR-6672 [B4] and NUREG-0170 [B14].

11. Dry Cask Storage:

A. Latent cancer fatality risk to the public is based on very preliminary information obtained from the ongoing NRC Dry Cask Storage PRA [B15]. The actual level of risk may be a few orders of magnitude less.

B. Latent fatality risk to the workers is based on the judgement that the annual dose will be approximately the same (or less) than the worker risk for spent fuel transportation.

12. Gas Chromatographs, Fixed Gauges, Small Sources, Field Radiography, Irradiators, Portable Gauges, Well Logging: Values derived from NUREG/CR-6642, "Risk Analysis and Evaluation of Regulatory Options for Nuclear Byproduct Materials Systems" [B5] (except for prompt fatality risk to workers from irradiators - see note 14).

13. Field Radiography: See discussion in Appendix A, Section A.6.

14. Irradiators: A risk study to assess the impact of the proposed rule changes estimated the current frequency of a life-threatening exposure of a worker to be about $5 \times 10^{-8}$ per year for a continuous facility and about $9 \times 10^{-8}$ per year for a batch facility, when operators are located onsite (NRC's current requirements). The basic risk results for not having the operator onsite would increase the risk of an accidental irradiation of a worker at a continuous irradiator by a factor of about 70 , to approximately $4 \times 10^{-6}$ per year. For a batch irradiator, the risk would increase by a factor of about 10 , to approximately $1 \times 10^{-6}$ per year. See Appendix A, Section A.5 for further discussion.

\section{B.2.2 Observations from Table B.1}

Several interesting observations can be made from Table B.1. First, it is seen that there are no credible mechanisms for prompt fatalities to the public. While prompt fatalities are, strictly speaking, not impossible, their probabilities are exceedingly low. Second, it is seen that for all but the entries for gaseous diffusion plants (criticality event, noted above) and for irradiators, there are no credible mechanisms for prompt fatalities to the workers. For latent cancer risks to the public, field radiography and uranium recovery are the highest risk areas. Gaseous diffusion plants, dry cask storage, spent fuel transportation, and gas chromatographs show the lowest risks to the 
public. The risk numbers in Table B.1 are the individual risks to the most exposed groups in each case. To obtain the collective risk from each entry, the exposed population must be factored into the assessment.

For workers, the individual annual risk ranges by a few orders of magnitude and tends to be in the range of one in one thousand latent cancer fatalities to one in one hundred thousand latent cancers fatalities.

Figure B.1 provides an additional perspective for these risks. Here only the individual latent cancer fatalities per year (LCF/yr) are shown. It is seen that, in the aggregate, the likelihood of risk to the workers is roughly two orders of magnitude higher than the public risk. For specific applications public and worker risks range from three orders of magnitude apart (gaseous diffusion plant) to less than one order of magnitude apart (in situ leach facilities and gas chromatographs).

In Figure B.2, the safety goal for U.S. nuclear power plant operation for latent cancer fatalities to the public is indicated ( $R S G=2 E-6 \mathrm{LCF} / \mathrm{yr}$ ). While this goal was developed for reactors, it may be instructive to see how the various materials and waste facilities and activities compare to the goal (especially since a specific goal does not yet exist for these areas). It is readily seen that this safety goal lies midway among the various nuclear materials uses and waste areas.

Another comparison can be made to the safety goals developed In the United Kingdom. The Health and Safety Executive has developed [B3] safety goals for the public and for workers for nuclear plants. There are two parameters of interest in the UK scheme. The Basic Safety Limit (BSL) is the risk value that a facility must stay below. Reduction of the risk in a cost-beneficial way should be achieved until the Basic Safety Objective (BSO) is achieved. Once the BSO is achieved, the reviewers need not seek further safety improvements from the licensee. The BSL and BSO are each given as a range of doses (associated with likelihood of occurrence). This information is converted here into latent cancer fatalities and shown in Figure B.2. Note that both upper bounds (UBSL and UBSO) and lower bound (LBSL and LBSO) values are given for the BSL and the BSO. In Figure B.2 several of the nuclear material use and waste activities fall between the BSL and the BSO.

Note further that the U.S. Reactor Safety Goal is bracketed by the upper bound of the UK BSO and the lower bound of the UK BSL. The UBSL is numerically equal to the LCF/yr implied by the an annual dose of $100 \mathrm{mrem} / \mathrm{yr}$, which is the public dose limit in for licensed activities under 10 CFR 20. The $25 \mathrm{mrem} / \mathrm{yr}$ residual dose limit for certain regulated activities (e.g. License Termination Rule) corresponds to $1.25 \mathrm{E}-5 \mathrm{LCF} / \mathrm{yr}$, which is midway (logarithmically) between the UBSL and LBSL in Figure B.2.

In Figure B.3, the worker safety goal developed by the UK is compared against the predicted latent cancer risks for the materials use and waste areas. These are again shown as a BSL and a BSO. Comparable goals (for accidental releases) have not yet been developed in the U.S. It is seen that some of the facilities and activities display risks between the BSL and BSO, a few are above the $\mathrm{BSL}$, and one is below the BSO. For reference, the occupational dose limit of $5 \mathrm{rem} / \mathrm{yr}$ in the U.S., corresponds to 2.5E-3 LCF/yr and this is above all of the risks shown in Figure B.3. 
Table B.1: Preliminary Annual Risk Estimates - For Perspective

(Notes 1, 2, 3, 4, 5)

\begin{tabular}{|c|c|c|c|c|c|c|c|c|c|c|c|c|c|c|c|}
\hline \multicolumn{16}{|c|}{ Preliminary Risk Estimates for Materials Use and Waste Areas - from Case Studies and Other Risk Studies } \\
\hline \multirow{2}{*}{$\begin{array}{l}\text { Risk } \\
\text { Measure } \\
\text { per yr. }\end{array}$} & \multirow{2}{*}{$\begin{array}{l}\text { Trojan } \\
\text { Site } \\
\text { Decom. } \\
\text { (Note 6) }\end{array}$} & \multicolumn{2}{|c|}{$\begin{array}{l}\text { Uranium Recovery } \\
\text { (Note 7) }\end{array}$} & \multirow{2}{*}{$\begin{array}{l}\text { Paducah } \\
\text { GDP } \\
\text { (Note 8) }\end{array}$} & \multicolumn{2}{|c|}{ Transport } & \multirow{2}{*}{$\begin{array}{c}\text { Dry } \\
\text { Cask } \\
\text { Storage } \\
\text { (Note 11) }\end{array}$} & \multirow{2}{*}{$\begin{array}{c}\text { Gas } \\
\text { Chrom. } \\
\text { (Note 12) }\end{array}$} & \multicolumn{2}{|c|}{$\begin{array}{l}\text { Fixed Gauges } \\
\text { (Note 12) }\end{array}$} & \multirow{2}{*}{$\begin{array}{c}\text { Small } \\
\text { Sources, } \\
\text { incl. } \\
\text { Static } \\
\text { Elim. } \\
\text { (Note 12) }\end{array}$} & \multirow{2}{*}{$\begin{array}{c}\text { Field } \\
\text { Radio- } \\
\text { graphy } \\
\text { (Note 12, } \\
13)\end{array}$} & \multirow{2}{*}{$\begin{array}{l}\text { Irradiators } \\
\text { (Note 12) }\end{array}$} & \multirow{2}{*}{$\begin{array}{c}\text { Portable } \\
\text { Gauges } \\
\text { (Note 12) }\end{array}$} & \multirow{2}{*}{$\begin{array}{c}\text { Well } \\
\text { Logging } \\
\text { (Note 12) }\end{array}$} \\
\hline & & Mill & ISL & & $\begin{array}{l}\text { Trojan } \\
\text { Vessel } \\
\text { (Note 9) }\end{array}$ & $\begin{array}{l}\text { Spent } \\
\text { Fuel } \\
\text { (Note 10) }\end{array}$ & & & Gamma & Beta & & & & & \\
\hline $\begin{array}{l}\text { Individ. } \\
\text { Prompt } \\
\text { Fatality } \\
\text { Risk to } \\
\text { Public }\end{array}$ & NC & NC & NC & NC & NC & NC & NC & NC & NC & NC & NC & NC & NC & NC & NC \\
\hline $\begin{array}{l}\text { Individ. } \\
\text { Latent } \\
\text { Cancer } \\
\text { Fatality } \\
\text { Risk to } \\
\text { Public }\end{array}$ & $5 \times 10^{-7}$ & $4 \times 10^{-5}$ & $4 \times 10^{-5}$ & $3 \times 10^{-7}$ & $\begin{array}{l}1 \times 10^{-5} \\
\left(3 \times 10^{-4}\right)\end{array}$ & $2 \times 10^{-8}$ & $10^{-8}$ & $1 \times 10^{-7}$ & $8 \times 10^{-6}$ & $8 \times 10^{-6}$ & $2 \times 10^{-6}$ & $3 \times 10^{-5}$ & $7 \times 10^{-6}$ & $3 \times 10^{-6}$ & $5 \times 10^{-6}$ \\
\hline $\begin{array}{l}\text { Individ. } \\
\text { Prompt } \\
\text { Fatality } \\
\text { Risk to } \\
\text { Workers }\end{array}$ & NC & NC & NC & $\mathrm{NC}$ & NC & $\mathrm{NC}$ & NC & $\mathrm{NC}$ & NC & NC & $\mathrm{NC}$ & NC & $\begin{array}{c}5 \times 10^{-8} \\
4 \times 10^{-6} \\
\text { (Note 14) }\end{array}$ & NC & $\mathrm{NC}$ \\
\hline $\begin{array}{l}\text { Individ. } \\
\text { Latent } \\
\text { Fatality } \\
\text { Risk to } \\
\text { Workers }\end{array}$ & $1 \times 10^{-4}$ & $2 \times 10^{-3}$ & $10^{-4}$ & $3 \times 10^{-4}$ & $\begin{array}{c}3 \times 10^{-2} \\
\left(7 \times 10^{-2}\right)\end{array}$ & $2 \times 10^{-5}$ & $2 \times 10^{-5}$ & $2 \times 10^{-7}$ & $4 \times 10^{-5}$ & $1 \times 10^{-4}$ & $2 \times 10^{-5}$ & $2 \times 10^{-3}$ & $2 \times 10^{-4}$ & $5 \times 10^{-4}$ & $1 \times 10^{-3}$ \\
\hline
\end{tabular}

Refer to notes in Appendix B, Section B.2.1, when reviewing this table. 
Figure B1: Materials Use and Waste Risks

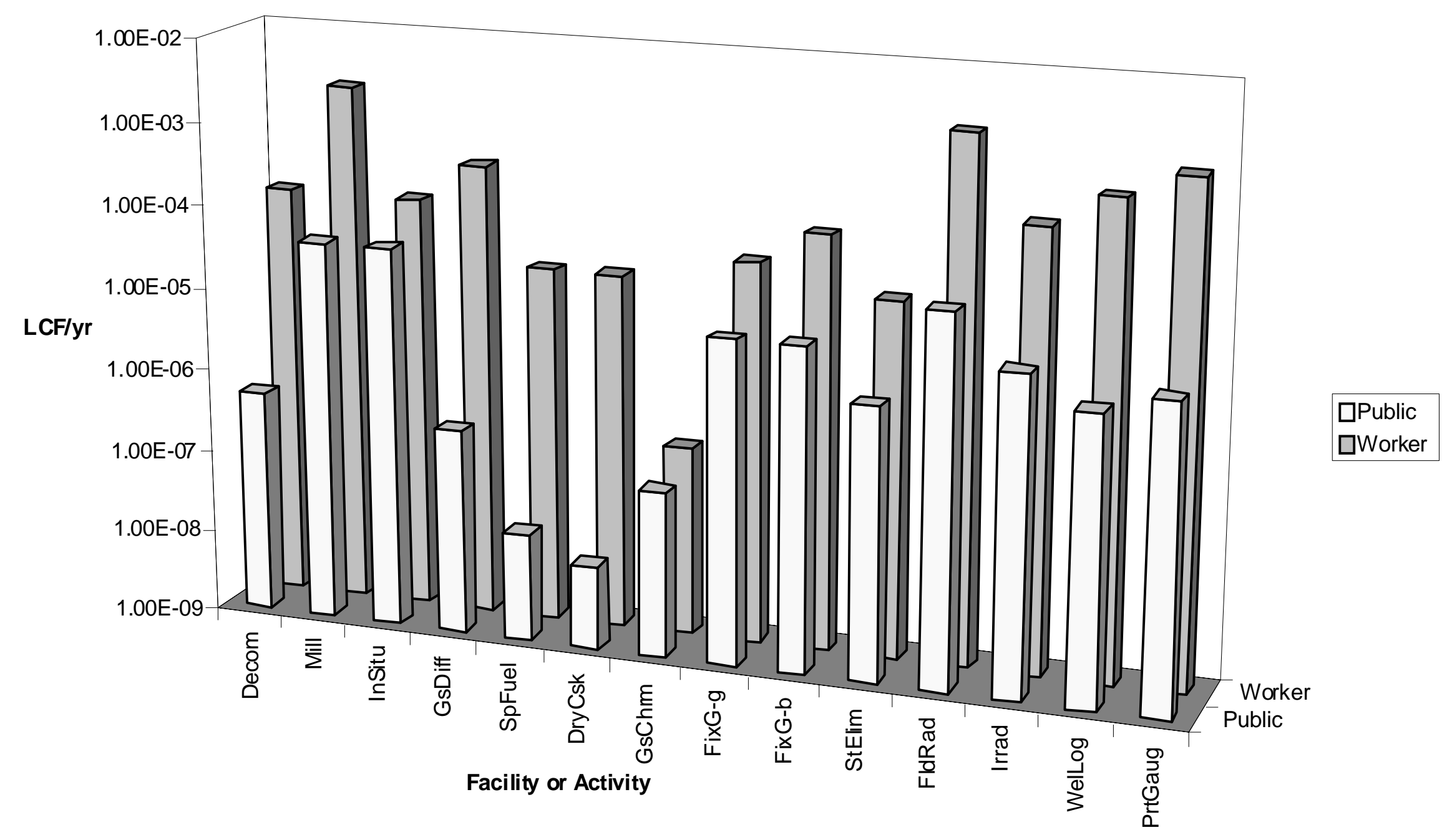


Figure B2: Indiv. Latent Cancer Fatalities-Public

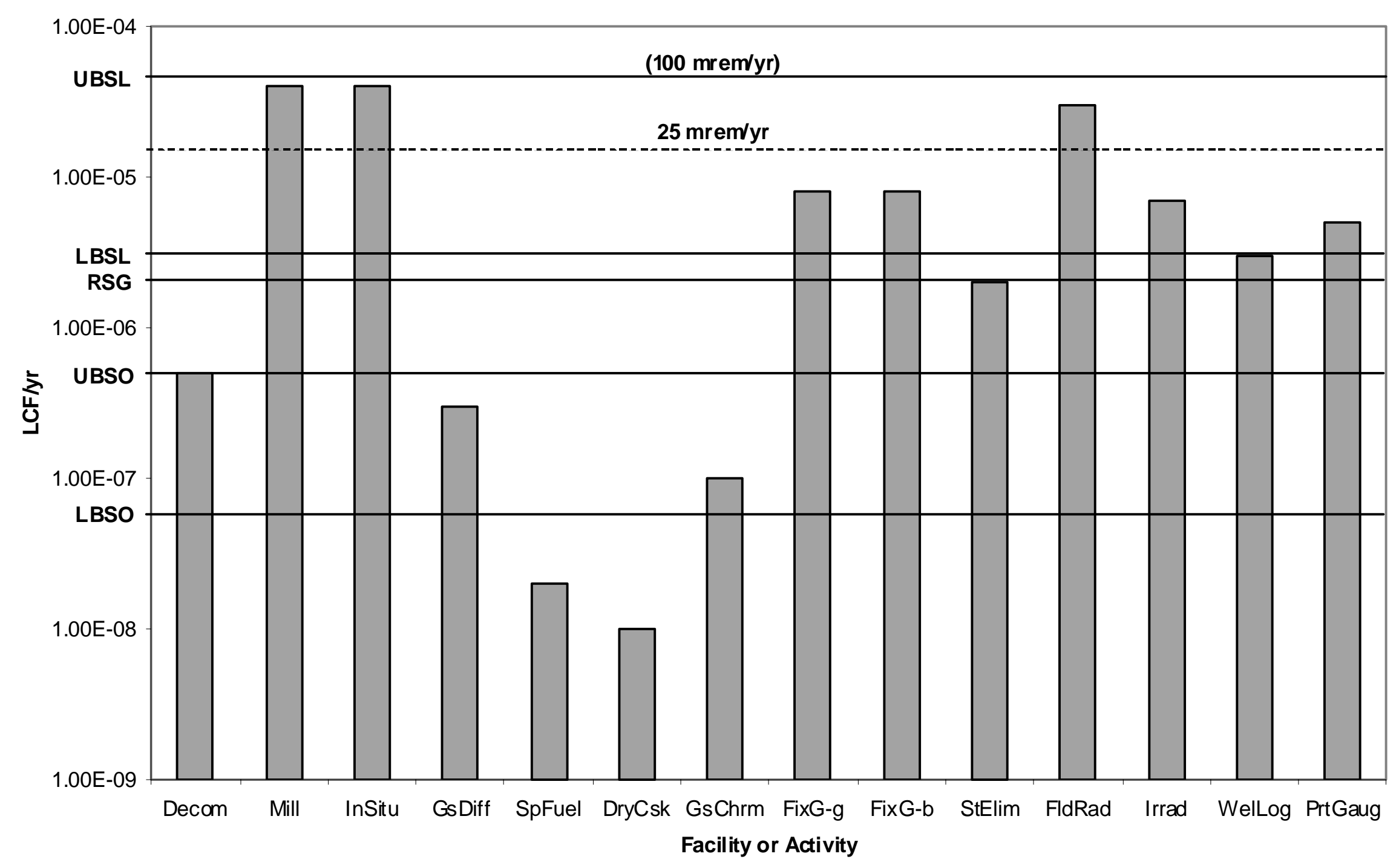


Figure B3: Indiv. Latent Cancer Fatalities-Worker

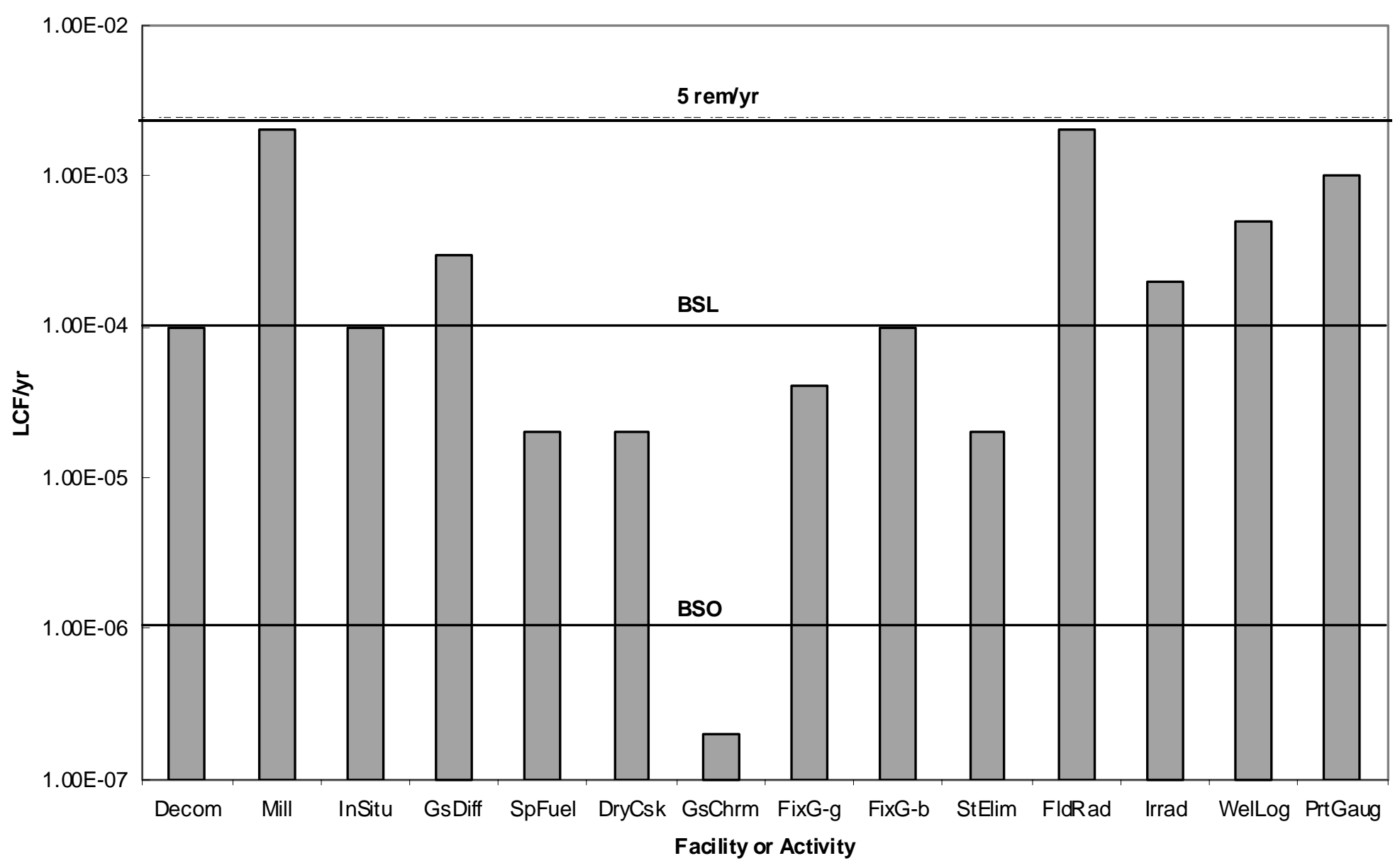




\section{B.3 References for Appendix B}

B1. US NRC, "Safety Goals for the Operation of Nuclear Power Plants: Policy Statement," Federal Register, Vol. 51, No. 149, August 1986.

B2. International Commission on Radiological Protection, ICRP 60, 1990 Recommendations of the International Commission on Radiological Protection, Pergamon Press, November 1990.

B3. United Kingdom Health and Safety Executive, "Safety Assessment Principles for Nuclear Plants", ISBN 011882043 5, 1992, http://www.hse.gov.uk/nsd/saps.htm.

B4. Sprung, J.L. et al., Re-examination of Spent Fuel Shipment Risk Estimates," NUREG/CR6672, Sandia National Laboratories, March 2000.

B5. Schmidt, E.R., et al. "Risk Analysis and Evaluation of Regulatory Options for Nuclear Byproduct Material Systems," NUREG/CR-6642, Scientech, Inc., February 2000.

B6. BEIR V, National Research Council, "Health Effects of Exposure to Low Levels of lonizing Radiation," , National Academy Press, Washington, DC, 1990.

B7. "Annual Report of the Trojan Nuclear Power Plant for 1999", PGE-1015-99, Letter from S. Quennoz to USNRC Document Contol Center, March 16, 2000, Docket 50-344

B8. "Annual Report of the Trojan Nuclear Power Plant for 2000", PGE-1015-2000, Letter from S. Quennoz to USNRC Document Contol Center, February 27, 2001, Docket 50-344 (reports available in ADAMS).

B9. US NRC, "Final Environmental Impact Statement for the Atlas Site," NUREG-1531, 1999.

B10. US NRC, "Final Generic Environmental Impact Statement on Uranium Milling," NUREG0706, September, 1980.

B11. Mackin, P. et al., "A Baseline Risk-Informed Performance-Based Approach for In Situ Leach Uranium Extraction Licensees," Center for Nuclear Waste Regulatory Analyses, NUREG/CR-6733, June 2001.

B12. US NRC, SECY 98-275, "Report to Congress on the Gaseous Diffusion PlantsLocated near Paducah, Kentucky, and Portsmouth, Ohio," November 24, 1998.

B13. Drummond, C.M. and D.R. Damon,"A Case Study on Transportation of the Trojan Reactor Vessel Package," US NRC, December 2001.

B14. US NRC, "Final Environmental Statement on the Transportation of Radioactive Material by Air and Other Modes," December 1977.

B15. US NRC, Office of Nuclear Regulatory Research, "Dry Cask Storage PRA Status and Initial Assessments", Briefing to the SFPO, July 20, 2001. 
RISK INFORMING THE MATERIALS AND WASTE ARENAS:

INTEGRATION OF CASE STUDIES AND RELATED RISK ASSESSMENTS

VOLUME 2: Case Study Plan and Case Study Reports

Prepared By:

Risk Task Group

Office of Nuclear Materials Safety and Safeguards

U.S. Nuclear Regulatory Commission

and

Brookhaven National Laboratory

December 2001

Revised February 2002 


\section{TABLE OF CONTENTS}

$\begin{array}{ll}\text { APPENDIX A: } & \text { Case Study Plan } \\ \text { APPENDIX B: } & \text { Regulation of Gas Chromatographs } \\ \text { APPENDIX C: } & \text { Regulation of Static Eliminators } \\ \text { APPENDIX D: } & \text { Regulation of Fixed Gauges } \\ \text { APPENDIX E: } & \text { Risk Informing Uranium Recovery } \\ \text { APPENDIX F: } & \begin{array}{l}\text { Risk Informing } 10 \text { CFR Part 76: Seismic Issues at Paducah Gaseous } \\ \text { Diffusion Plant }\end{array} \\ \text { APPENDIX G: } & \text { Risk Informing Site Decommissioning } \\ \text { APPENDIX H: } & \text { Transportation of the Trojan Reactor Vessel Package } \\ \text { APPENDIX I: } & \text { Seismic Exemption for the DOE/INEEL Three Mile Island - Unit } 2 \text { Fuel } \\ & \text { Debris Independent Spent Fuel Storage Installation }\end{array}$




\section{THIS DOCUMENT CONTAINS COVER PAGE AND TABLE OF CONTENTS ONLY}

THE ADAMS LOCATION OF APPENDICES ARE AS FOLLOWS:

\begin{tabular}{|c|l|c|}
\hline APPENDIX & \multicolumn{1}{|c|}{ TITLE } & $\begin{array}{c}\text { ADAMS } \\
\text { ASCENSION\# }\end{array}$ \\
\hline A & Case Study Plan & ML010040111 \\
\hline B & Regulation of Gas Chromatographs & ML012960268 \\
\hline C & Regulation of Static Eliminators & ML012960555 \\
\hline D & Regulation of Fixed Gauges & ML012960172 \\
\hline E & Risk Informing Uranium Recovery & ML013200060 \\
\hline F & $\begin{array}{l}\text { Risk Informing 10 CFR Part 76: Seismic Issues at } \\
\text { Paducah Gaseous Diffusion Plant }\end{array}$ & ML013050332 \\
\hline G & Risk Informing Site Decommissioning & ML013050324 \\
\hline H & Transportation of the Trojan Reactor Vessel Package & ML012970156 \\
\hline I & $\begin{array}{l}\text { Seismic Exemption for the DOE/INEEL Three Mile } \\
\text { Island - Unit 2 Fuel Debris Independent Spent Fuel } \\
\text { Storage Installation }\end{array}$ & ML013030006 \\
\hline
\end{tabular}




\title{
Plan for Using Risk Information in the Materials and Waste Arenas
}

\section{CASE STUDIES}

\author{
Risk Task Group \\ Office of Nuclear Materials Safety and Safeguards \\ October 2000
}




\section{TABLE OF CONTENTS}

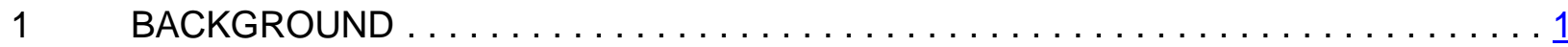

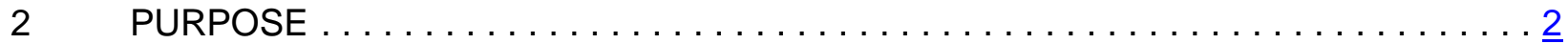

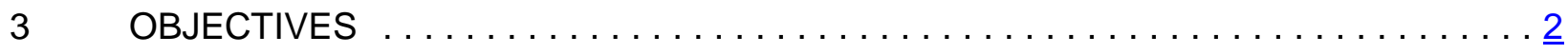

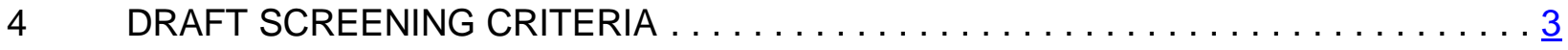

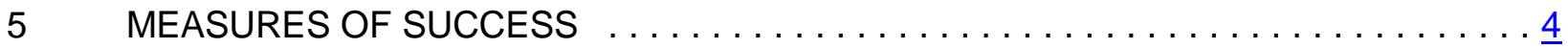

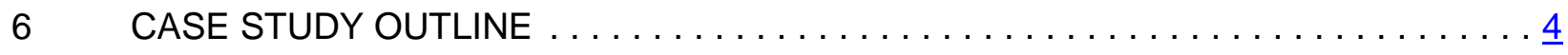

7 DRAFT QUESTIONS FOR CASE STUDIES $\ldots \ldots \ldots \ldots \ldots \ldots \ldots \ldots \ldots \ldots \ldots$

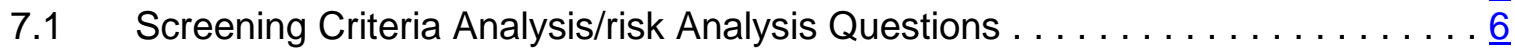

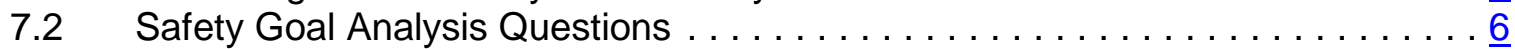

7.3 Questions upon Developing Draft Safety Goals $\ldots \ldots \ldots \ldots \ldots \ldots \ldots \ldots \underline{7}$ 


\section{Plan for Using Risk Information in the Materials and Waste Arenas: Case Studies}

In SECY-99-100, "Framework for Risk-Informed Regulation in the Office of Nuclear Material Safety and Safeguards (NMSS)," dated March 31, 1999, the Nuclear Regulatory Commission (NRC) staff proposed a framework for risk-informed regulation in the materials and waste arenas. On June 28, 1999, the Commission approved the staff's proposal. In the associated staff requirements memorandum, the Commission approved the staff's recommendation to implement a five-step process consisting of:

(1) identifying candidate regulatory applications that are amenable to expanded use of risk assessment information;

(2) making a decision on how to modify a regulation or regulated activity;

(3) changing current regulatory approaches;

(4) implementing risk-informed approaches; and

(5) developing or adapting existing tools and techniques of risk analysis to the regulation of nuclear materials safety and safeguards.

Step one of the five-step process will be accomplished by applying screening criteria to regulatory application areas as a means to identify the candidate regulatory applications. To be a candidate for expanded use of risk information in the materials and waste arenas, regulatory application areas must meet the screening criteria.

As part of the staff's effort to use an enhanced public participatory process in developing the framework, the staff held a public workshop in Washington, DC, on April 25 and 26, 2000. The staff published draft screening criteria in a Federal Register Notice (65 FR 14323, March 16, 2000) announcing the workshop. The purpose of the first part of the workshop was to solicit public comment on the draft screening criteria and their applications. The purpose of the second part of the workshop was to solicit public input for the process of developing safety goals for nuclear materials and waste applications.

The workshop included participation by representatives from NRC, Environmental Protection Agency, Department of Energy, Occupational Safety and Health Administration, Organization of Agreement States, Health Physics Society, Nuclear Energy Institute, environmental and citizen groups, licensees, and private consultants. A consensus among the workshop participants was that case studies and iterative investigations would be useful for the following purposes: (1) to test the screening criteria, (2) to show how the application of risk information has affected or could affect a particular area of the regulatory process, and (3) to develop safety goal parameters and a first draft of safety goals for each area. 


\section{PURPOSE}

The purpose of the case studies is (1) to illustrate what has been done and what could be done in the materials and waste arenas to alter the regulatory approach in a risk-informed manner, and (2) to establish a framework for using a risk-informed approach in the materials and waste arenas by testing the draft screening criteria, and determining the feasibility of safety goals. Once the screening criteria have been tested using a spectrum of case studies, the criteria can be modified as appropriate, placed in final form, and established as part of the framework for prioritizing the use of risk information in materials and waste regulatory applications.

The case studies will be used to begin the process of developing safety goals for applications in the materials and waste arenas. Specifically, safety goal parameters (e.g., public, worker, acute fatality, latent fatality, injury, property damage, environment damage, safeguards, absolute vs. relative) should be identified in each study. Each case study will determine the feasibility of safety goals in that area. If feasible, a first draft of safety goals will be developed. The case studies will also be used to check for and test any existing risk-informed framework (e.g., defense-in-depth) in the material and waste arenas.

All case studies will have these general objectives. However, certain case studies may have specialized objectives. For example, as one type of test of the screening criteria, a case study will be chosen in an area that the staff intuitively feels might not pass the screening criteria. These additional objectives are discussed in the case study outline which is included in this plan.

The intent of the case studies is not to reopen or reassess previous decisions made by the staff and the Commission. The information gained by performing the case studies may impact future decisions to be made by the staff and the Commission.

Questions have been developed for each case study to answer. Answering these questions will guide the case studies to meet the objectives outlined below. Each case study will be of limited scope, but collectively, the case studies will cover a broad spectrum of regulatory applications in the materials and waste arenas. The case studies have been selected in areas that the staff believes would specifically help in establishing a framework, as well as areas that would help to set the groundwork for establishing safety goals.

\section{OBJECTIVES}

Case studies will have the following objectives:

Objective 1: Produce a final version of screening criteria for the materials and waste arenas.

Objective 2: Illustrate how the application of risk information has improved or could improve a particular area of the regulatory process in the materials and waste arenas.

Objective 3: Determine the feasibility of safety goals in a particular area. If feasible, develop safety goal parameters, and a first draft of safety goals. If infeasible, document the reasons. 
Objective 4: Identify methods, data, and guidance needed to implement a risk-informed regulatory approach.

\section{$4 \quad$ DRAFT SCREENING CRITERIA}

Draft screening criteria were published in Federal Register Notices announcing the April 2000 workshop and a September 2000 public meeting (65 FR 14323, 03/16/00, and 65 FR 54323, 09/07/00, respectively). On the basis of comments received at the workshop, the public meeting, and discussions with the NMSS Risk Steering Group, the criteria have been revised. The revised draft screening criteria are as follows:

(1) Would a risk-informed regulatory approach help to resolve a question with respect to maintaining or improving the activity's safety?

(2) Could a risk-informed regulatory approach improve the efficiency or the effectiveness of the $\mathrm{NRC}^{1}$ regulatory process?

(3) Could a risk-informed regulatory approach reduce unnecessary regulatory burden for the applicant or licensee?

(4) Would a risk-informed approach help to effectively communicate a regulatory decision or situation?

If the answer to any of the above is yes, proceed to additional criteria; if not, the activity is considered to be screened out.

(5) Does information (data) and analytical models exist that are of sufficient quality or could they be reasonably developed to support risk-informing a regulatory activity?

If the answer to criterion 5 is yes, proceed to additional criteria; if not, the activity is considered to be screened out.

(6) Can startup and implementation of a risk-informed approach be realized at a reasonable cost to the $\mathrm{NRC}^{1}$, applicant or licensee, and/or the public, and provide a net benefit? The net benefit will be considered to apply to the public, the applicant or licensee, and the NRC ${ }^{1}$. The benefit to be considered can be improvement of public health and safety, improved protection of the environment, improved regulatory efficiency and effectiveness, improved communication to the public, and/or reduced regulatory burden (which translates to reduced cost to the public.)

If the answer to criterion 6 is yes, proceed to additional criteria; if not, the activity is considered to be screened out.

${ }^{1}$ For those regulatory processes in which Agreement States are involved, this criterion is applicable to Agreement States. 
(7) Do other factors exist (e.g., legislative, judicial, adverse stakeholder reaction) which would preclude changing the regulatory approach in an area, and therefore, limit the utility of implementing a risk-informed approach?

If the answer to criterion 7 is no, a risk-informed approach may be implemented; if the answer is yes, the activity may be given additional consideration or be screened out.

\section{$5 \quad$ MEASURES OF SUCCESS}

Success of the case studies will be measured by the following:

(1) If, based on the testing of the draft screening criteria, final screening criteria are established, the case studies will collectively meet Objective 1.

(2) If a case study can illustrate how the application of risk information has affected or could affect and improve a particular area of the regulatory process, the case study will meet Objective 2 .

(3) If a case study can determine the feasibility of establishing safety goals, and if feasible, develop the necessary safety goal parameters and a first draft of goals, the case study will meet Objective 3 .

(4) If a case study can develop the risk-informed regulatory approach sufficient to define the methods, data, and guidance needed and the feasibility of developing them, the case study will meet Objective 4.

When completed, the staff will present the results of the spectrum of case studies to the Commission.

\section{CASE STUDY OUTLINE}

I. Revise draft screening criteria based on workshop and other suggestions (completed prior to September 21, 2000, meeting).

II. Meet with the NRC historian and other appropriate individuals (NRC and non-NRC) for perspectives and insights on the materials and waste regulatory history.

III. Review tables from the NRC-EPA risk harmonization effort and other sources such as the National Academy of Sciences study to uncover any implicit objectives (goals) under the existing regulatory framework. Glean insights on any potential underlying safety goals.

IV Case Study Areas:

A. Gas Chromatographs (new and old designs, the line between general licenses and specific licenses for almost identical devices is unclear - illustrate how the 
application of risk information could improve a particular area of the regulatory process)

B. Fixed Gauges (some are specifically licensed, and others are under a general license; regulatory criteria for general versus specific license are not based on risk - illustrate how the application of risk information could improve a particular area of the regulatory process; also, this could be a test case for a safety goal on property damage)

C. Site Decommissioning - the study may focus on certain decommissioning incidents and certain selected sites (elements of implied safety goals may be found in Commission decisions)

D. Uranium Recovery Facilities (gaps in the regulations may be found; helpful in testing the screening criteria; if determined to be a good candidate for using risk, develop and use risk information for new Part 41 rulemaking effort)

E. Radioactive Material Transportation (elements of existing, implicit safety goals may be found in Commission decisions; public confidence and communication issue)

F. Part 76 (decide to use expanded risk information for gaseous diffusion plants or document the reasons why risk information will not improve the regulatory process in this area - contrast with new Part 70 approach; this decision-making process will be a good test for the draft screening criteria and will help establish consistency in applying risk information across materials and waste programs; also, possibly an area to look at chemical risks.)

G. Spent Fuel Interim Storage (study probabilistic hazards analysis exemptions and proposed rulemaking - implicit safety goals may be found; public confidence issues and burden considerations)

H. Static Eliminators (public confidence issue; risk communication issue regulatory changes were made even though perceived risk was low)

V Case study structure

A. Develop a set of questions for all case studies to answer.

B. Select a case-specific contact in each NMSS Division; obtain agreement with the Divisions on participation.

C. Public meeting to announce our plan for case studies (September 21, 2000).

D. Make any necessary revisions to plan based on input from public meeting.

E. Develop detailed approach and timeline for each case study including the need and level of involvement of contractor support. 
F. Begin work on case studies.

G. Test screening criteria for each case study.

H. Answer all questions for each case study.

I. Meet with case-specific stakeholders as input to case studies.

J. Develop recommendations for safety goals (will be done in parallel with above).

K. Document results.

L. Conduct public meeting to present results of case studies.

M. Inform Commission of results.

VI Assess the outcome and develop a plan to move forward.

7 DRAFT QUESTIONS FOR CASE STUDIES

\subsection{Screening Criteria Analysis/risk Analysis Questions}

(1) What risk information is currently available in this area? (Have any specific risk studies been done?)

(2) What is the quality of the study? (Is it of sufficient quality to support decisionmaking?)

(3) What additional studies would be needed to support decision-making and at what cost?

(4) How is/was risk information used and considered by the NRC and licensee in this area?

(5) What is the societal benefit of this regulated activity?

(6) What is the public perception/acceptance of risk in this area?

(7) What was the outcome when this application was put through the draft screening criteria? Did this application pass any of the screening criteria? Does the outcome seem reasonable? Why or why not?

\subsection{Safety Goal Analysis Questions}

(1) What is the basis for the current regulations in this area (e.g., legislative requirements, international compatibility, historical events, public confidence, undetermined, etc.)? 
(2) Are there any explicit safety goals or implicit safety goals embedded in the regulations, statements of consideration, or other documents (an example would be the acceptance of a regulatory exemption based in part on a risk analysis and the outcome)?

(3) What was the basis for the development of the strategic goals, performance goals, measures and metrics? How are they relevant/applicable to the area being studied and how do they relate/compare with the regulatory requirements? How would they relate to safety goals in this area?

(4) Are there any safety goals, limits, or other criteria implied by decisions or evaluations that have been made that are relevant to this area?

(5) If safety goals were to be developed in this area, would tools/data be available for measurement?

(6) Who are/were the populations at risk?

(7) What are/were, and what could be/have been, the various consequences to the populations at risk?

(8) What parameters should be considered for the safety goals (e.g., workers vs. public, individual vs. societal, accidents vs. normal operations, acute vs. latent fatality or serious injury, environmental and property damage)?

(9) On the basis of the answers to the questions above, would it be feasible to develop safety goals in this regulatory area?

(10) What methods, data results, safety goals, or regulatory requirements would be necessary to make it possible to risk-inform similar cases?

\subsection{Questions upon Developing Draft Safety Goals}

(1) Are the current regulations sufficient in that they reflect the objectives of the draft goals? Would major changes be required?

(2) Would the regulations need to be tightened?

(3) Are the regulations overly conservative and/or too prescriptive with respect to the goals?

(4) If these were the safety goals, what decisions would be made?

(5) Would these goals be acceptable to the public? 